\title{
The E2F1-responsive microRNA-449 promotes apoptosis
}

\author{
Dissertation \\ zur Erlangung des mathematischnaturwissenschaftlichen \\ Doktorgrades \\ "Doctor rerum naturalium" \\ der Georg-August-Universität Göttingen \\ vorgelegt von \\ Muriel Lizé \\ aus Pontoise, Frankreich
}

Göttingen, Juli 2010 
Anleiter:

Referent:

Koreferent:

Tag der mündlichen Prüfung:
Prof. Dr. Matthias Dobbelstein

Prof. Dr. Ralf Ficner

Prof. Dr. Tomas Pieler

23.08.2010 


\section{Index I-III}

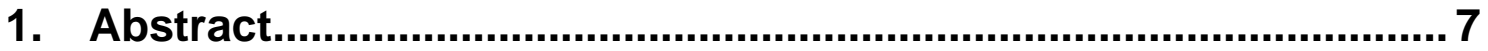

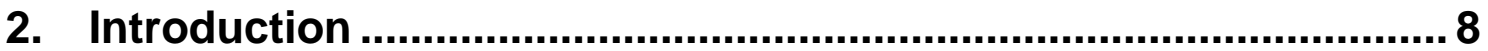

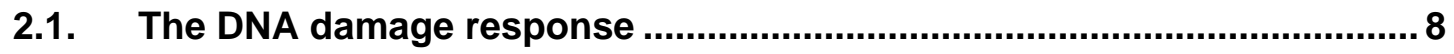

2.1.1. DNA damage in cancer \& cancer therapy ......................................... 8

2.1.2. Principal actors of the DNA damage response pathway ...................... 8

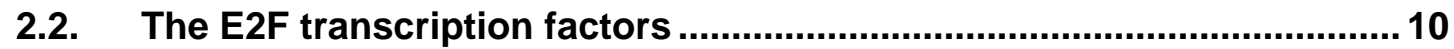

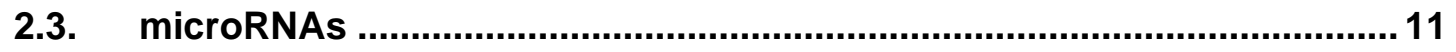

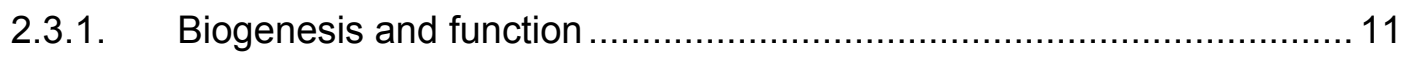

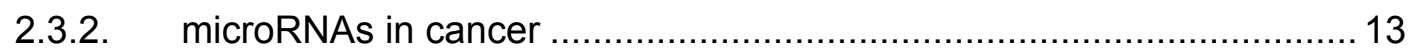

2.3.3. The miR-34/449 family of microRNAs ............................................ 13

2.4. Airway epithelium and its differentiation ............................................. 15

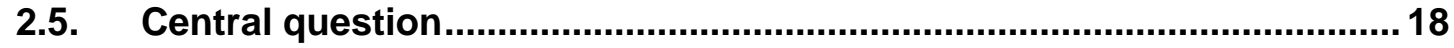

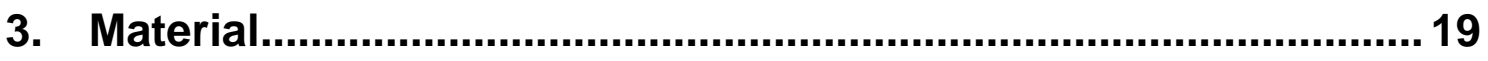

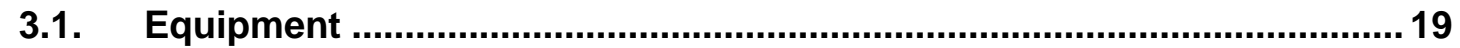

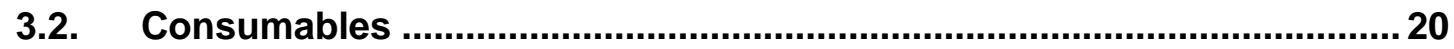

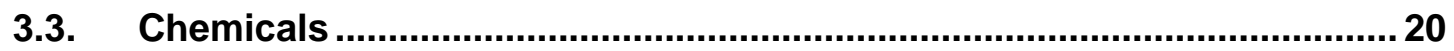

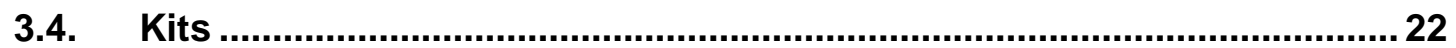

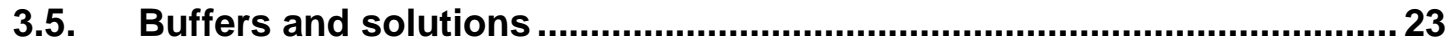

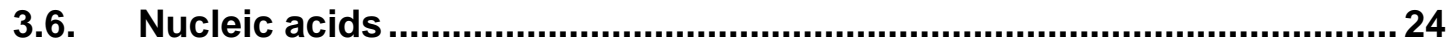

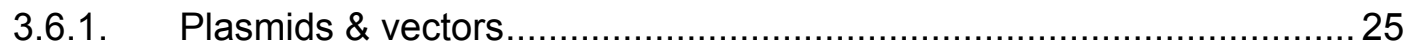

3.6.2. Synthetic microRNAs \& other small RNAs ................................... 25

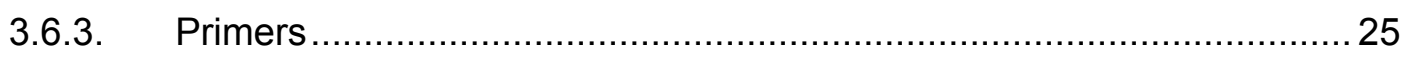

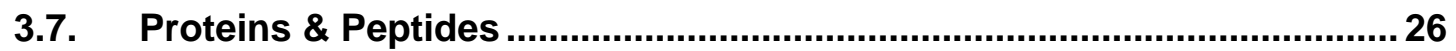

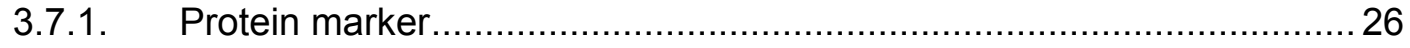

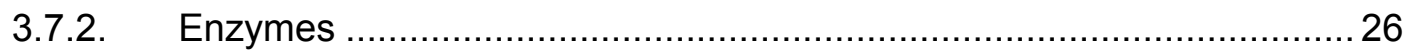

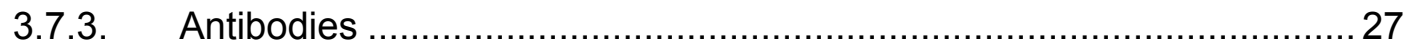

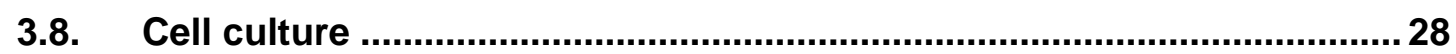

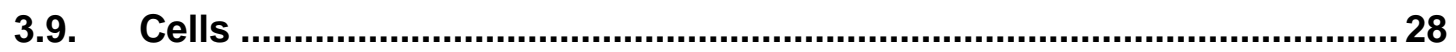

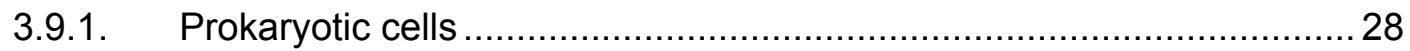




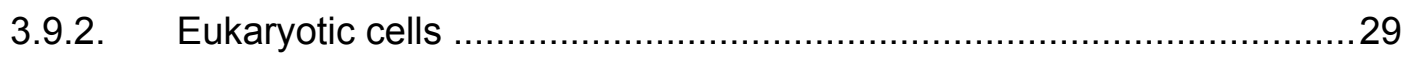

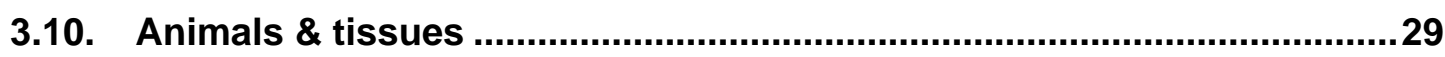

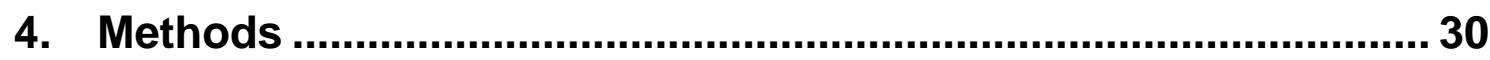

4.1. Cell biological methods...................................................................... 30

4.1.1. Isolation of human primary airway epithelial cells .............................30

4.1.2. Air-liquid interface cultures \& smoke condensate exposition ................30

4.1.3. Cell culture \& drug treatment of tumour cell lines .................................30

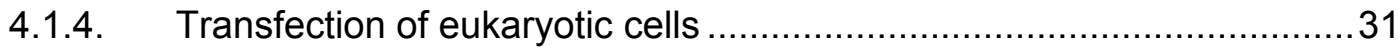

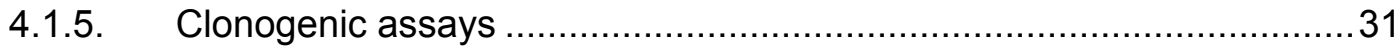

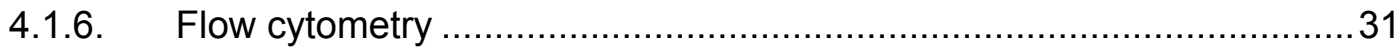

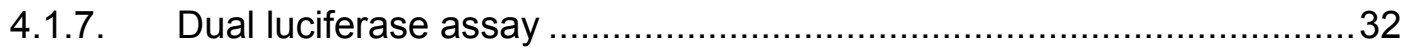

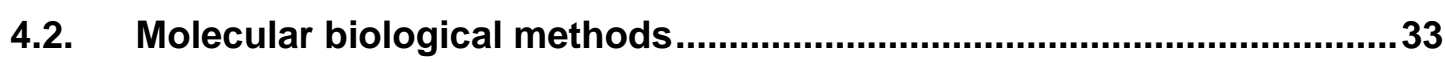

4.2.1. Transformation, cultivation and selection of bacteria ..........................33

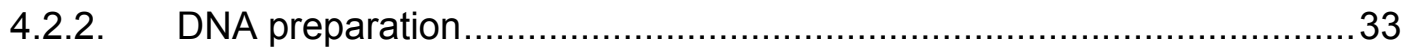

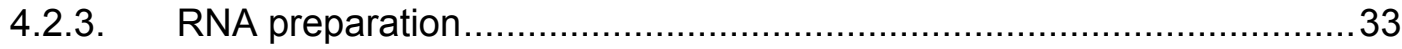

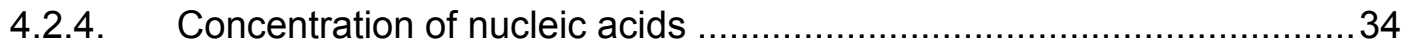

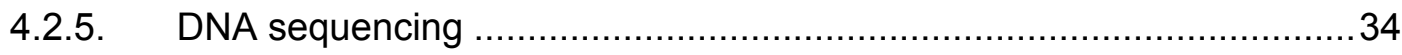

4.2.6. Reverse transcription of mRNA in cDNA ......................................... 34

4.2.7. Semi-quantitative Realtime PCR using SYBR Green...........................34

4.2.8. Reverse transcription of mature microRNAs and semi-quantitative Realtime

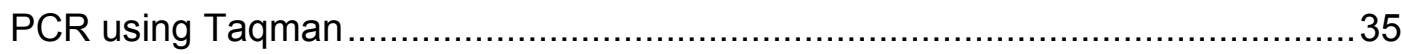

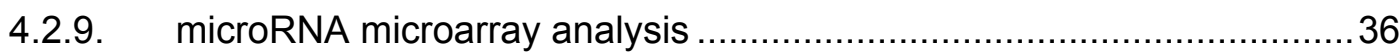

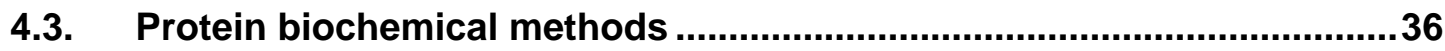

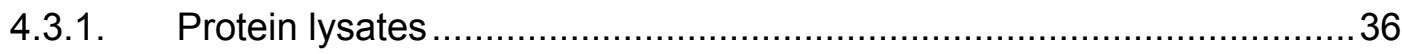

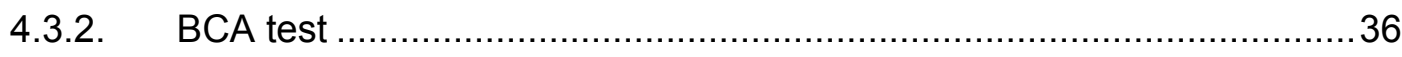

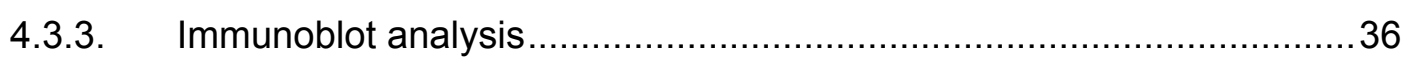

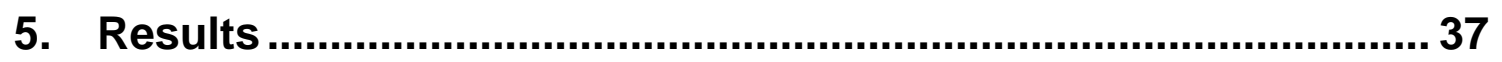

5.1. E2F1 regulates miRNA expression ....................................................... 37

5.2. microRNA-449 is strongly responsive to E2F1 and DNA damage..........38

5.3. miR-449 expression is coupled to its host gene CDC20B and reduced in

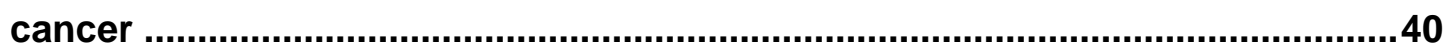

5.4. miR-449 induces apoptosis and cell cycle arrest ..............................42

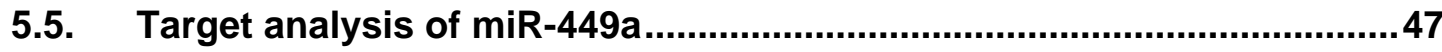

5.5.1. Negative feedback on the E2F pathway ..................................... 49 
5.5.2. miR-449 targets the histone deacetylases HDAC1 and SIRT1: a positive

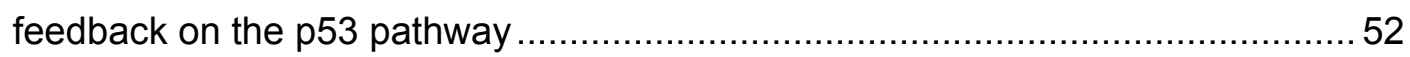

5.5.3. miR-449 provokes the accumulation of DNA damage .......................5 54

5.5.4. miR-449 targets vital mitosis checkpoints: Chk1 and BRCA1 ..............56

5.6. miR-449 expression correlates with the development of ciliated cells in lung in vivo 59

5.7. miR-449 levels sharply increase upon differentiation of airway epithelial cells 62

5.8. miR-449 levels further increase upon exposure of airway epithelia to tobacco smoke 64

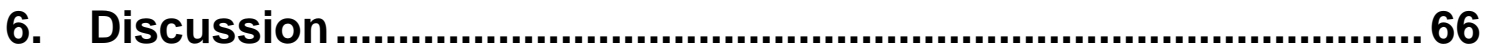

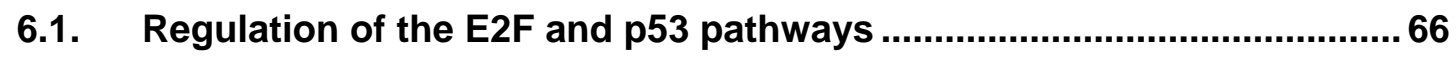

6.2. miR-449-mediated p53-independent apoptosis .....................................69

6.2.1. miR-449 as a regulator of cell cycle progression: cell death by mitotic catastrophe?

6.2.2. miR-449 \& DNA damage: a role in DNA repair? ................................70

6.3. miR-449 as a regulator of general gene expression .............................. 71

6.4. miR-449 in vivo: cell differentiation and development .......................... 72

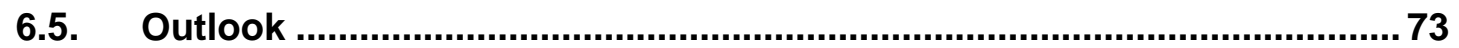

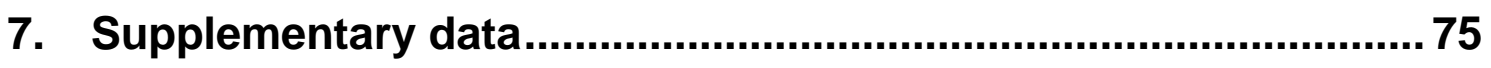

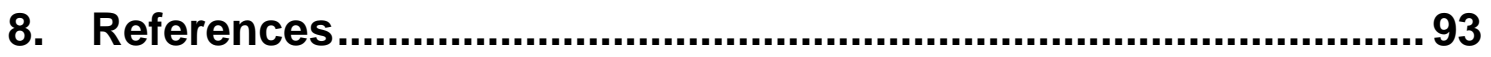

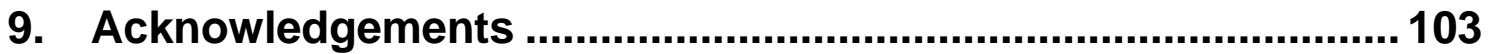

10. Curiculum Vitae......................................................................... 104 


\section{Figures \& Tables}

Fig. 2.1: Simplified overview of the DNA damage response ......................................... 9

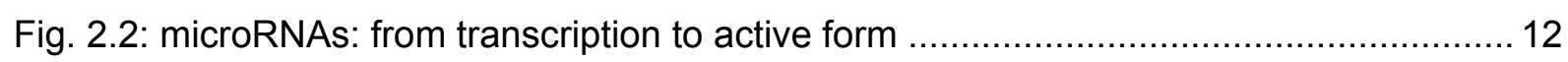

Fig. 2.3: Seed sequence comparison within the miR-34 family .................................... 14

Fig. 2.4: Position of the miR-449 cluster within the CDC20B gene ................................ 15

Fig. 2.5: Selective expression of transcription factors in the respiratory epithelium.............. 16

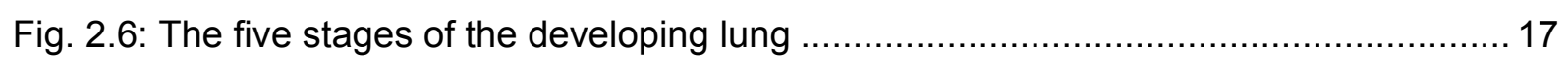

Fig. 2.7: microRNAs in the p53-E2F1 interdependent regulation of cell proliferation and cell

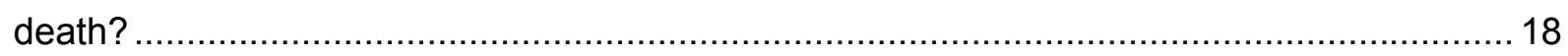

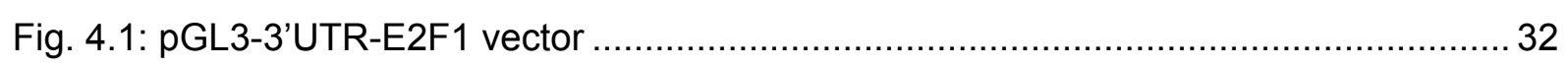

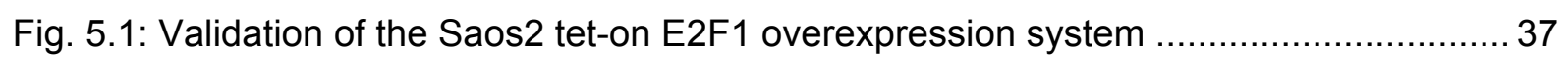

Fig. 5.2: E2F1-induced microRNAs identified by microRNA hybridization........................... 38

Fig. 5.3: miR-449a is induced by E2F1 overexpression and DNA damage ......................... 39

Fig. 5.4: miR-449a levels are reduced in tumour cells, and its expression pattern resembles

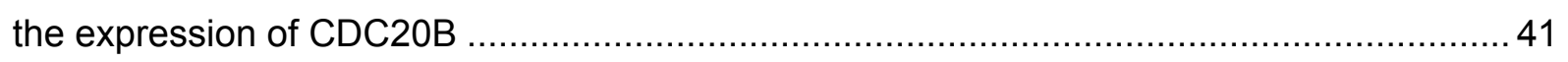

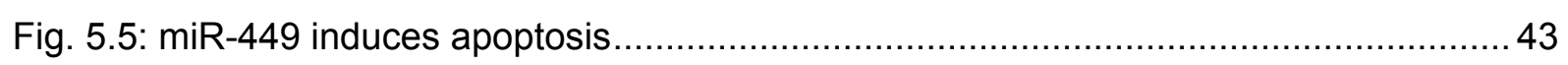

Fig. 5.6: miR-449 suppresses colony formation in a testicular carcinoma cell line ............... 44

Fig. 5.7: Alterations in DNA content by miR-449a and miR-34a ................................... 45

Fig. 5.8: Induction of caspase activity by miR-449a and miR-34a ................................. 45

Fig. 5.9: Knockdown of miR-449 reduces E2F1-mediated apoptosis ................................ 46

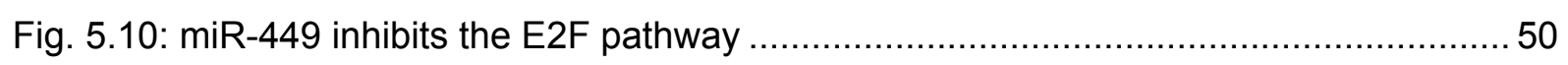

Fig. 5.11: miR-449 induces the p53 pathway while inhibiting the E2F pathway .................. 50

Fig. 5.12: no direct binding of miR-449 to the E2F1 3' UTR ....................................... 51

Fig. 5.13: HDAC1 and SIRT1 mRNA levels are reduced by miR-449 ............................. 53

Fig. 5.14: miR-449a, as well as its paralogue miR-34a, target SIRT1 .............................. 53

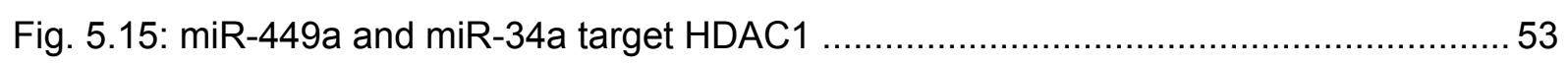

Fig. 5.16: miR-449 overexpression leads to gammaH2AX accumulation ........................... 54

Fig. 5.17: gammaH2AX accumulation after miR-449 is dependent on caspase activity........55

Fig. 5.18: Chk1 is downregulated by miR-449a and miR-34a ..................................... 56 
Fig. 5.19: miR-449a and miR-34a target BRCA1 but not Chk1 mRNA for degradation 57

Fig. 5.20: Chk1 knockdown by siRNA accumulates DNA damage similarly to miR-449a overexpression but in a caspase-independent manner 58

Fig. 5.21: The combined knockdown of the miR-449 targets SIRT1, CHK1 and E2F1 mimics miR-449-mediated apoptosis. 59

Fig. 5.22: miR-449a is highly abundant in lung tissue, in particular around birth 60

Fig. 5.23: Comparison of the miR-449a and miR-34a levels in various tissues in mouse ..... 61

Fig. 5.24: Strong miR-449a induction in differentiating human airway epithelial cells 63

Fig. 5.25: Levels of miR-449a and FoxJ1 mRNA in differentiating airway epithelia 64

Fig. 5.26: Further induction of miR-449a in airway epithelial cells exposed to tobacco smoke 65

Fig. 6.1: Mutual regulation of p53 and E2F1....... 68

Suppl. Fig. S 1: Apoptotic phenotype of Saos2 tet-on E2F1 cells after E2F1 induction 75

Suppl. Fig. S 2: rejected targets 75

Tab. 3.1: Oligonucleotides 25

Tab. 3.2: Primary antibodies 27

Tab. 3.3: Secondary antibodies. 27

Tab. 4.1: Home-made 10x qPCR Mix. 35

Tab. 4.2: Home-made 2x qPCR-Master Mix. 35

Tab. 4.3: Master mix per $1 \mu \mathrm{l}$ cDNA from the reaction described in 4.2.6 35

Tab. 4.4: Realtime PCR cycling program 35

Tab. 5.1: potential miR-449 targets 47

Supp. Tab. 1: microRNA micro-array data. 76 


\section{Abstract}

E2F1 is a positive regulator of cell cycle progression and also a potent inducer of apoptosis, especially when activated by DNA damage. To identify E2F1-inducible microRNAs, I performed array hybridization and found miR-449a and miR-449b (collectively termed miR449 ) to be strongly E2F1-responsive. The levels of miRNAs 449a and 449b, as well as their host gene $\mathrm{CDC} 20 \mathrm{~B}$, are strongly upregulated by E2F1 overexpression and DNA damage. Strikingly, miR-449 shares seed sequences and target genes with the miR-34 family, which has tumour suppressive properties. MiR-449 is expressed at high levels and very specifically in testes, lung, and trachea, but not in tumour cells. However, the expression of miR-449 can be reactivated in tumour cells lines by HDAC inhibition, suggesting epigenetic silencing in cancer. Furthermore, miR-449 expression is strongly induced during the mucociliary differentiation of pulmonary epithelia. Exposure to tobacco smoke further increases the levels of miR-449 in airways, consistent with its DNA damage responsiveness. Therefore, miR-449 can serve as an exquisitely sensitive and specific biomarker for the differentiation of mucociliary epithelium. Moreover, it may actively promote differentiation through its ability to block cell cycle progression, and provide a first line of defence against genotoxic stress by its proapoptotic functions.

In agreement with a putative tumour-suppressive role, miR-449 as well as miR-34 reduce proliferation, upregulate p53 activity and strongly promote apoptosis through both p53dependent and -independent mechanisms. Both miRNAs attenuate E2F1 function by reducing the levels of CDK6, CDK2, E2F1 and E2F3, implying a negative feedback mechanism for the E2F pathway. Moreover, miR-449 and miR-34 decrease the expression of the deacetylases SIRT1 and HDAC1, thereby resulting in p53 activation, which in turn leads to p21 induction and stronger cell cycle arrest in p53 wild type cells. Moreover, since histone deacetylases can regulate complete gene expression programmes, the down-regulation of HDAC1 and SIRT1 might dramatically change the expression patterns, and therefore influence cell fate. In fact, HDAC inhibition has been shown to be very effective in cancer therapy. In addition, miR-449 and miR-34 downregulate two important cell cycle checkpoint proteins, Chk1 and BRCA1, and this can lead to cell death through mitotic catastrophe by interfering with normal mitotic checkpoint regulation. Thus, miR-449 can induce apoptosis in tumour cells in a p53-independent manner.

While E2F1-induced miR-449 as well as p53-induced miR-34 promote p53 activity and apoptosis, they negatively regulate E2F1. Hence, the influence of E2F1 and p53 on each other and on cell fate decisions is sustained by the induction of two miRNA species from the same family. Both miR-449 and miR-34 could provide a twofold safety mechanism to avoid excessive E2F1-induced proliferation by leading to cell cycle arrest or apoptosis. 


\section{Introduction}

\subsection{The DNA damage response}

\subsubsection{DNA damage in cancer \& cancer therapy}

Today, the most common cause for mutations leading to cancer also paradoxically presents the best option for its therapy: DNA damage. This undesirable damage occurs, for instance, in cells exposed to ultraviolet, ionizing radiation or other genotoxic substances (tobacco smoke, asbestos, alkaloids, bromine or mercury containing compounds, etc.), and it potentially leads to tumorigenesis in a multi-step process starting with mutations of key parts of the DNA (Fearon and Vogelstein, 1990; Hanahan and Weinberg, 2000; Vogelstein and Kinzler, 1993). The very same damage is at the same time the most wanted impact of chemotherapeutics on cancer cells since it can lead to cell death. Most chemotherapeutics are designed to attack proliferating cells (Jackson and Bartek, 2009), assuming that cancer cells go through mitosis more frequently than normal cells. Almost all heavy side effects of such therapies can be explained by the fact that, among normal cells, we find highly proliferative tissues, where cells need to replicate continuously: hair follicles (hair loss), gastrointestinal mucosa (diarrhoea, nausea), immune system (immunosuppression \& infections), germ cells (sterility) etc. Therefore, it is important to develop therapies targeting cancer cells as specifically as possible. On a long-term basis this can be achieved by clarifying the pathways that differ in cancerous versus normal cells to allow accurate discrimination between benign and malignant cells during cancer therapy.

\subsubsection{Principal actors of the DNA damage response pathway}

The DNA damage response is very intricate and still not fully understood. It is very tightly regulated and linked to the cell cycle and cell death regulation (Fig. 2.1).

Depending on the damage, the kinases ATM (Ataxia telangiectasia mutated) and ATR (Ataxia telangiectasia and Rad3 related) can activate different checkpoints (CHK1/2, BRCA1), leading to the induction of cell cycle arrest, DNA repair and eventually, if the damage can not be repaired, cell death programmes like apoptosis. 


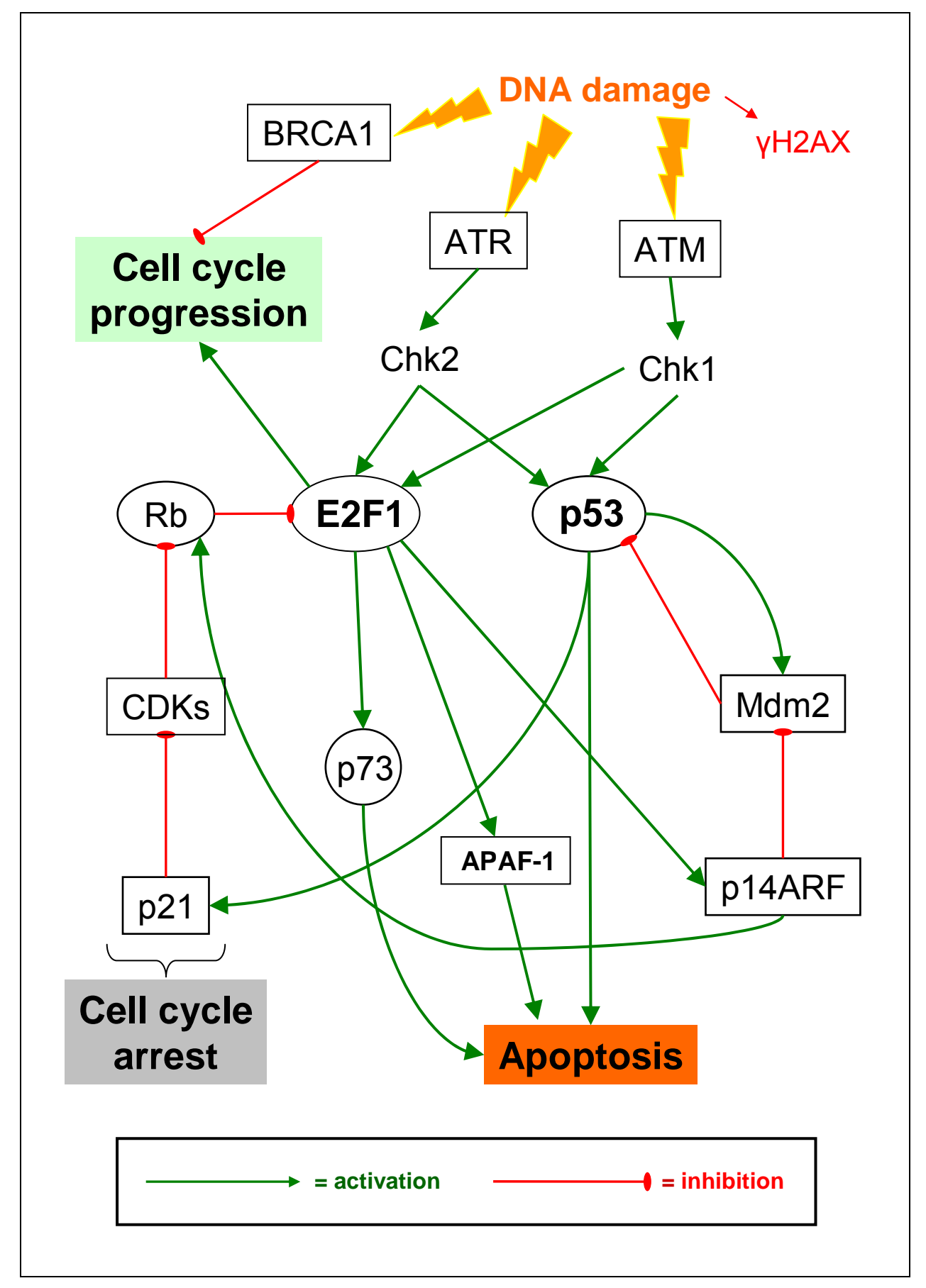

Fig. 2.1: Simplified overview of the DNA damage response

In response to DNA damage, the ATM and ATR kinases are activated and phosphorylate the kinases Chk2 and Chk1, which in turn activate E2F1 and p53. E2F1, which under other circumstances supports cell cycle progression, can then induce cell death by activating the p53 family member p73, or by stabilising the levels of p53 by transactivating the ARF tumour suppressor. In addition, E2F1 can induce apoptosis independently of p53 through direct APAF-1 and caspase induction. After DNA damage, p53 can induce apoptosis or cell cycle arrest, the latter leading to the inhibition of E2F1. Also the BRCA1 protein contributes to cell-cycle arrest and DNA repair by homologous recombination. (Kastan and Bartek, 2004). 
Two key players of this pathway are the transcription factors E2F1 and p53. The tumour suppressor p53 is activated by Chk1/2 (checkpoint proteins 1 and 2) and stabilised mostly through post-translational modifications, which leads to the transactivation of its downstream genes. This can either induce cell cycle arrest and repair of the damage, or apoptosis, depending on the form and degree of the inflicted DNA damage. The E2F1 transcription factor is also stabilised and activated after DNA damage, which can lead to apoptosis when surpassing a certain threshold. This will be explained in more details in chapter 2.2.

Two of the possible outcomes of DNA damage are cell cycle arrest or cell death by apoptosis. As pictured in Fig. 2.1, E2F1 and p53 cooperate very tightly in the regulation of both pathways (Sionov and Haupt, 1999).

To make their relationship even more intricate, p53 activity results in negative regulation of E2F1. Most notably, p53 induces the expression of the CDK inhibitor p21, thus leading to the accumulation of hypophosphorylated, active $\mathrm{Rb}$ pocket proteins which attenuates $\mathrm{E} 2 \mathrm{~F}$ activity through its sequestration. Hence, while E2F1 activity enhances p53 activity, p53 synergizes only with the proapoptotic activity of E2F1, while antagonizing E2F1-induced cell cycle progression (Polager and Ginsberg, 2009).

What exactly leads to the induction of apoptosis rather than cell cycle arrest is not quite clear and needs further investigation.

\subsection{The E2F transcription factors}

The E2F family of transcription factors are DNA binding proteins essential for cell cycle progression, and repressing E2F activity is the key mechanism by which the retinoblastoma $(\mathrm{Rb})$ family of pocket proteins exerts its tumour suppressive function (Qin et al., 1995; Rogoff and Kowalik, 2004). In many tumours, E2F activity is deregulated. Either Rb function is lost, or its phosphorylation status is constitutively changed through cyclin D1 overexpression (that phosphorylates $\mathrm{Rb}$ ) or loss of $\mathrm{p} 16$ (INK4A, CDK inhibitor inhibiting the phosphorylation of $\mathrm{Rb})$. In some other cases, infection with the human papilloma virus leads to the expression of oncoprotein E7 which disrupts Rb-E2F complexes (Sherr and McCormick, 2002).

There are nine different E2F transcription factors. Out of those, E2F1-6 function as heterodimers with members of the DP family (DP1 and DP2) and the DNA-binding specificity depends on the E2F present in the complex. E2F1-3a can, depending on the interaction with $\mathrm{Rb}$, activate or repress the transcription of certain genes. E2F3b-8 are primarily transcriptional repressors (DeGregori and Johnson, 2006; Polager and Ginsberg, 2009).

Cyclin dependent kinases (CDKs) phosphorylate and thereby inactivate pocket proteins $(\mathrm{Rb})$, allowing cell proliferation (Fig. 2.1). This in turn is controlled by CDK inhibitors like the p53- 
responsive p21 or the E2F1- and Foxo3a-responsive p27 (Sherr and Roberts, 1999). In addition to cell cycle regulation, E2F proteins are also capable of inducing programmed cell death. This occurs either dependently or independently of p53.

In response to DNA damage, E2F1 is phosphorylated by ATM/ATR (Lin et al., 2001) and Chk2 (Stevens et al., 2003), and therefore stabilised which leads to enhanced transcriptional activity (Bell and Ryan, 2004; Hershko et al., 2006). E2F1-induced p53-dependent apoptosis occurs mainly through direct transactivation of p14ARF/INK4a, which binds to and inactivates the p53 negative regulator Mdm2 (Bates et al., 1998; Haupt et al., 1997; Kubbutat et al., 1997; Pomerantz et al., 1998; Zhang et al., 1998). This in turn leads to p53 accumulation and eventually to p53-mediated apoptosis (Fig. 2.1). Independently of p53, E2F1 strongly induces the expression of TAp73 (Irwin et al., 2000; Lissy et al., 2000; Stiewe and Putzer, 2000), a p53-homologue that shares many activities of p53, including the activation of p14ARF (Bates et al., 1998; Yang and McKeon, 2000). Moreover, similarly to p53, E2F1 transactivates proapoptotic genes like Noxa, Puma and other BH3-only gene products. E2F1 also has other proapoptotic targets, not shared by p53. One of the most prominent ones, APAF-1 (apoptotic protease-activating factor 1 ), binds and activates procaspase 9 , thereby setting off apoptosis (Cain et al., 2002; Furukawa et al., 2002; Moroni et al., 2001; Rodriguez and Lazebnik, 1999; Saleh et al., 1999; Zou et al., 1997). Subsequently, caspase 9 activates the effector procaspases 3, 6 and 7 leading to DNA and protein cleavage, the hallmark of apoptosis (Budihardjo et al., 1999; Franklin and Robertson, 2007). Hence, both E2F1 and p53 are strong inducers of apoptosis, at least in part by transactivating an overlapping but not identical set of target genes (Polager and Ginsberg, 2009).

Consequently, E2F1 has a dual role in cancer. It is primarily considered to be an oncogene (Johnson, 2000; Johnson et al., 1994) because it is found over-expressed in various tumours. However, it was also shown that animals lacking E2F1 develop tumours spontaneously (Yamasaki et al., 1996). In certain contexts, E2F1 works as a tumoursuppressor and induces apoptosis (Johnson, 2000; Shan and Lee, 1994; Tsai et al., 1998; $\mathrm{Wu}$ and Levine, 1994) similarly to p53. Since most tumours have lost p53 expression or proper activity, E2F1 is an interesting target for cancer therapy. But the mechanisms regulating the decision between E2F1-induced apoptosis and cell cycle entry are not fully understood and remain a central question in cancer research.

\section{3. microRNAs}

\subsubsection{Biogenesis and function}


An important set of genes was only recently discovered: microRNAs. These small, noncoding RNAs represent a novel class of regulators for gene expression and many miRNAencoding regions are embedded in regular protein-coding genes (Ambros, 2004; Ambros and Lee, 2004; Bartel, 2004). Some microRNAs are ubiquitously distributed, whereas others are expressed in a highly tissue-specific manner (Lagos-Quintana et al., 2002; Landgraf et al., 2007). Rather than encoding proteins, they act as regulators of mRNA stability and/or protein synthesis through specific hybridization of the "seed sequence" (region from base 2 to base 8 of a mature microRNA) with mRNA target sequences, allowing each miRNA species to regulate a characteristic set of mRNAs (Filipowicz et al., 2008; Flynt and Lai, 2008; He and Hannon, 2004). The synthesis of their precursors closely resembles that of mRNAs starting with the transcription of a microRNA precursor called pri-miRNA through the RNA polymerase II (Fig. 2.2). The specific nucleases Drosha and Pasha (DGCR8, "Partner of Drosha") then recognise and cut the stem-loop structure to produce the pre-miRNA which can be transported to the cytoplasm for further processing through the ribonuclease Dicer.

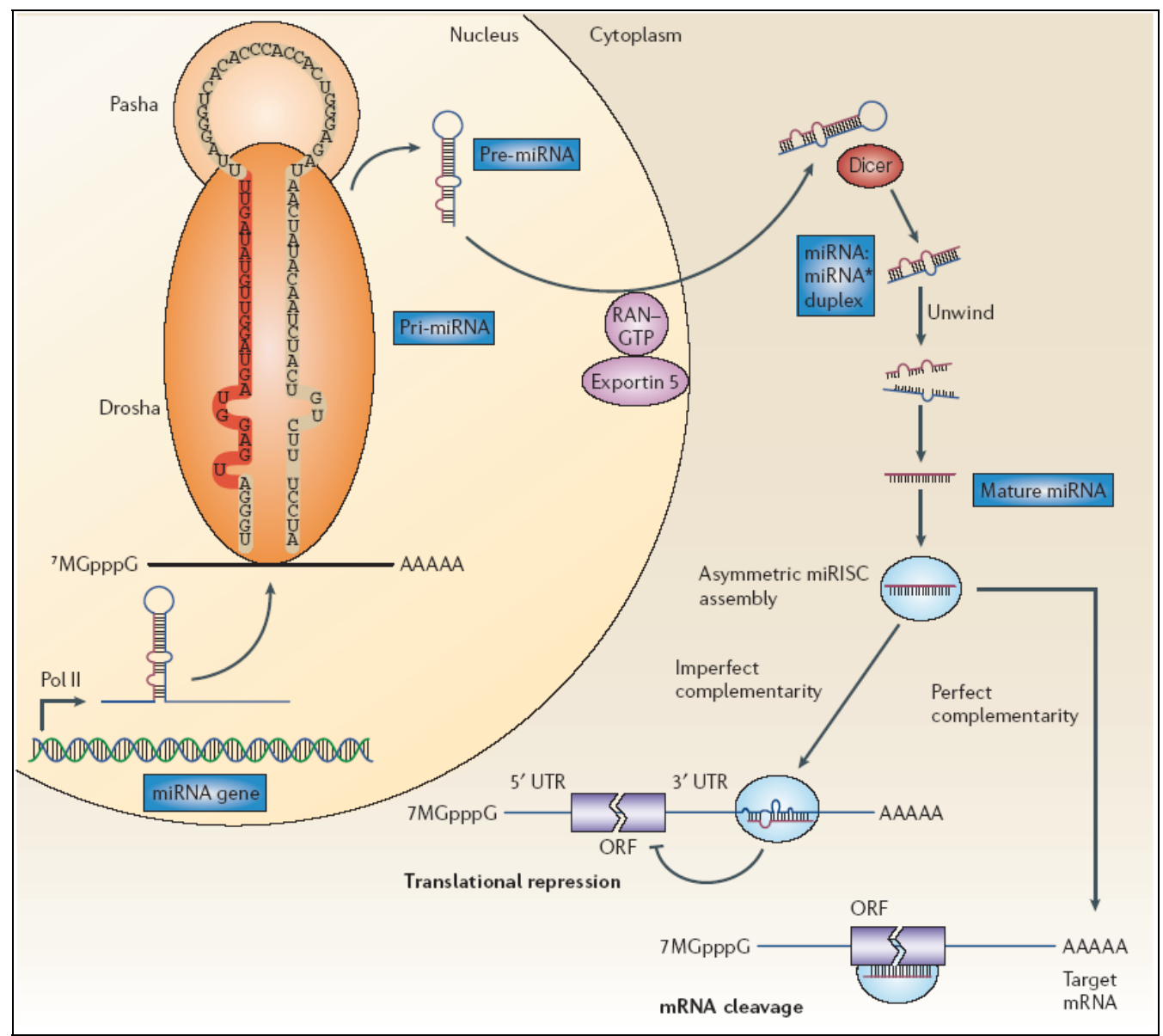

Fig. 2.2: microRNAs: from transcription to active form

Figure adopted from Nature Reviews Cancer April 2006 (Esquela-Kerscher and Slack, 2006). 
Mature microRNAs are around 20 bases long and can target mRNAs for degradation (perfect complementarity) or translational repression (imperfect match) (Esquela-Kerscher and Slack, 2006; He and Hannon, 2004; Kim, 2005). Unfortunately, the ability of miRNAs to regulate translation through imperfect binding impedes the accurate prediction of targets. Still, computational predictions are available: miRanda, PicTar, TargetScan and cbio among others.

\subsection{2. microRNAs in cancer}

Multiple links between miRNA activity and cancer have been established (Croce, 2009; Kumar et al., 2007). Several miRNAs have been described as oncogenes (Cho, 2007; Esquela-Kerscher and Slack, 2006) while others act as tumour suppressors (Friedman et al., 2009a; Lee et al., 2009; Lee and Dutta, 2007; Lin et al., 2009; Shenouda and Alahari, 2009; Welch et al., 2007). In fact, normal cells harbour totally different microRNA profiles than cancer cells (Calin and Croce, 2006). The miRNA profile of tumour cells can even be used to classify them since it reflects their origin and degree of transformation (Lu et al., 2005; Volinia et al., 2006).

Interestingly, p53 was found to induce the expression of some miRNAs. Most notably, the miR-34 family of miRNAs contributes to apoptosis and cell cycle arrest upon induction by p53 (Braun et al., 2008; Chang et al., 2007; Corney et al., 2007; Georges et al., 2008; Georges et al., 2009; He et al., 2007a; Hermeking, 2009a; Raver-Shapira et al., 2007; Tazawa et al., 2007).

Together with the fact that E2F1 can induce programmed cell death, these findings raise the question whether E2F1 may induce miRNAs that contribute to apoptosis. Indeed, E2F1responsive microRNAs were previously identified, like the miR-17-92 cluster (Novotny et al., 2007; Sylvestre et al., 2007; Woods et al., 2007) and at least partially characterized as to their functions in cancer, but so far mostly with anti-apoptotic functions (Petrocca et al., 2008a; Sylvestre et al., 2007; Yan et al., 2009) or no reported influence on apoptosis.

\subsubsection{The miR-34/449 family of microRNAs}

The characterisation of the miR-34 family of microRNAs started with the discovery of miR$34 \mathrm{a}$ as a p53-responsive gene capable of inducing apoptosis and cell cycle arrest in tumour cell lines (Bommer et al., 2007; Braun et al., 2008; Chang et al., 2007; Corney et al., 2007; Georges et al., 2008; Georges et al., 2009; He et al., 2007a; He et al., 2007b; He et al., 2007c; Hermeking, 2007; Hermeking, 2009a; Hermeking, 2009b; Raver-Shapira et al., 2007; Tarasov et al., 2007; Tazawa et al., 2007). MiR-34a is encoded separately; its homologues 
miR-34b and c share a common primary transcript. MiR-34 targets the histone deacetylases SIRT1 (Yamakuchi et al., 2008; Yamakuchi and Lowenstein, 2009) leading to the accumulation of acetylated and therefore highly active p53. Additionally, miR-34 downregulates several CDKs, cyclins and E2Fs (Lodygin et al., 2008; Sun et al., 2008; Tazawa et al., 2007; Welch et al., 2007), leading to cell cycle arrest and inhibition of the E2F pathway. The down-regulation of the anti-apoptotic protein BCL2 (B-cell CLL/lymphoma 2) could also contribute to miR-34-dependent apoptosis (Chang et al., 2007).

Later on, the miR-449 cluster encoding miR-449a and miR-449b was found to have similar sequence and secondary structure to the miR-34 family, and they were therefore classified as one family of microRNAs. In particular, they share the same seed sequence (Fig. 2.3) suggesting similar targets (Filipowicz et al., 2008). In line with the tumour-suppressive role of miR-34, miR-449 was shown to be significantly down-regulated in prostate cancer (Coppola et al., 2010; Noonan et al., 2009).

\begin{tabular}{|c|c|}
\hline & $\begin{array}{c}\text { seed } \\
\text { sequence }\end{array}$ \\
\hline miR-449a & UGGCAGUGUAUUGUUAGCUGGU \\
\hline $\operatorname{miR}-449 b$ & AGGCAGUGUAUUGUUAGCUGGC \\
\hline miR-34a & UGGCAGUGUCUUAGCUGGUUGU \\
\hline $\operatorname{miR}-34 b^{*}$ & UAGGCAGUGUCAUUAGCUGAUUG \\
\hline miR-34c & AGGCAGUGUAGUUAGCUGAUUGC \\
\hline
\end{tabular}

Fig. 2.3: Seed sequence comparison within the miR-34 family

Sequences of miR-449a and b, aligned with miR-34a, b and $c$. Shared seed sequence is shown in bold. Data published in Cell Death \& Differentiation, March 2010. Source of the sequences: http://www.mirbase.org/ (Faculty of Life Sciences, University of Manchester, previously hosted and supported by the Wellcome Trust Sanger Institute) (Griffiths-Jones, 2004; Griffiths-Jones, 2006; Griffiths-Jones et al., 2006; Griffiths-Jones et al., 2008)

MicroRNAs of the miR-34 family are highly conserved. MiR-449 was found in apes (rhesus macaque, chimpanzee, orang-utan), mouse, rat, dog, horse, cattle, chicken and frog. In human, the miR-449 cluster is located on chromosome 5 in a highly conserved region of the second intron of the CDC20B gene (Fig. 2.4), a homologue of CDC20 (involved in mitosis exit). Gene products of the CDC family are thought to have roles in cell cycle regulation, but only very little is known about the function of CDC20B. The CDC20B gene is also conserved in apes, dog, cow, horse and chicken which may reflect its importance. Interestingly, CDC20B was recently detected in different screens of lung tissue and airway epithelia, 
implicating a role of CDC20B or its host miR-449 in such tissues. E.g. it was upregulated after infection in the trachea of chicken (Wang et al., 2009) and, most notably, its expression was induced more than 180-fold in human mucociliary differentiation (Ross et al., 2007). This idea is supported by the fact that other miR-34 family members were also found to be expressed in the respiratory system and reduced in tumours (Bommer et al., 2007; Chang et al., 2007; Dong et al., 2010; Ji et al., 2009; Landgraf et al., 2007; Welch et al., 2007).

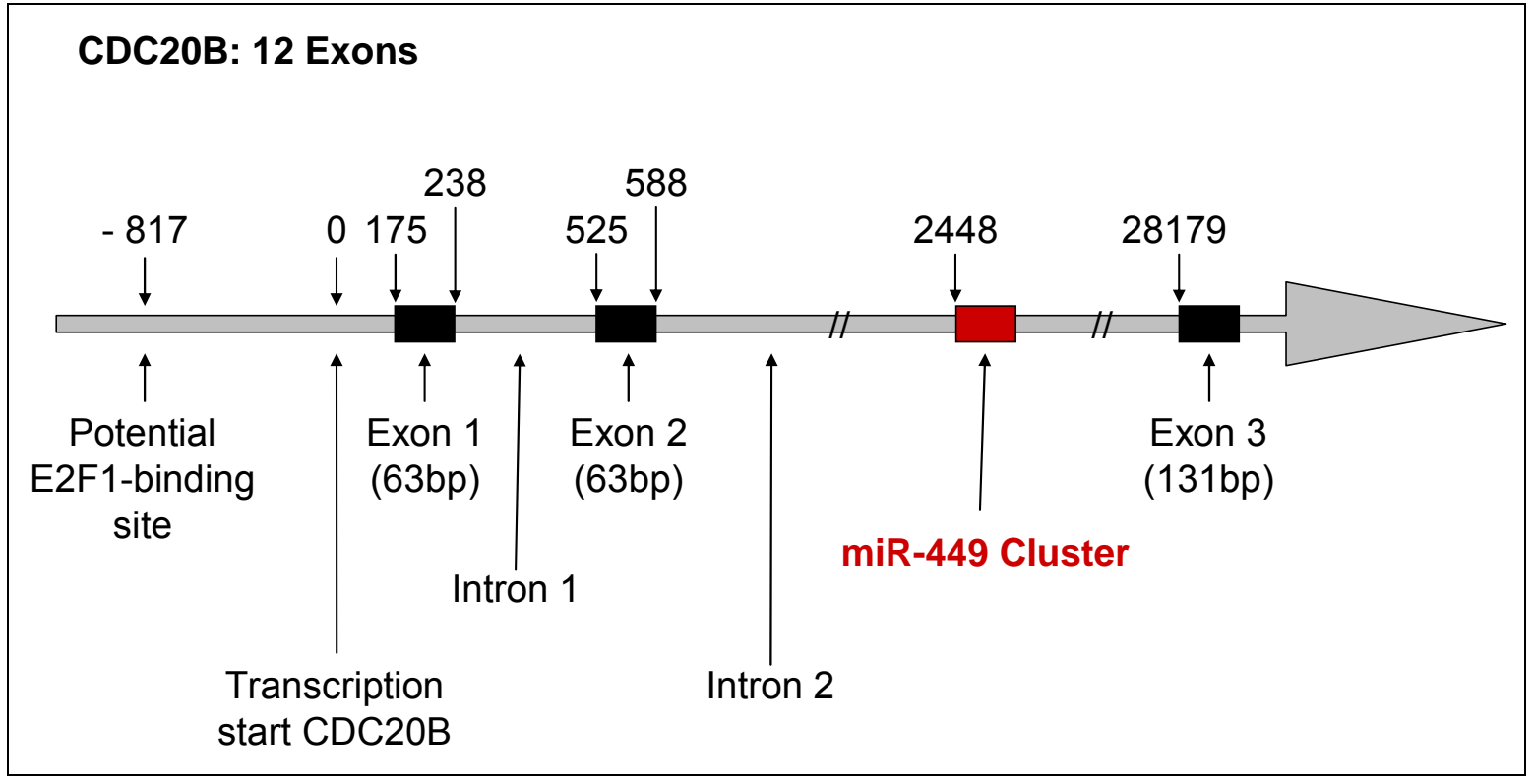

Fig. 2.4: Position of the miR-449 cluster within the CDC20B gene

The genomic region encoding both miR-449a and miR-449b is embedded into an intronic sequence of the mRNA-encoding gene CDC20B, consisting of 12 exons (Lize et al., 2010).

These data strongly suggest that the CDC20B host, miR-449, could be another tumoursuppressive microRNA playing a role in the first line defence of the respiratory tract and in the differentiation of airway epithelium.

\subsection{Airway epithelium and its differentiation}

Due to their "open" nature, airways are exposed to many risks. The air we breathe transports viruses, bacteria, small particles, smoke, solvents, toxins etc. All of these are potential threats to the respiratory tract and the integrity of the cells it is made of, especially to its "coating", the bronchial epithelium. To allow proper respiration and host defence, epithelial cells within the respiratory system must differentiate in a highly ordered fashion (Metzger et al., 2008). Particularly, the airway epithelium covering the trachea and bronchia must ensure proper ventilation and gas exchange, prevent the loss of fluid, and contribute to mucociliary 
clearance and host defence by avoiding the accumulation of toxic substances from the environment. Thus, it acts as a protective barrier. This epithelium forms a pseudo-stratified layer consisting of basal cells, Goblet cells (mucus secretion), Clara cells (secretion, detoxification and renewal of ciliated cells), and ciliated cells (Fig. 2.5). Defects in mucociliary clearance, the most important mechanism of defence in this tissue, are associated with respiratory disorders like cystic fibrosis or chronic obstructive pulmonary diseases (COPD) (Ross et al., 2007).

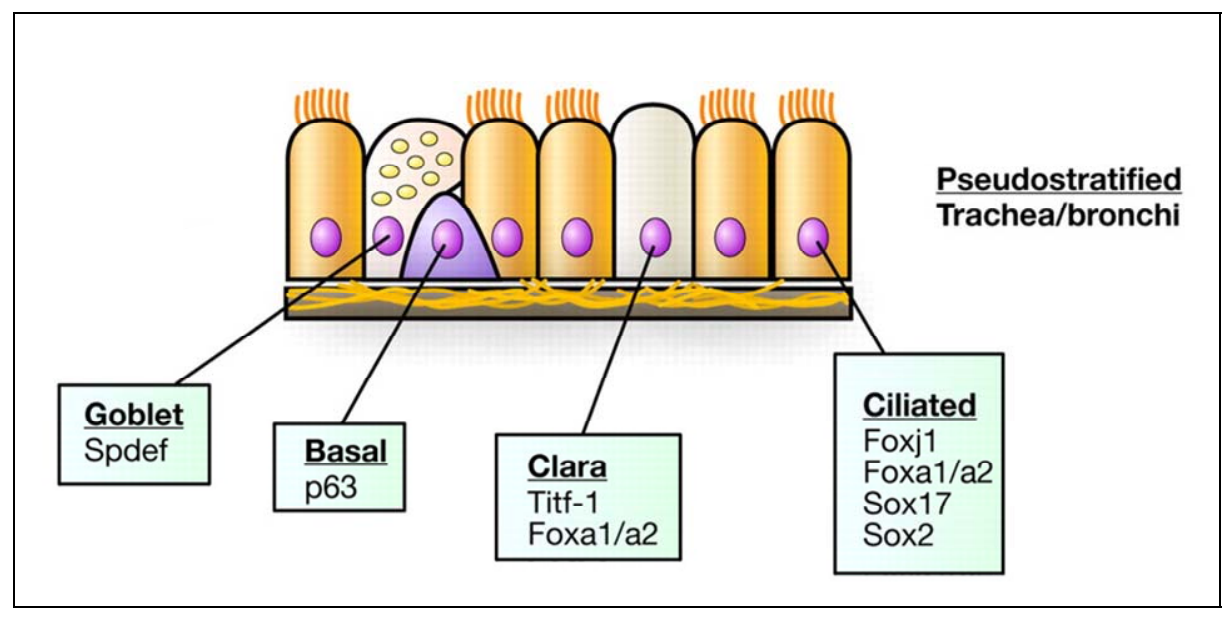

Fig. 2.5: Selective expression of transcription factors in the respiratory epithelium

Large conducting airways (trachea and bronchi) are lined by a pseudo-stratified epithelium consisting primarily of Goblet, basal, Clara (secretory), and ciliated cells. Transcription factors influencing cell type differentiation and gene expression are indicated. Adopted from the review "Transcriptional control of lung morphogenesis" (Maeda et al., 2007)

The process of mucociliary differentiation starts during the pseudo-glandular phases of lung development (around E12 in mouse) and continues until lung maturity (P5-P20) (Fig. 2.6 and Post and Copland, 2002).

Consequently, the differentiation of airway epithelia represents one of the most dramatic changes in cell function that occurs shortly before and after birth, essential for the survival of the organism. The development of the lung involves the activity of several transcription factors in a sequential and cell-specific manner (Fig. 2.5)((Chuang and McMahon, 2003; Maeda et al., 2007). However, our knowledge of the posttranscriptional master regulators behind this process remains incomplete at this stage. 


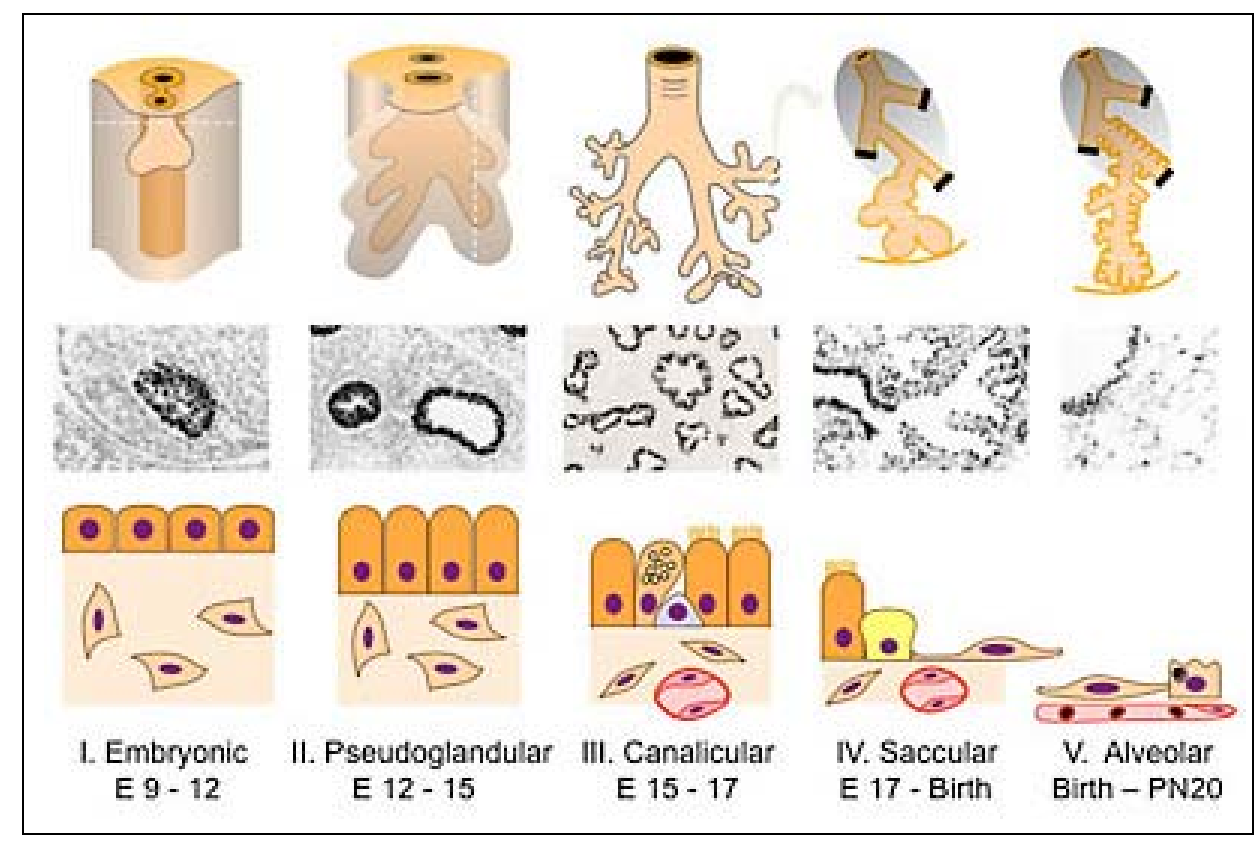

Fig. 2.6: The five stages of the developing lung

The organogenesis of the lung can be divided into five distinct stages: embryonic budding (incl. division of tracheal-oesophageal tube), pseudo-glandular (bronchial branches, acinar tubules and buds; vasculogenesis and innervation), canalicular (pulmonary vascular bed, pulmonary acinus, increasing innervation), saccular (peripheral airspaces, vascularity of the saccules, surfactant synthesis) and alveolar (alveoli, vascular system) phases, shown here for the mouse. Adopted from the homepage of the Whitsett lab, Pulmonary Biology, Cincinnati Children Hospital and (Maeda et al., 2007)

To gain insight into the differentiation process of bronchial epithelia, it has been recapitulated in a cell culture setting. Primary airway epithelial cells (AECs) can be obtained from human donors and maintained in culture. When such a cell monolayer is lifted from a liquid environment to the interface between liquid and air (air-liquid interface, ALI), a mucociliary differentiation program is initiated that reflects the physiological processes occurring in the lung (Bals et al., 2004). By analyzing the associated changes in mRNA levels, a number of differentially regulated genes were previously identified (Ross et al., 2007). Among those, the transcription factor FoxJ1 was suspected to represent one of the regulatory factors that govern downstream genes triggering differentiation (Bals et al., 2004; Brody et al., 2000; Chen et al., 1998; Maeda et al., 2007). Little is known about other master regulators that act at the same stage of differentiation.

Interestingly, mice deficient for $\mathrm{E} 2 \mathrm{~F} 1$ and $\mathrm{Rb}$ die at birth from respiratory failure, which could indicate a role for $\mathrm{E} 2 \mathrm{~F} 1 / \mathrm{Rb}$ in lung differentiation (Tsai et al., 1998). Additionally, the microRNA processing enzyme Dicer is required for proper pulmonary development (Harris et al., 2006), arguing that microRNAs are essential in this process. Moreover, microRNAs were found to be differentially regulated when lungs develop (Bhaskaran et al., 2009; Dong et al., 
2010; Lu et al., 2008; Wang et al., 2007; Williams et al., 2007; Zhang et al., 2010). Therefore, the evident question arising is whether the miR-34 family, especially the members highly expressed in respiratory tissues, or E2F1-responsive microRNAs play a role in lung development or the differentiation of bronchial epithelium.

\subsection{Central question}

The transcription factor E2F1 is very often deregulated in cancer and displays paradoxical activities as an oncogene which pushes cell proliferation and as a tumour suppressor that induces apoptosis. Yet, the balance and regulation between those two cell fates are not fully understood. MicroRNAs are a new class of regulatory genes, acting in the regulation of pathways on a new level.

The central purpose of this work was to identify and characterise new E2F1-responsive microRNAs which may play a role in controlling of the E2F1-mediated cellular decision between proliferation and death, and elucidate the physiological relevance of such microRNAs (Fig. 2.7).

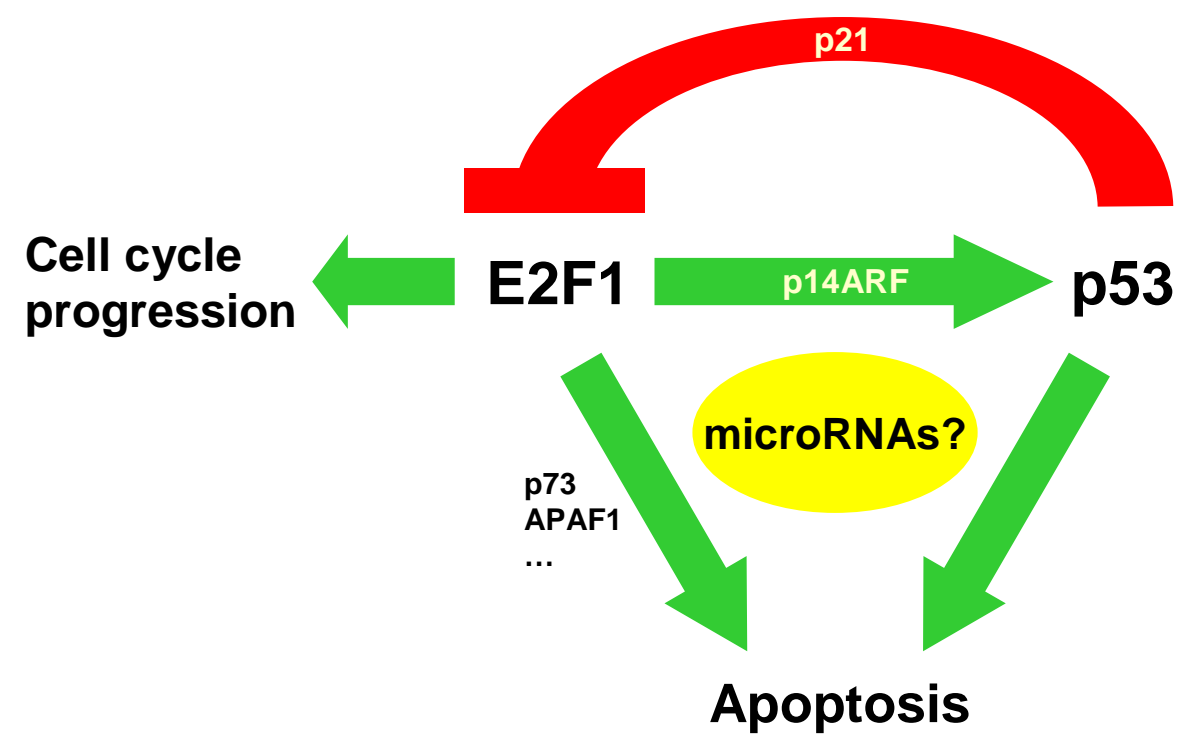

Fig. 2.7: microRNAs in the p53-E2F1 interdependent regulation of cell proliferation and cell death?

E2F1 transactivates not only cell cycle promoting factors, but also p14ARF, leading to p53 stabilisation. p53 in turn transactivates p21, a cyclin-dependent inhibitor, repressing the transcriptional activity of E2F1 and promoting cell cycle arrest. Both E2F1 and p53 are capable of inducing apoptosis through various mechanisms, eventually via the induction of proapoptotic microRNAs. 


\section{Material}

\subsection{Equipment}

Block Heater "Grant Boekel BBA2"

Camera "Power shot A620"

Developing machine "Optimax X-Ray Film Processor"

Model 1170-1-000

Epithelial ohmmeter EVOM

Foil welding apparatus "Vacupack plus F380 70"

Freezer $-80^{\circ} \mathrm{C}$ "Hera freeze"

Freezer $-20^{\circ} \mathrm{C}$

Gel documentation system „Gel Doc 2000“

Incubator (cell culture) "Hera Cell 150"Thermo Incubator

Laminar Flow „HeraSafe ${ }^{\circledR}$ “

Low Voltage Power Supplier "Standard Power Pack P25T“

Luminometer "Centro LB960" coupled to software

"MikroWin2000"

Magnetic stirrer "MR 3001"

Microscope „HBO 100“

Microscope "Hund Wetzlar Wilovert LL"

Microwave "MW 17705"

Mini centrifuge "GMC-060"

PCR-Machine "advanced primus 25“

PCR-Machine „Cycler Biometra $®$ T personal“

pH meter "CG 832“

Pipettes „Research“ (2.5 $\mu \mathrm{l}, 20 \mu \mathrm{l}, 200 \mu \mathrm{l}$ und $1000 \mu \mathrm{l})$

Pipet-Aid $®$ "portable XP"

Precision balance

Real-time PCR-machine „DNA Engine (PTC-200) Peltier

Thermal Cycler” linked to the detection system "Chromo $4^{\mathrm{TM}}$

Real-Time PCR Detector"

Refrigerator $4^{\circ} \mathrm{C}$ "Profi line"

Refrigerated centrifuge "Megafuge 1.0 R"

Refrigerated tabletop centrifuge " $5415 R$ "

Shaker incubator "Minitron“

Shaker „Promax 2020“

SDS-PAGE-Chamber „MiniVE“

Spectrophotometer "NanoDrop $®$ ND-100“

Tabletop centrifuge „5415D”
Grant Instruments

Canon

Protec Medizintechnik

World Precision Instruments

Krups

Thermo

Liebherr

INTAS

Memmert

Thermo

Whatman Biometra

Berthold Technologies

Heidolph Instruments

Karl Zeiss

Helmut Hund

Cinex

LMS Laboratory \& Medical Supplies

Peqlab Biotechnologie

Biometra

Schott

Eppendorf

Drummond

Sartorius

BioRad Laboratories

Liebherr

Thermo

Eppendorf

Infors

Heidolph Instruments

GE Healthcare

Peqlab Biotechnologie

Eppendorf 
Thermomixer "comfort"

Vacuum system "Vacusafe Comfort"

Vortex-Mixer „Vortex Genie 2“

Water bath WB14

Water bath TW20

Western transfer chamber (wet blot) „MiniVE Blotter”

Western transfer chamber (semi-dry blot)

Rocker „Rocky“

X-ray cassette $13 \times 18 \mathrm{~cm}$

Counting chamber Neubauer Improved
Eppendorf

IBS Integra Biosciences

Scientific Industries

Memmert

Julabo Labortechnik

GE Healthcare

Harnischmacher, Labor- und Kunststofftechnik

Schütt Labortechnik

Rego X-Ray

Brand

\subsection{Consumables}

$9,6 \mathrm{~cm}^{2}$-well / 3,9 $\mathrm{cm}^{2}$-well - cell culture plates

Adefodur developer concentrate

Adefodur fixer concentrate

Chamber slides system "LabTek®" (4 chambers)

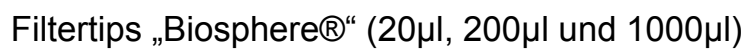

Whatman paper „GB002“

Gloves „Safe Skin PFE“

Cryotubes $(1.8 \mathrm{ml})$

Nitrocellulose protran transfer membrane BA83

Optical film sealing kit (96-well-plates)

Pasteur pipettes $150 \mathrm{~mm}$ and $230 \mathrm{mmWU}$ Mainz

PCR multiplate 96-well unskirted PCR plates (white)

PCR reaction tubes $(200 \mu \mathrm{l})$

PVDF membrane

Reaction tubes $(1,5 \mathrm{ml} / 2 \mathrm{ml})$

X-ray films (blue) RX 13x18 100BI

Screw tube $15 \mathrm{ml}, 120 \times 17 \mathrm{~mm}$, sterile

Screw tube $50 \mathrm{ml}, 114 \times 28 \mathrm{~mm}$, sterile

Heat sealing plastic film (transparent)

Cell culture dishes

Cell scraper $(16 \mathrm{~cm} / 25 \mathrm{~cm})$

Transwell six-well culture plates
Greiner

Adefochemie

Adefochemie

NUNC

Sarstedt

Schleicher \& Schuell

Kimberly Clark

NUNC

Schleicher \& Schuell

BioRad Laboratories

BioRad Laboratories

Sarstedt

Schleicher \& Schuell

Sarstedt

Fuji, Ernst Christiansen

Sarstedt

Sarstedt

Krups

Greiner

Sarstedt

Corning Life Science

\subsection{Chemicals}


2-propanol

Roth

Acetic acid

Roth

Ammonium persulphate (APS)

Roth

Ammonium sulphate ((NH4)2PO4)

Roth

Bromophenol blue

Sigma-Aldrich

Bovine serum albumin (BSA)

Roth

Calcium chloride $(\mathrm{CaCl})$

Roth

Camptothecin (CPT)

Sigma-Aldrich

Chloroform

Roth

Coelenterazine

Promega

Complete, EDTA-free

Roche

Coomassie Brilliant Blue

Sigma-Aldrich

D-Luciferin

ICN

DAPI (4,6 Diamidino-2-Phenyindole)

Sigma-Aldrich

Deoxycholate (DOC)

Applichem

Dimethylsulfoxid (DMSO)

AppliChem

Disodium-hydrogen-phosphate $\left(\mathrm{Na}_{2} \mathrm{HPO}_{4}\right)$

Merck

dNTP-Mix, 20mM

BioBudget

DTT (1,4-Dithiothreitol)

Roth

EDTA (ethylenediaminetetraacetate)

Jena Bioscience

Ethanol 99,9\%

Merck

Fluorescein reference standard

Invitrogen

Formaldehyde

Roth

Glycerine

Roth

Glycine p.A.

Roth

Glycogen, 20mg/ml

Fermentas

$\mathrm{H}_{2} \mathrm{O}$, RNase-Free

Ambion

$\mathrm{HCl}$ acid

Roth

HEPES

Roth

lodoacetamid

Applichem

Isoamyl alcohol

Roth

Magnesium chloride ( $\mathrm{MgCl})$

Merck

Manganese chloride $(\mathrm{MnCl})$

Roth

Methanol

Roth

$\mathrm{NaOH}$ pellets

Roth

Nuclease-free water

Promega

Nutlin-3a

Sigma-Aldrich

$\mathrm{pH}$ solution 10.01

Roth

$\mathrm{pH}$ solution 4.01

Roth

$\mathrm{pH}$ solution 7.01

Roth

Ponceau S

Roth

Potassium acetate ( $\mathrm{CH} 3 \mathrm{COOK})$ 
Potassium chloride $(\mathrm{KCl})$

Potassium dihydrogen phosphate $\left(\mathrm{KH}_{2} \mathrm{PO}_{4}\right)$

Protease inhibitor mix "Complete"

Rotiphorese Gel 30 (30\% acrylamide-solution)

SDS (sodium lauryl sulphate, Natriumdodecylsulfate)

Skimmed milk powder Naturaflor

Sodium azide $0.1 \mathrm{M}$ solution

Sodium acetate

Sodium carbonate

Sodium chloride $(\mathrm{NaCl})$

Sodium deoxycholate

Sodium dihydrogen phosphate

Sodium hydrogen carbonate

Sucrose

SYBR Green I

TEMED (N,N,N',N'-tetramethylendiamine)

Trasylol

Trehalose

Trichostatin A (TSA)

Tris

Triton $\mathrm{x}-100$

TRIzol ${ }^{\circledR}$ Reagent

Tween 20

Urea

\subsection{Kits}

$\mathrm{BCA}^{\mathrm{TM}}$ Protein Assay kit

Developer „Adevodur”

Dual-Luciferase $®$ Reporter Assay System

E.Z.N.A. Plasmid Miniprep Kit II

Fixer „Adevodur”

Lipofectamine $^{\mathrm{TM}} 2000$ transfection reagent

Sequencing mix and buffer "ABI Prism Big Dye Terminator

v3.1 cycle sequencing kit RR100"

SuperSignal West Dura extended duration

SuperSignal West Femto maximum sensitivity

Taq buffer $\left(\mathrm{NH}_{4}\right)_{2} \mathrm{SO}_{4}$ and $25 \mathrm{mM} \mathrm{MgCl}_{2}$

PureYield ${ }^{\mathrm{TM}}$ Plasmid Midiprep System

RNeasy® Mini Kit
Roth

Roth

Roche Diagnostics

Roth

Roth

Töpfer

Sigma-Aldrich

Roth

Roth

Roth

Applichem

Roth

Roth

Serva

Stratagene

Roth

AppliChem

USB Corporation

Bayer Vital

Roth

Roth

Invitrogen

AppliChem

Roth
Pierce

OMNILAB

Promega

Peqlab

OMNILAB

Invitrogen

Applied Biosystems

Pierce

Pierce

Fermentas

Promega

Qiagen 


\subsection{Buffers and solutions}

Coelenterazine solution (1500x stock): $\quad 3 \mathrm{mM}$ in Ethanol

$\begin{array}{lll}\text { Coomassie staining solution: } & \begin{array}{l}0.25 \% \\ 50 \%\end{array} & \begin{array}{l}\text { coomassie brilliant blue } \\ \text { methanol } \\ 10 \%\end{array} \\ \text { D-Luciferin solution (4x stock): } & 5 \mathrm{mg} & \text { D-Luciferin acid } \\ & 18 \mathrm{ml} & \text { Glycylglycine }[25 \mathrm{mM}](\mathrm{pH} 8.0) \\ & \text { store at }-80^{\circ} \mathrm{C} \text { in the dark }\end{array}$

EB buffer:

$10 \mathrm{mM}$ Tris $(\mathrm{pH} 8.5)$

Firefly Buffer (in dark bottle):

$\begin{array}{ll}25 \mathrm{mM} & \text { Glycylglycine } \\ 15 \mathrm{mM} & \mathrm{K}_{2} \mathrm{HPO}_{4} \\ 4 \mathrm{mM} & \text { EGTA } \\ \mathrm{pH} 8.0 & \end{array}$

Laemmli buffer (6x):

$\begin{array}{ll}0.35 \mathrm{M} & \text { tris } \mathrm{pH} 6.8 \\ 30 \% & \text { glycerin }(\mathrm{v} / \mathrm{v}) \\ 10 \% & \mathrm{SDS}(\mathrm{w} / \mathrm{v}) \\ 9.3 \% & \text { Dithiothreitol (DTT) }(\mathrm{w} / \mathrm{v}) \\ 0.02 \% & \text { bromphenol blue }(\mathrm{w} / \mathrm{v})\end{array}$

PBS (Phosphate Buffered Saline)(10x): $236.9 \mathrm{mM} \mathrm{NaCl}$

$2.7 \mathrm{mM} \quad \mathrm{KCl}$

$8.1 \mathrm{mM} \quad \mathrm{Na}_{2} \mathrm{HPO}_{4}$

$1.1 \mathrm{mM} \quad \mathrm{MgCl}_{2}$

$1.5 \mathrm{mM} \quad \mathrm{KH}_{2} \mathrm{PO}_{4}$

$1.2 \mathrm{mM} \quad \mathrm{CaCl}_{2}$

PBS ${ }^{\text {deficient }}$ : composition like PBS, but without $\mathrm{MgCl}_{2}$ und $\mathrm{CaCl}_{2}$.

PBST: composition like PBS with $0.1 \%$ Tween20.

Ponceau S solution:

$\begin{array}{ll}0.5 \mathrm{~g} & \text { ponceau S } \\ 1 \mathrm{ml} & \text { glacial acetic acid } \\ \text { ad } 100 \mathrm{ml} & \mathrm{ddH}_{2} \mathrm{O}\end{array}$

Renilla Buffer ( $\mathrm{pH} 5.1$; in dark bottle):

$\begin{array}{ll}1.1 \mathrm{M} & \mathrm{NaCl} \\ 2.2 \mathrm{mM} & \mathrm{Na}_{2} \mathrm{EDTA}\end{array}$


$0.22 \mathrm{M} \quad \mathrm{K}_{2} \mathrm{HPO}_{4}$

RIPA buffer:

SDS running buffer (10x):

Stripping buffer:

TBS (T
TBST:

Transfer buffer for wet blot:

Western salts (10x):

$\begin{array}{ll}0.1 \% & \text { triton } \mathrm{X}-100(\mathrm{v} / \mathrm{v}) \\ 0.1 \% & \text { desoxycholate }(\mathrm{v} / \mathrm{v}) \\ 0.1 \% & \text { SDS }(\mathrm{w} / \mathrm{v}) \\ 2 \mathrm{mM} & \text { Tris } / \mathrm{HCl}, \mathrm{pH} 8.5 \\ 9 \mathrm{mM} & \mathrm{NaCl} \\ 1 \mathrm{mM} & \text { EDTA } \\ 1.4 \% & \text { trasylol }(100000 \mathrm{KIE}) \\ 18.5 \% & \text { lodacetamide }\end{array}$

$151 \mathrm{~g} \quad$ Tris

$720 \mathrm{~g}$ glycine

$50 \mathrm{~g} \quad$ SDS

ad $5 \mathrm{~L} \quad \mathrm{ddH}_{2} \mathrm{O}$

$50 \mathrm{ml} \quad 1 \mathrm{M}$ Tris $\mathrm{pH} 6.8$

$400 \mathrm{ml} \quad 10 \% \mathrm{SDS}$

$10 \mathrm{ml} \quad \beta$-mercaptoethanol

ad $1 \mathrm{~L} \quad \mathrm{ddH}_{2} \mathrm{O}$

24,2 g Tris

$80 \mathrm{~g} \mathrm{NaCl}$

ad $1 \mathrm{~L} \quad \mathrm{ddH}_{2} \mathrm{O}$.

$100 \mathrm{ml} \quad 10 \times$ TBS

$0.1 \% \quad$ Tween20

ad $1 \mathrm{~L} \quad \mathrm{ddH}_{2} \mathrm{O}$

$100 \mathrm{ml} \quad$ Western Salts (10x)

$150 \mathrm{ml} \quad$ Methanol

$850 \mathrm{ml} \quad \mathrm{ddH}_{2} \mathrm{O}$

$60.55 \mathrm{~g} \quad$ Tris

$288 \mathrm{~g}$ glycine

$0.02 \%$ SDS

$\mathrm{ddH}_{2} \mathrm{O}$ ad $2 \mathrm{~L}, \mathrm{pH}=8.3$

\subsection{Nucleic acids}




\subsubsection{Plasmids \& vectors}

- miR-Vec library: microRNA expression plasmids with Blasticidine resistance for selection in eukaryotic cells, generous gift of R. Agami (Voorhoeve et al., 2006).

- pcDNA3-empty (Invitrogen): used as a control. Mammalian expression vector with CMV promoter and Ampicillin and Neomycin resistance cassettes.

- $\quad$ pcDNA3-E2F1: Mammalian expression vector pcDNA3 (Invitrogen) for E2F1.

- pGL3-Basic Vector (Promega): Firefly luciferase reporter vector (empty) with Ampicillin resistance.

- $\quad$ GGL3-3'UTR-E2F1: Luciferase reporter vector (pGL3-Basic, Promega) containing the 3'UTR of E2F1 (Fig. 4.1).

- pRL-tk (Promega): Renilla luciferase vector (control reporter) with Ampicillin resistance.

\subsubsection{Synthetic microRNAs \& other small RNAs}

Pre-miRs (miR-449a, miR-34a, NC\#1, NC\#2, miR-302*)

Ambion

LNAs (Locked Nucleic Acids) to miR-449a, miR-449b and scramble

Negative control siRNA \#1

Exiqon

Silencer select siRNA CDK6 (s51)

Ambion

Silencer validated siRNA CHEK1 (108)

Ambion

Custom siRNA to E2F1 (sense: GAAGUCCAAGAACCACAUCUU, antisense: GAUGUGGUUCUUGGACUUCUU)

Ambion

MISSION siRNA universal negative control \#1

Ambion

Pre-designed siRNA to SIRT1 (4113770, 4113771)

Sigma

Sigma

\subsubsection{Primers}

All primers were synthesized by Metabion and resuspended in nuclease-free water to a final concentration of $100 \mu \mathrm{M}$.

Tab. 3.1: Oligonucleotides

\begin{tabular}{|l|l|}
\hline human primers & sequence \\
\hline 36B4 forward & GATTGGCTACCCAACTGTTG \\
36B4 reverse & CAGGGGCAGCAGCCACAAA \\
\cline { 2 - 2 }
\end{tabular}




\begin{tabular}{|c|c|}
\hline $\begin{array}{l}\text { BCL2 for } \\
\text { BCL2 rev }\end{array}$ & $\begin{array}{l}\text { GTTTGGTTTTATTTGAAAACCTG } \\
\text { TTCTTTATAGTTCCCCACCATT }\end{array}$ \\
\hline BCL6 for & CAGATTTGTACAGGTGGCCC \\
\hline BRCA1 for & $\begin{array}{l}\text { AGAIIC I GAGAAGGGGL IGG } \\
\text { GCGTCCCCTCACAAATAAAT }\end{array}$ \\
\hline BRCA1 rev & CTTGACCATTCTGCTCCGTT \\
\hline $\begin{array}{l}\text { CDC20b for } \\
\text { CDC20b rev }\end{array}$ & $\begin{array}{l}\text { AACTTTGCGAAGAGGCTGTC } \\
\text { TCTTTCTCAGGCGGTGTCTT }\end{array}$ \\
\hline $\begin{array}{l}\text { CDK2 for } \\
\text { CDK2 rev }\end{array}$ & $\begin{array}{l}\text { GTGGTACCGAGCTCCTGAAA } \\
\text { GGAGAGGGTGAGATTAGGGC }\end{array}$ \\
\hline $\begin{array}{l}\text { CDK6 for } \\
\text { CDK6 rev }\end{array}$ & $\begin{array}{l}\text { AGACCCAAGAAGCAGTGTGG } \\
\text { AAGGAGCAAGAGCATTCAGC }\end{array}$ \\
\hline $\begin{array}{l}\text { Chk1 for } \\
\text { Chk1 rev }\end{array}$ & $\begin{array}{l}\text { TGTTGGATGAAAGGGATAAC } \\
\text { AAACATCAACTGGTTCTGC }\end{array}$ \\
\hline $\begin{array}{l}\text { E2F-1 forward } \\
\text { E2F-1 reverse }\end{array}$ & $\begin{array}{l}\text { CGGTGTCGTCGACCTGAACT } \\
\text { AGGACGTTGGTGATGTCATAGATG }\end{array}$ \\
\hline $\begin{array}{l}\text { FoxJ1 for } \\
\text { FoxJ1 rev }\end{array}$ & $\begin{array}{l}\text { GCCCAGGACCAGAATCGCT } \\
\text { GGAAGACGCGGAGCAATGAAACAC }\end{array}$ \\
\hline $\begin{array}{l}\text { GAPDH forward } \\
\text { GAPDH reverse }\end{array}$ & $\begin{array}{l}\text { TGAAGGTCGGAGTCAACGGATTTGGT } \\
\text { GCAGAGATGATGACCCTTTTGGCTC }\end{array}$ \\
\hline $\begin{array}{l}\text { HDAC1 forward } \\
\text { HDAC1 reverse }\end{array}$ & $\begin{array}{l}\text { ACCATGCAAAGAAGTCCGAG } \\
\text { GGCTTGAAAATGGCCTCATA }\end{array}$ \\
\hline $\begin{array}{l}\text { p21 forward } \\
\text { p21 reverse }\end{array}$ & $\begin{array}{l}\text { TAGGCGGTTGAATGAGAGG } \\
\text { AAGTGGGGAGGAGGAAGTAG }\end{array}$ \\
\hline $\begin{array}{l}\text { SIRT1 forward } \\
\text { SIRT1 reverse }\end{array}$ & $\begin{array}{l}\text { GAGATAACCTTCTGTTCGGTG } \\
\text { CGGCAATAAATCTTTAAGAAT }\end{array}$ \\
\hline \multicolumn{2}{|l|}{ murine primers } \\
\hline mmu CDKn1a(p21Cip1) fwd & GTGGCCTTGTCGCTGTCTT \\
\hline mmu CDKn1a(p21Cip1) rev & GCGCTTGGAGTGATAGAAATCTG \\
\hline mmu E2F1 fwd & AACTGGGCAGCTGAGGTGC \\
\hline mmu E2F1 rev & CAAGCCGCTTACCAATCCC \\
\hline mmuTAp73 fwd 382-402 & AGCAGAATGAGCGGCAGCGTT \\
\hline mmuTAp73 rev 544-523 & TGTTGGACTCCTCGCTGCCTGA \\
\hline
\end{tabular}

\subsection{Proteins \& Peptides}

\subsubsection{Protein marker}

PageRuler ${ }^{\mathrm{TM}}$ Prestained Protein Ladder $\quad$ Fermentas

\subsubsection{Enzymes}

M-MuLV reverse transkriptase

Protease 14

26
New England Biolabs GmbH

Sigma 
RNase Inhibitor

Taq Polymerase, hot start [5 units/ $\mu$ l]
New England Biolabs GmbH

Axon Labortechnik

\subsubsection{Antibodies}

Tab. 3.2: Primary antibodies

\begin{tabular}{|c|c|c|c|c|}
\hline Antigen & species & clone & $\begin{array}{l}\text { Dilution/ } \\
\text { Concentration }\end{array}$ & Company \\
\hline Acetyl-p53 (Lys382) & Rabbit, polyclonal & & 1:1000 & Cell Signaling \\
\hline Beta-actin & Mouse, monoclonal & AC-15 & 1:20000 $(0.08 \mu \mathrm{g} / \mathrm{ml})$ & Abcam \\
\hline CDK6 & Mouse, monoclonal & DCS83 & $1: 500$ & Cell Signaling \\
\hline Chk1 & Mouse, monoclonal & 2G1D5 & $1: 1000$ & Cell Signaling \\
\hline Cleaved caspase-3 (Asp175) & Rabbit, monoclonal & $5 \mathrm{~A} 1$ & $1: 400$ & Cell Signaling \\
\hline E2F1 & Mouse, monoclonal & KH95 & $1: 400(0.5 \mu \mathrm{g} / \mathrm{ml})$ & Santa Cruz \\
\hline E2F3 & Rabbit, monoclonal & $\mathrm{N}-20$ & $1: 1000$ & Santa Cruz \\
\hline $\begin{array}{l}\text { GammaH2AX (phospho- } \\
\text { histone H2A.X) (Ser139) }\end{array}$ & Mouse, monoclonal & JBW301 & $1: 5000$ & Upstate \\
\hline HDAC1 & Rabbit, polyclonal & & $1: 500$ & Cell Signaling \\
\hline Hsc70 & Mouse, monoclonal & B-6 & $1: 50000$ & Santa Cruz \\
\hline Noxa & Mouse, monoclonal & $114 C 307$ & $1: 400(1.25 \mu \mathrm{g} / \mathrm{ml})$ & Abcam \\
\hline p21WAF1 (Ab-1) & Mouse, monoclonal & EA10 & $1: 1000$ & Calbiochem \\
\hline p27 & Mouse, monoclonal & $F-8$ & $1: 1000$ & Santa Cruz \\
\hline p53 & Mouse, monoclonal & DO-1 & $1: 1000(0.2 \mu \mathrm{g} / \mathrm{ml})$ & Santa Cruz \\
\hline Parp-1 (Ab-2) & Mouse, monoclonal & & $1: 500$ & Calbiochem \\
\hline Phospho-Chk1(Ser317) & Rabbit, polyclonal & & $1: 500$ & Cell Signaling \\
\hline Phospho-Chk2 (Thr68) & Rabbit, polyclonal & & $1: 800(0.11 \mu \mathrm{g} / \mathrm{ml})$ & Cell Signaling \\
\hline Phospho-p38(Thr180/Tyr182) & Rabbit, polyclonal & & $1: 500$ & Cell Signaling \\
\hline Phospho-p53 (Ser15) & Mouse, monoclonal & $16 \mathrm{G} 8$ & $1: 800(0.125 \mu \mathrm{g} / \mathrm{ml})$ & Cell Signaling \\
\hline SIRT1 & Mouse, monoclonal & B-7 & $1: 500$ & Santa Cruz \\
\hline
\end{tabular}

Tab. 3.3: Secondary antibodies

\begin{tabular}{|l|l|l|}
\hline Name & Dilution/Concentration & Company \\
\hline $\begin{array}{l}\text { Peroxidase-conjugated affiniPure } \mathrm{F}\left(\mathrm{ab}^{\prime}\right)_{2} \text { Fragment, } \\
\text { donkey anti-mouse } \mathrm{IgG}(\mathrm{H}+\mathrm{L})\end{array}$ & $\begin{array}{l}1: 10000 \\
(0.08 \mu \mathrm{g} / \mathrm{ml})\end{array}$ & Jackson ImmunoResearch \\
\hline $\begin{array}{l}\text { Peroxidase-conjugated affiniPure } \mathrm{F}\left(\mathrm{ab}^{\prime}\right)_{2} \\
\text { donkey anti-rabbit } \mathrm{IgG}(\mathrm{H}+\mathrm{L})\end{array}$ & Jackson ImmunoResearch \\
\hline
\end{tabular}




\subsection{Cell culture}

\section{Bacteria:}

$\begin{array}{ll}\text { Agar } & \text { Sigma-Aldrich } \\ \text { Ampicillin [ad } 200 \mu \mathrm{g} / \mathrm{ml}] & \text { Sigma-Aldrich } \\ \text { Kanamycin [ad } 25 \mu \mathrm{g} / \mathrm{ml}] & \text { Sigma-Aldrich } \\ \text { Tryptone } & \text { Roth }\end{array}$

Yeast extract

Sigma-Aldrich

2YT medium: $1.6 \%$ tryptone $(\mathrm{w} / \mathrm{v}), 1 \%$ yeast extract $(\mathrm{w} / \mathrm{v})$ and $0.5 \% \mathrm{NaCl}(\mathrm{w} / \mathrm{v})$ in water.

LB medium: $1 \%$ tryptone $(\mathrm{w} / \mathrm{v}), 1 \%$ yeast extract $(\mathrm{w} / \mathrm{v})$ und $0.5 \% \mathrm{NaCl}(\mathrm{w} / \mathrm{v})$ in water.

LB agar plates: $15 \%$ Agar (w/v) in LB medium.

\section{Mammalian cells:}

$\begin{array}{ll}\text { Airway epithelial cell growth medium } & \text { Promocell } \\ \text { Blasticidine S HCL } & \text { Sigma-Aldrich } \\ \text { Ciprofloxacin (Ciprobay®200) } & \text { Bayer Vital } \\ \text { Dulbecco`s Modified Eagle Medium (DMEM) } & \text { GibcoBRL/Invitrogen } \\ \text { Fetal calf serum, FCS } & \text { GibcoBRL/Invitrogen } \\ \text { L-Glutamine } & \text { GibcoBRL/Invitrogen } \\ \text { McCoys 5A } & \text { GibcoBRL/Invitrogen } \\ \text { Penicillin / Streptomycin } & \text { GibcoBRL/Invitrogen } \\ \text { Tetracycline } & \text { Roth } \\ \text { Trypsin/EDTA } & \text { GibcoBRL/Invitrogen } \\ \text { Ultroser G serum substitute } & \text { Pall Life Science }\end{array}$

Media were completed with $10 \mu \mathrm{g} / \mathrm{ml}$ Ciprofloxacin, $50 \mathrm{U} / \mathrm{ml}$ Penicillin, $50 \mu \mathrm{g} / \mathrm{ml}$ Streptomycin, $2 \mu \mathrm{g} / \mathrm{ml}$ Tetracycline, 10\% FCS and $200 \mu \mathrm{M}$ L-Glutamine.

The differentiation medium for the AECS (DMEM/HamF12, 1:1) was supplemented with $2 \%$ Ultroser $\mathrm{G}$ serum substitute.

\subsection{Cells}

\subsubsection{Prokaryotic cells}

Electrocompetent cells Escherichia coli DH 10 B „Electromax“, Invitrogen 


\subsubsection{Eukaryotic cells}

\section{$\underline{\text { Tumour cell lines }}$}

- H1299 cells, from human lung adenocarcinoma, p53 deleted (from A. Levine)

- U2OS cells, from human osteosarcoma, wild-type p53, p14 ${ }^{\mathrm{ARF}}$ silenced (ATCC)

- HCT116 wt and -/- p53 cells, from human colon carcinoma with and without p53 (obtained from B. Vogelstein (Bunz et al., 1998))

- Saos2 cells, from human osteosarcoma, p53 and Rb deleted (ATCC)

- Saos2 tet-on E2F1 cells, from human osteosarcoma, p53 and Rb deleted, with tetinducible E2F1 (from K. Vousden (Phillips et al., 1999))

- GH cells, from human testicular teratocarcinoma, p53 wt but inactivated (from R. Loewer)

- 833KE cells, from human testicular teratocarcinoma, p53 wt but inactivated (from R. Loewer)

- T98G cells, from glioblastoma multiforme, p16 and p53 deleted (ATCC)

\section{Primary cells}

- Aero-epithelial cells (Elaut et al.), human primary bronchial epithelial cells (HBEC) obtained from human donors during large airways resection (see method section 4.1 .1 for detailed procedure).

\subsection{Animals \& tissues}

Male C57BL/6 mice (B6N, $n=3$ per group) were used for adult tissue analysis. At the age of 5 $(n=3), 10(n=4)$ or 11 weeks $(n=3)$, male B6N mice were killed by cervical dislocation and organs were isolated. Younger animals (P1, P3, P9 and P14) were killed by decapitation, sex was not determined. For embryonic stages, pregnant female $\mathrm{B} 6 \mathrm{~N}$ mice were killed at day 16.5 post coitum. Uteri containing the embryos were isolated and dissected in ice cold PBS. Embryonic lung tissue was isolated in cold PBS under a stereomicroscope. Animals were handled in accordance with the German Animal Protection Law and with the permission of the Bezirksregierung Braunschweig. 


\section{Methods}

\subsection{Cell biological methods}

\subsubsection{Isolation of human primary airway epithelial cells}

Human primary bronchial epithelial cells (HBEC) were isolated from large airways resected during surgery and cultivated as submersed or air liquid interface (ALI) cultures as described previously (Bals et al., 2004). Donors underwent lung transplantation due to pulmonary fibrosis. The protocol was approved by the ethics committee of the University of Marburg and informed consent was obtained from the patients. Briefly large airways were digested enzymatically with protease 14 . The cells were expanded in airway epithelial cell growth medium supplemented with growth factors and preserved in liquid nitrogen.

\subsubsection{Air-liquid interface cultures \& smoke condensate exposition}

HBECs were seeded in cell culture plates and grown until they reached $70-80 \%$ confluence. For the establishment of ALIs $2.5-3 \times 10^{5}$ cells/well were seeded in transwell six-well culture plates in airway epithelial cell growth medium supplemented with growth factors and $1 \%$ of a mixture of Penicillin and Streptomycin. The cells were incubated for 3 days in a standard cell culture incubator. The apical medium was removed and the basolateral medium replaced by differentiation medium (DMEM/HamF12, 1:1) containing 2\% Ultroser $G$ serum substitute. The cells were regarded as fully differentiated after reaching a transepithelial resistance greater than $1000 \mathrm{Ohms} / \mathrm{cm}^{2}$ as measured by an epithelial ohmmeter. Tissue cultures were exposed to volatile cigarette smoke (CS) as described previously (Beisswenger et al., 2004). Briefly, tissue cultures were exposed to CS for $15 \mathrm{~min}$ (= 3 cigarettes). After the exposure, the medium of the cultures was replaced immediately. Control cultures were incubated in the exposure chamber for the same time period without burning a cigarette.

\subsubsection{Cell culture \& drug treatment of tumour cell lines}

HCT116 cells with and without p53 were grown in McCoy's 5A, H1299, U2OS, GH and 833KE and Saos-2 cells without or with tet-inducible E2F1 were cultivated in Dulbecco's Modified Eagle's medium, each supplemented with 10\% foetal bovine serum. Camptothecin (CPT; solved in DMSO), a topoisomerase I inhibitor known to induce double-strand breaks 
(DSBs), was used at $2.9 \mu \mathrm{M}$. The Mdm2-inhibitor Nutlin-3a (in DMSO) was used at $8 \mu \mathrm{M}$ to accumulate p53. The caspase inhibitor Z-VAD (in DMSO) was used at $50 \mu \mathrm{m}$. Doxycycline (solved in water) was used for the induction of the tet-on system at $2 \mu \mathrm{g} / \mathrm{ml}$. Trichostatin $A$ (TSA), an antifungal antibiotic, selectively inhibits class I and II histone deacetylases, but not Sirtuins (class III HDACs). TSA was used at a final concentration of $250 \mathrm{nM}$.

\subsubsection{Transfection of eukaryotic cells}

\section{Transient transfection of cells with pre-microRNAs:}

Cells were reverse-transfected with synthetic pre-micro-RNAs (Ambion/Applied Biosystems). microRNA was diluted in $250 \mu \mathrm{l}$ medium without serum to get $10 \mathrm{nM}$ end concentration. $4 \mu \mathrm{l}$ Lipofectamine2000 (Invitrogen) was incubated with $250 \mu \mathrm{l}$ medium for $5 \mathrm{~min}$. The combination of both mixtures was incubated for $20 \mathrm{~min}$ at room temperature and added to a suspension of freshly trypsinated cell, followed by seeding in 6-well dishes.

\section{Transient transfection of cells with siRNAs:}

siRNAs were reverse transfected using the same protocol as for pre-microRNAs at $30 \mathrm{nM}$.

\section{Transient transfection of cells with plasmid-DNA:}

Cells were seeded in 6-well plates one day prior to transfection and forward transfected using the standard operating procedure for Lipofectamine2000 (8 $\mu$ L Lipofectamine2000 and $2,4 \mu \mathrm{g}$ DNA per well).

Stably transfected cells:

Stable transfection was achieved by selection of the transfected cells using Geneticin $[500 \mu \mathrm{g} / \mathrm{ml}]$ or Blasticidine $[10 \mu \mathrm{g} / \mathrm{ml}]$ depending on the resistance cassette of the transfected construct.

\subsubsection{Clonogenic assays}

Cells were transfected in 6-well plates with miR-vectors, a generous gift of R. Agami (Voorhoeve et al., 2006). Cultures were maintained for 2 to 3 weeks with Blasticidine $[10 \mu \mathrm{g} / \mathrm{ml}]$ selection of the transfectants, followed by fixation with $70 \%$ methanol at $4^{\circ} \mathrm{C}$ and staining with crystal violet.

\subsubsection{Flow cytometry}




\section{Analysis of cell cycle distribution using propidium iodide (PI) staining of the DNA content}

Attached cells combined with floating cells were harvested and fixed in $70 \%$ ethanol at $4^{\circ} \mathrm{C}$. The cells were then resuspended and incubated for 30 minutes in PBS containing $1 \mathrm{mg} / \mathrm{ml}$ RNase A, and stained with $15 \mu \mathrm{g} / \mathrm{ml}$ PI (end concentration), a fluorescent DNA intercalating agent. Samples were analyzed by the Guava/Millipore Easycyte Plus System using the Guava ExpressPro or ModFit Software.

\subsubsection{Dual luciferase assay}

Method adapted from "Noncommercial Dual Luciferase Enzyme Assay System for Reporter Gene Analysis", Analytical Chemistry 2000 (Dyer et al., 2000)

To find out if microRNAs could regulate E2F1 through binding to its 3'UTR we used the construct pictured in Fig. 4.1. If a microRNA binds to the 3'UTR and targets the mRNA for degradation or translational repression, luciferase activity should be decreased.

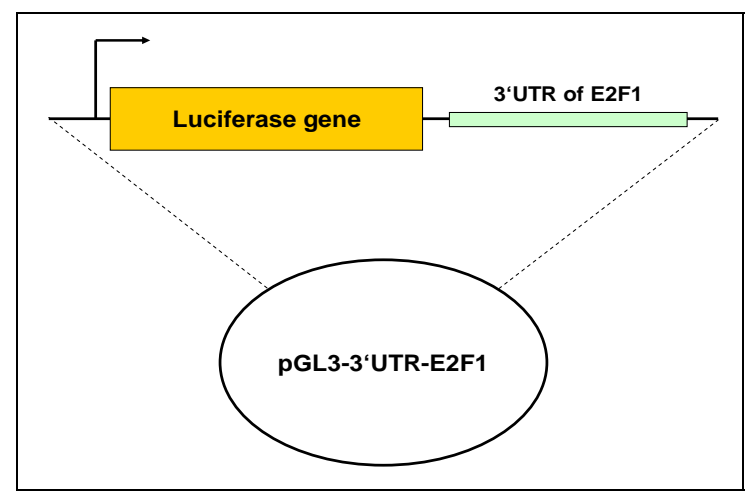

\section{Fig. 4.1: pGL3-3'UTR-E2F1 vector}

H1299 cells (20,000 per 96-well) were reverse transfected with pGL3-3'UTR-E2F1 (30ng), pRL-tk (50ng) and each miR-Vec (160ng) containing a microRNA or the hTR control using lipofectamine 2000 and incubated for $24 \mathrm{~h}$ at $37^{\circ} \mathrm{C}$. The cells were then shaked for $15 \mathrm{~min}$ at room temperature in 65 $\mu$ l Passive Lysis Buffer (Promega) per well. After short centrifugation, $40 \mu \mathrm{l}$ of the supernatant was transferred into a 96-well Optiwell plate. The following working reaction buffers were made fresh as follows.

Per $10 \mathrm{ml}$ Firefly Buffer (stock), addition of: $200 \mu \mathrm{l}$ of $1 \mathrm{M} \mathrm{MgSO}_{4}(\sim 15 \mathrm{mM}$ final concentration), $500 \mu \mathrm{l}$ of $100 \mathrm{mM}$ ATP $\mathrm{pH} 7.0$ ( $4 \mathrm{mM}$ final concentration), $15 \mu \mathrm{l}$ of $1 \mathrm{M}$ DTT $(\sim 1.25 \mathrm{mM}$ final concentration), $120 \mu \mathrm{l}$ of $10 \mathrm{mM}$ CoA $(0.1 \mathrm{mM}$ final concentration), $1 \mathrm{ml}$ Luciferin ( $80 \mu \mathrm{M}$ final concentration). Per $10 \mathrm{ml}$ Renilla Buffer (stock), addition of: $500 \mu \mathrm{l}$ of $10 \mathrm{mg} / \mathrm{ml}$ BSA 
( $0.5 \mathrm{mg} / \mathrm{ml}$ final concentration), $12 \mu \mathrm{l}$ of $1.3 \mathrm{M} \mathrm{NaN}$ ( $1.5 \mathrm{mM}$ final concentration), $2.5 \mu \mathrm{l}$ of $6 \mathrm{mM}$ Coelenterazine $(\sim 1.5 \mu \mathrm{M}$ final concentration).

Luminometer (Berthold Technologies) was set to dispense $100 \mu \mathrm{l}$ of working Firefly Buffer with a 2 second delay and a 10 second integration. This was followed by injection of $100 \mu$ of working Renilla Buffer with a 2 second delay and a 10 second integration.

\subsection{Molecular biological methods}

\subsubsection{Transformation, cultivation and selection of bacteria}

$50 \mu$ l of chemical competent E. coli DH10B were mixed with 100 ng DNA [0.5-1 $\mu$ l DNA] and incubated on ice for 30 min (can vary depending on plasmid size!). Cells were subsequently incubated for $10 \mathrm{~min}$ at $37^{\circ} \mathrm{C}$ and cooled down on ice for $10 \mathrm{~min}$. After addition of $50 \mu \mathrm{LB}$ or 2YT medium, cells were plated on agar containing Ampicillin [200 $\mu \mathrm{g} / \mathrm{ml}]$ or Kanamycin [25 $\mu \mathrm{g} / \mathrm{ml}$ (Sigma-Aldrich) depending on the resistance cassette of the plasmid and incubated overnight at $37^{\circ} \mathrm{C}$.

\subsubsection{DNA preparation}

Midi preparation of DNA was performed using the PureYield ${ }^{\text {TM }}$ Plasmid Midiprep System kit from Promega as recommended by the manufacturer.

\subsubsection{RNA preparation}

\section{$\underline{\text { Cell culture }}$}

For microRNA-analysis, total RNA was isolated using the mirVana RNA Isolation kit (Ambion). For mRNA analysis, total RNA was isolated either with TRIzol (Invitrogen) or with the RNeasy Mini Kit from Qiagen when it was necessary to discard the transfected premicro-RNAs from the preparation prior to reverse transcription.

\section{$\underline{\text { Murine tissues }}$}

Mice or embryos were sacrificed and organs were isolated. The tissue was homogenized in 1 $\mathrm{ml}$ of TRIzol (Invitrogen) and frozen in liquid nitrogen. After thawing, the lysate was chloroform-extracted and ethanol-precipitated. The pellet was dissolved in pre-heated $\left(95^{\circ} \mathrm{C}\right)$ miRVana elution buffer (Ambion). 


\subsubsection{Concentration of nucleic acids}

The concentration and purity of the isolated nucleic acids was measured using standard spectrophotometric quantification by the Nanodrop ${ }^{\mathrm{TM}} \mathrm{ND}-1000$.

\subsubsection{DNA sequencing}

Plasmid (200-400ng) or PCR product (10-30ng) was mixed to 8 pmol of the sequencing primer, sequence mix $(1.5 \mu \mathrm{l}$ or $1 \mu \mathrm{l}$ respectively) and sequence buffer $(1.5 \mu \mathrm{l}$ or $1 \mu \mathrm{l}$ respectively). Water was added to $10 \mu$ prior to sequence PCR $\left(10 \mathrm{sec}\right.$ at $96^{\circ} \mathrm{C}, 15 \mathrm{sec}$ at $55^{\circ} \mathrm{C}$ and $4 \mathrm{~min}$ at $60^{\circ} \mathrm{C}$ for 25 cycles). Each sample was incubated 5 min with $1 \mu \mathrm{l} 125 \mathrm{mM}$ EDTA, $1 \mu \mathrm{l} 3 \mathrm{M} \mathrm{NaAc}$ and $50 \mu \mathrm{l} 100 \% \mathrm{EtOH}$ and then centrifuged at 12,000 rpm for $15 \mathrm{~min}$. Supernatant was washed with $70 \mu \mathrm{l}$ of $70 \% \mathrm{EtOH}$, repelleted and dried. The sequencing was carried out in $30 \mu \mathrm{l} \mathrm{HPLC}$ water by the sequencing facility in our institute using the ABI 3100 Automated Capillary DNA Sequencer (Applied Biosystems).

\subsubsection{Reverse transcription of mRNA in cDNA}

To detect mRNA expression, the isolated RNA was reverse transcribed using the following procedure. $1 \mu \mathrm{g}$ of total RNA in $10 \mu \mathrm{LEPC}$ water was mixed with $2 \mu \mathrm{l}$ of a primer solution (containing $15 \mu \mathrm{M}$ random nonamers and $50 \mu \mathrm{M}$ dT23VN primers) and $4 \mu$ of a dNTP mix [2.5 mM], and heated for $5 \mathrm{~min}$ at $70^{\circ} \mathrm{C}$. Then, $4 \mu \mathrm{l}$ of the following master mix was added to each sample: $2 \mu \mathrm{l}$ 10X Reaction Buffer, $0.25 \mu$ R Rase Inhibitor (10 U), $0.125 \mu \mathrm{l}$ M-MuLV Reverse Transcriptase (25 U) and $1.625 \mu$ LEPC water. The samples were incubated at $42^{\circ} \mathrm{C}$ for $1 \mathrm{~h}$ for reverse transcription and at $95^{\circ} \mathrm{C}$ for $5 \mathrm{~min}$ for enzyme inactivation. The reaction was diluted to $50 \mu$ l by adding $30 \mu$ l water.

\subsubsection{Semi-quantitative Realtime PCR using SYBR Green}

For Realtime PCR applications, following home-made master mix was prepared as a $10 \mathrm{x}$ qPCR mix prior to use (Tab. 4.1). After sterilisation using a $0.2 \mu \mathrm{m}$ filter, further ingredients were added to the 10x qPCR Mix to produce the 2x qPCR-Master Mix (Tab. 4.2). The $2 x$ qPCR Mix was then aliquoted and snap frozen. The final reaction was mixed as shown in Tab. 4.3. The qPCR program is shown in Tab. 4.4. The list of the RT-PCR primer sets can be found in Tab. 3.1. The standard curve method was used for the relative quantification of gene expression. 
Tab. 4.1: Home-made 10x qPCR Mix

\begin{tabular}{|l|c|c|c|}
\hline component & stock conc. & for $50 \mathrm{ml}$ & final conc. \\
\hline Tris- $\mathrm{HCl}(\mathrm{pH} 8.8)$ & $1.5 \mathrm{M}$ & $25 \mathrm{ml}$ & $750 \mathrm{mM}$ \\
\hline$\left(\mathrm{NH}_{4}\right)_{2} \mathrm{SO}_{4}$ & $1 \mathrm{M}$ & $10 \mathrm{ml}$ & $200 \mathrm{mM}$ \\
\hline Tween-20 & $10 \%$ & $500 \mu \mathrm{l}$ & $0.10 \%$ \\
\hline $\mathrm{H}_{2} \mathrm{O}$ & & $14.5 \mathrm{ml}$ & \\
\hline
\end{tabular}

Tab. 4.2: Home-made 2x qPCR-Master Mix

\begin{tabular}{|c|c|c|c|c|}
\hline component & stock conc. & $\mu \mathrm{l}$ for 1 sample & $\mu \mathrm{l}$ for 3000 samples & final conc. \\
\hline 10 x qPCR Mix (Tab. 4.1) & $10 x$ & 2.5 & 7500 & $1 \mathrm{x}$ \\
\hline $\mathrm{MgCl}_{2}$ & $25 \mathrm{mM}$ & 3 & 9000 & $3 \mathrm{mM}$ \\
\hline Trehalose (in 10mM Tris $\mathrm{pH} 8.0$ ) & $1 \mathrm{M}$ & 7.5 & 22500 & \\
\hline Triton X-100 & $10 \%$ & 0.625 & 1875 & $0.25 \%$ \\
\hline Sybr Green & $1: 100$ & 0.0313 & 93.9 & $1: 80000$ \\
\hline dNTPs & $20 \mathrm{mM}$ & 0.25 & 750 & $0.2 \mathrm{mM}$ \\
\hline Taq-polymerase & $5 \mathrm{U} / \mu \mathrm{l}$ & 0.1 & 300 & $20 \mathrm{U} / \mathrm{ml}$ \\
\hline Total & & 14 & 42000 & \\
\hline
\end{tabular}

Tab. 4.3: Master mix per $1 \mu \mathrm{l}$ cDNA from the reaction described in 4.2.6

\begin{tabular}{|l|c|c|}
\cline { 2 - 3 } \multicolumn{1}{c|}{} & \multicolumn{2}{c|}{ for 1 sample } \\
\hline & Final concentration & Volume in $\mu \mathrm{l}$ \\
\hline $\mathrm{H}_{2} \mathrm{O}$ & $1 \mathrm{x}$ & 10 \\
\hline Primer forward $(10 \mu \mathrm{M})$ & & 8.2 \\
\hline Primer reverse $(10 \mu \mathrm{M})$ & $250 \mathrm{nM}$ & 0.4 \\
\hline \hline Total & $250 \mathrm{nM}$ & 0.4 \\
\hline
\end{tabular}

Tab. 4.4: Realtime PCR cycling program

\begin{tabular}{|c|c|c|}
\hline Time & Temperature & Comments \\
\hline $00: 02: 00$ & $95^{\circ} \mathrm{C}$ & Hot start \\
\hline $00: 00: 15$ & $95^{\circ} \mathrm{C}$ & melting + annealing + elongation \\
x 39 times
\end{tabular}

\subsubsection{Reverse transcription of mature microRNAs and semi- quantitative Realtime PCR using Taqman}

Stem-loop qRT-PCR for mature microRNAs was done using the TaqMan MicroRNA assays (Applied Biosystems) as recommended by the manufacturer. microRNA expression levels 
were normalized to RNU6b or to U6 snRNA (non-coding small nuclear RNA component of the U6 small nuclear ribonucleoprotein, part of the spliceosome).

\subsection{9. microRNA microarray analysis}

Saos 2 cells with an integrated, inducible ("tet-on") E2F1 expression construct (Phillips et al., 1999) were treated or not with doxycycline at a concentration of $2 \mu \mathrm{g} / \mathrm{ml}$ for 24 hours. RNA samples enriched for small RNA molecules were isolated by using the miRVana RNA Isolation kit (Ambion/Applied Biosystems). Array hybridization was carried out using the Exiqon system of arrayed locked nucleic acids (LNAs) as recommended by the manufacturer.

\subsection{Protein biochemical methods}

\subsubsection{Protein lysates}

Adherent and floating cells were combined and pelleted at $4^{\circ} \mathrm{C}$ and $500 \mathrm{~g}$. Pellet was dissolved in a lysis buffer made of RIPA, $2 x$ laemmli and $2.7 \mathrm{M}$ urea and cooked at $95^{\circ} \mathrm{C}$ and 1400 rpm for 5 minutes.

\subsubsection{BCA test}

The protein concentration of the 1:300 diluted samples (prepared as in 4.3.1) was determined using the $\mathrm{BCA}^{\mathrm{TM}}$ Protein Assay Kit from Pierce as recommended by the manufacturer and the BCA test mode of the Nanodrop.

\subsubsection{Immunoblot analysis}

After SDS-polyacrylamide gel electrophoresis and wet transfer to nitrocellulose, the membranes were blocked and incubated with antibodies in PBS containing 5\% non-fat milk powder or $5 \%$ bovine albumin fraction $V$ when the milk-phosphoprotein casein would interfere with proper staining (mostly because of its numerous phosphorylated sites). Primary antibodies used for detection are listed in Tab. 3.2. Detection was performed by HPR-conjugated antibodies (Tab. 3.3) and chemoluminescence. 


\section{Results}

\subsection{E2F1 regulates miRNA expression}

In order to identify E2F1-responsive microRNAs, we employed Saos2 cells with tetracycline/doxycycline-inducible E2F1 (Phillips et al., 1999), controlled for E2F1 and E2F1 target gene expression (Fig. 5.1), and isolated total RNA before and after doxycycline treatment. Upon E2F1 induction, this cell line was shown to undergo p53-independent apoptosis (Phillips et al., 1999 and Suppl. Fig. S 1).

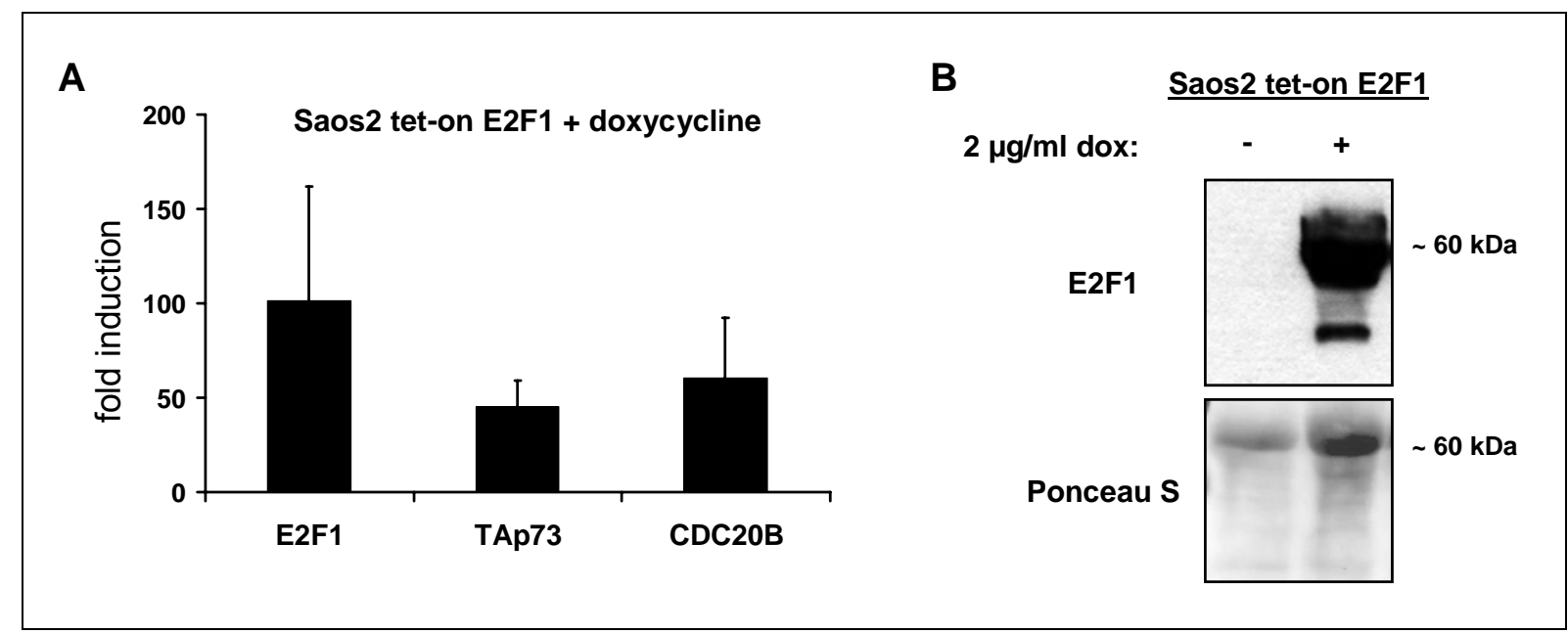

Fig. 5.1: Validation of the Saos2 tet-on E2F1 overexpression system

A, Induction of E2F1-responsive genes. Saos2 cells with an integrated, tet-on expression cassette for E2F1 were treated with doxycycline, followed by RT-PCR analysis of E2F1, TAp73, and CDC20B mRNA levels. Data published in Cell Death \& Differentiation, March 2010.

B, E2F1 accumulation in Saos2 tet-on E2F1 cells after doxycycline treatment. Cells were treated as in A and analysed by western blot as described in 4.3.1.

Subsequent fluorescence labelling and array hybridization identified a number of E2F1responsive microRNAs, some of which have been described as such earlier (Fig. 5.2 and Supp. Tab. 1), e. g. members of the miR-17-92 or 106b-25 clusters (Petrocca et al., 2008b; Pickering et al., 2009; Sylvestre et al., 2007). The strongest response, however, was observed with a pair of closely related microRNAs, miR-449a and miR-449b, recently reported as E2F1-inducible by another group (Yang et al., 2009), and collectively referred to as miR-449 from here on. 


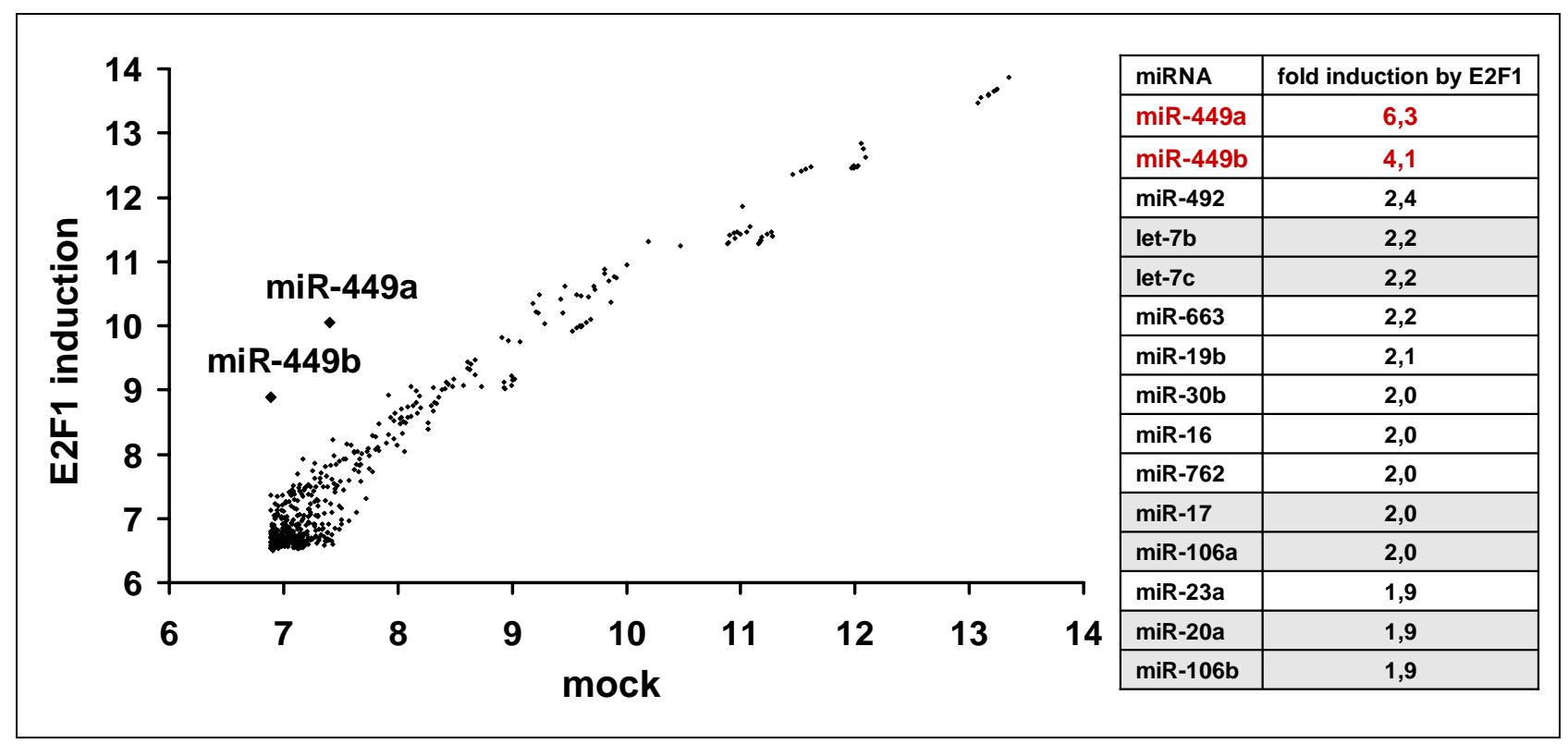

Fig. 5.2: E2F1-induced microRNAs identified by microRNA hybridization

Saos-2 cells with an integrated, tet-inducible expression cassette to synthesize E2F1 (Phillips et al., 1999) were treated with doxycycline or mock-treated. Twenty-four hours after infection, the cells were harvested. MicroRNAs from each sample were fluorescence-labelled and hybridized to a microRNA microarray. The fluorescence intensity corresponding to each microRNA with or without E2F1 overexpression is shown plotted against each other. The microRNAs most strongly upregulated by E2F1 are shown in the table (relative increase in miRNA levels upon E2F1 expression). Tinged with grey are the microRNAs already described as E2F1-responsive (Petrocca et al., 2008b; Pickering et al., 2009; Sylvestre et al., 2007). For a complete set of data, see Supp. Tab. 1. Data published in Cell Death \& Differentiation, March 2010.

These microRNAs show strong similarities to the other miR-34 family members miR-34a-c, especially within their 5 ' portion (Fig. 2.3) that is generally believed to act as a "seed sequence" that determines the specificity of target mRNAs (Filipowicz et al., 2008). Since miR-449a levels exceeded those of miR-449b in all systems analyzed so far (Fig. 5.2 and Landgraf et al., 2007), the further analysis focussed on miR-449a.

\section{2. microRNA-449 is strongly responsive to E2F1 and DNA damage}

The enhanced expression of miR-449a in response to E2F1 was first confirmed by RT-PCR in doxycycline-treated Saos2-cells with tet-on E2F1, whereas doxycycline did not enhance miR-449-levels in the parental Saos2 cells (Fig. 5.3A). Moreover, a transiently transfected expression plasmid for E2F1 induced miR-449a in H1299 and U2OS cells, ensuring E2F1responsiveness as a more general property of miR-449a. 


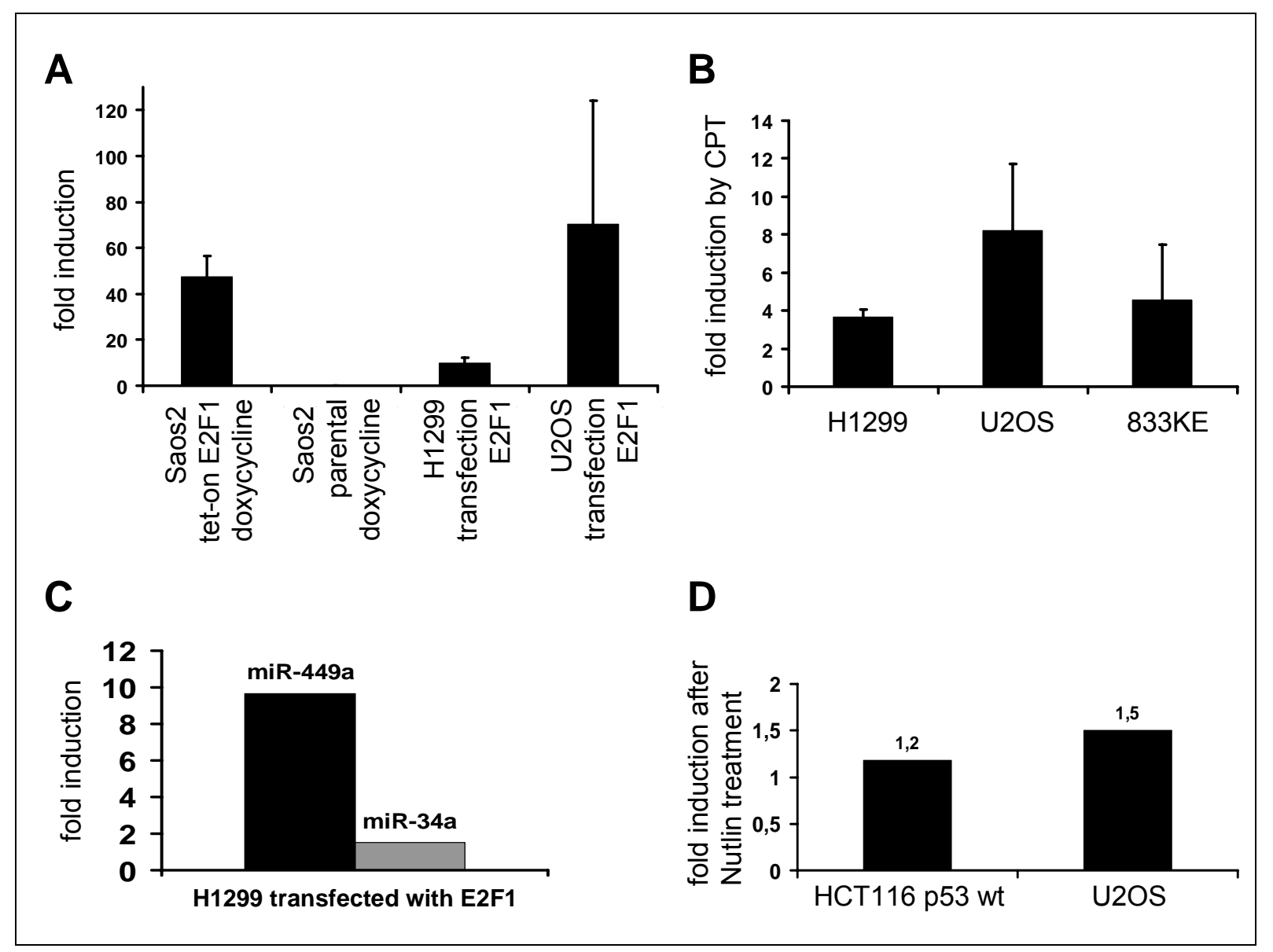

Fig. 5.3: miR-449a is induced by E2F1 overexpression and DNA damage

A, miR-449a induction by E2F1 over-expression. RNA was extracted from Saos2-tet-E2F1 cells with or without earlier doxycycline treatment, or from H1299 or U2OS cells transfected with empty vector or an E2F1 expression plasmid. The levels of miR-449a were determined by RT-PCR analysis and normalized relative to a constitutively expressed small RNA, RNU6b. The ratio of miR-449a levels with versus without E2F1 overexpression was calculated from three independent experiments along with the standard error in each case.

B, miR-449a induction by DNA damage. Cells of the indicated lines (H1299, lung adenocarcinoma, p53 deleted, U2OS, osteosarcoma, p53 wild type; 833KE, testicular cancer and p53 mutant) were treated with Camptothecin (CPT) followed by RT-PCR analysis of miR-449a levels as in A.

C, Failure of E2F1 to induce miR-34a. H1299 cells were transfected to over-express E2F1, or with empty vector plasmid. MicroRNA levels were determined by RT-PCR as in A.

D, Failure of p53 to induce miR-449. HCT116 p53 wt or U2OS cells (both containing wild type p53) were treated with the pharmacological Mdm2 inhibitor Nutlin-3a to induce p53 activity, followed by RTPCR analysis of miR-449a levels. The samples were obtained and analyzed exactly as in a previous report (Braun et al., 2008), where miR-34a was induced more than 3-fold.

Data published in Cell Death \& Differentiation, March 2010. 
Finally, DNA damage by Camptothecin (CPT), a known trigger of E2F1 activity (Polager and Ginsberg, 2009), enhanced miR-449a expression regardless of the p53 status (Fig. 5.3B). In contrast, E2F1 induced miR-34a far less efficiently than miR-449a (Fig. 5.3C). Conversely, p53 activation by the pharmacological Mdm2-antagonist Nutlin-3a (Vassilev et al., 2004), although capable of inducing miR-34a (Braun et al., 2008), failed to increase the levels of miR-449a (Fig. 5.3D).

Consistent with these data, as I will show later, exposure of epithelial cells to cigarette smoke led to equal induction of E2F1 and miR-449a (Fig. 5.26).

Thus, miR-449 is E2F1- and, probably as a consequence, DNA damage-responsive.

\section{3. miR-449 expression is coupled to its host gene CDC20B and reduced in cancer}

Next, we sought to determine the pattern of miR-449 expression in various tissues and tumour cells. The genomic region encoding both miR-449a and miR-449b is embedded into an intronic sequence of the mRNA-encoding gene CDC20B, a paralogue of CDC20 (Fig. 2.4). RT-PCR analysis revealed that CDC20B was induced by E2F1 as well (Fig. 5.1A).

In human, high levels of miR-449 were found in lung, trachea and testes, and still considerable amounts in cervix and oesophagus. The expression pattern of CDC20B largely reflected the levels of miR-449 in human tissues (Fig. 5.4A). mir-449 thus seems to be regulated through activation of its host gene, as confirmed by another group through chromatin immunoprecipitation showing E2F1 binding to the CDC20B/miR-449 core promoter region (Yang et al., 2009).

High levels of miR-449a in testes, lung, and trachea were again found in murine tissues (Fig. 5.4B). In contrast to pulmonary and testicular tissues, all tumour-derived cell lines under study, including testicular cancer cells ( $\mathrm{GH}$ and 833KE) and a lung adenocarcinoma cell line (H1299), contained far lower amounts of miR-449 (Fig. 5.4C), at least compatible with the idea that miR-449 may display tumour-suppressive activities.

Other evidences supporting the idea of miR-449 down-regulation in cancer are found in the literature. MiR-449 levels were lower in prostate tumours compared to matched controls, and its overexpression in prostate tumour cells led to growth arrest and apoptosis (Noonan et al. 2009; Weichert et al. 2008). 


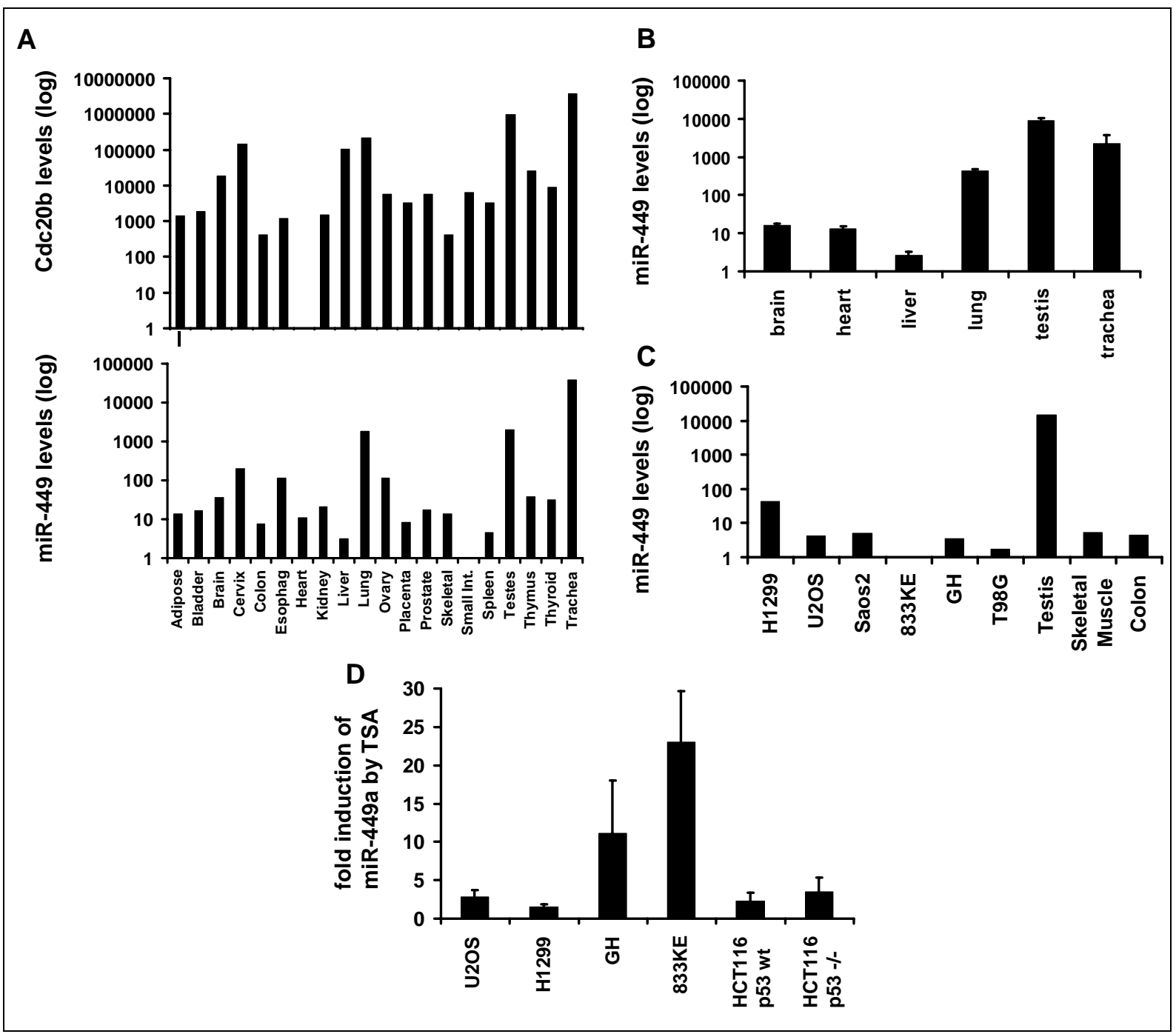

Fig. 5.4: miR-449a levels are reduced in tumour cells, and its expression pattern resembles the expression of CDC20B

A, Parallel expression of CDC20B and miR-449a in a variety of human tissues (RNA panel, Ambion), as quantified by RT-PCR.

B, miR-499a expression levels in murine tissues.

C, miR-499a levels in human cancer-derived cell lines (H1299, lung adenocarcinoma; U2OS and Saos2, osteosarcoma; GH and 833KE, testicular carcinoma; T98G, glioblastoma), as compared with human tissues.

D, Increase of miR-449a levels in testicular cancer cells upon HDAC inhibition. Cells of the indicated lines (U2OS, osteosarcoma; H1299, lung adenocarcinoma; GH and 833KE, testicular carcinoma; HCT116, colon carcinoma) were treated with the histone deacetylase (HDAC) inhibitor Trichostatin A (TSA), followed by miR-449a quantitation through RT-PCR. The ratio of miR-449a levels with or without TSA was calculated and is displayed along with the standard error from three independent experiments.

Data published in Cell Death \& Differentiation, March 2010. 
Cells undergo severe epigenetic changes during tumorigenesis, mostly through modulation of the methylation and acetylation states of promoter regions, thereby leading to the silencing of tumour suppressive genes and enhanced transcription of oncogenes (Ellis et al., 2009; Espino et al., 2005; Kalebic, 2003). To test whether the down-regulation of miR-449 in cancer cells could be due to epigenetic silencing, we treated the cells with Trichostatin A, a pharmacological inhibitor of histone deacetylases (HDACs). HDACs are thought to deacetylate histones to make the chromatin more compact thereby clogging the access to certain promoters and silencing genes. Their inhibition strongly increased miR-449 levels in cell lines from testicular cancer, albeit less efficiently in other cell lines (Fig. 5.4D). This argues that epigenetic silencing may lead to miR-449 down-regulation in the corresponding tumour cells. However, histone deacetylation seems not to be the only mechanism by which miR-449 is silenced in cancer, as Yang et al. (2009) found miR-449 expression to be repressed by histone $\mathrm{H} 3$ Lys27 trimethylation in breast tumour cells.

The down-regulation of miR-449 in tumour cell lines compared to normal tissue indicates a potential tumour-suppressive role for miR-449. This, and its similarity to miR-34, raised the question whether miR-449 could be involved in growth arrest or cell death.

\section{4. miR-449 induces apoptosis and cell cycle arrest}

Since E2F1 is a potent inducer of apoptosis (Suppl. Fig. S 1), especially in the context of DNA damage, I wanted to investigate whether miR-449 could contribute to the induction of E2F1-mediated apoptosis. Interestingly, miR-34, the p53-responsive homologue of miR-449, was already shown to exhibit proapoptotic activity. Hence, we tested whether miR-449 may act in parallel to miR-34 in growth suppression and apoptosis.

Firstly, we investigated the ability of miR-449 to affect colony formation and survival in clonogenic assays. Therefore, we transfected plasmids encoding each microRNA into HCT116 cells with or without p53, followed by antibiotic selection of stable transfectants. Both miR-34a and miR-449 suppressed clonogenic survival in this system, in a partially p53independent fashion (Fig. 5.5 A and B). This colony suppression was especially strong in the testicular carcinoma cells from the $\mathrm{GH}$ line, where miR-449 expression led to total colony suppression (Fig. 5.6). This might reflect the importance of the loss of miR-449 in cancer arising from testicular tissue, since even though the highest levels of endogenous miR-449 were found in testis, miR-449 was barely detectable in testicular carcinoma (Fig. 5.4C). 


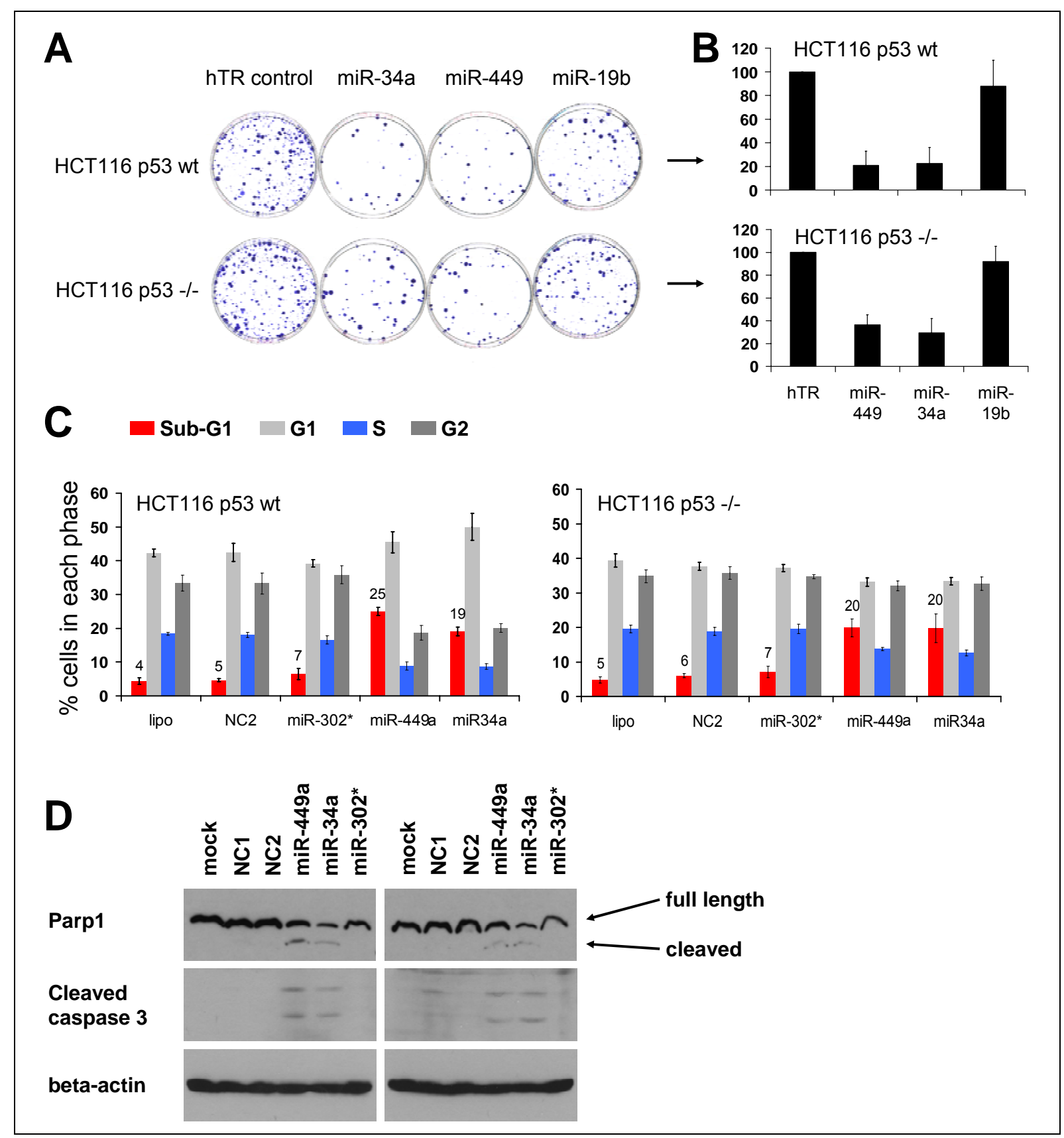

Fig. 5.5: miR-449 induces apoptosis

A, Reduced clonogenic survival on continuous expression of miR-449 and miR-34a. HCT116 wt or p53 -/- cells were transfected with expression plasmids for miR-449a/b, miR-34a, or controls, followed by selection of stably transfected cells. Colonies were fixed and stained with crystal violet two weeks after transfection.

B, Quantification of the assays shown in A, performed by digitally determining the area covered by crystal violet-stained cells. The results of five independent experiments are summarized along with the standard error in each case.

C, Induction of a sub-G1 shoulder and decreased S-Phase fraction by miR-449a and miR-34a. HCT116 cells with or without p53 were transiently transfected with synthetic miR-449a, miR-34a or control miRNAs. At $48 \mathrm{~h}$ post transfection, the cells were fixed, stained with propidium iodide and subjected to flow cytometry. The percentage of (presumably apoptotic) cells in the sub-G1 fraction was 
calculated in each case based on the distribution of staining intensities (exemplified in Fig. 5.7). Results from three independent experiments are shown along with the standard error.

D, Induction of caspase activity by miR-449a and miR-34a. HCT116 cells were treated as in b, followed by immunoblot analysis of poly-ADP ribose polymerase (PARP) (the lower band is characteristic of a caspase-derived cleavage fragment) and cleaved caspase 3.

Data published in Cell Death \& Differentiation, March 2010.

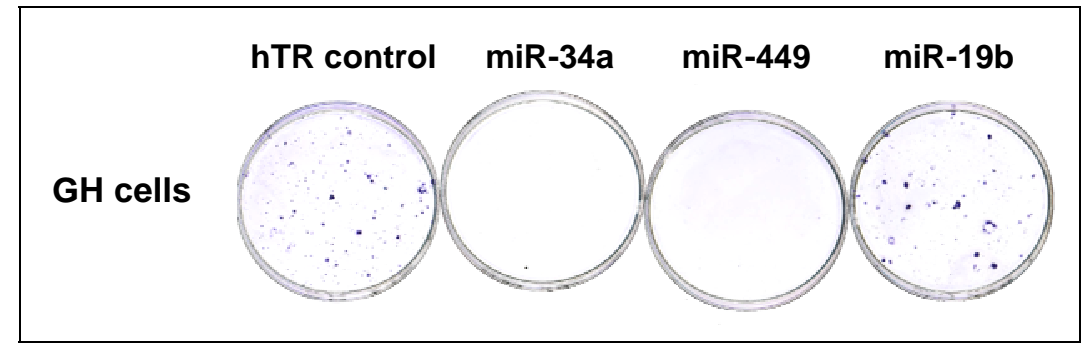

Fig. 5.6: miR-449 suppresses colony formation in a testicular carcinoma cell line

Suppressed clonogenic survival on continuous expression of miR-449 and miR-34a. GH cells were transfected with expression plasmids for miR-449a/b, miR-34a, or with control plasmids, followed by Blasticidine selection of stably transfected cells, as in $5.5 \mathrm{~A}$. Two weeks after transfection, colonies were fixed and stained with crystal violet.

To further elucidate the mechanisms behind this suppressive effect, we analyzed the DNA content of transiently miRNA-transfected cells by flow cytometry to determine cell cycle distribution of the cells. MiR-34a and miR-449a each led to the accumulation of cells in a sub-G1 shoulder (Fig. 5.5C and Fig. 5.7), arguing that both microRNAs induce apoptosis.

To confirm that the observed Sub-G1 fraction, indicative of cell death, was due to apoptosis, we decided to test the cells for caspase activity. Under the same conditions, cleaved polyADP-ribose polymerase (PARP) and cleaved caspase 3 were detected by immunoblot analysis in different cell lines, independently of their p53 status (Fig. 5.5D and Fig. 5.8), further supporting this notion. Thus, miR-449 induces apoptosis, at least partially through p53-independent mechanisms. 


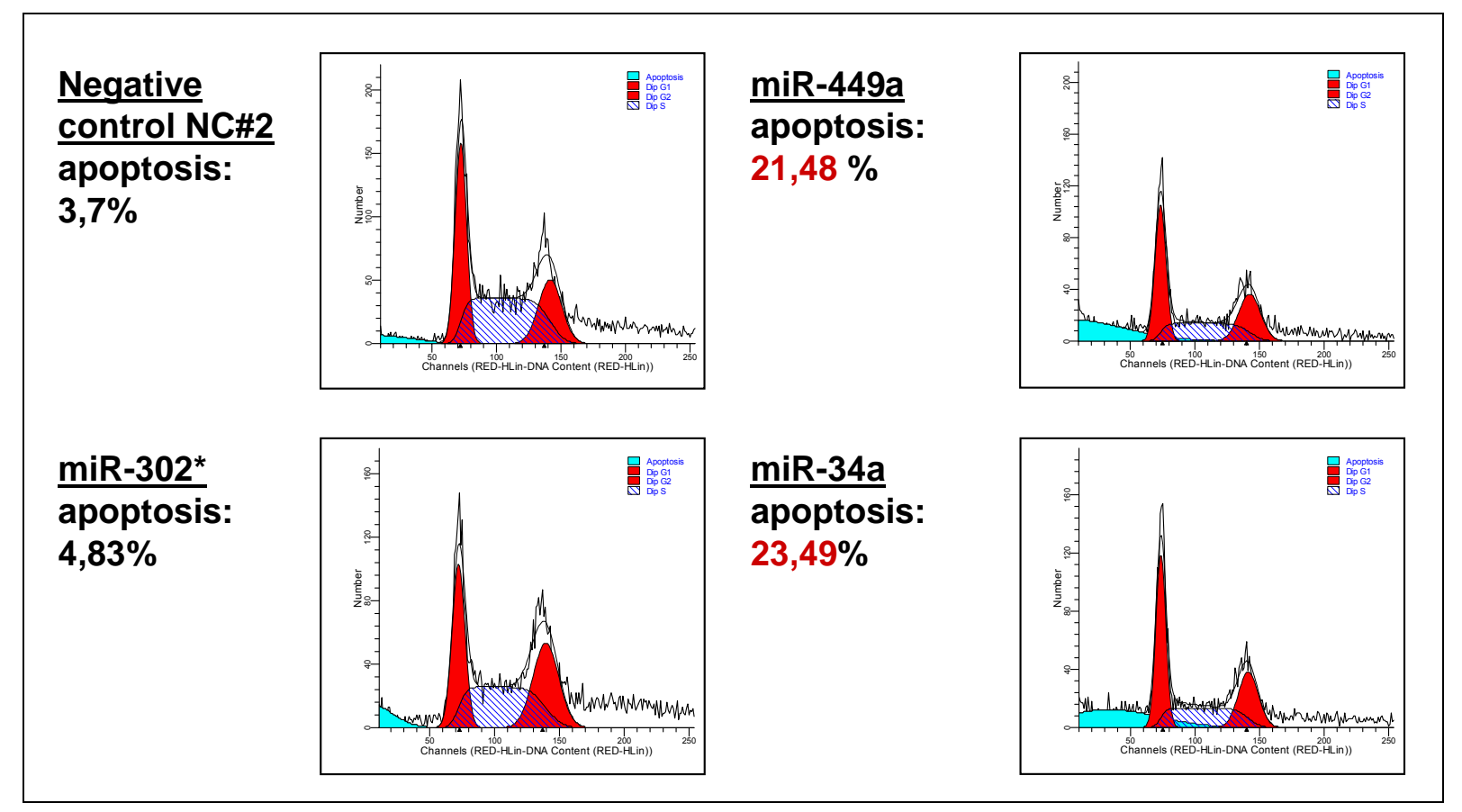

Fig. 5.7: Alterations in DNA content by miR-449a and miR-34a

HCT116 cells (wt p53) were transfected with the indicated microRNAs, NC\#2 and miR-302* being negative controls, followed by propidium iodide staining and flow cytometry (cf. legend to Fig. 5.5C). The number of cells in each window of staining intensity is shown by histograms. The fraction of SubG1 cells (green overlay) was determined by ModFit analysis. Similar effects were found in p53deficient HCT116. Data published in Cell Death \& Differentiation, March 2010.

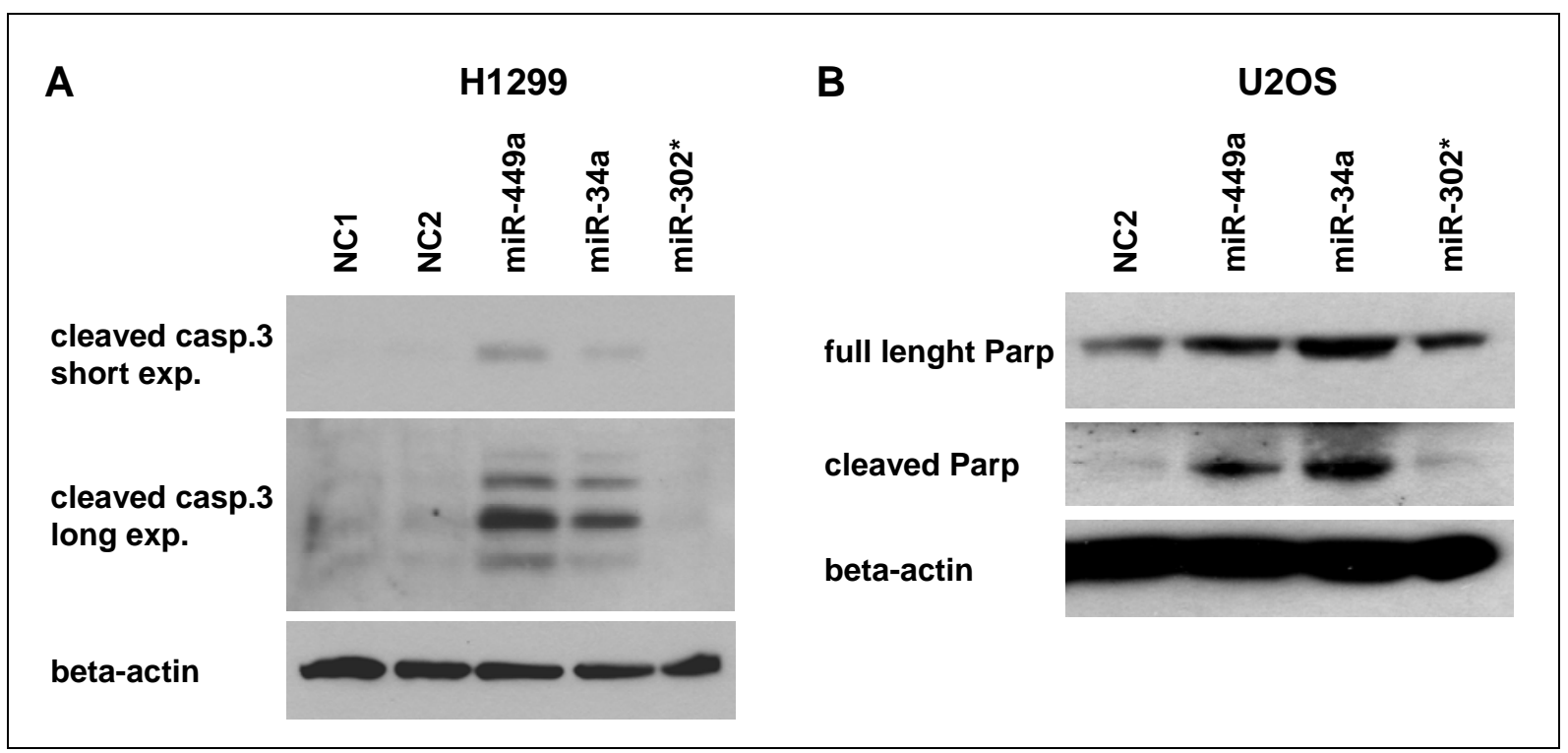

Fig. 5.8: Induction of caspase activity by miR-449a and miR-34a

H1299 (p53 deleted) (A) or U2OS (p53 wild-type) (B) cells were transfected with the indicated microRNAs, followed by immunoblot analysis of cleaved caspase 3 and poly-ADP ribose polymerase (PARP) (the lower band being characteristic of a caspase-derived cleavage fragment) respectively. 
Next, I wanted to investigate whether miR-449 antagonisation would alleviate E2F1mediated, p53-independent apoptosis. Since no tumour cell line harbouring high miR-449 levels was available, I decided to use again Saos2 tet-on E2F1 cells. After induction with doxycycline, they express miR-449 levels that are reasonably high, even though still lower compared to normal tissue. Interestingly, E2F1 overexpression led to apoptotic appearance of the cells in preliminary tests (Suppl. Fig. S 1). In fact, we could observe PARP1 and caspase 3 cleavage after E2F1 induction (Fig. 5.9), and knockdown of miR-449 using the LNA (locked nucleic acid) technology (Naguibneva et al., 2006) slightly reduced caspase activity. Moreover, gammaH2AX accumulation, probably due to DNA cleavage following apoptosis, was also partially reduced by miR-449 antagonisation. Thus, miR-449 is one of the effectors of E2F1-mediated, p53-independent apoptosis.

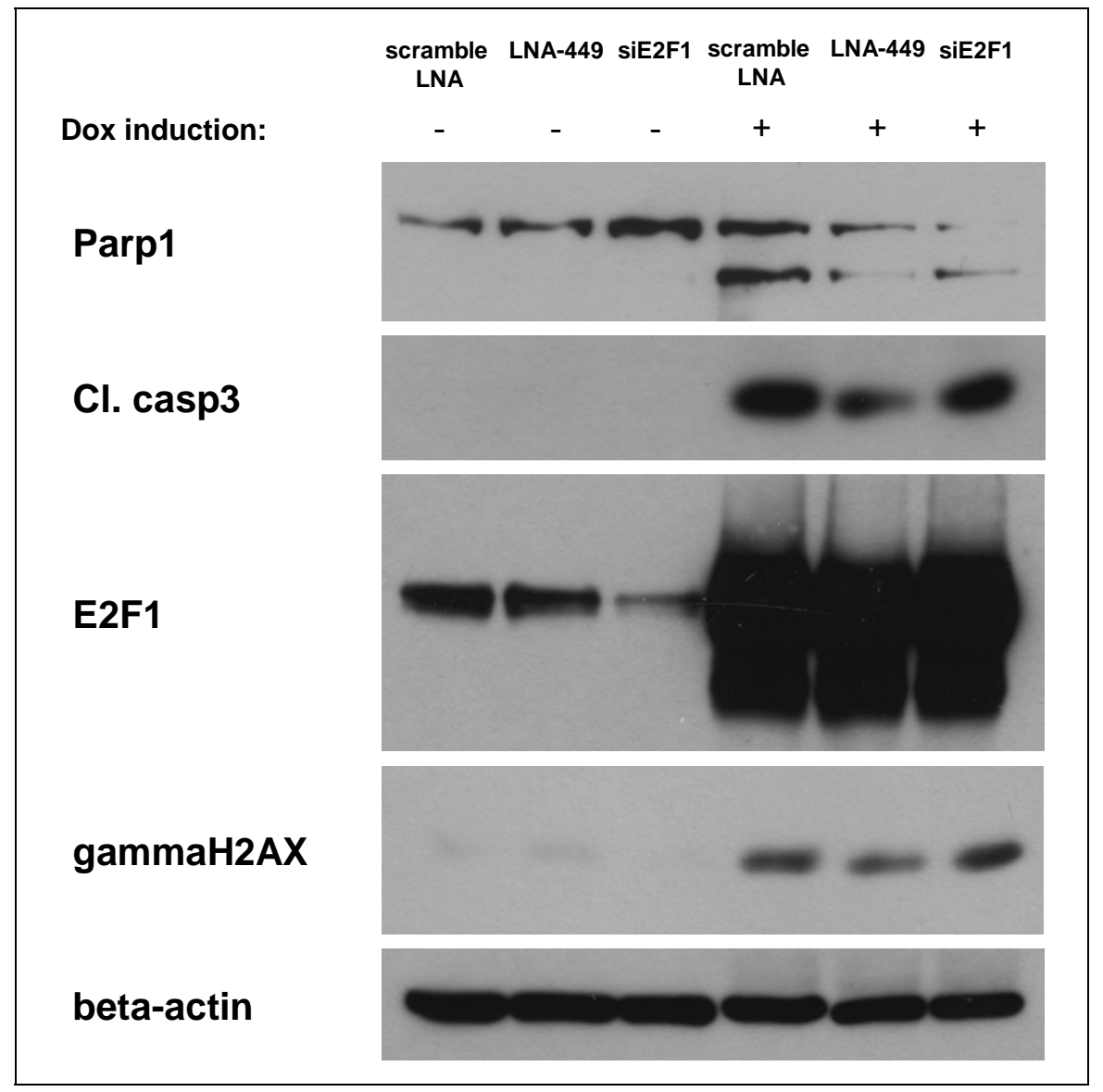

\section{Fig. 5.9: Knockdown of miR-449 reduces E2F1-mediated apoptosis}

Saos2 tet-on E2F1 cells (p53 -/-) were transfected with LNA against miR-449 or scramble control or with a siRNA against E2F1 and treated with doxycycline or mock. 24h post transfection cells were harvested for immunoblot analysis. E2F1 staining served as a control for correct induction and as an indicator of transfection efficiency (where siRNA against E2F1 was used). Note that E2F1 overexpression alone was able to induce DNA damage as shown by gammaH2AX accumulation. 


\subsection{Target analysis of miR-449a}

To identify possible mechanisms behind miR-449-induced cell death, we analysed putative target genes for miR-449a. Due to the very short microRNA seed sequence and to the ability of microRNAs to bind to their targets by imperfect complementarity, it is very difficult to predict microRNA targets accurately. Fortunately, prediction softwares can give good hints about probable targets. Using the databases and microRNA targets prediction softwares TargetScan, Miranda and cbio, and taking into account the shared seed sequence with miR34 , we looked for the most likely targets of miR-449 (Tab. 5.1).

\section{Tab. 5.1: potential miR-449 targets}

Potential targets analysis using the hits from Miranda (John et al., 2004), TargetScan (Friedman et al., 2009b) and cbio (Vert et al., 2006), as well as published data for the miR-34 family. The targets analysed in the course of this work are highlighted in grey.

\begin{tabular}{|c|c|c|c|c|c|c|c|}
\hline gene & miranda & sites & species & targetscan & sites & cbio & publications \\
\hline ACBD3 & & & & hsa-miR-449 & 1 & 1 & \\
\hline ACCN1 & miR-449a & 16 & 3 & hsa-miR-449 & 1 & 1 & \\
\hline AKT1 & $\operatorname{miR}-449 a+b$ & 16 & 3 & & & 1 & \\
\hline ANK2 & & & & hsa-miR-449 & 1 & & \\
\hline ANK3 & $\operatorname{miR}-449 a+b$ & 13 & 1 & hsa-miR-449 & 2 & & \\
\hline BCAN & $\operatorname{miR}-449 a+b$ & 20 & 5 & & & 1 & \\
\hline BCAS3 & $\operatorname{miR}-449 a+b$ & 20 & 5 & & & 1 & \\
\hline BCL2 & & & & hsa-miR-34c & 1 & 2 & described as miR-34a target (Ji et al., 2008) \\
\hline $\mathrm{BNC2}$ & & & & hsa-miR-449 & 3 & & \\
\hline BTBD11 & $\operatorname{miR}-449 a+b$ & 18 & 3 & hsa-miR-449 & 2 & 1 & \\
\hline C11orf17 & miR-449a & 22 & 5 & & & 1 & \\
\hline C8orf13 & & & & hsa-miR-449 & 4 & 2 & \\
\hline CALCR & & & & hsa-miR-449 & 2 & 1 & \\
\hline CCND1 & & & & hsa-miR-449 & 1 & & described as miR-34a target (Sun et al., 2008) \\
\hline CCNE2 & $\operatorname{miR}-449 a+b$ & 12 & 7 & hsa-miR-449 & 1 & & \\
\hline CD151 & miR-449a+b & 27 & 6 & & & & \\
\hline CD47 & & & & hsa-miR-449 & 3 & & \\
\hline CDC25A & & & & & & & confirmed miR-449 target (Yang et al., 2009) \\
\hline CDK6 & & & & hsa-miR-449 & 3 & 2 & $\begin{array}{l}\text { described as miR-34 and miR-449 target (Sun } \\
\text { et al., 2008; Yang et al., 2009) }\end{array}$ \\
\hline CNTNAP2 & & & & hsa-miR-449 & 1 & 2 & \\
\hline COL12A1 & & & & hsa-miR-449 & 1 & 1 & \\
\hline CRSP8 & $m i R-449 a+b$ & 20 & 1 & & & 1 & \\
\hline DBC1 & miR-449a+b & 17 & 7 & hsa-miR-449 & 1 & 1 & \\
\hline DHRS13 & $\operatorname{miR}-449 a+b$ & 28 & 4 & & & & \\
\hline DKFZP686E2158 & & & & hsa-miR-449 & 1 & & \\
\hline DLL1 & $\operatorname{miR}-449 a$ & 20 & 8 & hsa-miR-449 & 3 & & $\begin{array}{l}\text { Potential miR-34 and miR-449 target (Hoesel } \\
\text { et al., 2010) }\end{array}$ \\
\hline \multicolumn{8}{|r|}{ ( } \\
\hline E2F3 & & & & & 1 & 1 & \\
\hline E2F5 & $\operatorname{miR}-449 a+b$ & 24 & 9 & & & 1 & $\begin{array}{l}\text { described as miR-449 target (Redshaw et al., } \\
\text { 2009) }\end{array}$ \\
\hline EML5 & miR-449a+b & 12 & 7 & hsa-miR-449 & 1 & & \\
\hline ESRRA & $\operatorname{miR}-449 a+b$ & 25 & 6 & hsa-miR-34a & 1 & & \\
\hline FAM123B & miR-449b & & & hsa-miR-449 & 4 & & \\
\hline
\end{tabular}




\begin{tabular}{|c|c|c|c|c|c|c|c|}
\hline FAM76A & miR-449a & 18 & 5 & hsa-miR-449 & 3 & 1 & \\
\hline FGD6 & $m i R-449 a+b$ & 22 & 4 & hsa-miR-449 & 1 & & \\
\hline FOXG1B & $m i R-449 a+b$ & 20 & 7 & hsa-miR-34a & 1 & & \\
\hline FUT8 & $m i R-449 a+b$ & 21 & 9 & hsa-miR-449 & 1 & 1 & \\
\hline GALNT7 & & & & hsa-miR-449 & 2 & 2 & \\
\hline GMFB & & & & hsa-miR-449 & 1 & & \\
\hline GPR22 & & & & hsa-miR-449 & 1 & 1 & \\
\hline GRM7 & & & & hsa-miR-449 & 1 & & \\
\hline HDAC1 & & & & & & & $\begin{array}{l}\text { described as miR-449 target (Noonan et al., } \\
\text { 2009) }\end{array}$ \\
\hline HDMX & & & & & & & $\begin{array}{l}\text { described as miR-34a target (Markey and } \\
\text { Berberich, 2008) }\end{array}$ \\
\hline HMGA2 & & & & & & & described as miR-34a target (Ji et al., 2008) \\
\hline HTR2C & & & & hsa-miR-449 & 1 & & \\
\hline IKBKG & $m i R-449 a+b$ & 25 & 4 & & & & \\
\hline IL16 & $m i R-449 a+b$ & 10 & 1 & & 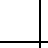 & 1 & \\
\hline JAKMIP1 & $m i R-449 a+b$ & 10 & 5 & hsa-miR-449 & 1 & 1 & \\
\hline KLF4 & & & & hsa-miR-449 & 1 & 1 & \\
\hline LEF1 & miR-449a & 15 & 4 & & 1 & & \\
\hline LOXL3 & $m i R-449 a+b$ & 21 & 6 & hsa-miR-34c & 2 & 2 & \\
\hline LYST & miR-449b & & & hsa-miR-449 & 2 & & \\
\hline LZTS2 & $m i R-449 a+b$ & 21 & 6 & hsa-miR-34a & 1 & & \\
\hline MARCH5 & & & & hsa-miR-449 & 1 & & \\
\hline MGAT4A & & & & hsa-miR-449 & 2 & & \\
\hline MLLT3 & & & & hsa-miR-449 & 1 & 1 & \\
\hline Notch1 & & & & hsa-miR-449 & 2 & & described as miR-34 target (Ji et al., 2008) \\
\hline NUMBL & miR-449a & 24 & 6 & hsa-miR-449 & 2 & 2 & \\
\hline ORC6L & $m i R-449 a+b$ & 24 & 5 & & & & \\
\hline PEA15 & & & & hsa-miR-449 & 1 & 1 & \\
\hline PGM1 & $m i R-449 a+b$ & 23 & 7 & hsa-miR-449 & 1 & & \\
\hline PKP4 & $m i R-449 a+b$ & 13 & 9 & hsa-miR-449 & 1 & & \\
\hline PLCG1 & & & & hsa-miR-449 & 1 & 2 & \\
\hline PNOC & $m i R-449 a+b$ & 21 & 5 & hsa-miR-34a & 1 & 2 & \\
\hline PPP2R3A & & & & hsa-miR-449 & 2 & 1 & \\
\hline PREB & $m i R-449 a+b$ & 25 & 6 & & & & \\
\hline RASGEF1C & $m i R-449 a+b$ & 25 & 4 & & & & \\
\hline RIMS2 & $m i R-449 a+b$ & 7 & 1 & & & 1 & \\
\hline RNF111 & $m i R-449 a+b$ & 11 & 13 & & & 1 & \\
\hline SATB2 & & & & hsa-miR-449 & 2 & 1 & \\
\hline SEMA4C & miR-449a & 25 & 9 & hsa-miR-34c & 2 & 2 & \\
\hline SEMA4F & & & & hsa-miR-449 & 3 & 1 & \\
\hline SHANK3 & & & & hsa-miR-449 & 2 & 1 & \\
\hline SIRT1 & & & & hsa-miR-34a & 2 & 1 & $\begin{array}{l}\text { described as miR-34a target (Yamakuchi et al., } \\
\text { 2008) }\end{array}$ \\
\hline SIRT6 & $m i R-449 a+b$ & 26 & 5 & & & & \\
\hline SIT1 & $m i R-449 a+b$ & 25 & 4 & & & & \\
\hline SLCO3A1 & $m i R-449 a+b$ & 17 & 6 & hsa-miR-449 & 1 & 1 & \\
\hline SUPT6H & $m i R-449 a+b$ & 25 & 5 & & & 1 & \\
\hline SYT1 & & & & hsa-miR-449 & 3 & 2 & \\
\hline TBL1XR1 & & & & hsa-miR-449 & 1 & & \\
\hline TMCC3 & & & & hsa-miR-449 & 2 & & \\
\hline TMEM109 & $m i R-449 a+b$ & 14 & 5 & hsa-miR-34a & 1 & & \\
\hline TMEM22 & $m i R-449 a+b$ & 9 & 8 & & & 1 & \\
\hline VAMP2 & & & & hsa-miR-449 & 3 & & \\
\hline VPS4A & $m i R-449 a+b$ & 22 & 6 & & & 1 & \\
\hline XYLT1 & $m i R-449 a+b$ & 14 & 5 & hsa-miR-449 & 4 & 1 & \\
\hline ZDHHC17 & & & & hsa-miR-449 & 1 & & \\
\hline ZNF207 & $m i R-449 a+b$ & 19 & 10 & $34 a$ & 1 & 1 & \\
\hline ZNF644 & & & & hsa-miR-449 & 1 & & \\
\hline
\end{tabular}


From these predictions, many different protein-coding genes could be regulated by miR-449. Complex patterns of gene regulation have previously been reported for miR-34 (Chang et al., 2007; Corney et al., 2007; He et al., 2007a; Hermeking, 2009a; Raver-Shapira et al., 2007; Tazawa et al., 2007). However, it is reasonable to assume that a few profoundly regulated target mRNAs may still serve as key targets to mediate the biological functions of miR-34a and miR-449a.

In order to find targets potentially explaining the observed phenotypes after miR-449 overexpression, mainly growth arrest and apoptosis, therefore I decided to further investigate putative targets with roles in the regulation of cell cycle or cell death.

The first candidates were the antiapoptotic genes BCL2 and BCL6, whose knockdown could lead to apoptosis. Therefore, we checked their expression by quantitative RT-PCR (Suppl. Fig. S 2) and, for BCL2, also by western blot analysis (data not shown). Unfortunately, miR449 did not affect them. Surprisingly, we could not see any down-regulation of BCL2, which was previously shown to be a direct target of miR-34 ( $\mathrm{Ji}$ et al., 2008), even after overexpression of miR-34a (Suppl. Fig. S 2D). This could be due to the different experimental settings and the tissue provenance of the cells used.

Additionally, there was no direct negative regulation of miR-449a on its host gene CDC20B (Suppl. Fig. S 2B) at least on the mRNA level, but strong effects were found on the E2F and p53 pathways, as discussed in section 5.5.1.

\subsubsection{Negative feedback on the E2F pathway}

I was particularly interested in the underlying mechanisms of miR-449-mediated cell cycle arrest and apoptosis. Therefore, my attention was turned to the E2F1 pathway. I first tested the effects of miR-449a and miR-34a on CDK6, a predicted target gene (Tab. 5.1) with a role in cell cycle regulation. CDKs are known to activate the E2F pathways through the inhibition of pocket proteins (e.g. Rb). CDK6 as well as CDK2 mRNAs were strongly down-regulated after miR-449 overexpression (Fig. 5.10 A and B).

A strong down-regulation of CDK6 was further confirmed on the protein level (Fig. 5.11A). Moreover, E2F1 and E2F3 themselves were found to be down-regulated by miR-449a and miR-34a in p53-deficient cells (Fig. 5.11B). However, at least for E2F1, this down-regulation seems to be indirect since miR-449a, unlike other microRNAs, was unable to bind to the 3'UTR of E2F1 and inhibit translation in reporter assays (Fig. 5.12). 


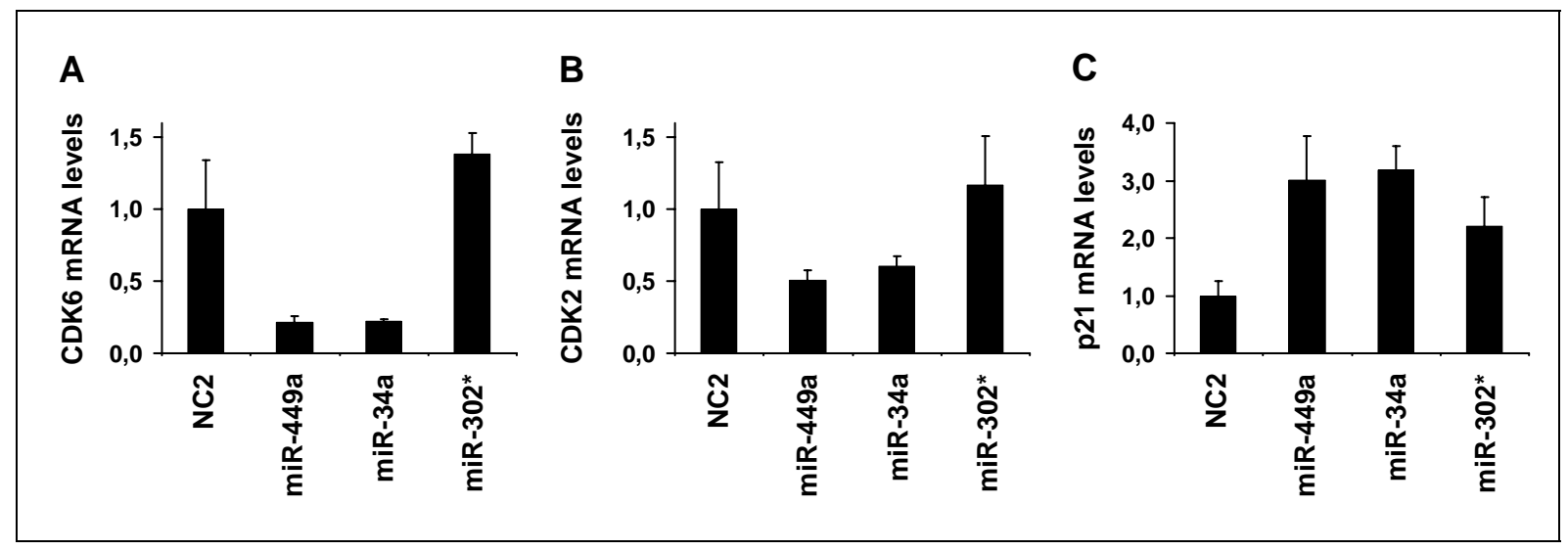

\section{Fig. 5.10: miR-449 inhibits the E2F pathway}

H1299 cells transfected with the indicated microRNAs or controls ( $N C 2$ and miR-302*) were analysed by RT-PCR to determine the mRNA levels of the cyclin-dependent kinases CDK6 (A) and CDK2 (B), and the cyclin-dependent kinase inhibitor p21 (C). Displayed are the mean results of 3 independent experiments with error bars normalised to $18 \mathrm{~S}$ rRNA levels in each sample.

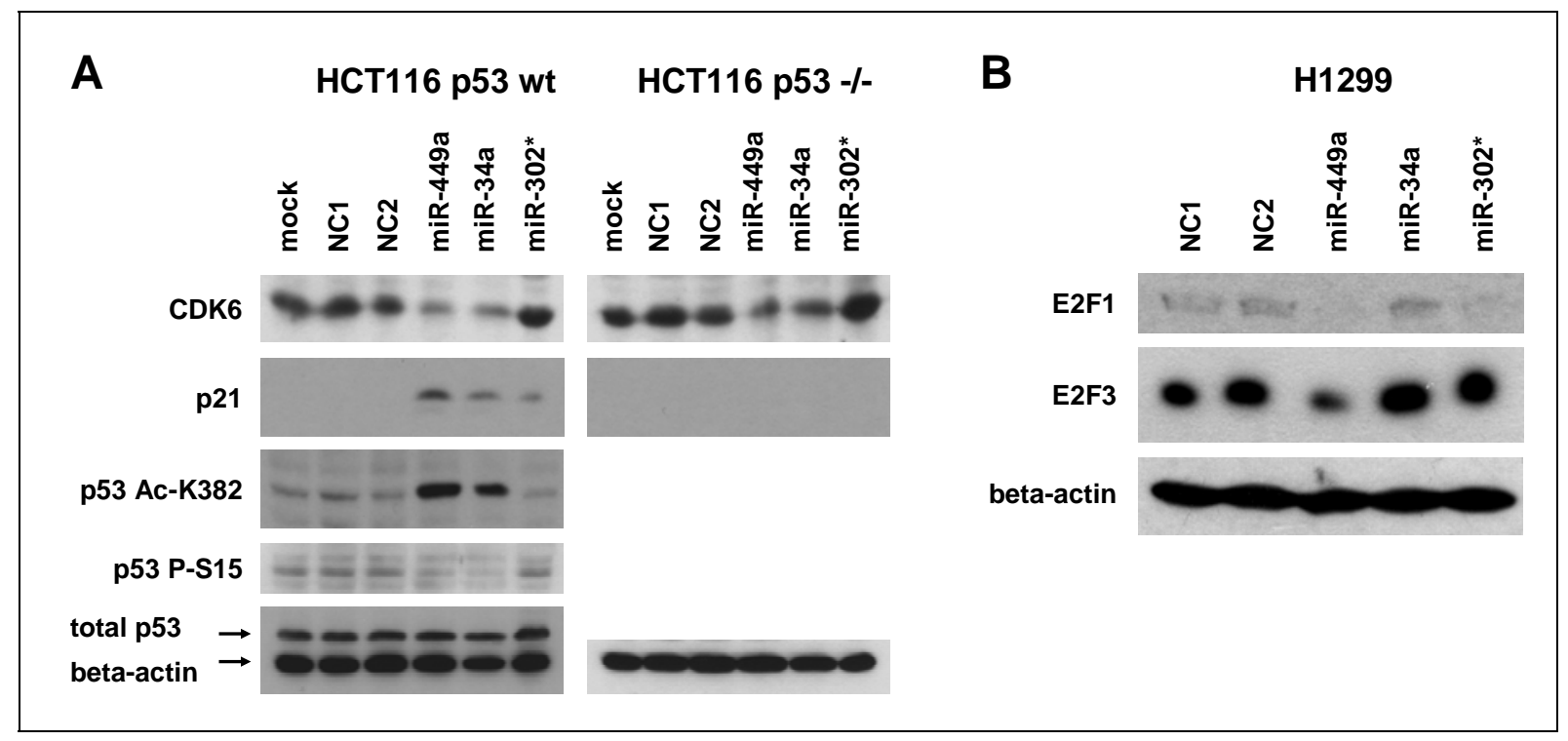

Fig. 5.11: miR-449 induces the p53 pathway while inhibiting the E2F pathway

A, HCT116 p53 wild type (wt) or HCT116 p53-/- cells were transfected with the indicated microRNAs for $48 \mathrm{~h}$, followed by immunoblot analysis to detect the indicated gene products and modifications with specific antibodies. p53 staining was only performed in HCT116 p53 wt cells (but lack of p53 was confirmed in HCT116 p53-/- cells in additional experiments, data not shown)(Lize et al., 2010).

B, Same analysis as in A using $\mathrm{H} 1299$ cells (p53 -/-).

The negative feedback of miR-449 on the E2F pathway is further reinforced by the fact that p21 - a CDK inhibitor also contributing in the p53-mediated inhibition of E2F1 transcriptional activity - was shown to be strongly induced after miR-449 over-expression, probably due to 
the accumulation of the highly active acetylated form of p53 (Fig. 5.11A). However, other factors may be involved in the miR-449-mediated induction of $\mathrm{p} 21$, since it could be observed in p53-deficient cells (Fig. 5.10C).

Consistent with the negative regulation of the E2F pathway, the E2F1 proapoptotic targets TAp73, Noxa and APAF1 were not induced and therefore probably not involved in miR-449mediated apoptosis (data not shown).

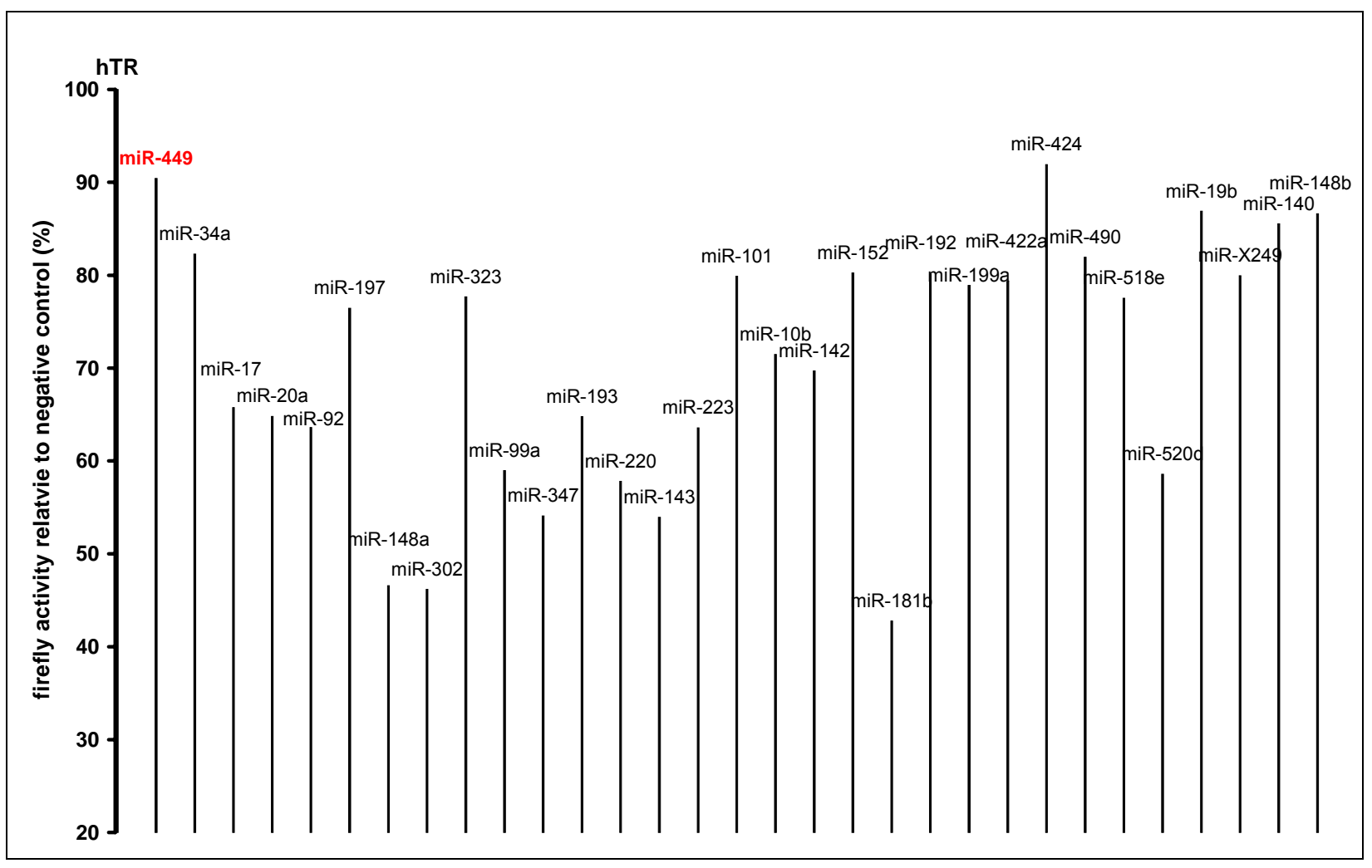

Fig. 5.12: no direct binding of miR-449 to the E2F1 3' UTR

H1299 cells were co-transfected with the pGL3-3'UTR-E2F1 Firefly vector (Renilla as internal standard) and plasmids containing the indicated microRNAs (miR-Vec library, kind gift of R. Agami) for $24 \mathrm{~h}$, followed by analysis of luciferase activity. Displayed are the mean results of 3 independent experiments, each performed in technical triplicates.

This argues that miR-449a provides a negative feedback loop that attenuates E2F1 activity in situations where cell death can be avoided. A reduction of CDK6 and CDK2 is in line with the observed decrease of cells in S phase (Fig. 5.5C and Fig. 5.7), presumably due to the hypophosphorylation and consecutive activation of $\mathrm{Rb}$ family pocket proteins. MiR-449 may thus prevent the accumulation of cells with excessive E2F1 activity in two ways: providing a direct negative feedback on E2F1 activity, and eliminating cells with uncontrollable E2F1. 


\subsection{2. miR-449 targets the histone deacetylases HDAC1 and SIRT1: a positive feedback on the 953 pathway}

Due to the activation of p53 in response to miR-449 (Fig. 5.11A), it was tempting to speculate whether general regulators of gene transcription could be involved. Histone deacetylases are important regulators of gene expression which are thought to regulate entire pathways through major changes in the "transcriptome" (Dannenberg et al., 2005; Gialitakis et al., 2006; Reid et al., 2005). Histone deacetylases prevent the transcription of certain genes through the removal of acetyl groups from histones, thereby enhancing chromatin condensation (Coppola et al., 2010). They are often upregulated in cancer (Weichert et al. 2008) and HDAC inhibitors show a very effective tumour-suppressive activity in some animal models (Qian et al. 2007; Wedel et al. 2008). Recently, HDAC1 was reported as a target of miR-449 (Noonan et al., 2009). SIRT1 belongs to another class of histone deacetylases, the Sirtuins (class III), and was also predicted as a target of the miR-34 family (Tab. 5.1) and reported for miR-34a (Yamakuchi et al., 2008).

Accordingly, both miR-449a and miR-34a were capable of down-regulating the histone deacetylases HDAC1 and SIRT1 at the mRNA (Fig. 5.13) and protein levels (Fig. 5.14 and Fig. 5.15), independently of the p53 status of the cells. However, the negative regulation could of SIRT1 mRNA (Fig. 5.13A) was much weaker than suggested by the strong decrease in protein levels, suggesting translational repression rather than mRNA destabilisation as the main mechanism in this case.

Since SIRT1 is known to directly affect the acetylation of p53 (Langley et al., 2002; Luo et al., 2001; Solomon et al., 2006; Vaziri et al., 2001; Yamakuchi et al., 2008), this observation is in line with the previously shown accumulation of acetylated p53 and its target p21 (Fig. 5.11A), despite unchanged levels of global p53 and phosphorylated p53. The down-regulation of SIRT1 by miR-449 therefore provides a positive feedback on the p53 pathway, thereby potentially inducing cell cycle arrest or apoptosis in p53 wild-type cells. Unfortunately, this does not explain the induction of apoptosis in p53-deleted cells.

However, whereas HDAC inhibition was able to induce some apoptosis in p53-deficient cells, probably in part due to the resulting enhanced miR-449 expression in most tumour cell lines (Fig. 5.4D), SIRT1 inhibition alone did not phenocopy miR-449-mediated apoptosis in p53deficient cells, suggesting the collaboration of several miR-449 targets for the proper induction of programmed cell death. 


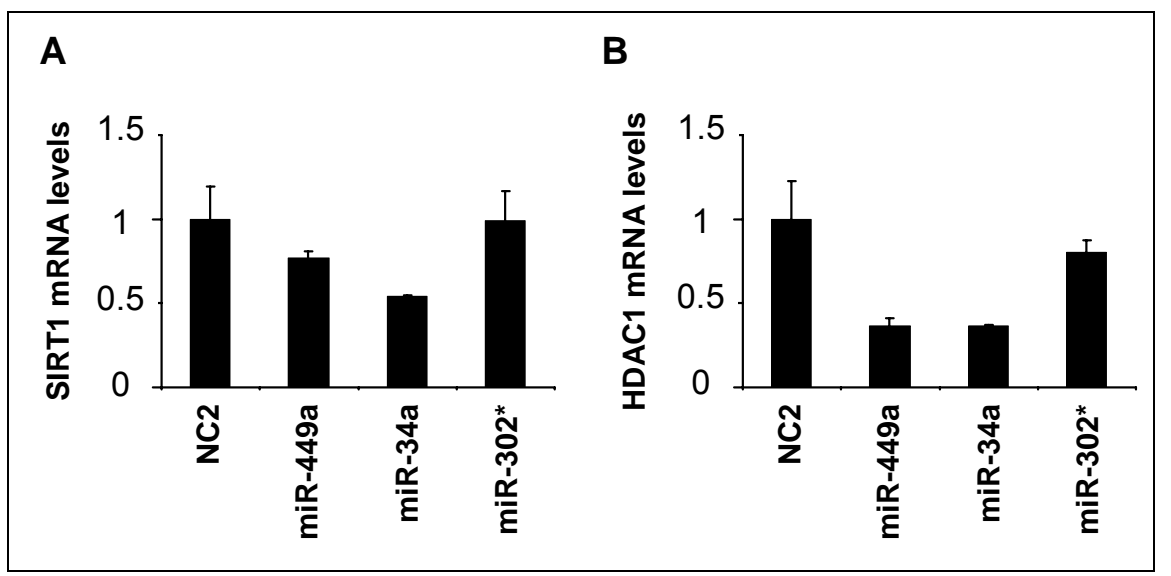

Fig. 5.13: HDAC1 and SIRT1 mRNA levels are reduced by miR-449

H1299 cells were transfected with the indicated microRNAs, 48h post transfection the RNA was analysed by RT-PCR using specific primers for the histone deacetylases SIRT1 (A) and HDAC1 (B).

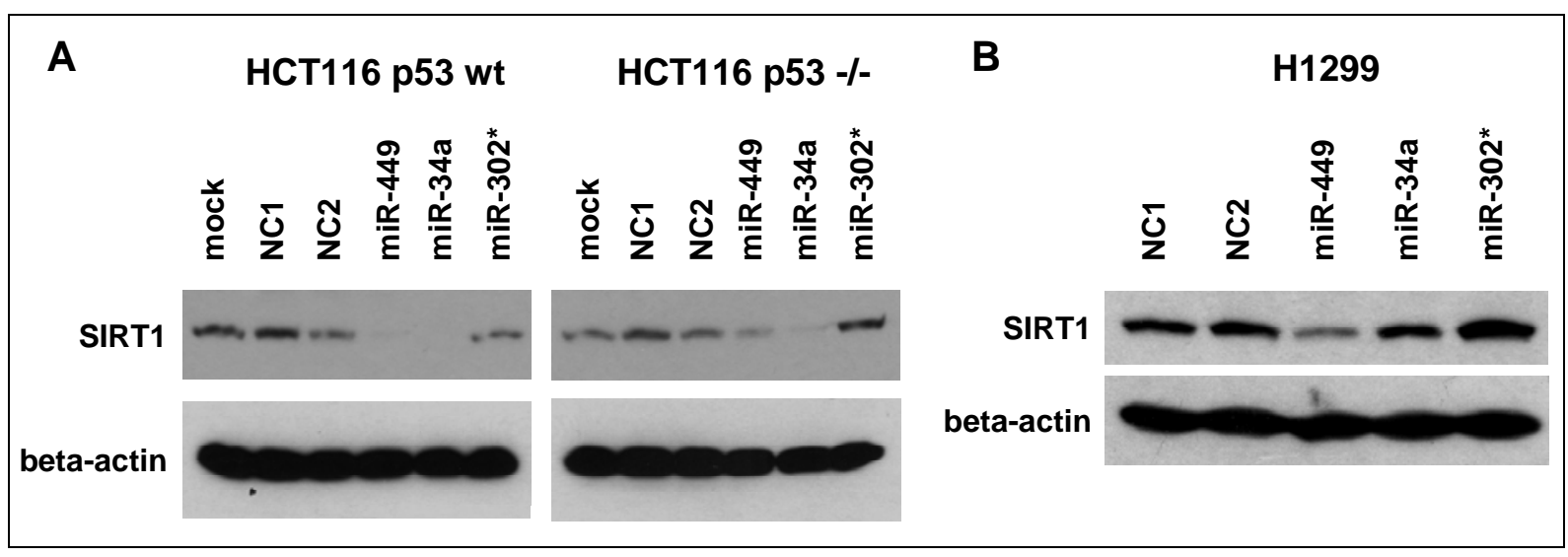

Fig. 5.14: miR-449a, as well as its paralogue miR-34a, target SIRT1

A, HCT116 p53 wt or HCT116 p53-/- cells were transfected with the indicated microRNAs for 48h, followed by immunoblot analysis of SIRT1 and beta-actin as a loading control (Lizé et al., 2010).

B, H1299 cells (p53 -/-) were transfected with the indicated microRNAs for $48 \mathrm{~h}$, followed by immunoblot analysis of SIRT1 and beta-actin as a loading control.

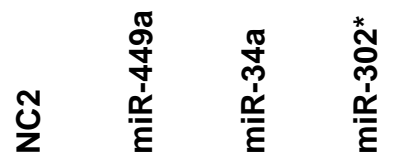

HDAC1

Hsc70

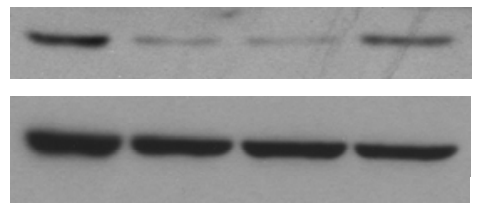

Fig. 5.15: miR-449a and miR-34a target HDAC1

Analysis of HDAC1 protein levels in H1299 as described for SIRT1 in Fig. 5.14 B. Hsc70 is a loading control. Experiment performed by Ines Rudolf under my supervision. 


\subsection{3. miR-449 provokes the accumulation of DNA damage}

Surprisingly, phosphorylated Histone 2AX (a marker of DNA damage, Fig. 2.1) was detected at increased levels following E2F1 induction (Fig. 5.9) and miR-449 overexpression (Fig. 5.16), arguing that miR-449a and miR-34a are perhaps capable of increasing the susceptibility of cells to DNA damage. Additionally, miR-449 seemed to slightly enhance the accumulation of DNA damage after chemotherapeutic treatment Fig. 5.16B). Interestingly, E2F1-mediated phospho-H2AX (gammaH2AX) accumulation was slightly alleviated by concurrent knockdown of miR-449a (Fig. 5.9).

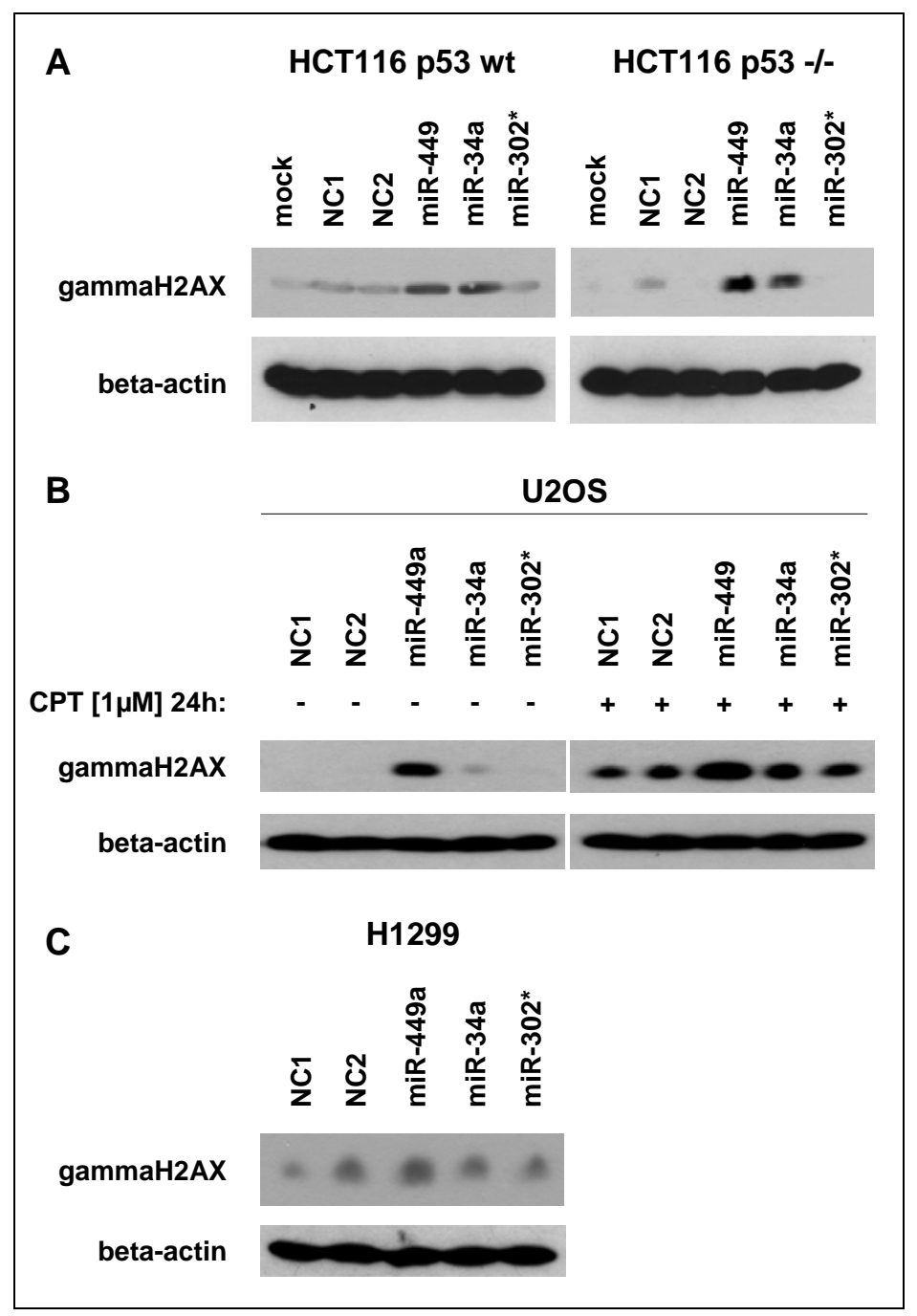

Fig. 5.16: miR-449 overexpression leads to gammaH2AX accumulation

A, Lysates of HCT116 p53 wt or p53-/- cells transfected with the indicated microRNAs for 48h were analysed by immunoblot for gammaH2AX and beta-actin levels (Lizé et al., 2010).

B, U2OS cells (p53 wild type) were transfected for $72 \mathrm{~h}$ and treated with the DNA damaging agent Camptothecin (CPT) or mock for $24 \mathrm{~h}$, followed by the same analysis. 
C, $\mathrm{H} 1299$ cells were transfected with the indicated microRNAs for $72 \mathrm{~h}$, followed by the same analysis. Note that the increase in gammaH2AX upon miR-449a transfection was less pronounced in these cells than in HCT116 or U2OS cells.

Although not fully explained at present, the miR-449 mediated accumulation of the DNA damage marker gammaH2AX would be in line with the known ability of E2F1 to induce a DNA damage response, and with similar responses to oncogenic stress during early cancerogenesis (Bartkova et al., 2005). Additionally, it was shown that HDAC1 inhibition was sufficient to accumulate DNA damage (Kim et al., 2008).

This effect, however, seems to be dependent on caspase activity, since it could be repressed by caspase inhibition with Z-VAD (Fig. 5.17).

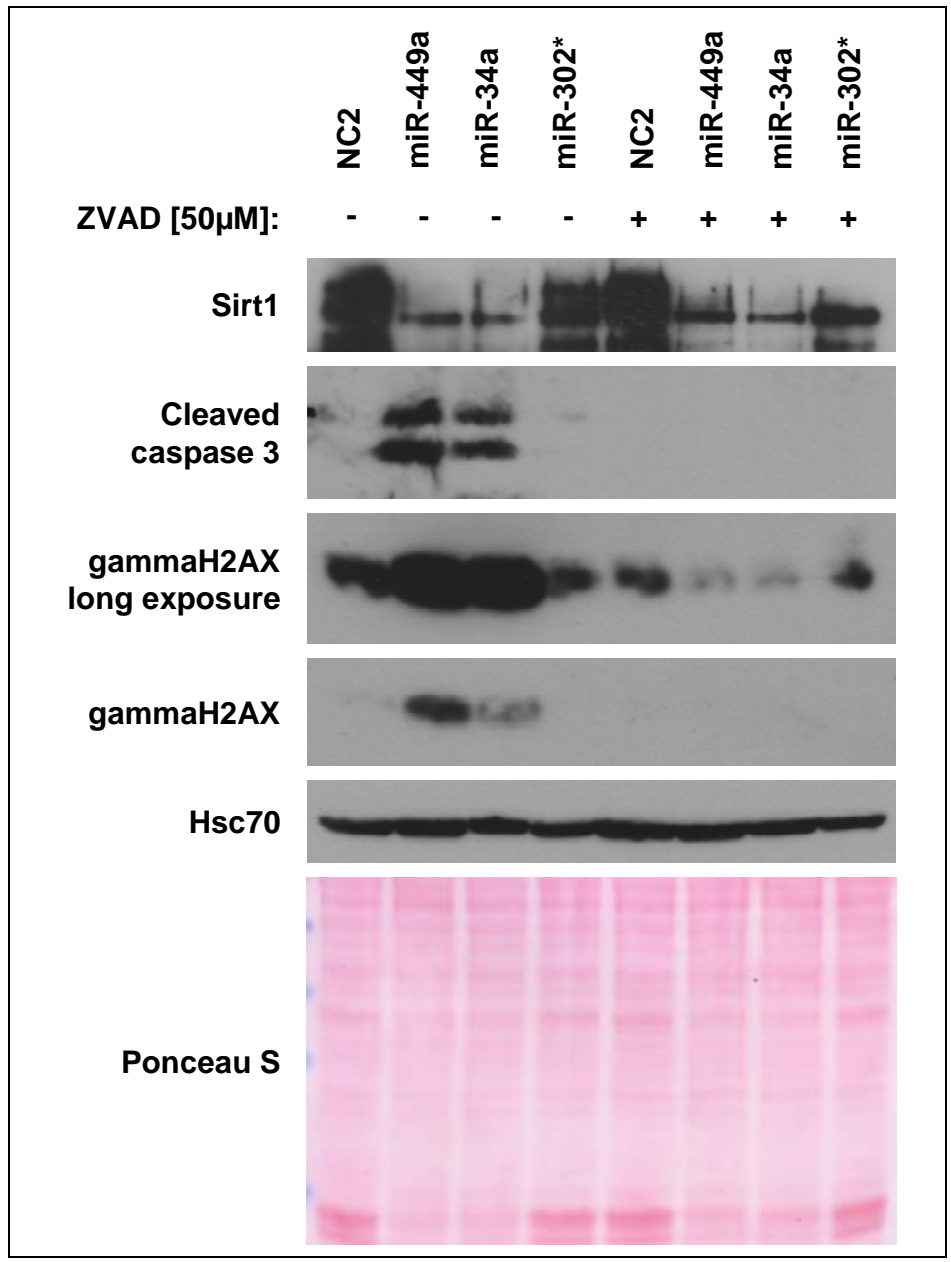

Fig. 5.17: gammaH2AX accumulation after miR-449 is dependent on caspase activity

H1299 cells were simultaneously transfected with the indicated microRNAs and treated with the caspase inhibitor ZVAD or mock for $72 \mathrm{~h}$, followed by immunoblot analysis using specific antibodies. The blot was stained with $\mathrm{Hsc70}$ and Ponceau $\mathrm{S}$ as loading and transfer controls. Staining of cleaved caspase 3 and SIRT1 were used as control of the transfection efficiency. 


\subsection{4. miR-449 targets vital mitosis checkpoints: Chk1 and BRCA1}

It was recently reported that the knockdown of the checkpoint protein Chk1 could lead to an enhanced accumulation of DNA damage and apoptosis by caspase activation (Pan et al., 2009; Romagnoli et al., 2009; Wang et al., 2004), a phenotype similar to the one observed after miR-449 overexpression. Hence, I next tested whether miR-449 would affect Chk1 activity or levels and therefore promote apoptosis and DNA damage accumulation.

Both miR-449a and miR-34a were able to down-regulate not only the active, phosphorylated form of Chk1, but also its overall levels (Fig. 5.18). Since the mRNA levels of Chk1 remained largely unchanged (Fig. 5.19A), miR-449 might act through translational repression in this case (Fig. 2.2). Additionally, BRCA1 (breast cancer 1), another checkpoint protein, was affected at least at the mRNA level (Fig. 5.19B).

Since both Chk1 and BRCA1 have been implicated in the DNA repair pathway of homologous recombination (Helleday, 2010), their knockdown by miR-449 could contribute to the observed enhanced susceptibility to DNA damage and, as a consequence, to apoptosis.

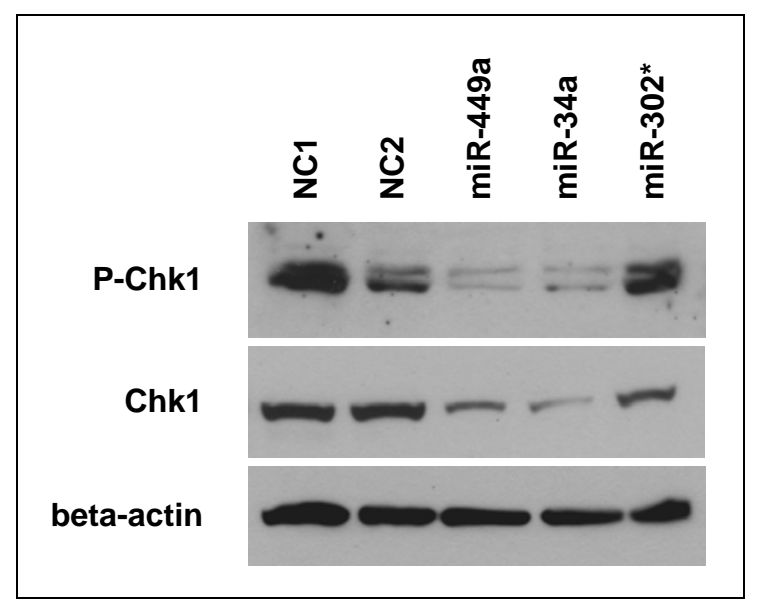

Fig. 5.18: Chk1 is downregulated by miR-449a and miR-34a

H1299 cells (p53 -/-) were transfected with the indicated microRNAs for $48 \mathrm{~h}$, followed by immunoblot analysis of Chk1 and phospho-Chk1 (Ser317; P-Chk1) and beta-actin as a loading control. 


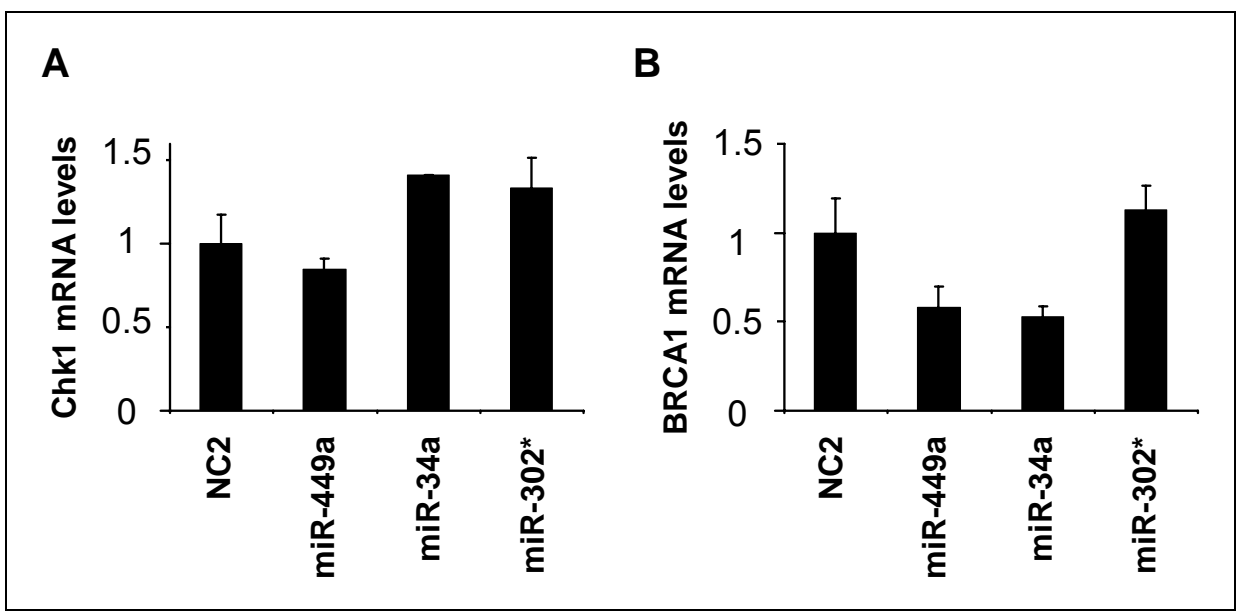

Fig. 5.19: miR-449a and miR-34a target BRCA1 but not Chk1 mRNA for degradation

H1299 cells were transfected with the indicated microRNAs, 48h post transfection the RNA was analysed by quantitative RT-PCR using specific primers for the mRNA of CHK1 (A) and BRCA1 (B).

However, although the siRNA-mediated knockdown of Chk1 in the same cell line accomplished similar gammaH2AX accumulation as miR-449 (Fig. 5.20), it failed to induce apoptosis equally (data not shown). In addition, the siRNA-mediated gammaH2AX accumulation was independent of caspase activity (as shown in Fig. 5.20 after ZVAD treatment) quite in contrary to the miR-449-mediated gammaH2AX accumulation (Fig. 5.17). Surprisingly, the knockdown of Chk1 reduced the E2F1 levels, maybe due to a decreased stability of the protein since Chk1-mediated phosphorylation of E2F1 is known to stabilise it (Fig. 2.1). The knockdown of E2F1 reduced Chk1 levels as expected, since Chk1 is E2F1responsive (Verlinden et al., 2007). 


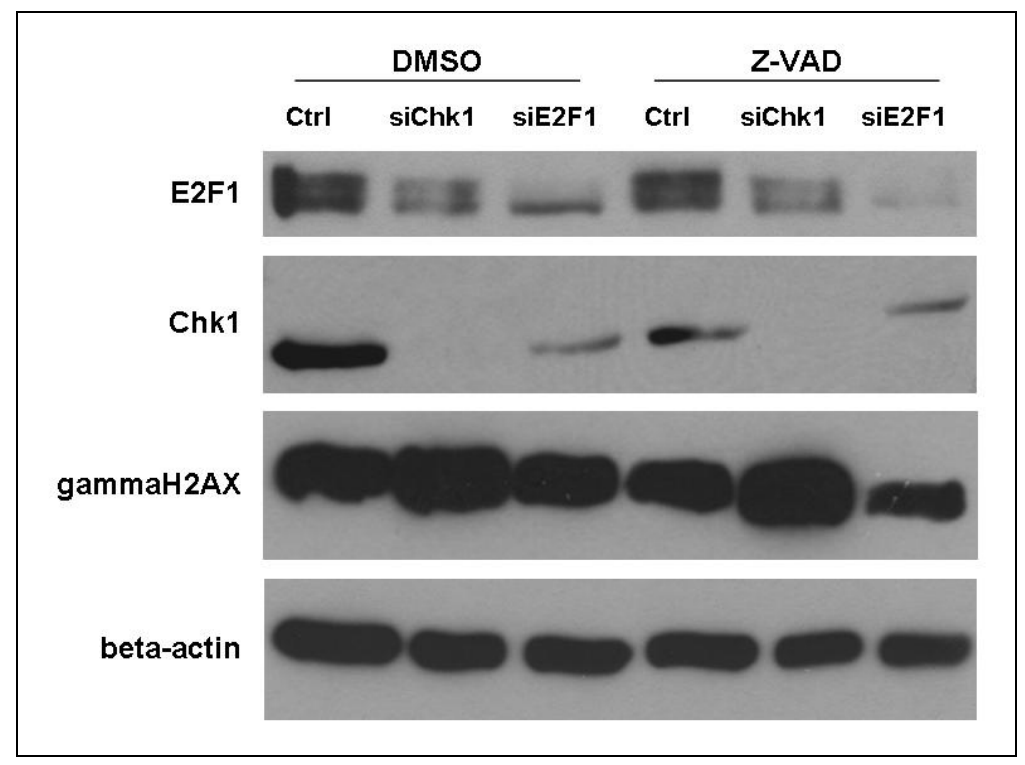

Fig. 5.20: Chk1 knockdown by siRNA accumulates DNA damage similarly to miR-449a overexpression but in a caspase-independent manner

H1299 cells were simultaneously transfected with the indicated siRNAs and treated with the caspase inhibitor ZVAD or mock for $48 \mathrm{~h}$, followed by immunoblot analysis using specific antibodies. Beta-actin served as loading control. Experiment performed by Miriam Weiss under my supervision.

Since the individual inhibition of the miR-449 targets CDK6, SIRT1, E2F1 or Chk1 failed to fully phenocopy miR-449-mediated, p53-independent apoptosis, I decided to combine the knockdown of more than one target at a time. As shown in Fig. 5.21, the cumulated knockdowns of SIRT1 with Chk1 or E2F1 were most efficient in inducing caspase cleavage while reduction of CDK6 seemed to have a rather protective effect, as expected for cell cycle arrest.

According to these preliminary results, the hypothesis of a cumulative effect of several miR449 targets to achieve full effect is currently under investigation. However, it is in agreement with the hypothesis that microRNAs act through several targets to regulate complete pathways and cell fate decisions. 


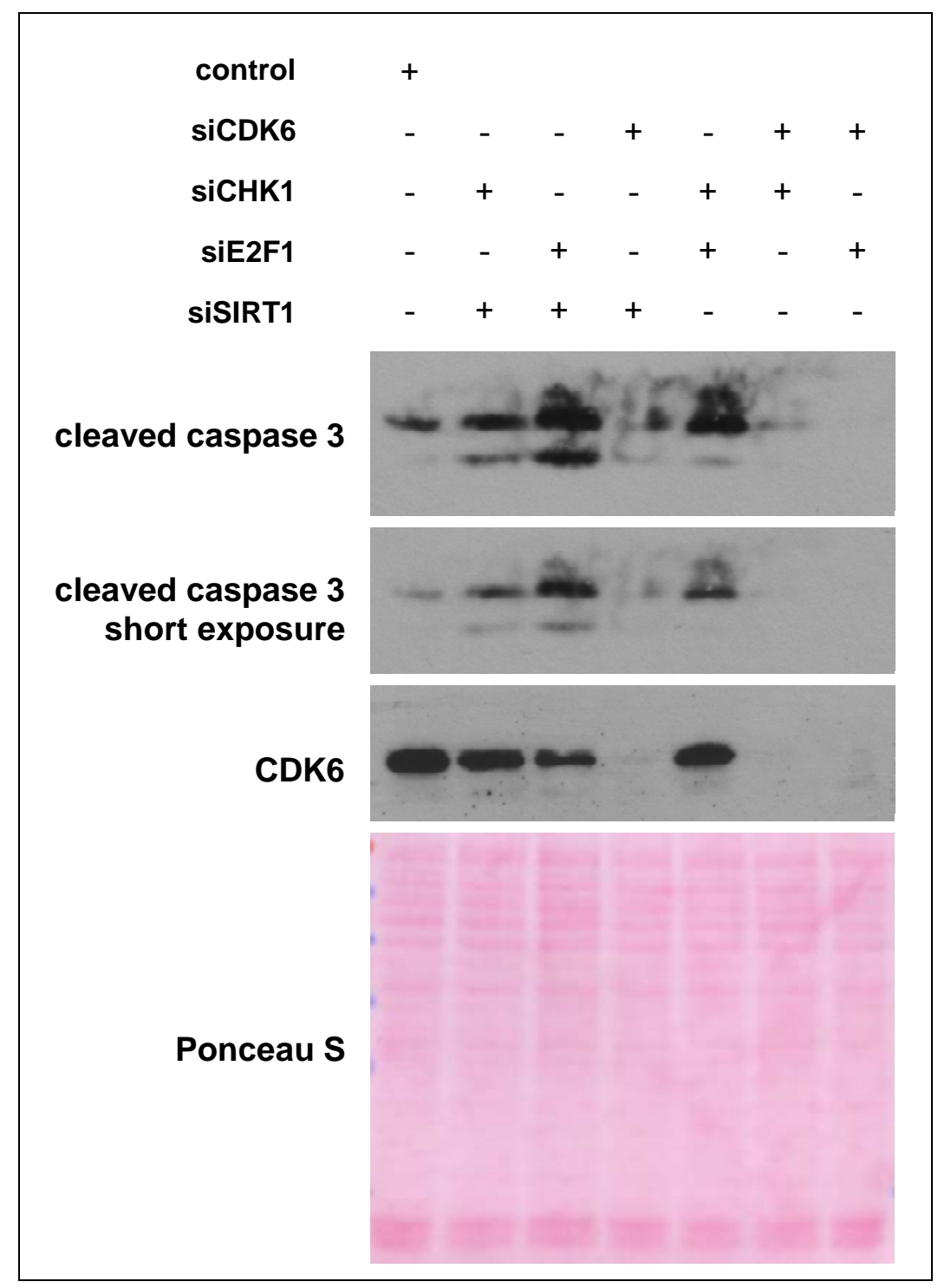

Fig. 5.21: The combined knockdown of the miR-449 targets SIRT1, CHK1 and E2F1 mimics miR-449-mediated apoptosis

H1299 cells were transfected with a combination of the indicated 2 siRNAs in each lane. Control transfection was achieved by combining 2 different scramble siRNAs. $48 \mathrm{~h}$ post transfection the cells were harvested and analysed by immunoblot using a specific antibody against the cleaved form of caspase 3 to assess apoptosis. CDK6 was stained as a control of transfection efficiency. Ponceau $S$ staining shows an equal protein amount in each lane.

\section{6. miR-449 expression correlates with the development of ciliated cells in lung in vivo}

To gain insight into the expression patterns, and therefore putative role of miR-449a and miR-34a in vivo, we assessed the levels of both microRNA species in murine tissues by quantitative RT-PCR. Whereas miR-34a showed a broader distribution, miR-449a was largely restricted to testes and lung (Fig. 5.22A), in accordance with my first findings in 
human and mouse (Fig. 5.4 A and B). In these tissues, miR-449a levels appear to exceed those of miR-34a (Fig. 5.23).

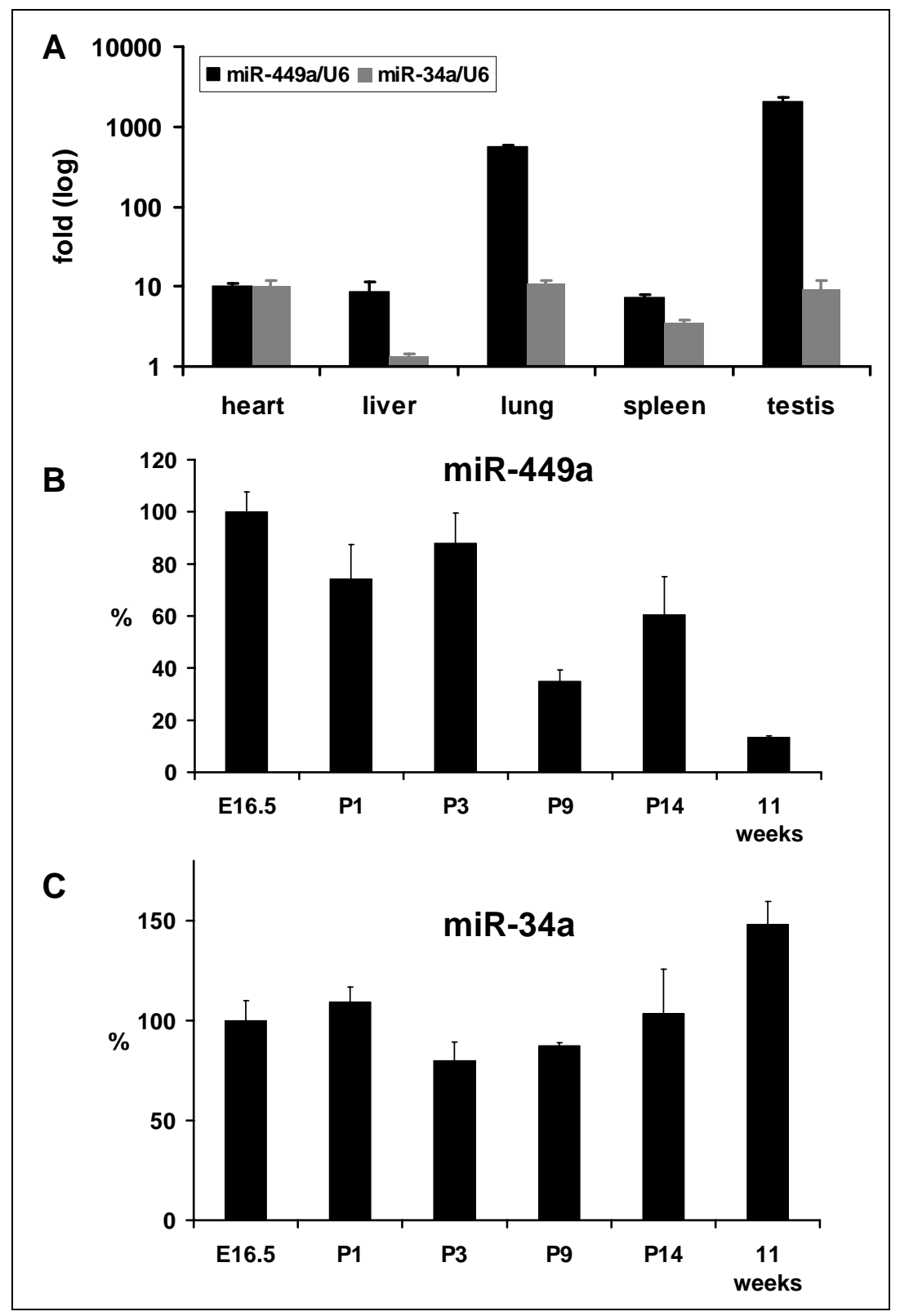

Fig. 5.22: miR-449a is highly abundant in lung tissue, in particular around birth

RNA was extracted from the indicated tissues obtained from C57BL/6 mice, followed by quantitative RT-PCR to determine the levels of microRNAs miR-34a and miR-449a.

A, Tissues were obtained from adult mice, 11 weeks of age.

B/C, Lung tissue was prepared from mouse embryos at stage E16.5 (shortly before birth), day 1, 3, 9 and 14 after birth, and 11 weeks after birth, followed by quantification of miR-449a (B) and miR-34a (C).

From the manuscript Lizé et al., submitted for peer review in June 2010. 
To assess the temporal pattern of miR-449a expression in the lung, RNA was extracted form murine pulmonary tissue shortly before and after birth. MiR-449a was highly expressed in the lungs of mouse embryos at stage E16 (i. e. 3 days before term) and then steadily decreased (Fig. 5.22B). In contrast, the levels of miR-34a remained largely unchanged (Fig. 5.22C). Thus, miR-449a is specifically expressed in pulmonary tissue, but mostly during the time around birth.

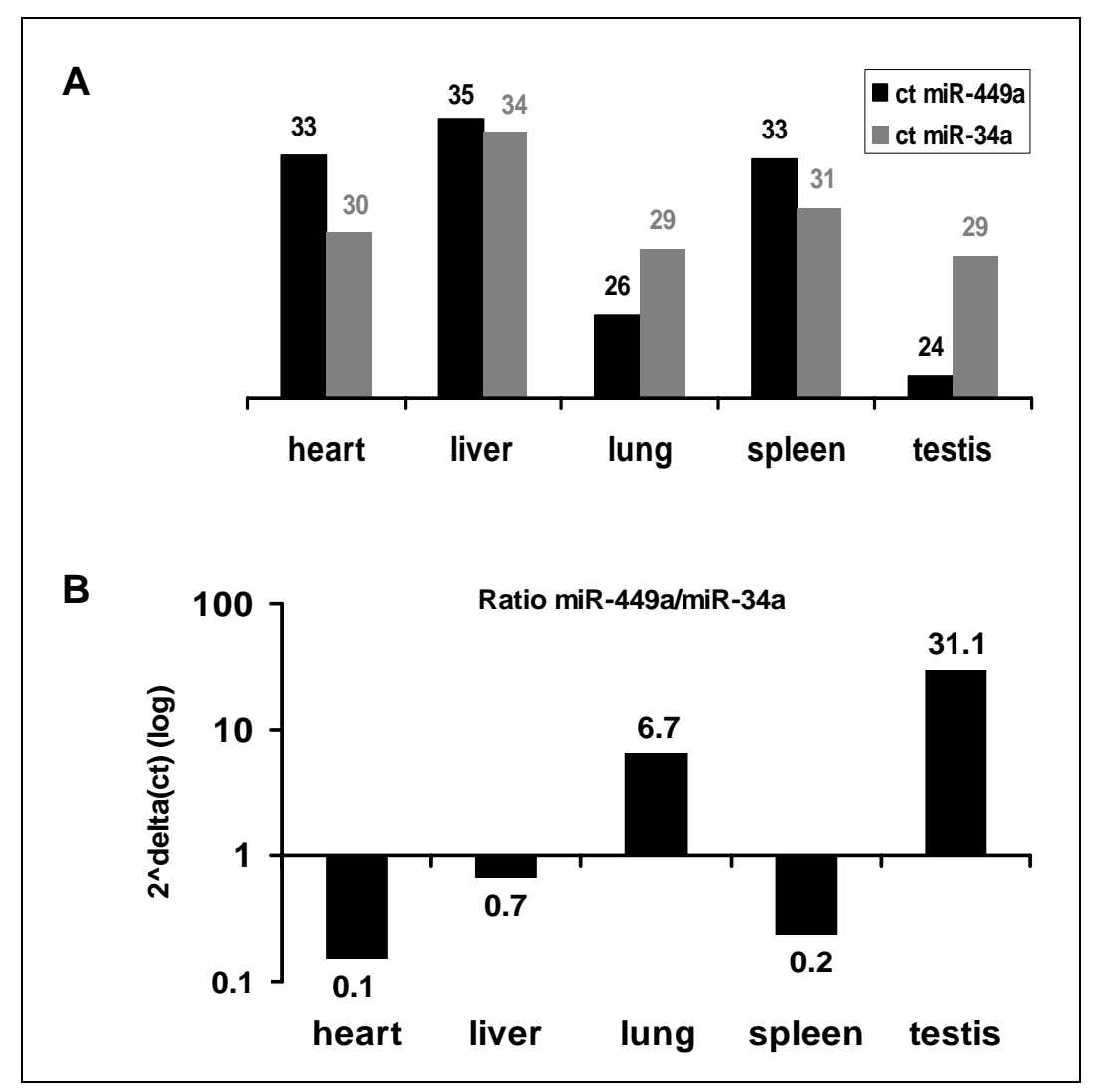

Fig. 5.23: Comparison of the miR-449a and miR-34a levels in various tissues in mouse

A, The results of RT-PCR (cf. Fig. 5.22) are shown as ct values (i. e. the number of PCR cycles required to obtain a pre-defined amount of the corresponding PCR product). Note that a low ct value corresponds to a high amount of template. Assuming similar efficiencies of PCR amplification, it is concluded that miR-449 levels are higher than miR-34a levels in lung and testes, but not in other tissues under study.

B, The ratio of miR-449a and miR-34a levels was calculated, approximating the amplification factor by 2. It is thereby estimated that the levels of miR-449 exceed those of miR-34a by a factor of 6.7 in lung tissue and by 31.1 in testicular tissue. Note that this comparison is limited by the efficiency of PCR amplification and therefore only represents an estimation.

From the manuscript Lizé et al., submitted for peer review in June 2010.

Since mucociliary epithelia are a major component of the respiratory tract, it can be speculated that they represent the site of high miR-449a levels. Interestingly, the highest 
levels of miR-449 (found shortly before and after birth) correlate with the time span where mucociliary differentiation takes place (Fig. 2.6) to ensure proper breathing at birth.

\section{7. miR-449 levels sharply increase upon differentiation of airway epithelial cells}

To test whether mucociliary epithelium was the site of high miR-449 expression, we employed a system to recapitulate aero-epithelial cell differentiation in vitro. Human AECs were lifted to the liquid air interface and thereby induced to fully differentiate as described previously (Bals et al., 2004). At several time points, RNA was extracted to quantify microRNA levels. Before airlift, miR-449a was barely detectable by RT-PCR. Strikingly, however, miR-449a levels sharply increased 100-fold within 7 days, and more than 1000-fold within the following week in AECs from different donors (Fig. 5.24A and Fig. 5.25).

In parallel, the host gene CDC20B (containing the miR-449a encoding region within an intron) was upregulated (Fig. 5.24B), as reported previously (Ross et al., 2007), although not as dramatically as miR-449a. A similar pattern was found for a previously described putative master regulator of AEC differentiation (as introduced in Fig. 2.5), FoxJ1 (Fig. 5.24B and Fig. 5.25). Simultaneously, the generation of a seal with high electrical resistance was observed, indicating the generation of a differentiated cell monolayer (Fig. 5.24C).

In contrast to miR-449a, the levels of miR-34a remained largely unchanged (Fig. 5.24A). Curiously, the levels of E2F1 mRNA also remained unaffected (Fig. 5.24B), in contrast to the mutual regulation of E2F1 and miR-449a previously described for cells of different origin that undergo DNA damage (Fig. 5.3B). 


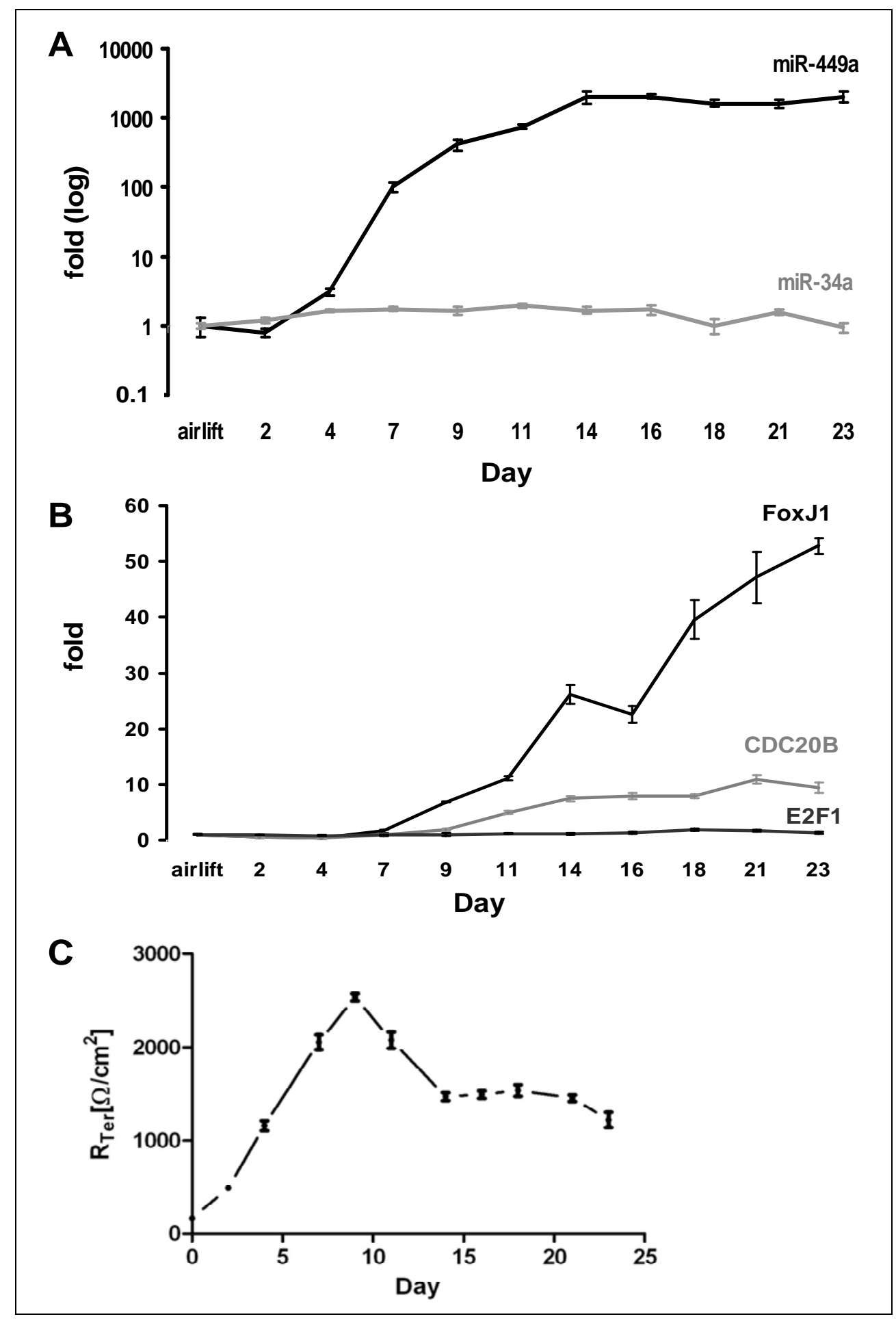

Fig. 5.24: Strong miR-449a induction in differentiating human airway epithelial cells

Airway epithelial cells (AECs) were cultivated for 3 days in liquid media and lifted to the interface between the media and the air. At the indicated time points (days after airlift), samples of the cells were harvested to prepare RNA, followed by RT-PCR to quantitate specific RNA species.

A, The levels of microRNAs $34 a$ and $449 a$ were quantified.

B, The abundance of the indicated mRNA species was assessed

C, The electrical resistance of the cell monolayer was measured to ensure full differentiation.

From the manuscript Lizé et al., submitted for peer review in June 2010. 


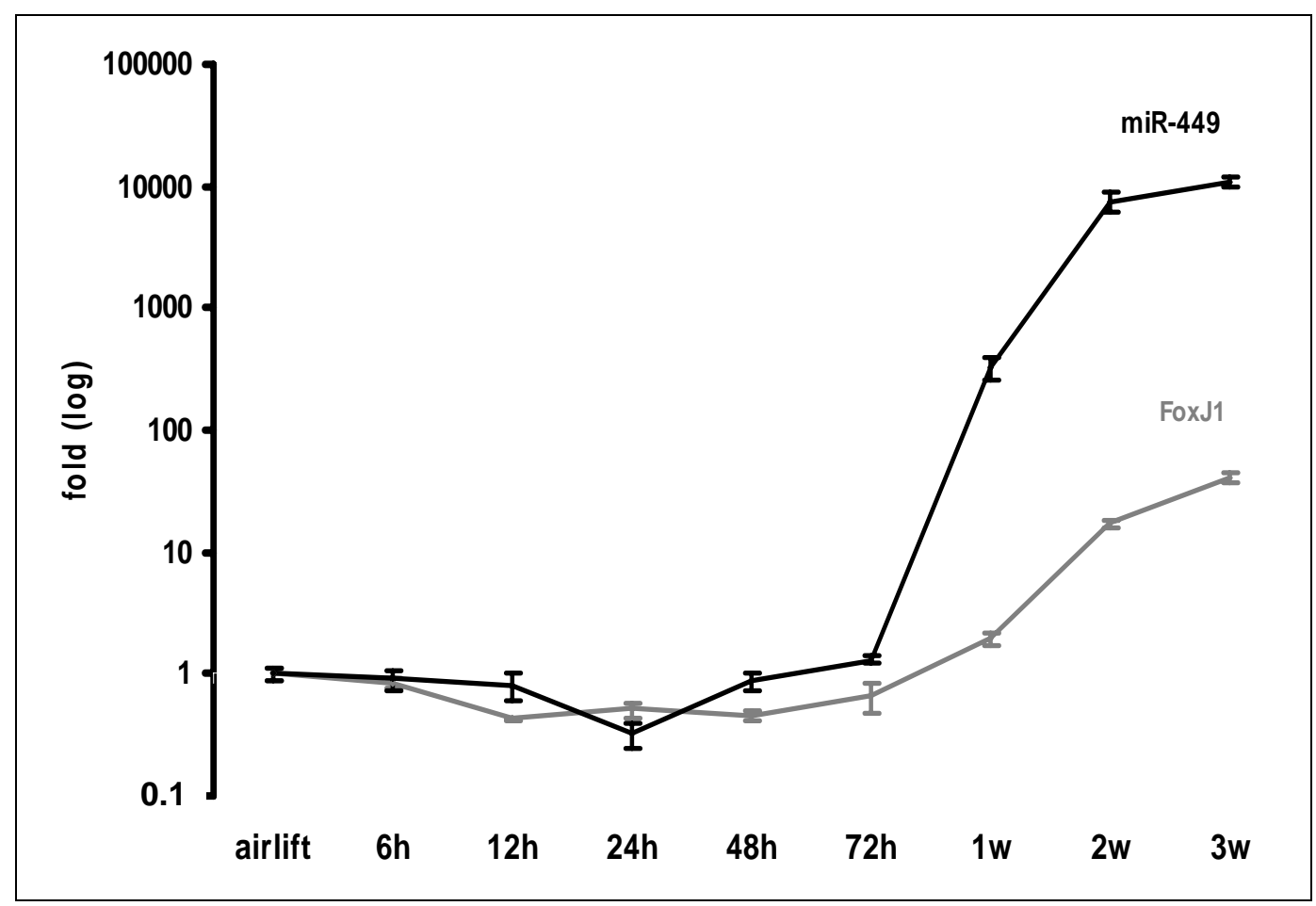

Fig. 5.25: Levels of miR-449a and FoxJ1 mRNA in differentiating airway epithelia

AECs were obtained from a different individual than in Fig. 5.24, followed by airlift and RNA preparation at the indicated time points. RNA levels were analyzed as described in the legend to Fig. 5.24. $\mathrm{h}=$ hours, $\mathrm{d}=$ days, $\mathrm{w}=$ weeks. From the manuscript Lizé et al., submitted for peer review in June 2010.

In conclusion, miR-449a represents a highly specific marker for differentiated AECs, perhaps acting as a master regulator of the AEC-specific gene expression program. To my knowledge, and in comparison to other differentially regulated genes, the increase in miR449 a represents the strongest change in gene expression levels that occurs upon AEC differentiation.

\section{8. miR-449 levels further increase upon exposure of airway epithelia to tobacco smoke}

During the first characterisation of miR-449a, its up-regulation in response to DNA damage was shown (Fig. 5.3B), and similar findings were reported for miR-34a (Hermeking, 2007). To assess this in the context of airway epithelia, I exposed a differentiated AEC monolayer to tobacco smoke, as previously described by my collaborators (Beisswenger et al., 2004). 
This procedure increased the levels of miR-449a even further (Fig. 5.26A). This increase was also found for the mRNA encoding E2F1 (Fig. 5.26B), possibly explaining the up-regulation of miR-449a.

Similarly, miR-34a levels were increased under such circumstances (Fig. 5.26A), perhaps as a result of the known p53-responsiveness of miR-34a (Hermeking, 2007).

This is in contrast to a number of other microRNA species that were previously found downregulated by tobacco smoke exposure (Schembri et al., 2009).

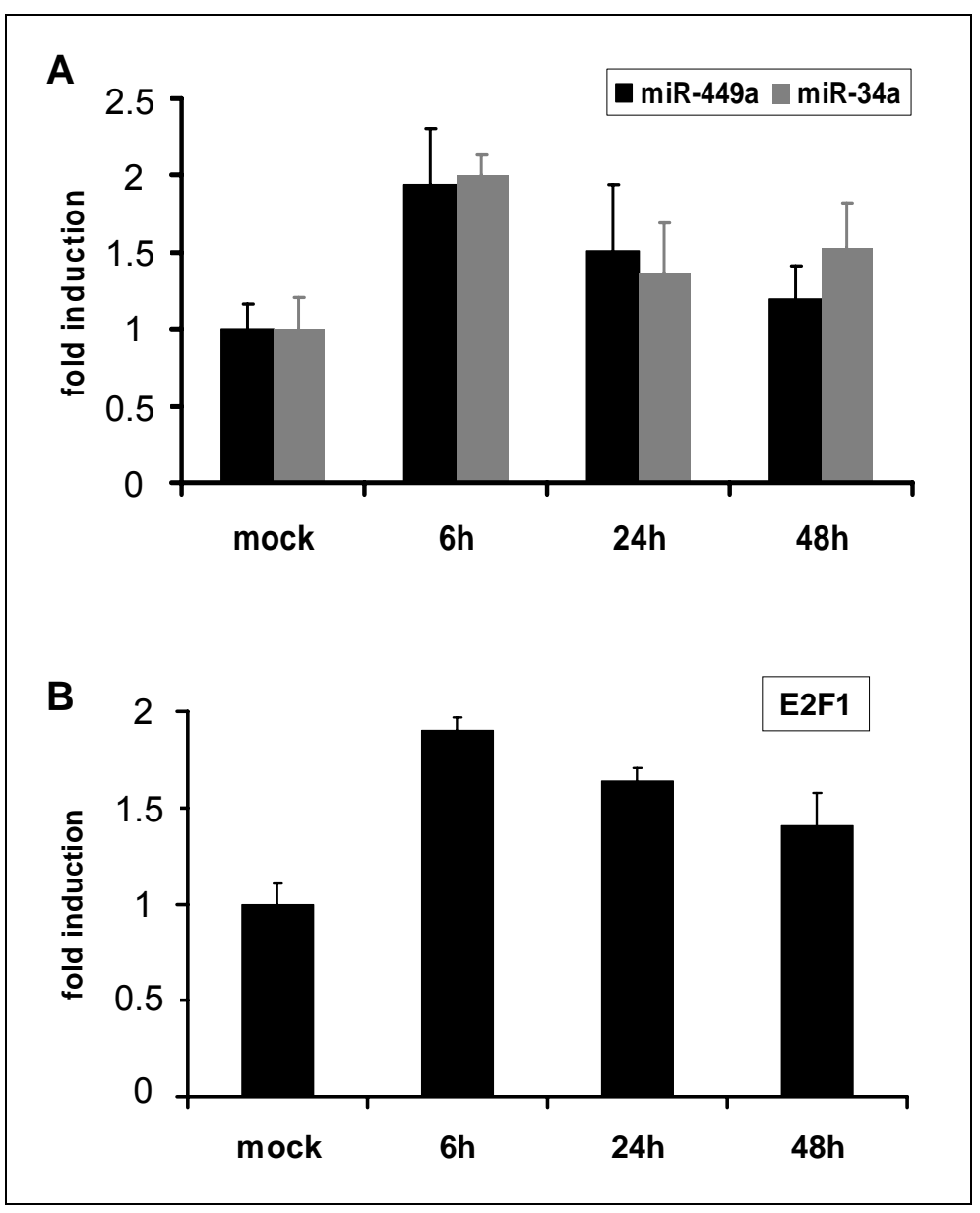

Fig. 5.26: Further induction of miR-449a in airway epithelial cells exposed to tobacco smoke

A fully differentiated monolayer of AECs (more exactly the very same AECs as obtained in Fig. 5.25), were exposed to cigarette smoke for $15 \mathrm{~min}$ ( $=3$ cigarettes) or mock-treated at 21 days after airlift, followed by RT-PCR quantification of microRNA-449a and -34a levels (A) and E2F1 mRNA (B). From the manuscript Lizé et al., submitted for peer review in June 2010.

Thus, miR-449a is further regulated by genotoxic stress, as it occurs in response to exposure of AECs to tobacco smoke. Unlike the differentiation-associated up-regulation of miR-449a, the induction of miR-449a by genotoxicity may be a result of the DNA damage dependent activation of E2F1. 


\section{Discussion}

E2F1 has a paradoxical role in cancer, sometimes acting as an oncogene (Johnson, 2000; Johnson et al., 1994), sometimes as a tumour-suppressor (Johnson, 2000; Shan and Lee, 1994; Tsai et al., 1998; Wu and Levine, 1994; Yamasaki et al., 1996). This reflects the ability of E2F1 to promote cell proliferation or cell death by apoptosis depending on the cellular context. However, the regulation of the life or death decision made by E2F1 is still poorly understood.

The results reported in this thesis describe miR-449 as a new E2F1-responsive microRNA from the miR-34 family. The activity of this microRNA recapitulates many properties of E2F1p53 interdependence in the regulation of cell proliferation and cell death. Indeed, in response to DNA damage, miR-449 can promote apoptosis and p53 activity (like E2F1) while repressing E2F1 activity (like p53).

MiR-449, as well as its poorly described host gene CDC20B, is expressed at high levels in a tissue-specific manner, mainly in differentiated pulmonary tissue or tissue from the reproduction tracts. In line with its tumour-suppressive function, miR-499 is strongly downregulated in cancer, most probably through epigenetic inactivation.

In tumour cell lines, the reactivation of miR-449 expression by drug treatment or its reintroduction both lead to growth arrest and apoptosis, and might therefore have therapeutic relevance in cancer arising from pulmonary or reproductive tissues like lung or testis.

\subsection{Regulation of the E2F and p53 pathways}

The results presented here demonstrate that miR-449 provides a negative feedback to E2F1 and a positive feedback to p53 activity, reinforcing the E2F1-p53 interdependence summarized in the model presented in Fig. 6.1A.

Both p53 and E2F1 are activated in response to DNA damage, and they subsequently induce proapoptotic genes. However, the mutual regulation of E2F1 and p53 is asymmetric. E2F1 induces the expression of p14arf, thereby stabilising p53, and of TAp73, leading to enhanced induction of p53 target genes. On the other hand, p53 transactivates the gene encoding p21, a CDK inhibitor that negatively regulates E2F1.

MiR-449 recapitulates this asymmetric, mutual regulation. The negative regulation of the E2F pathway by miR-449 occurs through several, different mechanisms pointing to the importance of this effect. First, miR-449 targets CDK2 and CDK6, two cyclin-dependent kinases responsible for the phosphorylation of pocket proteins (e.g. Rb). As a result, 
hypophosphorylated $\mathrm{Rb}$ can bind to and inactivate E2F. Interestingly, miR-449 not only inhibits E2F activity but also affects E2F1 and E2F3 protein levels. Since miR-449 does not directly bind to the 3'UTR of E2F1, this suggests that it regulates E2F1 stability. Furthermore, another miR-449 target, SIRT1, has been linked to cell cycle regulation through E2F inhibition. SIRT1 is known to deacetylate Rb (Wong and Weber, 2007). A knock-down of SIRT1 as a result of miR-449 expression leads to the accumulation of acetylated, active $\mathrm{Rb}$ (through the obstruction of inhibitory phosphorylation sites), thereby inactivating E2F and promoting growth arrest. In p53 wild type cells, the negative regulation of E2F1 by miR-449 is further supported by the upregulation of the p53-reponsive CDK inhibitor p21 (Fig. 6.1A). This is probably due to the down-regulation of SIRT1, which allows the accumulation of a highly active, acetylated form of p53 (Yamakuchi et al., 2008). This p53 activation may result in the induction of p53-dependent apoptosis, as described earlier consequently to SIRT1 down-regulation (Sun et al., 2007). However, the knockdown of SIRT1 alone did not fully phenocopy the proapoptotic effects of miR-34 or miR-449 under the conditions used in my study, although it did suppress clonogenic survival in preliminary tests. Nevertheless, this does not exclude a contribution of SIRT1 down-regulation to the observed cell death when combined with broader gene regulation.

Thus, the activities of the miR-34 family reported here are in analogy to the classical model of E2F-p53 mutual regulation (Fig. 6.1A). Firstly, miR-34 and miR-449 are each capable of promoting apoptosis, presumably by antagonizing an overlapping set of pro-survival genes. On top of this, both microRNAs activate p53 while attenuating E2F1 (Fig. 6.1B), thereby repressing cell proliferation. This strongly argues that microRNAs of the $34 / 449$ family fortify both the proapoptotic activities of p53 and E2F1, but also the asymmetric mutual regulation of these two factors. 


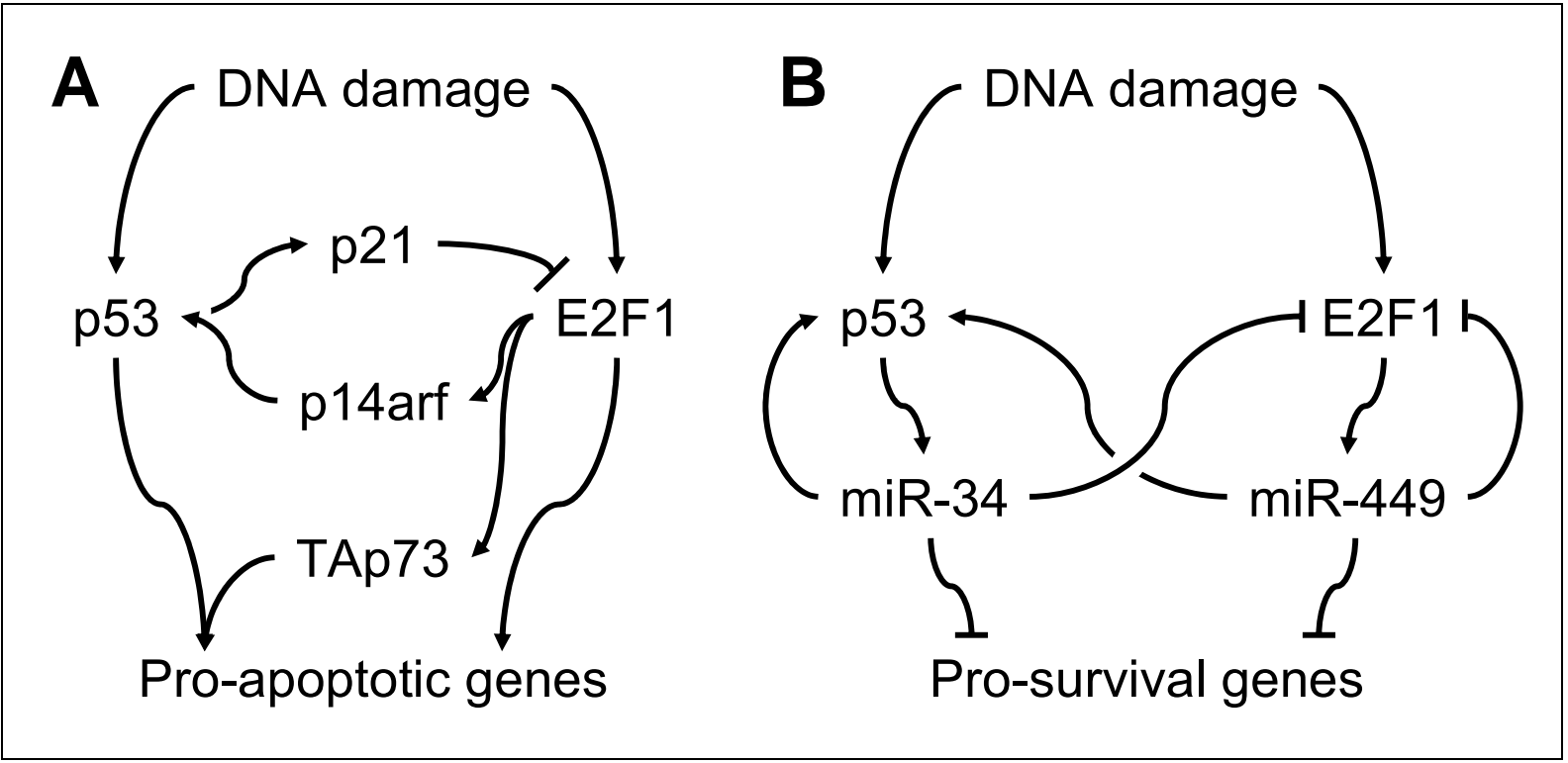

\section{Fig. 6.1: Mutual regulation of $\mathrm{p} 53$ and E2F1}

A, Mutual regulation through protein-coding target genes. DNA damage activates p53 and E2F1, and both induce an overlapping set of proapoptotic target genes. Although E2F1 further enhances p53 activity through p14arf and TAp73, p53 inhibits E2F1 through the CDK inhibitor p21.

$B$, This asymmetric mutual regulation is recapitulated and presumably fortified by microRNAs. On DNA damage, p53 induces miR-34 and E2F1 increases the levels of miR449 family members. Both microRNAs induce apoptosis by antagonizing the expression of prosurvival genes. In addition to this, both microRNAs support p53 activity (for example, through enhanced acetylation), but negatively regulate E2F1 (for example, by down-regulating CDK6). Arrowheads symbolize activation and bars inhibition.

Lizé et al., Cell Death \& Differentiation, March 2010.

However, since both miRNAs were shown to induce cell death in p53 deficient cells, they must also trigger proapoptotic mechanisms independently of p53. Extensive studies on miR34 target genes have revealed a multitude of potential genes as being miR-34-regulated (Chang et al., 2007; He et al., 2007a). It therefore can be assumed that miR-449 has a similarly broad spectrum of target mRNAs, largely excluding a monocausal model to explain its proapoptotic effects. In fact, the combined knockdown of two miR-449 targets, namely SIRT1 and E2F1, in contrast to individual inhibition, was able to activate caspase cleavage in p53-deficient cells.

As the majority of tumour cells have lost proper p53 activity, the mechanisms behind miR449-induced p53-independent apoptosis could be of high therapeutic relevance. 


\section{2. miR-449-mediated p53-independent apoptosis}

Most tumour cell lines have lost proper p53-activity, thereby overcoming the induction of apoptosis in response to DNA damage. The reexpression of miR-449 however was able to induce apoptosis independently of the p53 status of the cell, which might be of high therapeutic value. During this work, several pathways potentially involved in the miR-449mediated p53-independent apoptosis were investigated.

In contrast to the results of other studies (Ji et al., 2008), the down-regulation of antiapoptotic proteins from the BCL-family, namely BCL2 and BCL6, could not be confirmed as the mechanism by which miR-449 induces apoptosis, at least not in the cell lines used in our lab.

Moreover, the E2F1-responsive p53-homologue TAp73 is not relevant for the observed phenotype since it wasn't induced after miR-449 expression. This probably reflects the inhibition of E2F1 activity. In line with this, another proapoptotic, E2F1-responsive gene APAF1 was not induced by miR-449, excluding APAF1 accumulation as the mechanism behind miR-449-mediated p53-independent apoptosis (although caspase mediated APAF1 cleavage was observed in response to miR-449, data not shown).

In the following paragraphs, several potential mechanisms for miR-449-mediated p53independent apoptosis are discussed.

\subsection{1. miR-449 as a regulator of cell cycle progression: cell death by mitotic catastrophe?}

On top of the negative regulation of cell proliferation by inhibition of the E2F pathway, miR449 seems to also affect mitosis regulation.

The first hint was given by the fact that miR-449a and miR-449b are both encoded in an intron of the CDC20B gene. While little is known about the function of this gene, its paralogue CDC20 is an essential component of the cellular machinery that enables the anaphase promoting complex to destruct its targets in a timely fashion, allowing progression through mitosis (Yu, 2007). Moreover, several mitosis-promoting genes, e. g. Polo-like kinase and others, have previously been identified as E2F1-targets, implying E2F1 in mitotic progression (Ren et al., 2002). It is tempting to speculate that E2F1 regulates mitosis through CDC20B/miR-449 induction, and uncontrolled E2F1-activity is avoided by miR-449 negative feedback.

In fact, miR-449 modulates the histone deacetylase HDAC1, which has been shown to be required for the correct formation of chromatin after DNA replication (Milutinovic et al., 2002). MiR-449 might therefore disturb proper mitosis exit through the down-regulation of HDAC1. 
Consistently, HDAC inhibition can lead to G2/M arrest (Milutinovic et al., 2002). As an interesting, additional link, BRCA1 (breast cancer 1), another miR-449 target, was shown to interact with both Rb and HDAC1 (Yarden and Brody, 1999).

Among its targets, miR-449 also down-regulates two major cell cycle checkpoint proteins, Chk1 (checkpoint kinase 1) and BRCA1, both shown to be deregulated in cancer (Enders, 2008; Yarden et al., 2002), and both closely related to mitotic catastrophe (Huang et al., 2005). Most notably, Chk1 contributes to many cell cycle checkpoints (G1/S, intra-S, G2/M and mitotic spindle checkpoint) including the mitotic exit DNA damage checkpoint (Dai and Grant, 2010; Huang et al., 2005). Chk1 depletion is therefore expected to prevent proper, damage-free cell cycle progression and to promote the G1 entry of damaged mitotic cells (Lee et al., 2010). This causes cell death by mitotic catastrophe (Canman, 2001; Fishler et al., 2010). In fact, Chk1 inhibition or deletion killed mammary tumour cells in a recent study (Fishler et al., 2010). Interestingly, cell death following Chk1 depletion is usually accompanied by caspase-3 activation and accumulation of double-stranded DNA breaks (Xiao et al., 2005) as observed after miR-449 overexpression. Furthermore, the inhibition of BRCA1 similarly induces cell cycle arrest and mitotic catastrophe (Tominaga et al., 2007). Thus, miR-449 might induce p53-independent apoptosis by promoting mitotic catastrophe through the inhibition of key regulators of cell cycle progression and mitosis exit, namely HDAC1, BRCA1 and Chk1.

That way, in normal, differentiated cells, miR-449 would preferably inhibit cell cycle entry and promote growth arrest through the inhibition of the E2F pathway. In tumour cells, however, uncontrolled proliferation could overcome this arrest signal and, together with enhanced genetic instability, push miR-449 regulation toward the induction of cell death by mitotic catastrophe.

\subsection{2. miR-449 \& DNA damage: a role in DNA repair?}

In this work, several links between miR-449 and DNA damage were found. First, miR-449 is induced by DNA damage, probably as a consequence of its E2F1 responsiveness. Additionally, besides apoptosis, one of the phenotypes observed after miR-449- as well as E2F1-overexpression in tumour cells was the accumulation of a DNA damage marker, gammaH2AX, arguing that miR-449 may sensitise cells to intrinsic DNA damage.

Tumour cells constantly undergo replicative stress (Bartkova et al., 2006; Di Micco et al., 2006), therefore they need efficient DNA repair for survival. During cancer development, tumour cells acquire genetic instability, through mutation, depletion or inhibition of several tumour-suppressor genes e.g. p53 and BRCA1. These genes contribute to the protection of genome integrity not only through the induction of apoptosis in DNA repair defective cells 
(e.g. p53) but also through direct involvement in DNA repair (e.g. BRCA1). Even though tumour cells with defects in the homologous recombination machinery are still viable, this is mostly due to the maintenance of "backup" mechanisms (Helleday, 2010; Helleday et al., 2008). Targeting the last functional parts of this machinery might kill cancer cells effectively, as lately shown for HDAC (Adimoolam et al., 2007) and PARP inhibitors (Bryant et al., 2005; Farmer et al., 2005; Fong et al., 2009; Helleday et al., 2005).

Interestingly, miR-449 targets several proteins with a role in DNA repair. For instance, HDAC1 (Adimoolam et al., 2007), BRCA1 (O'Donovan and Livingston, 2010), SIRT1 (Helleday, 2010; Uhl et al., 2010) and Chk1 (Stracker et al., 2009) have been shown to play a role in homologous recombination (Helleday, 2010). In cancer cells, even in p53-defective

cells, the inhibition of homologous recombination could become fatal because of the excessive accumulation of DNA damage.

Unfortunately, even though miR-449 can be linked to mitotic catastrophe and tumour cell death as a consequence of DNA repair impairment, the exact mechanisms behind miR-449mediated, p53-independent cell death are still unclear and need further investigation.

\section{3. $\mathrm{miR}-449$ as a regulator of general gene expression}

Certainly, the downregulation of the histone deacetylases SIRT1 and HDAC1 by miR-449 shown here not only affects DNA repair, but also general gene expression, through epigenetic modulation (i.e. acetylation of histones) and regulation of the activity of transcription factors (through acetylation levels of e.g. p53, Sp1).

Interestingly, HDACs, in contrast to microRNAs from the miR-34 family, are overexpressed in various cancers (Halkidou et al., 2004; Patra et al., 2001; Weichert et al., 2008a; Weichert et al., 2008b; Wilson et al., 2006; Zhang et al., 2005). This mostly correlates with poor prognosis (Weichert, 2009). HDAC inhibitors have been shown to efficiently kill tumour cells, and accordingly, HDAC inhibitors are currently in clinical trials (Carew et al., 2008; Moradei et al., 2008; Shankar and Srivastava, 2008). Interestingly, also another histone deacetylase is targeted by miR-449. SIRT1 was shown to be highly expressed in cancer, and its knockdown was able to induce apoptosis independently of p53 (Stunkel et al., 2007), accompanied by caspase activation (Alcendor et al., 2004). The specific inhibition of SIRT1 has also been shown to sensitise tumour cells to chemotherapeutics (Wang et al., 2008).

However, the mechanism leading to HDAC overexpression in cancer is not yet clear. Mir-449 is generally reduced in tumour cells, mainly through epigenetic silencing (Noonan et al., 2009). Cells might be selected for miR-449 silencing since they may otherwise undergo cell cycle arrest or apoptosis. The fact that E2F1 is frequently overactive in cancer may further 
increase the need for miR-449 silencing. Therefore, the loss of miR-449 observed in cancer may contribute to HDAC1 enhanced expression, thereby eventually contributing to carcinogenesis through "cell reprogramming" (Trosko, 2009). Intriguingly, miR-449 itself is induced by HDAC inhibition. Thus, miR-449 induction may even contribute to cell death upon HDAC inhibitor treatment.

Hence, HDACs keep miR-449 low in tumour cells while miR-449 keeps HDACs low in noncancerous cells. This mutual regulation might provide a "switch" for general gene expression, such as often observed in tumorigenesis or differentiation.

\section{4. miR-449 in vivo: cell differentiation and development}

MiR-449 is strongly induced during the mucociliary differentiation of airway epithelium, and its expression in the murine lung is highest around birth, when this process is needed the most.

To my knowledge, this is the first description of a microRNA that displays strong specificity for mucociliary differentiation, although several microRNAs, including miR-449a, were reported to be expressed in lung tissue depending on the developmental stage (Dong et al., 2010; Lu et al., 2008). MiR-449a undergoes the strongest induction of gene expression that was so far observed during AEC differentiation. This observation raises the possibility that miR-449, perhaps in addition to FoxJ1, serves as a master regulator to ensure the proper differentiation of this vital cell population.

Previous studies have used microarray hybridization to identify changes in mRNA levels that occur in the course of AEC differentiation. Strikingly, one of the most differentially expressed genes found in this study was the miR-449 host gene, CDC20B (Ross et al., 2007). The mRNA of $\mathrm{CDC} 20 \mathrm{~B}$ and miR-449 are usually coregulated. Therefore, it is probable that at least some of the regulatory mechanisms that govern miR-449 up-regulation upon AEC differentiation apply to its host gene CDC20B as well. However, it is remarkable that the upregulation of miR-449a was even stronger than that of CDC20B. Differences in PCR efficiency cannot be fully ruled out since microRNAs and mRNAs were measured using different methods. However, it is tempting to speculate that AEC differentiation is associated with increased efficiency of miR-449a processing from its precursor RNA, explaining the additional increase. Interestingly, some of the miR-449 targets described in my thesis were found to be downregulated during AEC differentiation, most notably Chk1 and CDKs (Ross et al., 2007). It is therefore very probable that miR-449a not only marks differentiated AECs but also serves as an active regulator of this differentiation process. MiR-449 is a potent inducer of cell cycle arrest, and this may contribute to terminal differentiation. In addition, miR-449 reduces the levels of the histone deacetylases SIRT1 and HDAC1, pleiotropic regulators of 
transcription, possibly contributing to a differentiation-associated gene expression program. An active function of miR-449a in mucociliary cell differentiation would be in agreement with its high expression levels shortly before and after birth, when the demand for such a differentiation program is the highest.

The cellular origin of cancer has been discussed heavily during the past 100 years. There are two main theories: reprogramming of differentiated cells or blockage of differentiation programming (Sell, 1993; Trosko, 2009). The downregulation of HDACs by miR-449 could contribute to such a reprogramming, pushing the cells toward differentiation. In fact, besides histone deacetylases, I found several regulators of differentiation among the putative miR449 targets (Tab. 5.1). For instance, KLF4 was shown recently to be one of the four genes sufficient to reprogram fibroblasts into embryonic stem-like cells (Takahashi and Yamanaka, 2006). Additionally, HMGA2 has been involved in the maintenance of an undifferentiated state in cancer (Droge and Davey, 2008). An active Notch signalling has been associated with immature, proliferating cells (Axelson et al., 2005) and Notch1 is found among the putative miR-449 targets (Tab. 5.1). Also the activation of p53 by miR-449 can suppress cellular dedifferentiation (Zhao and $\mathrm{Xu}, 2010$ ) through the suppression of the pluripotency factor Nanog (Lin et al., 2005). Finally, miR-449 was shown to be involved in development in another report (Redshaw et al., 2009), in this case implicating the down-regulation of another member of the E2F family, E2F5.

Besides differentiation, miR-449a is also capable of inducing apoptosis, and this activity may help miR-449a to provide a first line defence mechanism upon genotoxic stress (as seen in response to cigarette smoke) or virus infection (Wang et al., 2009) in airways. The further upregulation of miR-449 upon smoke exposure may ensure the elimination of cells with damaged DNA and thus prevent the occurrence of malignancies. While miR-34 acts as a general effector of p53-induced apoptosis in a broad range of tissues, its cousin miR-449 appears to exert a comparable tumour suppressive role specifically in airway epithelia.

\subsection{Outlook}

The E2F family is essential for cell proliferation. However, its uncontrolled activity is one of the most widely acknowledged reasons for malignant growth. MiR-449 prevents the accumulation of cells with excessive E2F1 activity in two ways. Firstly, it directly antagonises E2F1. Secondly, it eliminates those cells when necessary through the induction of apoptosis. As both mechanisms can occur independently of p53, miR-449 may represent an essential barrier to cancer progression in cells that have already lost p53 function through mutations.

Since tumour cells are generally prone to a constitutive DNA damage response (Bartkova et al., 2005), they might undergo apoptosis in response to miR-449 or miR-34 at an enhanced 
rate compared to normal cells. This is supported by the fact that, while little reexpression of miR-449 in tumour cells already stimulates an apoptotic response, non-cancerous tissues tolerate very high levels of miR-449. This makes miR-449 an interesting candidate for cancer therapy. HDAC inhibitors are already being tested in clinical trials. However, their lack of specificity could lead to several side effects. Also drugs targeting the DNA repair machinery are currently under study. MiR-449, by targeting not only HDACS but also several members of the DNA repair machinery, might offer a more tumour-specific, safer therapeutic approach. Additionally, residual expression levels of miR-449 and miR-34a, and their inducibility by E2F1 and p53, may represent a determinant for cancer cell death in response to irradiation or chemotherapy. The assessment of miR-449 expression might therefore be of interest in tumour diagnostics and in the prognosis of the outcome of DNA damaging treatments.

Finally, these results identify miR-449a as an exquisitely specific biomarker of differentiated airway epithelia, and moreover suggest a role for miR-449 in the differentiation of airway epithelium and its first line defence in vivo. 


\section{Supplementary data}

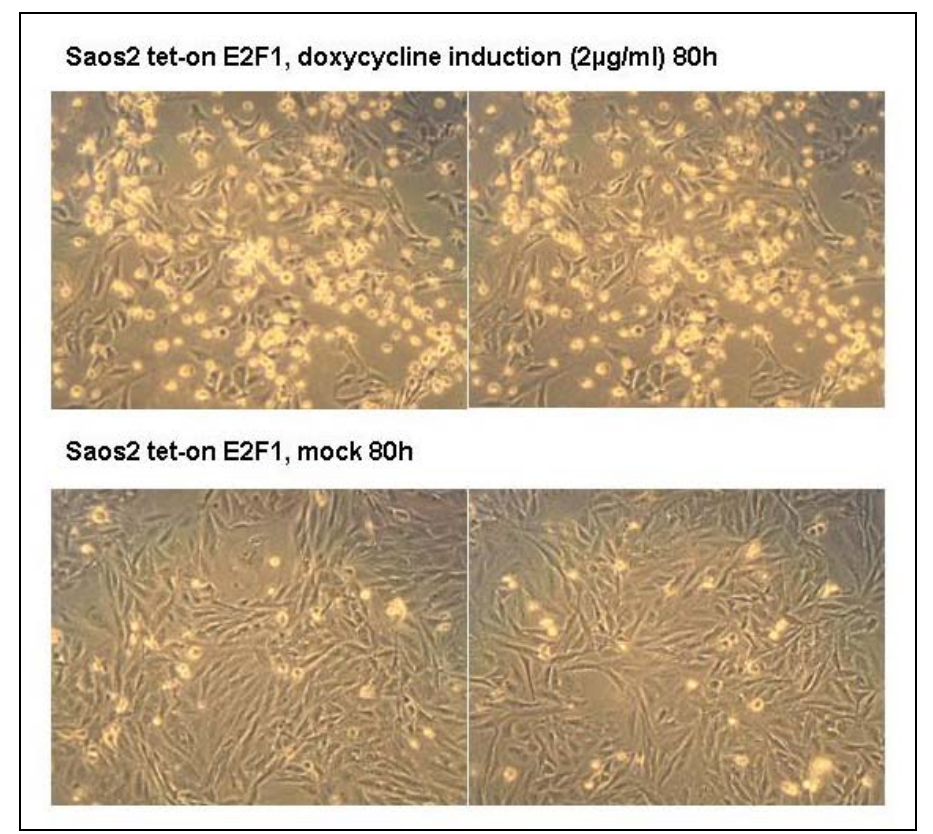

Suppl. Fig. S 1: Apoptotic phenotype of Saos2 tet-on E2F1 cells after E2F1 induction

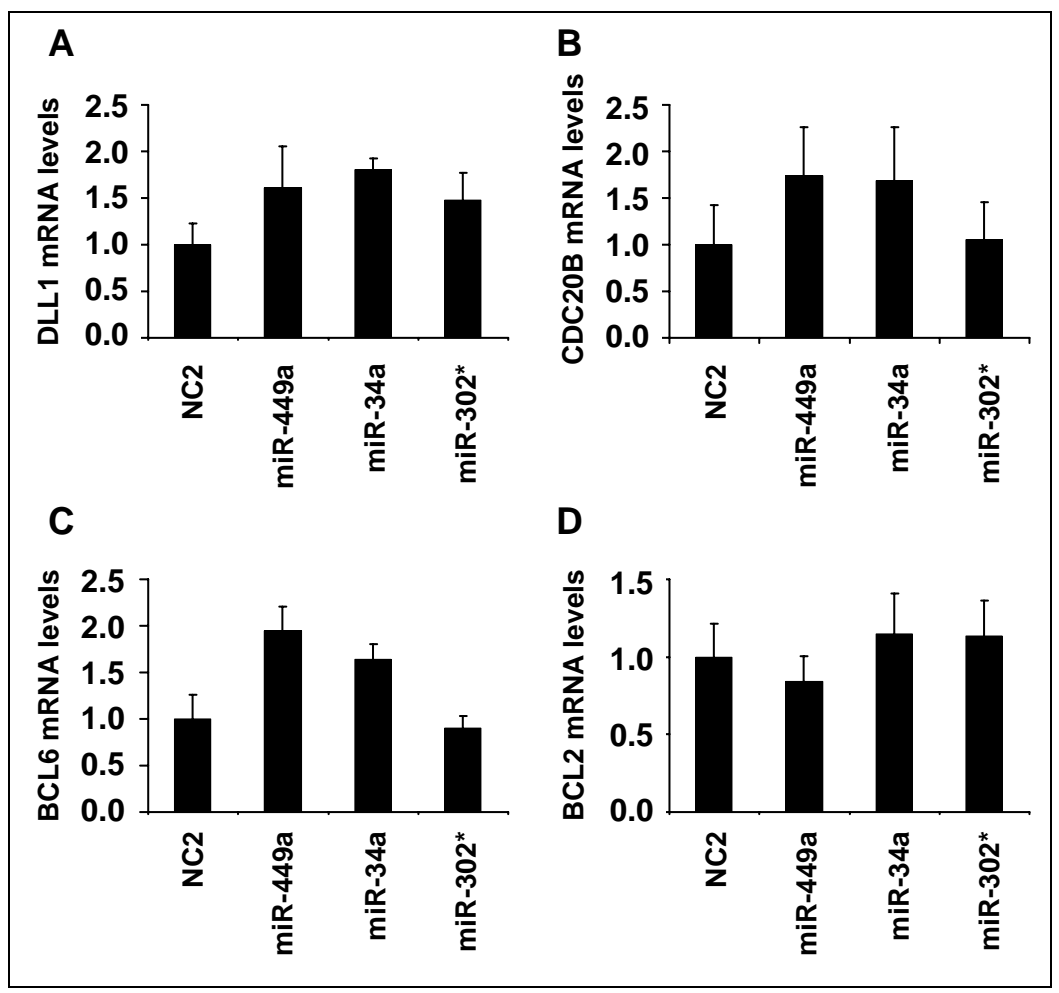

\section{Suppl. Fig. S 2: rejected targets}

H1299 cells were transfected with the indicated microRNAs, followed by RT-PCR to determine the mRNA levels of DLL1 (A), the microRNAs-449 host gene CDC20B (B), BCL6 (C) and BCL2 (D). Displayed are the mean results of 3 independent experiments with error bars normalised to the $18 \mathrm{~S}$ rRNA levels in each sample. 
Supp. Tab. 1: microRNA micro-array data

The area shaded in grey is considered as non-responsive for it contains the negative controls, and the induction is not significant.

\begin{tabular}{|c|c|c|c|c|c|c|c|}
\hline Name & $\begin{array}{c}\log 2(С y 3) \\
\text { Control }\end{array}$ & $\begin{array}{l}\text { Cy3 SD } \\
\text { Control }\end{array}$ & $\begin{array}{c}\log 2(\text { Cy5) } \\
\text { E2F }\end{array}$ & $\begin{array}{c}\text { Cy5 SD } \\
\text { E2F }\end{array}$ & $\begin{array}{l}\text { Difference: } \\
\text { Control-E2F }\end{array}$ & $\begin{array}{c}\log \\
\text { induction }\end{array}$ & $\begin{array}{c}\text { fold } \\
\text { induction }\end{array}$ \\
\hline mmu-miR-449a & 7,402 & 0,061 & 10,047 & 0,059 & $-2,645$ & 2,645 & 6,253 \\
\hline hsa-miR-449b & 6,885 & 0,097 & 8,914 & 0,060 & $-2,028$ & 2,028 & 4,080 \\
\hline hsa-miR-492 & 9,240 & 0,079 & 10,481 & 0,073 & $-1,241$ & 1,241 & 2,364 \\
\hline mmu-let-7b & 9,177 & 0,069 & 10,344 & 0,113 & $-1,167$ & 1,167 & 2,245 \\
\hline mmu-let-7c & 9,457 & 0,046 & 10,620 & 0,052 & $-1,162$ & 1,162 & 2,238 \\
\hline hsa-miR-663 & 10,188 & 0,042 & 11,317 & 0,091 & $-1,130$ & 1,130 & 2,188 \\
\hline mmu-miR-19b & 9,813 & 0,109 & 10,882 & 0,153 & $-1,069$ & 1,069 & 2,098 \\
\hline mmu-miR-30b & 9,213 & 0,116 & 10,223 & 0,108 & $-1,010$ & 1,010 & 2,014 \\
\hline mmu-miR-16 & 9,809 & 0,051 & 10,816 & 0,099 & $-1,007$ & 1,007 & 2,009 \\
\hline mmu-miR-762 & 7,920 & 0,057 & 8,918 & 0,079 & $-0,998$ & 0,998 & 1,997 \\
\hline mmu-miR-17 & 9,422 & 0,083 & 10,414 & 0,091 & $-0,992$ & 0,992 & 1,989 \\
\hline hsa-miR-106a & 9,232 & 0,066 & 10,200 & 0,093 & $-0,967$ & 0,967 & 1,955 \\
\hline mmu-miR-23a & 10,007 & 0,055 & 10,942 & 0,120 & $-0,936$ & 0,936 & 1,913 \\
\hline miRPlus_17952 & 8,114 & 0,096 & 9,048 & 0,171 & $-0,934$ & 0,934 & 1,911 \\
\hline mmu-miR-20a & 9,568 & 0,042 & 10,482 & 0,072 & $-0,915$ & 0,915 & 1,885 \\
\hline mmu-miR-106b & 8,910 & 0,042 & 9,819 & 0,066 & $-0,908$ & 0,908 & 1,877 \\
\hline mmu-let-7a & 11,453 & 0,094 & 12,355 & 0,113 & $-0,902$ & 0,902 & 1,869 \\
\hline mmu-miR-23b & 9,715 & 0,087 & 10,614 & 0,130 & $-0,899$ & 0,899 & 1,865 \\
\hline miRPlus_27561 & 11,528 & 0,074 & 12,403 & 0,133 & $-0,875$ & 0,875 & 1,834 \\
\hline miRPlus_21472 & 11,565 & 0,116 & 12,434 & 0,165 & $-0,869$ & 0,869 & 1,826 \\
\hline hsa-let-7a & 9,897 & 0,063 & 10,763 & 0,064 & $-0,867$ & 0,867 & 1,824 \\
\hline miRPlus_17890 & 9,605 & 0,052 & 10,468 & 0,039 & $-0,862$ & 0,862 & 1,818 \\
\hline mmu-miR-711 & 11,617 & 0,068 & 12,476 & 0,100 & $-0,859$ & 0,859 & 1,814 \\
\hline mmu-miR-21 & 9,845 & 0,030 & 10,699 & 0,078 & $-0,854$ & 0,854 & 1,808 \\
\hline mmu-miR-494 & 11,018 & 0,154 & 11,867 & 0,133 & $-0,849$ & 0,849 & 1,801 \\
\hline mmu-miR-15b & 9,727 & 0,064 & 10,571 & 0,112 & $-0,845$ & 0,845 & 1,796 \\
\hline mmu-let-7d & 9,915 & 0,041 & 10,755 & 0,042 & $-0,840$ & 0,840 & 1,790 \\
\hline mmu-miR-720 & 8,609 & 0,085 & 9,443 & 0,098 & $-0,834$ & 0,834 & 1,783 \\
\hline mmu-miR-93 & 8,158 & 0,172 & 8,992 & 0,124 & $-0,834$ & 0,834 & 1,782 \\
\hline miRPlus_28431 & 8,967 & 0,140 & 9,766 & 0,155 & $-0,800$ & 0,800 & 1,741 \\
\hline mmu-miR-101a & 7,433 & 0,106 & 8,220 & 0,112 & $-0,788$ & 0,788 & 1,726 \\
\hline hsa_SNORD3@ & 10,468 & 0,023 & 11,253 & 0,014 & $-0,785$ & 0,785 & 1,723 \\
\hline hsa-miR-623 & 8,681 & 0,044 & 9,463 & 0,083 & $-0,782$ & 0,782 & 1,719 \\
\hline spike_control_i & 12,057 & 0,235 & 12,837 & 0,106 & $-0,780$ & 0,780 & 1,717 \\
\hline mmu-miR-24 & 9,666 & 0,045 & 10,441 & 0,072 & $-0,775$ & 0,775 & 1,711 \\
\hline mmu-miR-26a & 8,636 & 0,171 & 9,407 & 0,137 & $-0,771$ & 0,771 & 1,707 \\
\hline mmu-miR-29a & 9,284 & 0,145 & 10,041 & 0,073 & $-0,757$ & 0,757 & 1,690 \\
\hline mmu-miR-667 & 7,167 & 0,142 & 7,921 & 0,076 & $-0,755$ & 0,755 & 1,687 \\
\hline mmu-let-7i & 9,443 & 0,097 & 10,192 & 0,123 & $-0,749$ & 0,749 & 1,681 \\
\hline mmu-miR-19a & 8,310 & 0,096 & 9,035 & 0,111 & $-0,725$ & 0,725 & 1,653 \\
\hline hsa-miR-498 & 8,613 & 0,101 & 9,337 & 0,040 & $-0,723$ & 0,723 & 1,651 \\
\hline mmu-miR-30a & 8,188 & 0,027 & 8,909 & 0,064 & $-0,721$ & 0,721 & 1,648 \\
\hline mmu-miR-301a & 8,626 & 0,082 & 9,323 & 0,127 & $-0,697$ & 0,697 & 1,621 \\
\hline mmu-miR-30c & 8,426 & 0,033 & 9,118 & 0,018 & $-0,693$ & 0,693 & 1,616 \\
\hline hsa-miR-671-5p & 8,630 & 0,037 & 9,311 & 0,045 & $-0,682$ & 0,682 & 1,604 \\
\hline hsa-miR-665 & 9,073 & 0,028 & 9,753 & 0,040 & $-0,680$ & 0,680 & 1,602 \\
\hline U6-snRNA-2 & 12,075 & 0,036 & 12,753 & 0,020 & $-0,678$ & 0,678 & 1,600 \\
\hline mmu-miR-212 & 8,491 & 0,066 & 9,169 & 0,064 & $-0,678$ & 0,678 & 1,600 \\
\hline U6-snRNA-1 & 8,029 & 0,032 & 8,705 & 0,039 & $-0,677$ & 0,677 & 1,598 \\
\hline mmu-miR-185 & 7,972 & 0,200 & 8,636 & 0,131 & $-0,664$ & 0,664 & 1,584 \\
\hline
\end{tabular}




\begin{tabular}{|c|c|c|c|c|c|c|c|}
\hline mmu-miR-107 & 8,086 & 0,079 & 8,738 & 0,110 & $-0,652$ & 0,652 & 1,571 \\
\hline spike_control_b & 8,163 & 0,152 & 8,810 & 0,102 & $-0,648$ & 0,648 & 1,567 \\
\hline rno-miR-93 & 8,442 & 0,060 & 9,085 & 0,087 & $-0,643$ & 0,643 & 1,562 \\
\hline mmu-miR-26a_MM1 & 7,838 & 0,059 & 8,475 & 0,061 & $-0,638$ & 0,638 & 1,556 \\
\hline mmu-miR-106a & 7,938 & 0,064 & 8,570 & 0,072 & $-0,633$ & 0,633 & 1,550 \\
\hline mmu-miR-15a & 8,129 & 0,058 & 8,755 & 0,028 & $-0,626$ & 0,626 & 1,543 \\
\hline mmu-miR-22 & 8,386 & 0,023 & 9,001 & 0,041 & $-0,615$ & 0,615 & 1,531 \\
\hline mmu-miR-320 & 8,410 & 0,216 & 9,020 & 0,053 & $-0,610$ & 0,610 & 1,526 \\
\hline mmu-miR-99b & 7,553 & 0,272 & 8,151 & 0,079 & $-0,598$ & 0,598 & 1,513 \\
\hline mmu-miR-207 & 7,269 & 0,583 & 7,863 & 0,055 & $-0,594$ & 0,594 & 1,509 \\
\hline hsa-miR-330-3p & 6,097 & 0,526 & 6,688 & 0,227 & $-0,591$ & 0,591 & 1,506 \\
\hline hsa-miR-602 & 7,121 & 0,158 & 7,696 & 0,047 & $-0,575$ & 0,575 & 1,490 \\
\hline hsa_SNORD6 & 8,479 & 0,042 & 9,053 & 0,040 & $-0,574$ & 0,574 & 1,489 \\
\hline mmu-miR-210 & 7,962 & 0,051 & 8,531 & 0,012 & $-0,568$ & 0,568 & 1,483 \\
\hline mmu-miR-27b & 8,673 & 0,027 & 9,236 & 0,084 & $-0,562$ & 0,562 & 1,477 \\
\hline spike_control_b & 8,016 & 0,142 & 8,561 & 0,431 & $-0,545$ & 0,545 & 1,459 \\
\hline mmu-miR-709 & 7,593 & 0,038 & 8,135 & 0,038 & $-0,542$ & 0,542 & 1,456 \\
\hline miRPlus_27564 & 8,026 & 0,055 & 8,566 & 0,084 & $-0,540$ & 0,540 & 1,454 \\
\hline miRPlus_17921 & 6,511 & 0,495 & 7,047 & 0,322 & $-0,537$ & 0,537 & 1,450 \\
\hline spike_control_i & 12,091 & 0,080 & 12,627 & 0,087 & $-0,536$ & 0,536 & 1,450 \\
\hline miRPlus_17832 & 8,355 & 0,119 & 8,889 & 0,137 & $-0,534$ & 0,534 & 1,448 \\
\hline mmu-miR-103 & 7,442 & 0,181 & 7,974 & 0,045 & $-0,531$ & 0,531 & 1,445 \\
\hline spike_control_a & 6,553 & 0,445 & 7,077 & 0,258 & $-0,524$ & 0,524 & 1,438 \\
\hline spike_control_b & 8,195 & 0,235 & 8,717 & 0,292 & $-0,522$ & 0,522 & 1,436 \\
\hline spike_control_j & 13,347 & 0,052 & 13,865 & 0,038 & $-0,518$ & 0,518 & 1,432 \\
\hline mmu-miR-689 & 7,774 & 0,131 & 8,289 & 0,047 & $-0,514$ & 0,514 & 1,428 \\
\hline mmu-miR-668 & 10,902 & 0,440 & 11,407 & 0,469 & $-0,505$ & 0,505 & 1,419 \\
\hline mmu-miR-546 & 9,866 & 0,063 & 10,364 & 0,042 & $-0,498$ & 0,498 & 1,412 \\
\hline spike_control_i & 11,991 & 0,063 & 12,487 & 0,150 & $-0,496$ & 0,496 & 1,411 \\
\hline mmu-miR-770-3p & 6,258 & 0,380 & 6,751 & 0,114 & $-0,493$ & 0,493 & 1,408 \\
\hline spike_control_h & 10,945 & 0,197 & 11,437 & 0,157 & $-0,492$ & 0,492 & 1,406 \\
\hline spike_control_h & 10,971 & 0,111 & 11,462 & 0,224 & $-0,490$ & 0,490 & 1,405 \\
\hline$m m u-m i R-125 b-5 p$ & 8,090 & 0,079 & 8,580 & 0,030 & $-0,490$ & 0,490 & 1,404 \\
\hline spike_control_i & 11,992 & 0,039 & 12,480 & 0,113 & $-0,489$ & 0,489 & 1,403 \\
\hline rno-miR-347 & 8,319 & 0,088 & 8,806 & 0,131 & $-0,487$ & 0,487 & 1,401 \\
\hline spike_control_b & 8,111 & 0,194 & 8,597 & 0,420 & $-0,487$ & 0,487 & 1,401 \\
\hline hsa_SNORD2 & 8,578 & 0,051 & 9,064 & 0,080 & $-0,486$ & 0,486 & 1,401 \\
\hline hsa-miR-371-5p & 7,255 & 0,063 & 7,741 & 0,587 & $-0,486$ & 0,486 & 1,401 \\
\hline spike_control_i & 11,970 & 0,102 & 12,455 & 0,126 & $-0,485$ & 0,485 & 1,399 \\
\hline mmu-miR-467b* & 6,596 & 0,075 & 7,071 & 0,298 & $-0,474$ & 0,474 & 1,389 \\
\hline mmu-miR-20b & 7,803 & 0,059 & 8,274 & 0,108 & $-0,471$ & 0,471 & 1,386 \\
\hline spike_control_c & 6,888 & 0,296 & 7,358 & 0,093 & $-0,470$ & 0,470 & 1,385 \\
\hline spike_control_i & 11,984 & 0,036 & 12,454 & 0,064 & $-0,470$ & 0,470 & 1,385 \\
\hline hsa-miR-615-3p & 6,583 & 0,118 & 7,051 & 0,639 & $-0,468$ & 0,468 & 1,383 \\
\hline spike_control_i & 12,015 & 0,086 & 12,480 & 0,169 & $-0,465$ & 0,465 & 1,380 \\
\hline spike_control_i & 12,028 & 0,049 & 12,491 & 0,064 & $-0,462$ & 0,462 & 1,378 \\
\hline spike_control_b & 8,174 & 0,110 & 8,636 & 0,202 & $-0,462$ & 0,462 & 1,377 \\
\hline spike_control_h & 11,078 & 0,035 & 11,538 & 0,029 & $-0,460$ & 0,460 & 1,376 \\
\hline mmu-miR-143 & 8,296 & 0,021 & 8,754 & 0,035 & $-0,459$ & 0,459 & 1,374 \\
\hline mmu-miR-675-5p & 6,496 & 0,260 & 6,954 & 0,792 & $-0,458$ & 0,458 & 1,374 \\
\hline spike_control_c & 6,866 & 0,293 & 7,323 & 0,058 & $-0,457$ & 0,457 & 1,373 \\
\hline spike_control_b & 8,049 & 0,168 & 8,506 & 0,133 & $-0,457$ & 0,457 & 1,373 \\
\hline spike_control_j & 13,097 & 0,348 & 13,548 & 0,337 & $-0,451$ & 0,451 & 1,367 \\
\hline spike_control_j & 13,240 & 0,034 & 13,685 & 0,062 & $-0,445$ & 0,445 & 1,361 \\
\hline mmu-miR-98 & 8,340 & 0,024 & 8,783 & 0,031 & $-0,444$ & 0,444 & 1,360 \\
\hline hsa-miR-768-3p & 7,369 & 0,101 & 7,812 & 0,133 & $-0,443$ & 0,443 & 1,360 \\
\hline spike_control_b & 8,025 & 0,105 & 8,468 & 0,179 & $-0,442$ & 0,442 & 1,359 \\
\hline
\end{tabular}




\begin{tabular}{|c|c|c|c|c|c|c|c|}
\hline spike_control_j & 13,213 & 0,031 & 13,650 & 0,103 & $-0,437$ & 0,437 & 1,354 \\
\hline spike_control_j & 13,166 & 0,072 & 13,603 & 0,121 & $-0,437$ & 0,437 & 1,354 \\
\hline mmu-miR-330* & 6,306 & 0,526 & 6,739 & 0,028 & $-0,433$ & 0,433 & 1,350 \\
\hline spike_control_j & 13,231 & 0,078 & 13,660 & 0,115 & $-0,429$ & 0,429 & 1,346 \\
\hline hsa-miR-500* & 7,084 & 0,092 & 7,511 & 0,047 & $-0,427$ & 0,427 & 1,344 \\
\hline mmu-miR-27a & 7,618 & 0,065 & 8,044 & 0,076 & $-0,426$ & 0,426 & 1,344 \\
\hline spike_control_h & 10,999 & 0,139 & 11,424 & 0,127 & $-0,425$ & 0,425 & 1,343 \\
\hline spike_control_d & 9,683 & 0,056 & 10,107 & 0,050 & $-0,425$ & 0,425 & 1,342 \\
\hline spike_control_j & 13,168 & 0,091 & 13,592 & 0,080 & $-0,424$ & 0,424 & 1,342 \\
\hline spike_control_h & 11,049 & 0,058 & 11,463 & 0,100 & $-0,414$ & 0,414 & 1,333 \\
\hline mmu-miR-222 & 8,070 & 0,134 & 8,481 & 0,121 & $-0,411$ & 0,411 & 1,330 \\
\hline mmu-miR-340-5p & 7,413 & 0,036 & 7,825 & 0,063 & $-0,411$ & 0,411 & 1,330 \\
\hline mmu-miR-690 & 6,327 & 0,414 & 6,735 & 0,190 & $-0,407$ & 0,407 & 1,326 \\
\hline spike_control_h & 10,949 & 0,045 & 11,355 & 0,055 & $-0,406$ & 0,406 & 1,325 \\
\hline spike_control_h & 10,889 & 0,032 & 11,294 & 0,089 & $-0,405$ & 0,405 & 1,324 \\
\hline spike_control_d & 9,561 & 0,120 & 9,965 & 0,143 & $-0,405$ & 0,405 & 1,324 \\
\hline spike_control_h & 10,880 & 0,107 & 11,282 & 0,100 & $-0,402$ & 0,402 & 1,321 \\
\hline mmu-miR-32 & 7,486 & 0,028 & 7,888 & 0,048 & $-0,401$ & 0,401 & 1,321 \\
\hline$m m u-m i R-342-3 p$ & 6,947 & 0,034 & 7,348 & 0,031 & $-0,401$ & 0,401 & 1,321 \\
\hline spike_control_d & 9,598 & 0,033 & 9,999 & 0,056 & $-0,401$ & 0,401 & 1,321 \\
\hline spike_control_d & 9,595 & 0,121 & 9,996 & 0,105 & $-0,401$ & 0,401 & 1,320 \\
\hline mmu-miR-18a & 7,623 & 0,051 & 8,024 & 0,025 & $-0,401$ & 0,401 & 1,320 \\
\hline spike_control_j & 13,076 & 0,193 & 13,475 & 0,143 & $-0,398$ & 0,398 & 1,318 \\
\hline hsa_negative_control_3 & 6,632 & 0,467 & 7,030 & 0,835 & $-0,398$ & 0,398 & 1,318 \\
\hline mmu-miR-191 & 7,647 & 0,088 & 8,044 & 0,110 & $-0,397$ & 0,397 & 1,317 \\
\hline spike_control_d & 9,647 & 0,057 & 10,043 & 0,074 & $-0,396$ & 0,396 & 1,316 \\
\hline mmu-miR-706 & 6,521 & 0,360 & 6,916 & 0,646 & $-0,395$ & 0,395 & 1,315 \\
\hline mmu-miR-30d & 7,524 & 0,054 & 7,918 & 0,035 & $-0,394$ & 0,394 & 1,314 \\
\hline spike_control_d & 9,528 & 0,161 & 9,917 & 0,157 & $-0,389$ & 0,389 & 1,309 \\
\hline hsa-miR-32* & 7,922 & 0,084 & 8,309 & 0,092 & $-0,387$ & 0,387 & 1,308 \\
\hline mmu-miR-100 & 7,547 & 0,037 & 7,933 & 0,096 & $-0,386$ & 0,386 & 1,307 \\
\hline spike_control_d & 9,610 & 0,118 & 9,995 & 0,149 & $-0,385$ & 0,385 & 1,306 \\
\hline mmu-miR-452 & 7,141 & 0,056 & 7,524 & 0,051 & $-0,383$ & 0,383 & 1,304 \\
\hline spike_control_a & 6,605 & 0,317 & 6,985 & 0,242 & $-0,380$ & 0,380 & 1,302 \\
\hline hsa-miR-18b & 7,462 & 0,027 & 7,841 & 0,077 & $-0,379$ & 0,379 & 1,301 \\
\hline spike_control_a & 6,451 & 0,060 & 6,830 & 0,040 & $-0,379$ & 0,379 & 1,300 \\
\hline mmu-miR-374 & 7,327 & 0,046 & 7,705 & 0,047 & $-0,378$ & 0,378 & 1,299 \\
\hline miRPlus_17867 & 6,549 & 0,261 & 6,926 & 0,686 & $-0,377$ & 0,377 & 1,298 \\
\hline$m m u-m i R-666-5 p$ & 6,510 & 0,034 & 6,886 & 0,022 & $-0,376$ & 0,376 & 1,298 \\
\hline spike_control_d & 9,603 & 0,115 & 9,976 & 0,111 & $-0,374$ & 0,374 & 1,296 \\
\hline spike_control_c & 6,993 & 0,104 & 7,363 & 0,033 & $-0,370$ & 0,370 & 1,292 \\
\hline mmu-miR-300 & 6,136 & 0,456 & 6,505 & 0,056 & $-0,369$ & 0,369 & 1,291 \\
\hline mmu-miR-130a & 8,308 & 0,042 & 8,675 & 0,059 & $-0,367$ & 0,367 & 1,290 \\
\hline hsa-miR-557 & 7,079 & 0,047 & 7,442 & 0,006 & $-0,363$ & 0,363 & 1,286 \\
\hline spike_control_g & 7,080 & 0,105 & 7,443 & 0,046 & $-0,363$ & 0,363 & 1,286 \\
\hline spike_control_g & 7,046 & 0,202 & 7,408 & 0,049 & $-0,362$ & 0,362 & 1,285 \\
\hline spike_control_a & 6,695 & 0,260 & 7,056 & 0,215 & $-0,361$ & 0,361 & 1,284 \\
\hline mmu-miR-744 & 7,268 & 0,059 & 7,623 & 0,044 & $-0,355$ & 0,355 & 1,279 \\
\hline mmu-miR-199a-3p/199b & 7,744 & 0,097 & 8,093 & 0,111 & $-0,350$ & 0,350 & 1,274 \\
\hline miRPlus_17947 & 6,495 & 0,316 & 6,842 & 0,532 & $-0,347$ & 0,347 & 1,272 \\
\hline spike_control_c & 7,054 & 0,079 & 7,400 & 0,034 & $-0,346$ & 0,346 & 1,271 \\
\hline spike_control_a & 6,437 & 0,029 & 6,780 & 0,087 & $-0,343$ & 0,343 & 1,268 \\
\hline spike_control_c & 7,131 & 0,046 & 7,471 & 0,056 & $-0,340$ & 0,340 & 1,266 \\
\hline hsa-miR-502-3p & 7,083 & 0,030 & 7,418 & 0,025 & $-0,336$ & 0,336 & 1,262 \\
\hline hsa-miR-635 & 6,459 & 0,317 & 6,791 & 0,340 & $-0,332$ & 0,332 & 1,259 \\
\hline spike_control_c & 7,089 & 0,034 & 7,420 & 0,034 & $-0,331$ & 0,331 & 1,258 \\
\hline miRPlus_30271 & 6,536 & 0,056 & 6,865 & 0,591 & $-0,328$ & 0,328 & 1,256 \\
\hline
\end{tabular}




\begin{tabular}{|c|c|c|c|c|c|c|c|}
\hline spike_control_a & 6,471 & 0,039 & 6,795 & 0,045 & $-0,324$ & 0,324 & 1,252 \\
\hline mmu-miR-801 & 8,733 & 0,169 & 9,057 & 0,180 & $-0,324$ & 0,324 & 1,252 \\
\hline hsa-miR-503 & 7,684 & 0,066 & 8,003 & 0,109 & $-0,318$ & 0,318 & 1,247 \\
\hline spike_control_b & 7,727 & 0,531 & 8,043 & 0,607 & $-0,316$ & 0,316 & 1,245 \\
\hline hsa-miR-518a-5p/527 & 6,778 & 0,369 & 7,092 & 0,123 & $-0,314$ & 0,314 & 1,243 \\
\hline hsa-miR-802 & 6,289 & 0,497 & 6,603 & 0,039 & $-0,314$ & 0,314 & 1,243 \\
\hline spike_control_g & 7,214 & 0,105 & 7,520 & 0,147 & $-0,306$ & 0,306 & 1,237 \\
\hline miRPlus_17869 & 7,315 & 0,040 & 7,620 & 0,026 & $-0,304$ & 0,304 & 1,235 \\
\hline mmu-miR-31* & 6,806 & 0,095 & 7,108 & 0,889 & $-0,302$ & 0,302 & 1,233 \\
\hline spike_control_c & 6,923 & 0,259 & 7,223 & 0,202 & $-0,300$ & 0,300 & 1,231 \\
\hline hsa-miR-486-3p & 7,066 & 0,051 & 7,365 & 0,146 & $-0,300$ & 0,300 & 1,231 \\
\hline spike_control_a & 6,603 & 0,232 & 6,899 & 0,175 & $-0,296$ & 0,296 & 1,228 \\
\hline mmu-miR-703 & 6,325 & 0,053 & 6,620 & 0,068 & $-0,295$ & 0,295 & 1,227 \\
\hline hsa-miR-362-3p & 7,063 & 0,028 & 7,357 & 0,040 & $-0,294$ & 0,294 & 1,226 \\
\hline spike_control_g & 7,188 & 0,018 & 7,480 & 0,027 & $-0,292$ & 0,292 & 1,224 \\
\hline mmu-miR-466d-3p_MM1 & 6,461 & 0,402 & 6,751 & 0,050 & $-0,289$ & 0,289 & 1,222 \\
\hline spike_control_c & 7,093 & 0,050 & 7,383 & 0,066 & $-0,289$ & 0,289 & 1,222 \\
\hline miRPlus_28575 & 7,372 & 0,095 & 7,659 & 0,027 & $-0,287$ & 0,287 & 1,220 \\
\hline spike_control_g & 7,202 & 0,066 & 7,486 & 0,041 & $-0,284$ & 0,284 & 1,218 \\
\hline spike_control_g & 7,144 & 0,042 & 7,428 & 0,058 & $-0,283$ & 0,283 & 1,217 \\
\hline hsa-miR-658 & 7,820 & 0,147 & 8,102 & 0,140 & $-0,282$ & 0,282 & 1,216 \\
\hline hsa-miR-765 & 8,037 & 0,142 & 8,318 & 0,055 & $-0,281$ & 0,281 & 1,215 \\
\hline mmu-miR-423-5p & 7,897 & 0,078 & 8,177 & 0,064 & $-0,280$ & 0,280 & 1,215 \\
\hline mmu-miR-361 & 7,961 & 0,132 & 8,241 & 0,062 & $-0,280$ & 0,280 & 1,215 \\
\hline hsa-miR-320 & 7,808 & 0,072 & 8,080 & 0,072 & $-0,272$ & 0,272 & 1,208 \\
\hline hsa-miR-501-3p & 6,613 & 0,360 & 6,878 & 0,319 & $-0,265$ & 0,265 & 1,201 \\
\hline hsa_SNORD10 & 7,661 & 0,038 & 7,925 & 0,036 & $-0,263$ & 0,263 & 1,200 \\
\hline spike_control_g & 7,180 & 0,056 & 7,442 & 0,039 & $-0,261$ & 0,261 & 1,198 \\
\hline rno-miR-376b-3p & 6,249 & 0,500 & 6,506 & 0,073 & $-0,257$ & 0,257 & 1,195 \\
\hline mmu-miR-410 & 6,718 & 0,020 & 6,970 & 0,871 & $-0,252$ & 0,252 & 1,191 \\
\hline spike_control_g & 7,238 & 0,041 & 7,488 & 0,013 & $-0,250$ & 0,250 & 1,189 \\
\hline spike_control_a & 6,723 & 0,184 & 6,968 & 0,262 & $-0,245$ & 0,245 & 1,185 \\
\hline mmu-miR-574-3p & 6,478 & 0,095 & 6,723 & 0,270 & $-0,245$ & 0,245 & 1,185 \\
\hline rno-miR-541 & 7,023 & 0,361 & 7,267 & 0,134 & $-0,244$ & 0,244 & 1,184 \\
\hline mmu-miR-363 & 6,685 & 0,351 & 6,928 & 0,106 & $-0,243$ & 0,243 & 1,184 \\
\hline hsa-miR-422a_MM2 & 6,959 & 0,040 & 7,201 & 0,033 & $-0,243$ & 0,243 & 1,183 \\
\hline mmu-miR-467a*/467d* & 6,792 & 0,063 & 7,034 & 0,049 & $-0,242$ & 0,242 & 1,183 \\
\hline mmu-miR-744 & 7,317 & 0,024 & 7,558 & 0,044 & $-0,241$ & 0,241 & 1,181 \\
\hline mmu-miR-370 & 6,727 & 0,194 & 6,966 & 0,176 & $-0,238$ & 0,238 & 1,180 \\
\hline miRPlus_28454 & 6,672 & 0,227 & 6,908 & 0,151 & $-0,236$ & 0,236 & 1,178 \\
\hline hsa-miR-625 & 6,893 & 0,076 & 7,129 & 0,056 & $-0,236$ & 0,236 & 1,178 \\
\hline hsa-miR-519d & 7,831 & 0,087 & 8,065 & 0,078 & $-0,234$ & 0,234 & 1,176 \\
\hline No known hsa target & 7,745 & 0,045 & 7,972 & 0,080 & $-0,226$ & 0,226 & 1,170 \\
\hline mmu-miR-590-5p & 6,995 & 0,046 & 7,218 & 0,030 & $-0,223$ & 0,223 & 1,167 \\
\hline mmu-miR-92b & 6,835 & 0,018 & 7,058 & 0,027 & $-0,223$ & 0,223 & 1,167 \\
\hline miRPlus_17896 & 7,015 & 0,068 & 7,237 & 0,483 & $-0,222$ & 0,222 & 1,166 \\
\hline mmu-miR-125a-5p & 8,267 & 0,067 & 8,488 & 0,096 & $-0,221$ & 0,221 & 1,165 \\
\hline hsa-miR-96* & 7,158 & 0,021 & 7,375 & 0,026 & $-0,218$ & 0,218 & 1,163 \\
\hline spike_control_f & 8,997 & 0,155 & 9,212 & 0,110 & $-0,216$ & 0,216 & 1,161 \\
\hline hsa-miR-9* & 6,722 & 0,059 & 6,937 & 0,313 & $-0,215$ & 0,215 & 1,161 \\
\hline mmu-miR-10b & 7,044 & 0,280 & 7,259 & 0,062 & $-0,215$ & 0,215 & 1,161 \\
\hline miRPlus_11201 & 7,277 & 0,298 & 7,491 & 0,069 & $-0,214$ & 0,214 & 1,160 \\
\hline mmu-miR-30a* & 6,671 & 0,102 & 6,884 & 0,089 & $-0,213$ & 0,213 & 1,159 \\
\hline rno-miR-376c & 6,354 & 0,045 & 6,564 & 0,027 & $-0,210$ & 0,210 & 1,157 \\
\hline mmu-miR-138 & 7,637 & 0,040 & 7,846 & 0,078 & $-0,209$ & 0,209 & 1,156 \\
\hline mmu-miR-489 & 6,497 & 0,022 & 6,706 & 0,022 & $-0,208$ & 0,208 & 1,155 \\
\hline mmu-miR-134 & 6,618 & 0,316 & 6,825 & 0,434 & $-0,207$ & 0,207 & 1,154 \\
\hline
\end{tabular}




\begin{tabular}{|c|c|c|c|c|c|c|c|}
\hline mmu-miR-874 & 6,338 & 0,065 & 6,543 & 0,023 & $-0,205$ & 0,205 & 1,153 \\
\hline miRPlus_17834 & 6,685 & 0,060 & 6,889 & 0,602 & $-0,204$ & 0,204 & 1,152 \\
\hline mmu-miR-378 & 7,090 & 0,120 & 7,293 & 0,088 & $-0,202$ & 0,202 & 1,151 \\
\hline spike_control_e & 11,179 & 0,203 & 11,379 & 0,154 & $-0,199$ & 0,199 & 1,148 \\
\hline mmu-miR-805 & 6,359 & 0,012 & 6,557 & 0,017 & $-0,198$ & 0,198 & 1,147 \\
\hline hsa-miR-630 & 6,676 & 0,420 & 6,870 & 0,354 & $-0,194$ & 0,194 & 1,144 \\
\hline hsa-miR-483-5p & 7,422 & 0,072 & 7,616 & 0,045 & $-0,194$ & 0,194 & 1,144 \\
\hline hsa_negative_control_7 & 6,432 & 0,285 & 6,626 & 0,284 & $-0,193$ & 0,193 & 1,144 \\
\hline spike_control_e & 11,234 & 0,035 & 11,422 & 0,074 & $-0,188$ & 0,188 & 1,139 \\
\hline spike_control_e & 11,269 & 0,087 & 11,455 & 0,072 & $-0,186$ & 0,186 & 1,138 \\
\hline spike_control_f & 8,929 & 0,068 & 9,113 & 0,074 & $-0,184$ & 0,184 & 1,136 \\
\hline mmu-miR-219 & 6,420 & 0,354 & 6,604 & 0,161 & $-0,184$ & 0,184 & 1,136 \\
\hline hsa-miR-374b & 6,729 & 0,033 & 6,910 & 0,042 & $-0,181$ & 0,181 & 1,133 \\
\hline hsa-miR-526b* & 6,519 & 0,394 & 6,698 & 0,339 & $-0,179$ & 0,179 & 1,132 \\
\hline hsa-miR-95 & 6,616 & 0,368 & 6,794 & 0,352 & $-0,179$ & 0,179 & 1,132 \\
\hline mmu-miR-9* & 6,728 & 0,300 & 6,906 & 0,065 & $-0,178$ & 0,178 & 1,131 \\
\hline hsa-miR-886-5p & 6,723 & 0,163 & 6,899 & 0,562 & $-0,176$ & 0,176 & 1,129 \\
\hline mmu-miR-322* & 6,697 & 0,127 & 6,871 & 0,559 & $-0,175$ & 0,175 & 1,129 \\
\hline rno-miR-503 & 6,771 & 0,063 & 6,945 & 0,053 & $-0,174$ & 0,174 & 1,128 \\
\hline mmu-miR-193 & 6,949 & 0,249 & 7,123 & 0,057 & $-0,174$ & 0,174 & 1,128 \\
\hline rno-miR-352 & 7,172 & 0,060 & 7,345 & 0,030 & $-0,174$ & 0,174 & 1,128 \\
\hline hsa-miR-1 & 6,624 & 0,365 & 6,797 & 0,469 & $-0,173$ & 0,173 & 1,128 \\
\hline hsa-miR-548a-5p & 6,499 & 0,244 & 6,672 & 0,317 & $-0,173$ & 0,173 & 1,127 \\
\hline mmu-miR-455 & 6,802 & 0,095 & 6,975 & 0,017 & $-0,173$ & 0,173 & 1,127 \\
\hline hsa-miR-656 & 6,423 & 0,045 & 6,595 & 0,020 & $-0,172$ & 0,172 & 1,127 \\
\hline hsa-miR-30b* & 7,661 & 0,030 & 7,833 & 0,032 & $-0,172$ & 0,172 & 1,126 \\
\hline hsa-miR-302b & 6,747 & 0,048 & 6,916 & 0,602 & $-0,169$ & 0,169 & 1,124 \\
\hline miRPlus_30209 & 6,407 & 0,033 & 6,576 & 0,015 & $-0,169$ & 0,169 & 1,124 \\
\hline mmu-miR-30e & 7,672 & 0,200 & 7,840 & 0,098 & $-0,168$ & 0,168 & 1,124 \\
\hline hsa-let-7d & 7,216 & 0,137 & 7,381 & 0,077 & $-0,165$ & 0,165 & 1,121 \\
\hline mmu-miR-761 & 6,451 & 0,013 & 6,614 & 0,003 & $-0,164$ & 0,164 & 1,120 \\
\hline mmu-miR-183 & 6,767 & 0,025 & 6,930 & 0,026 & $-0,163$ & 0,163 & 1,119 \\
\hline mmu-miR-182 & 6,795 & 0,058 & 6,957 & 0,087 & $-0,162$ & 0,162 & 1,119 \\
\hline mmu-miR-34b-5p & 6,340 & 0,320 & 6,502 & 0,029 & $-0,162$ & 0,162 & 1,119 \\
\hline hsa-miR-566 & 6,605 & 0,064 & 6,766 & 0,310 & $-0,160$ & 0,160 & 1,117 \\
\hline hsa-miR-583 & 7,121 & 0,238 & 7,279 & 0,115 & $-0,158$ & 0,158 & 1,116 \\
\hline spike_control_f & 9,012 & 0,117 & 9,170 & 0,127 & $-0,158$ & 0,158 & 1,116 \\
\hline mmu-miR-365 & 7,267 & 0,012 & 7,424 & 0,005 & $-0,157$ & 0,157 & 1,115 \\
\hline mmu-miR-129-5p & 7,343 & 0,046 & 7,498 & 0,038 & $-0,155$ & 0,155 & 1,113 \\
\hline spike_control_f & 9,006 & 0,036 & 9,160 & 0,104 & $-0,154$ & 0,154 & 1,113 \\
\hline hsa-miR-515-5p & 6,624 & 0,220 & 6,777 & 0,270 & $-0,154$ & 0,154 & 1,112 \\
\hline spike_control_f & 9,019 & 0,077 & 9,171 & 0,102 & $-0,153$ & 0,153 & 1,112 \\
\hline mmu-miR-199a-5p & 7,996 & 0,063 & 8,144 & 0,098 & $-0,148$ & 0,148 & 1,108 \\
\hline spike_control_e & 11,175 & 0,162 & 11,322 & 0,132 & $-0,147$ & 0,147 & 1,107 \\
\hline miRPlus_28232 & 6,982 & 0,027 & 7,129 & 0,032 & $-0,147$ & 0,147 & 1,107 \\
\hline hsa-miR-559 & 6,475 & 0,083 & 6,621 & 0,022 & $-0,147$ & 0,147 & 1,107 \\
\hline mmu-miR-543 & 6,643 & 0,426 & 6,790 & 0,413 & $-0,147$ & 0,147 & 1,107 \\
\hline mmu-miR-130b & 7,621 & 0,119 & 7,767 & 0,092 & $-0,146$ & 0,146 & 1,106 \\
\hline spike_control_e & 11,176 & 0,038 & 11,321 & 0,097 & $-0,145$ & 0,145 & 1,106 \\
\hline mmu-miR-693-5p & 6,664 & 0,071 & 6,808 & 0,272 & $-0,144$ & 0,144 & 1,105 \\
\hline rno-miR-376a & 6,418 & 0,380 & 6,562 & 0,115 & $-0,144$ & 0,144 & 1,105 \\
\hline mmu-miR-708 & 6,750 & 0,189 & 6,893 & 0,148 & $-0,144$ & 0,144 & 1,105 \\
\hline miRPlus_17900 & 6,778 & 0,275 & 6,920 & 0,032 & $-0,142$ & 0,142 & 1,103 \\
\hline hsa-miR-887 & 6,615 & 0,421 & 6,755 & 0,050 & $-0,140$ & 0,140 & 1,102 \\
\hline miRPlus_17941 & 6,837 & 0,411 & 6,976 & 0,666 & $-0,139$ & 0,139 & 1,101 \\
\hline hsa-miR-151-3p & 6,944 & 0,313 & 7,076 & 0,048 & $-0,132$ & 0,132 & 1,096 \\
\hline mmu-miR-700 & 6,864 & 0,030 & 6,994 & 0,084 & $-0,130$ & 0,130 & 1,094 \\
\hline
\end{tabular}




\begin{tabular}{|c|c|c|c|c|c|c|c|}
\hline mmu-miR-291b-5p & 6,517 & 0,067 & 6,645 & 0,131 & $-0,129$ & 0,129 & 1,093 \\
\hline mmu-miR-431 & 6,696 & 0,065 & 6,824 & 0,401 & $-0,128$ & 0,128 & 1,093 \\
\hline spike_control_e & 11,163 & 0,103 & 11,291 & 0,062 & $-0,128$ & 0,128 & 1,093 \\
\hline hsa-miR-525-3p & 6,468 & 0,105 & 6,596 & 0,048 & $-0,127$ & 0,127 & 1,092 \\
\hline hsa-miR-518f* & 6,847 & 0,512 & 6,974 & 0,271 & $-0,127$ & 0,127 & 1,092 \\
\hline miRPlus_17930 & 6,669 & 0,314 & 6,795 & 0,272 & $-0,126$ & 0,126 & 1,091 \\
\hline spike_control_e & 11,276 & 0,049 & 11,400 & 0,080 & $-0,124$ & 0,124 & 1,090 \\
\hline mmu-miR-298 & 8,269 & 0,074 & 8,393 & 0,019 & $-0,124$ & 0,124 & 1,090 \\
\hline mmu-miR-741 & 6,382 & 0,504 & 6,506 & 0,090 & $-0,124$ & 0,124 & 1,089 \\
\hline miRPlus_30317 & 6,435 & 0,065 & 6,557 & 0,039 & $-0,123$ & 0,123 & 1,089 \\
\hline hsa_negative_control_2 & 6,919 & 0,049 & 7,041 & 0,769 & $-0,122$ & 0,122 & 1,088 \\
\hline spike_control_e & 11,153 & 0,057 & 11,274 & 0,036 & $-0,121$ & 0,121 & 1,088 \\
\hline hsa-miR-193b & 7,381 & 0,085 & 7,501 & 0,056 & $-0,120$ & 0,120 & 1,087 \\
\hline mmu-miR-760 & 6,808 & 0,041 & 6,927 & 0,007 & $-0,119$ & 0,119 & 1,086 \\
\hline mmu-miR-29b & 7,070 & 0,238 & 7,188 & 0,052 & $-0,118$ & 0,118 & 1,085 \\
\hline mmu-miR-551b & 7,247 & 0,191 & 7,363 & 0,075 & $-0,116$ & 0,116 & 1,084 \\
\hline miRPlus_17653 & 6,692 & 0,170 & 6,807 & 0,425 & $-0,116$ & 0,116 & 1,084 \\
\hline mmu-miR-183* & 6,602 & 0,065 & 6,713 & 0,017 & $-0,110$ & 0,110 & 1,080 \\
\hline mmu-miR-873 & 7,002 & 0,119 & 7,111 & 0,154 & $-0,109$ & 0,109 & 1,078 \\
\hline mmu-miR-141 & 6,720 & 0,166 & 6,829 & 0,416 & $-0,108$ & 0,108 & 1,078 \\
\hline hsa-miR-621 & 6,483 & 0,048 & 6,590 & 0,027 & $-0,108$ & 0,108 & 1,077 \\
\hline hsa-miR-373* & 6,647 & 0,051 & 6,752 & 0,225 & $-0,105$ & 0,105 & 1,075 \\
\hline hsa-miR-193a-5p & 7,444 & 0,065 & 7,547 & 0,024 & $-0,103$ & 0,103 & 1,074 \\
\hline hsa-miR-455-3p & 6,652 & 0,040 & 6,754 & 0,059 & $-0,102$ & 0,102 & 1,074 \\
\hline hsa-miR-629* & 6,725 & 0,037 & 6,826 & 0,035 & $-0,101$ & 0,101 & 1,072 \\
\hline mmu-miR-215 & 6,465 & 0,060 & 6,564 & 0,019 & $-0,099$ & 0,099 & 1,071 \\
\hline spike_control_f & 8,933 & 0,054 & 9,029 & 0,043 & $-0,097$ & 0,097 & 1,069 \\
\hline hsa-miR-215 & 6,576 & 0,258 & 6,672 & 0,128 & $-0,096$ & 0,096 & 1,069 \\
\hline mmu-miR-195 & 6,930 & 0,066 & 7,021 & 0,043 & $-0,091$ & 0,091 & 1,065 \\
\hline miRPlus_17945 & 6,797 & 0,053 & 6,886 & 0,037 & $-0,089$ & 0,089 & 1,064 \\
\hline mmu-miR-181a & 6,952 & 0,283 & 7,041 & 0,071 & $-0,089$ & 0,089 & 1,064 \\
\hline miRPlus_17951 & 6,470 & 0,028 & 6,556 & 0,030 & $-0,086$ & 0,086 & 1,061 \\
\hline rno-miR-382* & 6,558 & 0,057 & 6,640 & 0,018 & $-0,082$ & 0,082 & 1,058 \\
\hline miRPlus_30908 & 6,542 & 0,026 & 6,622 & 0,014 & $-0,080$ & 0,080 & 1,057 \\
\hline mmu-miR-381 & 6,612 & 0,029 & 6,692 & 0,020 & $-0,080$ & 0,080 & 1,057 \\
\hline spike_control_f & 8,938 & 0,057 & 9,017 & 0,060 & $-0,079$ & 0,079 & 1,057 \\
\hline mmu-miR-151-5p & 6,870 & 0,049 & 6,950 & 0,035 & $-0,079$ & 0,079 & 1,056 \\
\hline hsa-miR-20b* & 6,773 & 0,402 & 6,851 & 0,090 & $-0,078$ & 0,078 & 1,056 \\
\hline mmu-miR-697 & 6,670 & 0,430 & 6,745 & 0,262 & $-0,075$ & 0,075 & 1,054 \\
\hline miRPlus_17865 & 7,095 & 0,254 & 7,170 & 0,053 & $-0,075$ & 0,075 & 1,053 \\
\hline hsa-miR-499-3p & 6,509 & 0,552 & 6,584 & 0,170 & $-0,075$ & 0,075 & 1,053 \\
\hline spike_control_f & 8,993 & 0,041 & 9,068 & 0,046 & $-0,075$ & 0,075 & 1,053 \\
\hline No known hsa target & 6,539 & 0,052 & 6,613 & 0,029 & $-0,074$ & 0,074 & 1,053 \\
\hline hsa-miR-384 & 6,498 & 0,244 & 6,569 & 0,059 & $-0,071$ & 0,071 & 1,051 \\
\hline rno-miR-542-5p & 7,501 & 0,072 & 7,572 & 0,034 & $-0,071$ & 0,071 & 1,050 \\
\hline hsa-miR-519e* & 6,849 & 0,412 & 6,916 & 0,130 & $-0,067$ & 0,067 & 1,048 \\
\hline mmu-miR-214 & 7,654 & 0,120 & 7,719 & 0,128 & $-0,066$ & 0,066 & 1,046 \\
\hline mmu-miR-184 & 6,924 & 0,125 & 6,989 & 0,142 & $-0,065$ & 0,065 & 1,046 \\
\hline mmu-miR-691 & 6,871 & 0,052 & 6,935 & 0,042 & $-0,064$ & 0,064 & 1,046 \\
\hline hsa-miR-647 & 6,429 & 0,460 & 6,491 & 0,041 & $-0,062$ & 0,062 & 1,044 \\
\hline $\mathrm{mmu}-\mathrm{miR}-20 \mathrm{~b}^{*}$ & 6,817 & 0,402 & 6,879 & 0,544 & $-0,062$ & 0,062 & 1,044 \\
\hline mmu-miR-202-3p & 6,803 & 0,126 & 6,864 & 0,452 & $-0,061$ & 0,061 & 1,043 \\
\hline mmu-miR-362-5p & 6,776 & 0,028 & 6,837 & 0,019 & $-0,061$ & 0,061 & 1,043 \\
\hline hsa-miR-520g & 6,737 & 0,068 & 6,795 & 0,362 & $-0,058$ & 0,058 & 1,041 \\
\hline mmu-miR-804 & 6,710 & 0,259 & 6,766 & 0,351 & $-0,056$ & 0,056 & 1,040 \\
\hline hsa-miR-589* & 6,526 & 0,034 & 6,582 & 0,026 & $-0,055$ & 0,055 & 1,039 \\
\hline miRPlus_28534 & 6,453 & 0,023 & 6,507 & 0,040 & $-0,055$ & 0,055 & 1,039 \\
\hline
\end{tabular}




\begin{tabular}{|c|c|c|c|c|c|c|c|}
\hline mmu-miR-675-3p & 6,517 & 0,052 & 6,570 & 0,046 & $-0,053$ & 0,053 & 1,037 \\
\hline hsa-miR-640 & 6,533 & 0,017 & 6,585 & 0,036 & $-0,052$ & 0,052 & 1,037 \\
\hline mmu-miR-429 & 6,550 & 0,025 & 6,600 & 0,030 & $-0,050$ & 0,050 & 1,035 \\
\hline hsa-miR-487a & 6,562 & 0,021 & 6,612 & 0,041 & $-0,049$ & 0,049 & 1,035 \\
\hline rno-miR-101a_MM1 & 6,781 & 0,314 & 6,826 & 0,355 & $-0,044$ & 0,044 & 1,031 \\
\hline hsa-miR-199a-3p/199b-3p & 6,982 & 0,026 & 7,026 & 0,036 & $-0,044$ & 0,044 & 1,031 \\
\hline hsa-miR-574-5p & 7,470 & 0,097 & 7,514 & 0,136 & $-0,043$ & 0,043 & 1,030 \\
\hline mmu-miR-125b-3p & 6,714 & 0,288 & 6,755 & 0,203 & $-0,041$ & 0,041 & 1,029 \\
\hline hsa-miR-610 & 6,688 & 0,599 & 6,727 & 0,202 & $-0,040$ & 0,040 & 1,028 \\
\hline hsa-miR-493 & 6,542 & 0,037 & 6,579 & 0,028 & $-0,037$ & 0,037 & 1,026 \\
\hline miRPlus_17956 & 6,666 & 0,381 & 6,702 & 0,064 & $-0,036$ & 0,036 & 1,025 \\
\hline hsa-miR-185* & 7,110 & 0,199 & 7,146 & 0,173 & $-0,036$ & 0,036 & 1,025 \\
\hline mmu-miR-673-5p & 6,432 & 0,398 & 6,467 & 0,088 & $-0,035$ & 0,035 & 1,024 \\
\hline hsa-miR-222* & 6,596 & 0,047 & 6,628 & 0,243 & $-0,033$ & 0,033 & 1,023 \\
\hline miRPlus_32832 & 6,538 & 0,112 & 6,570 & 0,061 & $-0,032$ & 0,032 & 1,023 \\
\hline mmu-miR-369-5p & 6,581 & 0,059 & 6,612 & 0,033 & $-0,031$ & 0,031 & 1,022 \\
\hline mmu-miR-376c & 6,641 & 0,022 & 6,671 & 0,025 & $-0,030$ & 0,030 & 1,021 \\
\hline mmu-miR-153 & 6,538 & 0,040 & 6,568 & 0,016 & $-0,030$ & 0,030 & 1,021 \\
\hline hsa-miR-105 & 6,807 & 0,023 & 6,829 & 0,025 & $-0,022$ & 0,022 & 1,015 \\
\hline hsa-miR-19b-1* & 6,584 & 0,049 & 6,605 & 0,012 & $-0,021$ & 0,021 & 1,014 \\
\hline hsa-miR-576-3p & 6,571 & 0,043 & 6,592 & 0,013 & $-0,021$ & 0,021 & 1,014 \\
\hline hsa-miR-891a & 6,811 & 0,079 & 6,829 & 0,044 & $-0,018$ & 0,018 & 1,013 \\
\hline mmu-miR-181b & 7,753 & 0,070 & 7,770 & 0,048 & $-0,018$ & 0,018 & 1,012 \\
\hline hsa-miR-192 & 6,666 & 0,016 & 6,682 & 0,015 & $-0,016$ & 0,016 & 1,011 \\
\hline miRPlus_17861 & 7,572 & 0,063 & 7,588 & 0,028 & $-0,016$ & 0,016 & 1,011 \\
\hline hsa-miR-541* & 6,533 & 0,056 & 6,549 & 0,022 & $-0,015$ & 0,015 & 1,011 \\
\hline mmu-miR-713 & 6,609 & 0,045 & 6,624 & 0,019 & $-0,015$ & 0,015 & 1,011 \\
\hline mmu-miR-500 & 6,818 & 0,019 & 6,831 & 0,023 & $-0,013$ & 0,013 & 1,009 \\
\hline hsa-miR-217 & 6,568 & 0,021 & 6,580 & 0,010 & $-0,013$ & 0,013 & 1,009 \\
\hline hsa-miR-638 & 6,898 & 0,123 & 6,910 & 0,010 & $-0,012$ & 0,012 & 1,008 \\
\hline mmu-miR-99b* & 6,775 & 0,055 & 6,787 & 0,035 & $-0,012$ & 0,012 & 1,008 \\
\hline hsa-miR-302c* & 7,006 & 0,327 & 7,018 & 0,038 & $-0,011$ & 0,011 & 1,008 \\
\hline mmu-miR-126-3p & 6,979 & 0,041 & 6,988 & 0,015 & $-0,010$ & 0,010 & 1,007 \\
\hline mmu-miR-425* & 6,597 & 0,434 & 6,604 & 0,047 & $-0,007$ & 0,007 & 1,005 \\
\hline hsa-miR-675 & 6,613 & 0,016 & 6,619 & 0,023 & $-0,006$ & 0,006 & 1,004 \\
\hline mmu-miR-196a & 7,451 & 0,237 & 7,457 & 0,072 & $-0,006$ & 0,006 & 1,004 \\
\hline hsa-miR-519b-3p & 6,609 & 0,494 & 6,613 & 0,206 & $-0,004$ & 0,004 & 1,003 \\
\hline mmu-miR-490 & 6,604 & 0,067 & 6,608 & 0,031 & $-0,004$ & 0,004 & 1,002 \\
\hline mmu-miR-743a & 6,591 & 0,060 & 6,595 & 0,014 & $-0,003$ & 0,003 & 1,002 \\
\hline mmu-let-7f & 7,030 & 0,028 & 7,030 & 0,016 & 0,000 & 0,000 & 1,000 \\
\hline mmu-miR-496 & 6,607 & 0,068 & 6,606 & 0,011 & 0,001 & $-0,001$ & 0,999 \\
\hline hsa_SNORD13 & 7,235 & 0,171 & 7,233 & 0,059 & 0,003 & $-0,003$ & 0,998 \\
\hline hsa-miR-544 & 6,584 & 0,021 & 6,581 & 0,014 & 0,003 & $-0,003$ & 0,998 \\
\hline mmu-miR-495 & 6,521 & 0,458 & 6,517 & 0,042 & 0,004 & $-0,004$ & 0,997 \\
\hline hsa-miR-526b & 6,720 & 0,202 & 6,716 & 0,039 & 0,004 & $-0,004$ & 0,997 \\
\hline rno-miR-336 & 6,714 & 0,434 & 6,708 & 0,012 & 0,006 & $-0,006$ & 0,996 \\
\hline mmu-miR-714 & 6,695 & 0,048 & 6,690 & 0,011 & 0,006 & $-0,006$ & 0,996 \\
\hline mmu-miR-704 & 6,624 & 0,064 & 6,618 & 0,018 & 0,006 & $-0,006$ & 0,996 \\
\hline hsa_SNORD4A & 7,295 & 0,066 & 7,289 & 0,046 & 0,006 & $-0,006$ & 0,996 \\
\hline hsa-miR-599 & 6,617 & 0,021 & 6,610 & 0,010 & 0,007 & $-0,007$ & 0,995 \\
\hline mmu-miR-146b & 6,871 & 0,023 & 6,864 & 0,013 & 0,007 & $-0,007$ & 0,995 \\
\hline mmu-miR-699 & 6,536 & 0,075 & 6,528 & 0,017 & 0,008 & $-0,008$ & 0,995 \\
\hline hsa-miR-518c* & 7,275 & 0,034 & 7,266 & 0,037 & 0,009 & $-0,009$ & 0,994 \\
\hline hsa-miR-550* & 6,687 & 0,029 & 6,675 & 0,033 & 0,012 & $-0,012$ & 0,992 \\
\hline mmu-miR-763 & 7,006 & 0,216 & 6,994 & 0,734 & 0,012 & $-0,012$ & 0,992 \\
\hline hsa-miR-662 & 6,561 & 0,476 & 6,546 & 0,122 & 0,015 & $-0,015$ & 0,990 \\
\hline hsa-miR-876-5p & 6,764 & 0,330 & 6,746 & 0,317 & 0,018 & $-0,018$ & 0,988 \\
\hline
\end{tabular}




\begin{tabular}{|c|c|c|c|c|c|c|c|}
\hline miRPlus_17847 & 6,766 & 0,209 & 6,747 & 0,229 & 0,018 & $-0,018$ & 0,987 \\
\hline hsa-miR-325 & 6,760 & 0,352 & 6,741 & 0,242 & 0,020 & $-0,020$ & 0,987 \\
\hline mmu-miR-421 & 6,918 & 0,041 & 6,898 & 0,031 & 0,020 & $-0,020$ & 0,986 \\
\hline miRPlus_32953 & 6,731 & 0,060 & 6,710 & 0,029 & 0,021 & $-0,021$ & 0,986 \\
\hline mmu-miR-295 & 6,622 & 0,379 & 6,601 & 0,092 & 0,021 & $-0,021$ & 0,985 \\
\hline mmu-miR-764-5p & 6,651 & 0,083 & 6,630 & 0,020 & 0,022 & $-0,022$ & 0,985 \\
\hline hsa_SNORD15A & 8,056 & 2,194 & 8,034 & 2,800 & 0,022 & $-0,022$ & 0,985 \\
\hline hsa-miR-564 & 6,635 & 0,058 & 6,613 & 0,059 & 0,023 & $-0,023$ & 0,984 \\
\hline mmu-miR-221 & 7,303 & 0,037 & 7,279 & 0,035 & 0,023 & $-0,023$ & 0,984 \\
\hline mmu-miR-379 & 6,781 & 0,144 & 6,757 & 0,307 & 0,024 & $-0,024$ & 0,984 \\
\hline mmu-miR-455* & 6,900 & 0,274 & 6,875 & 0,061 & 0,025 & $-0,025$ & 0,983 \\
\hline hsa-miR-617 & 6,746 & 0,016 & 6,721 & 0,024 & 0,025 & $-0,025$ & 0,983 \\
\hline miRPlus_17841 & 6,610 & 0,063 & 6,584 & 0,016 & 0,026 & $-0,026$ & 0,982 \\
\hline hsa-miR-517* & 6,595 & 0,470 & 6,567 & 0,151 & 0,028 & $-0,028$ & 0,981 \\
\hline hsa-miR-619 & 6,660 & 0,461 & 6,629 & 0,280 & 0,031 & $-0,031$ & 0,979 \\
\hline mmu-miR-142-5p & 6,670 & 0,070 & 6,638 & 0,029 & 0,033 & $-0,033$ & 0,978 \\
\hline mmu-miR-144 & 6,644 & 0,065 & 6,611 & 0,015 & 0,033 & $-0,033$ & 0,977 \\
\hline mmu-miR-718 & 6,678 & 0,038 & 6,644 & 0,028 & 0,034 & $-0,034$ & 0,977 \\
\hline hsa-miR-302d & 6,709 & 0,420 & 6,673 & 0,254 & 0,036 & $-0,036$ & 0,975 \\
\hline hsa-miR-16-1* & 6,661 & 0,016 & 6,625 & 0,007 & 0,036 & $-0,036$ & 0,975 \\
\hline hsa-miR-516b & 6,775 & 0,027 & 6,738 & 0,024 & 0,036 & $-0,036$ & 0,975 \\
\hline hsa-miR-641 & 6,623 & 0,014 & 6,585 & 0,019 & 0,038 & $-0,038$ & 0,974 \\
\hline mmu-miR-148a* & 6,591 & 0,042 & 6,553 & 0,026 & 0,038 & $-0,038$ & 0,974 \\
\hline mmu-miR-194 & 6,642 & 0,023 & 6,603 & 0,034 & 0,039 & $-0,039$ & 0,973 \\
\hline mmu-miR-208 & 6,819 & 0,045 & 6,778 & 0,021 & 0,041 & $-0,041$ & 0,972 \\
\hline mmu-miR-9 & 7,447 & 0,044 & 7,405 & 0,036 & 0,041 & $-0,041$ & 0,972 \\
\hline hsa-miR-628-3p & 6,821 & 0,229 & 6,778 & 0,054 & 0,043 & $-0,043$ & 0,971 \\
\hline mmu-miR-448 & 6,749 & 0,043 & 6,705 & 0,210 & 0,044 & $-0,044$ & 0,970 \\
\hline mmu-miR-409-3p & 6,647 & 0,023 & 6,602 & 0,025 & 0,044 & $-0,044$ & 0,970 \\
\hline No known hsa target & 6,668 & 0,050 & 6,621 & 0,008 & 0,047 & $-0,047$ & 0,968 \\
\hline mmu-miR-670 & 6,672 & 0,037 & 6,624 & 0,016 & 0,048 & $-0,048$ & 0,967 \\
\hline miRPlus_17868 & 6,624 & 0,039 & 6,575 & 0,020 & 0,049 & $-0,049$ & 0,966 \\
\hline mmu-miR-486 & 6,751 & 0,028 & 6,701 & 0,013 & 0,050 & $-0,050$ & 0,966 \\
\hline hsa-let-7e* & 6,626 & 0,063 & 6,576 & 0,041 & 0,051 & $-0,051$ & 0,965 \\
\hline hsa-miR-542-3p & 6,750 & 0,062 & 6,697 & 0,035 & 0,053 & $-0,053$ & 0,964 \\
\hline hsa-miR-337-5p & 6,589 & 0,505 & 6,536 & 0,123 & 0,053 & $-0,053$ & 0,964 \\
\hline mmu-miR-380-5p & 6,604 & 0,063 & 6,551 & 0,037 & 0,053 & $-0,053$ & 0,964 \\
\hline mmu-miR-190 & 7,034 & 0,108 & 6,980 & 0,083 & 0,053 & $-0,053$ & 0,964 \\
\hline mmu-miR-875-5p & 6,659 & 0,054 & 6,605 & 0,022 & 0,054 & $-0,054$ & 0,964 \\
\hline hsa-miR-489 & 6,646 & 0,079 & 6,592 & 0,057 & 0,054 & $-0,054$ & 0,963 \\
\hline hsa-miR-649 & 6,663 & 0,029 & 6,608 & 0,016 & 0,055 & $-0,055$ & 0,963 \\
\hline mmu-miR-423-3p & 6,670 & 0,034 & 6,614 & 0,019 & 0,056 & $-0,056$ & 0,962 \\
\hline miRPlus_31515 & 6,623 & 0,034 & 6,567 & 0,008 & 0,056 & $-0,056$ & 0,962 \\
\hline hsa-miR-181a-2* & 6,782 & 0,019 & 6,726 & 0,022 & 0,056 & $-0,056$ & 0,962 \\
\hline hsa-miR-525-5p & 7,033 & 0,018 & 6,975 & 0,023 & 0,058 & $-0,058$ & 0,961 \\
\hline hsa-miR-768-5p & 7,781 & 0,214 & 7,721 & 0,085 & 0,059 & $-0,059$ & 0,960 \\
\hline mmu-miR-331-5p & 6,620 & 0,045 & 6,560 & 0,041 & 0,060 & $-0,060$ & 0,960 \\
\hline hsa-miR-607 & 6,650 & 0,025 & 6,591 & 0,008 & 0,060 & $-0,060$ & 0,960 \\
\hline hsa-miR-657 & 6,692 & 0,071 & 6,632 & 0,013 & 0,060 & $-0,060$ & 0,959 \\
\hline mmu-miR-742 & 6,728 & 0,056 & 6,668 & 0,023 & 0,060 & $-0,060$ & 0,959 \\
\hline hsa-miR-552 & 6,686 & 0,057 & 6,624 & 0,015 & 0,061 & $-0,061$ & 0,958 \\
\hline mmu-miR-137 & 6,811 & 0,024 & 6,747 & 0,238 & 0,064 & $-0,064$ & 0,957 \\
\hline mmu-miR-540-3p & 6,810 & 0,351 & 6,746 & 0,251 & 0,064 & $-0,064$ & 0,957 \\
\hline hsa-miR-885-5p & 6,798 & 0,059 & 6,733 & 0,033 & 0,065 & $-0,065$ & 0,956 \\
\hline hsa-miR-33b* & 6,678 & 0,135 & 6,613 & 0,027 & 0,065 & $-0,065$ & 0,956 \\
\hline mmu-miR-568 & 6,592 & 0,046 & 6,524 & 0,065 & 0,068 & $-0,068$ & 0,954 \\
\hline hsa-miR-299-3p & 6,692 & 0,029 & 6,624 & 0,008 & 0,068 & $-0,068$ & 0,954 \\
\hline
\end{tabular}




\begin{tabular}{|c|c|c|c|c|c|c|c|}
\hline mmu-miR-139-5p & 6,575 & 0,428 & 6,505 & 0,056 & 0,069 & $-0,069$ & 0,953 \\
\hline hsa-miR-500 & 7,138 & 0,053 & 7,069 & 0,006 & 0,069 & $-0,069$ & 0,953 \\
\hline mmu-miR-10a & 7,222 & 0,074 & 7,153 & 0,045 & 0,070 & $-0,070$ & 0,953 \\
\hline mmu-miR-7a & 7,218 & 0,076 & 7,148 & 0,065 & 0,070 & $-0,070$ & 0,953 \\
\hline rno-miR-346 & 6,642 & 0,034 & 6,570 & 0,015 & 0,072 & $-0,072$ & 0,952 \\
\hline mmu-miR-1 & 6,862 & 0,041 & 6,790 & 0,073 & 0,072 & $-0,072$ & 0,951 \\
\hline hsa-miR-614 & 6,637 & 0,119 & 6,564 & 0,013 & 0,072 & $-0,072$ & 0,951 \\
\hline mmu-miR-384-3p & 6,795 & 0,633 & 6,722 & 0,264 & 0,073 & $-0,073$ & 0,950 \\
\hline hsa-miR-554 & 6,691 & 0,024 & 6,616 & 0,018 & 0,076 & $-0,076$ & 0,949 \\
\hline mmu-miR-24-1*/24-2* & 6,832 & 0,055 & 6,757 & 0,038 & 0,076 & $-0,076$ & 0,949 \\
\hline hsa-miR-624 & 6,668 & 0,056 & 6,592 & 0,023 & 0,076 & $-0,076$ & 0,949 \\
\hline mmu-miR-324-5p & 7,127 & 0,022 & 7,051 & 0,022 & 0,076 & $-0,076$ & 0,949 \\
\hline miRPlus_17932 & 6,991 & 0,070 & 6,915 & 0,500 & 0,076 & $-0,076$ & 0,949 \\
\hline hsa-miR-645 & 6,706 & 0,025 & 6,629 & 0,019 & 0,077 & $-0,077$ & 0,948 \\
\hline hsa_SNORD118 & 7,527 & 0,055 & 7,450 & 0,075 & 0,077 & $-0,077$ & 0,948 \\
\hline hsa-miR-577 & 6,611 & 0,073 & 6,533 & 0,056 & 0,077 & $-0,077$ & 0,948 \\
\hline hsa-miR-604 & 6,671 & 0,016 & 6,593 & 0,031 & 0,077 & $-0,077$ & 0,948 \\
\hline mmu-miR-196b & 7,127 & 0,033 & 7,049 & 0,016 & 0,078 & $-0,078$ & 0,948 \\
\hline mmu-miR-127 & 6,931 & 0,092 & 6,850 & 0,033 & 0,080 & $-0,080$ & 0,946 \\
\hline rno-miR-489 & 6,629 & 0,080 & 6,549 & 0,014 & 0,080 & $-0,080$ & 0,946 \\
\hline hsa-miR-758 & 6,786 & 0,025 & 6,704 & 0,379 & 0,081 & $-0,081$ & 0,945 \\
\hline hsa-miR-549 & 6,656 & 0,056 & 6,574 & 0,020 & 0,082 & $-0,082$ & 0,945 \\
\hline mmu-miR-148b & 7,362 & 0,041 & 7,279 & 0,037 & 0,082 & $-0,082$ & 0,945 \\
\hline miRPlus_28993 & 6,990 & 0,023 & 6,907 & 0,028 & 0,083 & $-0,083$ & 0,944 \\
\hline hsa-miR-412 & 6,667 & 0,048 & 6,583 & 0,019 & 0,084 & $-0,084$ & 0,944 \\
\hline hsa-miR-17* & 6,911 & 0,039 & 6,828 & 0,043 & 0,084 & $-0,084$ & 0,944 \\
\hline miRPlus_17820 & 6,585 & 0,432 & 6,500 & 0,089 & 0,084 & $-0,084$ & 0,943 \\
\hline hsa-miR-582-3p & 6,630 & 0,041 & 6,544 & 0,030 & 0,085 & $-0,085$ & 0,943 \\
\hline mmu-miR-688 & 6,929 & 0,023 & 6,843 & 0,024 & 0,086 & $-0,086$ & 0,942 \\
\hline mmu-miR-488* & 6,695 & 0,072 & 6,609 & 0,023 & 0,086 & $-0,086$ & 0,942 \\
\hline hsa-miR-596 & 6,659 & 0,091 & 6,573 & 0,039 & 0,087 & $-0,087$ & 0,942 \\
\hline mmu-miR-188-3p & 6,655 & 0,030 & 6,567 & 0,022 & 0,088 & $-0,088$ & 0,941 \\
\hline mmu-miR-31 & 7,012 & 0,011 & 6,924 & 0,070 & 0,088 & $-0,088$ & 0,941 \\
\hline hsa-miR-769-5p & 6,786 & 0,035 & 6,696 & 0,012 & 0,089 & $-0,089$ & 0,940 \\
\hline rno-miR-1 & 6,861 & 0,129 & 6,771 & 0,309 & 0,090 & $-0,090$ & 0,940 \\
\hline hsa-miR-490-5p & 6,708 & 0,032 & 6,618 & 0,023 & 0,090 & $-0,090$ & 0,939 \\
\hline hsa-miR-454* & 6,751 & 0,089 & 6,660 & 0,026 & 0,091 & $-0,091$ & 0,939 \\
\hline hsa-miR-661 & 6,788 & 0,131 & 6,695 & 0,141 & 0,093 & $-0,093$ & 0,938 \\
\hline hsa-miR-520g/520h & 6,698 & 0,330 & 6,605 & 0,051 & 0,093 & $-0,093$ & 0,937 \\
\hline hsa-miR-637 & 6,794 & 0,029 & 6,700 & 0,021 & 0,094 & $-0,094$ & 0,937 \\
\hline hsa-miR-376c & 6,590 & 0,413 & 6,496 & 0,060 & 0,094 & $-0,094$ & 0,937 \\
\hline hsa-miR-452 & 7,296 & 0,391 & 7,201 & 0,052 & 0,095 & $-0,095$ & 0,936 \\
\hline miRPlus_11239 & 6,709 & 0,069 & 6,613 & 0,032 & 0,096 & $-0,096$ & 0,935 \\
\hline miRPlus_17880 & 6,893 & 0,139 & 6,796 & 0,335 & 0,097 & $-0,097$ & 0,935 \\
\hline hsa-miR-432* & 6,684 & 0,014 & 6,586 & 0,033 & 0,098 & $-0,098$ & 0,934 \\
\hline mmu-miR-186 & 7,679 & 0,213 & 7,581 & 0,040 & 0,098 & $-0,098$ & 0,934 \\
\hline hsa-miR-297 & 6,743 & 0,028 & 6,645 & 0,026 & 0,099 & $-0,099$ & 0,934 \\
\hline hsa-miR-562 & 6,702 & 0,040 & 6,604 & 0,018 & 0,099 & $-0,099$ & 0,934 \\
\hline hsa-miR-767-5p & 6,770 & 0,011 & 6,671 & 0,012 & 0,099 & $-0,099$ & 0,933 \\
\hline mmu-miR-203 & 6,876 & 0,055 & 6,776 & 0,028 & 0,099 & $-0,099$ & 0,933 \\
\hline hsa-miR-654-5p & 6,718 & 0,060 & 6,618 & 0,017 & 0,099 & $-0,099$ & 0,933 \\
\hline hsa-miR-521 & 6,650 & 0,037 & 6,550 & 0,026 & 0,100 & $-0,100$ & 0,933 \\
\hline miRPlus_28790 & 6,606 & 0,392 & 6,505 & 0,020 & 0,101 & $-0,101$ & 0,933 \\
\hline hsa-miR-606 & 6,617 & 0,080 & 6,516 & 0,043 & 0,101 & $-0,101$ & 0,932 \\
\hline hsa-miR-556-5p & 6,710 & 0,090 & 6,608 & 0,036 & 0,102 & $-0,102$ & 0,932 \\
\hline miRPlus_27560 & 7,005 & 0,047 & 6,904 & 0,038 & 0,102 & $-0,102$ & 0,932 \\
\hline rno-miR-664 & 6,915 & 0,061 & 6,810 & 0,032 & 0,104 & $-0,104$ & 0,930 \\
\hline
\end{tabular}




\begin{tabular}{|c|c|c|c|c|c|c|c|}
\hline mmu-miR-464 & 6,686 & 0,056 & 6,581 & 0,022 & 0,105 & $-0,105$ & 0,930 \\
\hline mmu-miR-132 & 6,782 & 0,123 & 6,677 & 0,045 & 0,105 & $-0,105$ & 0,930 \\
\hline mmu-miR-154* & 6,676 & 0,404 & 6,570 & 0,104 & 0,106 & $-0,106$ & 0,929 \\
\hline mmu-miR-146a & 6,661 & 0,060 & 6,554 & 0,017 & 0,107 & $-0,107$ & 0,929 \\
\hline hsa-miR-198 & 6,910 & 0,025 & 6,802 & 0,109 & 0,108 & $-0,108$ & 0,928 \\
\hline hsa-miR-192* & 6,688 & 0,052 & 6,579 & 0,013 & 0,109 & $-0,109$ & 0,927 \\
\hline mmu-miR-671-3p & 6,702 & 0,043 & 6,592 & 0,040 & 0,111 & $-0,111$ & 0,926 \\
\hline mmu-miR-152 & 7,083 & 0,045 & 6,972 & 0,014 & 0,111 & $-0,111$ & 0,926 \\
\hline miRPlus_17955 & 6,689 & 0,045 & 6,578 & 0,036 & 0,111 & $-0,111$ & 0,926 \\
\hline mmu-miR-491 & 6,779 & 0,018 & 6,668 & 0,040 & 0,111 & $-0,111$ & 0,926 \\
\hline mmu-miR-539 & 6,883 & 0,279 & 6,770 & 0,252 & 0,114 & $-0,114$ & 0,924 \\
\hline hsa-miR-345 & 6,866 & 0,021 & 6,752 & 0,010 & 0,114 & $-0,114$ & 0,924 \\
\hline hsa-miR-422a & 6,732 & 0,272 & 6,616 & 0,084 & 0,116 & $-0,116$ & 0,923 \\
\hline hsa-miR-133a/133b & 6,830 & 0,016 & 6,714 & 0,051 & 0,116 & $-0,116$ & 0,923 \\
\hline miRPlus_17840 & 6,855 & 0,041 & 6,738 & 0,098 & 0,116 & $-0,116$ & 0,923 \\
\hline hsa-miR-453 & 6,750 & 0,057 & 6,633 & 0,023 & 0,117 & $-0,117$ & 0,922 \\
\hline hsa-miR-593* & 6,708 & 0,063 & 6,590 & 0,033 & 0,117 & $-0,117$ & 0,922 \\
\hline mmu-let-7i* & 6,717 & 0,031 & 6,599 & 0,017 & 0,117 & $-0,117$ & 0,922 \\
\hline hsa-miR-585 & 6,843 & 0,023 & 6,726 & 0,013 & 0,117 & $-0,117$ & 0,922 \\
\hline $\begin{array}{l}\text { hsa-miR-518e*/519a*/519b- } \\
5 p / 519 c-5 p / 522^{*} / 523^{*}\end{array}$ & 6,887 & 0,051 & 6,767 & 0,021 & 0,120 & $-0,120$ & 0,920 \\
\hline mmu-let-7e & 7,017 & 0,017 & 6,896 & 0,065 & 0,120 & $-0,120$ & 0,920 \\
\hline hsa-miR-600 & 6,731 & 0,064 & 6,610 & 0,029 & 0,121 & $-0,121$ & 0,919 \\
\hline hsa-miR-376a & 6,719 & 0,036 & 6,598 & 0,021 & 0,122 & $-0,122$ & 0,919 \\
\hline miRPlus_17933 & 6,779 & 0,024 & 6,656 & 0,035 & 0,122 & $-0,122$ & 0,919 \\
\hline mmu-miR-684 & 6,742 & 0,062 & 6,619 & 0,019 & 0,123 & $-0,123$ & 0,918 \\
\hline mmu-miR-197 & 7,177 & 0,058 & 7,053 & 0,031 & 0,124 & $-0,124$ & 0,918 \\
\hline mmu-miR-676* & 6,699 & 0,040 & 6,574 & 0,064 & 0,125 & $-0,125$ & 0,917 \\
\hline miRPlus_17824 & 6,708 & 0,027 & 6,582 & 0,016 & 0,125 & $-0,125$ & 0,917 \\
\hline hsa-miR-934 & 7,063 & 0,193 & 6,937 & 0,076 & 0,126 & $-0,126$ & 0,916 \\
\hline mmu-miR-29c & 6,843 & 0,045 & 6,715 & 0,023 & 0,128 & $-0,128$ & 0,915 \\
\hline hsa-miR-567 & 6,595 & 0,331 & 6,467 & 0,105 & 0,128 & $-0,128$ & 0,915 \\
\hline hsa-miR-515-3p & 6,775 & 0,115 & 6,647 & 0,074 & 0,128 & $-0,128$ & 0,915 \\
\hline mmu-miR-409-5p & 6,735 & 0,028 & 6,606 & 0,020 & 0,129 & $-0,129$ & 0,914 \\
\hline mmu-miR-712* & 6,812 & 0,036 & 6,682 & 0,005 & 0,130 & $-0,130$ & 0,914 \\
\hline hsa-miR-597 & 6,779 & 0,163 & 6,648 & 0,050 & 0,131 & $-0,131$ & 0,913 \\
\hline hsa_negative_control_8 & 6,668 & 0,023 & 6,537 & 0,021 & 0,131 & $-0,131$ & 0,913 \\
\hline hsa-miR-520b/520c-3p & 6,744 & 0,023 & 6,612 & 0,018 & 0,132 & $-0,132$ & 0,913 \\
\hline mmu-miR-377 & 6,705 & 0,047 & 6,573 & 0,019 & 0,132 & $-0,132$ & 0,913 \\
\hline hsa-miR-613 & 6,758 & 0,122 & 6,626 & 0,038 & 0,132 & $-0,132$ & 0,912 \\
\hline mmu-miR-28 & 6,935 & 0,136 & 6,801 & 0,233 & 0,134 & $-0,134$ & 0,911 \\
\hline mmu-miR-378* & 6,762 & 0,021 & 6,628 & 0,035 & 0,134 & $-0,134$ & 0,911 \\
\hline hsa-miR-565 & 6,935 & 0,017 & 6,801 & 0,019 & 0,135 & $-0,135$ & 0,911 \\
\hline hsa-miR-182* & 6,669 & 0,040 & 6,532 & 0,020 & 0,136 & $-0,136$ & 0,910 \\
\hline hsa-miR-555 & 6,631 & 0,084 & 6,494 & 0,044 & 0,136 & $-0,136$ & 0,910 \\
\hline miRPlus_17860 & 6,749 & 0,088 & 6,612 & 0,107 & 0,137 & $-0,137$ & 0,909 \\
\hline mmu-miR-99a & 6,849 & 0,033 & 6,711 & 0,019 & 0,138 & $-0,138$ & 0,909 \\
\hline miRPlus_17899 & 6,861 & 0,054 & 6,718 & 0,016 & 0,143 & $-0,143$ & 0,905 \\
\hline mmu-miR-33 & 7,026 & 0,063 & 6,883 & 0,371 & 0,143 & $-0,143$ & 0,905 \\
\hline mmu-miR-687 & 6,702 & 0,047 & 6,559 & 0,021 & 0,143 & $-0,143$ & 0,905 \\
\hline mmu-miR-501-5p & 6,809 & 0,033 & 6,665 & 0,058 & 0,144 & $-0,144$ & 0,905 \\
\hline rno-miR-369-3p & 6,708 & 0,031 & 6,564 & 0,029 & 0,144 & $-0,144$ & 0,905 \\
\hline mmu-miR-674 & 6,828 & 0,038 & 6,684 & 0,106 & 0,144 & $-0,144$ & 0,905 \\
\hline mmu-let-7g & 6,843 & 0,019 & 6,699 & 0,014 & 0,144 & $-0,144$ & 0,905 \\
\hline mmu-miR-710 & 7,236 & 0,069 & 7,091 & 0,040 & 0,145 & $-0,145$ & 0,905 \\
\hline hsa-miR-519c-5p_MM1 & 6,855 & 0,034 & 6,710 & 0,020 & 0,145 & $-0,145$ & 0,904 \\
\hline hsa-miR-346 & 6,875 & 0,027 & 6,728 & 0,027 & 0,147 & $-0,147$ & 0,903 \\
\hline rno-miR-337 & 6,996 & 0,197 & 6,849 & 0,316 & 0,148 & $-0,148$ & 0,903 \\
\hline
\end{tabular}




\begin{tabular}{|c|c|c|c|c|c|c|c|}
\hline mmu-miR-346 & 6,862 & 0,253 & 6,714 & 0,224 & 0,148 & $-0,148$ & 0,903 \\
\hline hsa-miR-769-3p & 6,955 & 0,060 & 6,807 & 0,093 & 0,148 & $-0,148$ & 0,903 \\
\hline hsa-miR-524-3p & 6,770 & 0,032 & 6,621 & 0,012 & 0,149 & $-0,149$ & 0,902 \\
\hline mmu-miR-671-5p & 6,814 & 0,063 & 6,664 & 0,055 & 0,150 & $-0,150$ & 0,901 \\
\hline hsa-miR-569 & 6,770 & 0,032 & 6,619 & 0,019 & 0,151 & $-0,151$ & 0,900 \\
\hline mmu-miR-434-3p & 6,815 & 0,052 & 6,661 & 0,133 & 0,154 & $-0,154$ & 0,899 \\
\hline mmu-miR-200c & 6,788 & 0,025 & 6,633 & 0,012 & 0,155 & $-0,155$ & 0,898 \\
\hline hsa-miR-302c & 6,759 & 0,023 & 6,604 & 0,037 & 0,155 & $-0,155$ & 0,898 \\
\hline mmu-miR-223 & 6,921 & 0,042 & 6,765 & 0,044 & 0,156 & $-0,156$ & 0,898 \\
\hline rno-miR-369-5p & 6,632 & 0,286 & 6,476 & 0,065 & 0,156 & $-0,156$ & 0,897 \\
\hline mmu-miR-34a & 6,809 & 0,102 & 6,653 & 0,041 & 0,156 & $-0,156$ & 0,897 \\
\hline hsa-miR-369-5p & 6,800 & 0,035 & 6,644 & 0,076 & 0,156 & $-0,156$ & 0,897 \\
\hline hsa-miR-518a-3p & 6,783 & 0,026 & 6,624 & 0,036 & 0,159 & $-0,159$ & 0,895 \\
\hline mmu-miR-669c & 6,908 & 0,061 & 6,749 & 0,015 & 0,159 & $-0,159$ & 0,895 \\
\hline mmu-miR-695 & 7,075 & 0,295 & 6,915 & 0,483 & 0,160 & $-0,160$ & 0,895 \\
\hline mmu-miR-193b & 6,855 & 0,031 & 6,693 & 0,041 & 0,162 & $-0,162$ & 0,894 \\
\hline hsa-miR-636 & 6,798 & 0,018 & 6,636 & 0,036 & 0,162 & $-0,162$ & 0,894 \\
\hline mmu-miR-759 & 6,737 & 0,033 & 6,573 & 0,008 & 0,164 & $-0,164$ & 0,892 \\
\hline mmu-miR-532-5p & 7,169 & 0,036 & 7,003 & 0,033 & 0,166 & $-0,166$ & 0,891 \\
\hline mmu-miR-145* & 6,684 & 0,040 & 6,518 & 0,027 & 0,166 & $-0,166$ & 0,891 \\
\hline mmu-miR-298 & 6,723 & 0,062 & 6,557 & 0,045 & 0,166 & $-0,166$ & 0,891 \\
\hline rno-miR-20a* & 6,774 & 0,034 & 6,607 & 0,017 & 0,167 & $-0,167$ & 0,891 \\
\hline hsa-miR-34b* & 6,778 & 0,056 & 6,610 & 0,153 & 0,167 & $-0,167$ & 0,890 \\
\hline mmu-miR-149 & 6,808 & 0,051 & 6,638 & 0,011 & 0,170 & $-0,170$ & 0,889 \\
\hline rno-miR-142-5p & 6,752 & 0,026 & 6,582 & 0,041 & 0,171 & $-0,171$ & 0,888 \\
\hline mmu-miR-678 & 6,840 & 0,023 & 6,669 & 0,036 & 0,171 & $-0,171$ & 0,888 \\
\hline hsa-miR-512-3p & 6,768 & 0,033 & 6,596 & 0,009 & 0,173 & $-0,173$ & 0,887 \\
\hline mmu-miR-487b & 7,235 & 0,049 & 7,062 & 0,082 & 0,173 & $-0,173$ & 0,887 \\
\hline miRPlus_28535 & 6,933 & 0,054 & 6,759 & 0,023 & 0,173 & $-0,173$ & 0,887 \\
\hline mmu-miR-433 & 6,790 & 0,039 & 6,617 & 0,053 & 0,174 & $-0,174$ & 0,887 \\
\hline hsa-miR-660 & 7,033 & 0,053 & 6,859 & 0,087 & 0,174 & $-0,174$ & 0,886 \\
\hline miRPlus_32902 & 6,880 & 0,030 & 6,705 & 0,057 & 0,174 & $-0,174$ & 0,886 \\
\hline mmu-miR-34c & 6,901 & 0,057 & 6,725 & 0,029 & 0,176 & $-0,176$ & 0,885 \\
\hline No known hsa target & 7,212 & 0,022 & 7,036 & 0,038 & 0,176 & $-0,176$ & 0,885 \\
\hline hsa-miR-506 & 6,773 & 0,260 & 6,596 & 0,095 & 0,177 & $-0,177$ & 0,885 \\
\hline mmu-miR-669a & 6,848 & 0,357 & 6,670 & 0,099 & 0,178 & $-0,178$ & 0,884 \\
\hline hsa-miR-542-5p & 6,808 & 0,260 & 6,629 & 0,047 & 0,178 & $-0,178$ & 0,884 \\
\hline hsa-miR-519e & 7,031 & 0,033 & 6,853 & 0,016 & 0,179 & $-0,179$ & 0,883 \\
\hline rno-miR-291a-5p & 6,888 & 0,039 & 6,709 & 0,021 & 0,180 & $-0,180$ & 0,883 \\
\hline hsa-miR-558 & 6,792 & 0,093 & 6,612 & 0,032 & 0,181 & $-0,181$ & 0,882 \\
\hline mmu-miR-686 & 6,736 & 0,344 & 6,555 & 0,058 & 0,181 & $-0,181$ & 0,882 \\
\hline mmu-miR-693-3p & 6,814 & 0,036 & 6,633 & 0,025 & 0,181 & $-0,181$ & 0,882 \\
\hline mmu-miR-34c & 6,836 & 0,081 & 6,655 & 0,027 & 0,181 & $-0,181$ & 0,882 \\
\hline hsa-miR-518d-3p & 6,753 & 0,302 & 6,570 & 0,065 & 0,183 & $-0,183$ & 0,881 \\
\hline mmu-miR-200a & 6,833 & 0,052 & 6,650 & 0,021 & 0,183 & $-0,183$ & 0,881 \\
\hline mmu-miR-33* & 6,824 & 0,093 & 6,640 & 0,013 & 0,183 & $-0,183$ & 0,881 \\
\hline mmu-miR-376a* & 6,886 & 0,145 & 6,702 & 0,206 & 0,183 & $-0,183$ & 0,881 \\
\hline mmu-miR-877 & 7,412 & 0,062 & 7,228 & 0,054 & 0,183 & $-0,183$ & 0,881 \\
\hline mmu-miR-467b & 6,804 & 0,013 & 6,618 & 0,010 & 0,186 & $-0,186$ & 0,879 \\
\hline mmu-miR-188-5p & 7,049 & 0,146 & 6,863 & 0,431 & 0,186 & $-0,186$ & 0,879 \\
\hline mmu-miR-411 & 6,773 & 0,037 & 6,586 & 0,037 & 0,187 & $-0,187$ & 0,879 \\
\hline hsa-miR-329 & 6,816 & 0,027 & 6,626 & 0,020 & 0,191 & $-0,191$ & 0,876 \\
\hline hsa-miR-339-3p & 6,767 & 0,056 & 6,576 & 0,050 & 0,191 & $-0,191$ & 0,876 \\
\hline hsa-miR-560 & 6,730 & 0,028 & 6,539 & 0,048 & 0,191 & $-0,191$ & 0,876 \\
\hline hsa-miR-429 & 6,817 & 0,019 & 6,624 & 0,046 & 0,193 & $-0,193$ & 0,875 \\
\hline mmu-miR-350 & 6,776 & 0,020 & 6,583 & 0,020 & 0,194 & $-0,194$ & 0,874 \\
\hline mmu-miR-369-3p & 7,013 & 0,504 & 6,817 & 0,302 & 0,195 & $-0,195$ & 0,873 \\
\hline
\end{tabular}




\begin{tabular}{|c|c|c|c|c|c|c|c|}
\hline mmu-miR-92a & 6,995 & 0,078 & 6,800 & 0,046 & 0,196 & $-0,196$ & 0,873 \\
\hline hsa-miR-220 & 6,809 & 0,022 & 6,613 & 0,026 & 0,196 & $-0,196$ & 0,873 \\
\hline hsa-miR-631 & 6,690 & 0,070 & 6,494 & 0,045 & 0,196 & $-0,196$ & 0,873 \\
\hline hsa-miR-587 & 6,695 & 0,028 & 6,497 & 0,058 & 0,198 & $-0,198$ & 0,872 \\
\hline hsa-miR-767-3p & 6,740 & 0,120 & 6,541 & 0,049 & 0,199 & $-0,199$ & 0,871 \\
\hline mmu-miR-451 & 6,713 & 0,042 & 6,513 & 0,120 & 0,200 & $-0,200$ & 0,870 \\
\hline mmu-miR-681 & 6,845 & 0,078 & 6,645 & 0,025 & 0,200 & $-0,200$ & 0,870 \\
\hline mmu-miR-217 & 6,831 & 0,022 & 6,630 & 0,010 & 0,201 & $-0,201$ & 0,870 \\
\hline mmu-miR-331-3p & 6,878 & 0,036 & 6,676 & 0,015 & 0,202 & $-0,202$ & 0,869 \\
\hline hsa-miR-890 & 6,905 & 0,030 & 6,703 & 0,021 & 0,202 & $-0,202$ & 0,869 \\
\hline mmu-miR-140 & 7,122 & 0,018 & 6,918 & 0,024 & 0,204 & $-0,204$ & 0,868 \\
\hline hsa-miR-876-3p & 6,991 & 0,059 & 6,786 & 0,024 & 0,205 & $-0,205$ & 0,868 \\
\hline mmu-miR-425 & 7,162 & 0,067 & 6,956 & 0,056 & 0,206 & $-0,206$ & 0,867 \\
\hline hsa-miR-611 & 6,908 & 0,038 & 6,701 & 0,075 & 0,207 & $-0,207$ & 0,867 \\
\hline hsa-miR-891b & 6,814 & 0,043 & 6,606 & 0,033 & 0,208 & $-0,208$ & 0,866 \\
\hline hsa-miR-15a* & 6,722 & 0,055 & 6,512 & 0,026 & 0,209 & $-0,209$ & 0,865 \\
\hline mmu-miR-25 & 7,107 & 0,035 & 6,897 & 0,026 & 0,210 & $-0,210$ & 0,864 \\
\hline hsa-miR-143* & 6,834 & 0,056 & 6,623 & 0,039 & 0,211 & $-0,211$ & 0,864 \\
\hline mmu-miR-205 & 7,131 & 0,514 & 6,920 & 0,352 & 0,211 & $-0,211$ & 0,864 \\
\hline hsa-miR-770-5p & 6,815 & 0,059 & 6,603 & 0,019 & 0,212 & $-0,212$ & 0,863 \\
\hline mmu-miR-380-3p & 6,910 & 0,045 & 6,697 & 0,021 & 0,212 & $-0,212$ & 0,863 \\
\hline $\begin{array}{l}\text { mmu-miR-465a-3p/465b- } \\
3 p / 465 c-3 p\end{array}$ & 6,868 & 0,078 & 6,656 & 0,023 & 0,213 & $-0,213$ & 0,863 \\
\hline hsa-miR-605 & 6,859 & 0,032 & 6,646 & 0,042 & 0,213 & $-0,213$ & 0,863 \\
\hline hsa-miR-548c-3p & 6,843 & 0,044 & 6,630 & 0,022 & 0,213 & $-0,213$ & 0,863 \\
\hline hsa-miR-572 & 6,979 & 0,040 & 6,766 & 0,060 & 0,213 & $-0,213$ & 0,863 \\
\hline hsa-miR-766 & 6,996 & 0,061 & 6,782 & 0,028 & 0,214 & $-0,214$ & 0,862 \\
\hline miRPlus_17811 & 6,846 & 0,034 & 6,630 & 0,020 & 0,215 & $-0,215$ & 0,861 \\
\hline hsa-miR-644 & 6,803 & 0,075 & 6,587 & 0,014 & 0,216 & $-0,216$ & 0,861 \\
\hline mmu-miR-674* & 6,798 & 0,004 & 6,582 & 0,022 & 0,216 & $-0,216$ & 0,861 \\
\hline rno-miR-421 & 6,829 & 0,048 & 6,612 & 0,013 & 0,217 & $-0,217$ & 0,860 \\
\hline mmu-miR-721 & 6,859 & 0,061 & 6,642 & 0,014 & 0,217 & $-0,217$ & 0,860 \\
\hline rno-miR-450a & 6,949 & 0,315 & 6,732 & 0,041 & 0,217 & $-0,217$ & 0,860 \\
\hline mmu-miR-192 & 6,855 & 0,043 & 6,638 & 0,031 & 0,218 & $-0,218$ & 0,860 \\
\hline rno-miR-505 & 6,863 & 0,021 & 6,644 & 0,025 & 0,220 & $-0,220$ & 0,859 \\
\hline miRPlus_32900 & 6,939 & 0,621 & 6,719 & 0,104 & 0,220 & $-0,220$ & 0,859 \\
\hline hsa-miR-18b* & 6,866 & 0,026 & 6,645 & 0,033 & 0,221 & $-0,221$ & 0,858 \\
\hline miRPlus_17891 & 7,015 & 0,145 & 6,792 & 0,047 & 0,224 & $-0,224$ & 0,856 \\
\hline rno-miR-148b-5p & 6,858 & 0,059 & 6,634 & 0,020 & 0,224 & $-0,224$ & 0,856 \\
\hline$m m u-m i R-450 b-5 p$ & 6,747 & 0,282 & 6,522 & 0,053 & 0,225 & $-0,225$ & 0,856 \\
\hline hsa-miR-551a & 7,115 & 0,070 & 6,890 & 0,034 & 0,225 & $-0,225$ & 0,856 \\
\hline mmu-miR-133a & 6,834 & 0,149 & 6,609 & 0,010 & 0,225 & $-0,225$ & 0,856 \\
\hline hsa-miR-643 & 6,845 & 0,060 & 6,619 & 0,046 & 0,226 & $-0,226$ & 0,855 \\
\hline miRPlus_27869 & 6,943 & 0,059 & 6,716 & 0,020 & 0,227 & $-0,227$ & 0,855 \\
\hline mmu-miR-218 & 7,133 & 0,043 & 6,901 & 0,033 & 0,232 & $-0,232$ & 0,851 \\
\hline mmu-miR-705 & 6,977 & 0,211 & 6,744 & 0,066 & 0,233 & $-0,233$ & 0,851 \\
\hline hsa-miR-488* & 6,846 & 0,045 & 6,613 & 0,156 & 0,233 & $-0,233$ & 0,851 \\
\hline mmu-miR-335-5p & 6,855 & 0,115 & 6,621 & 0,004 & 0,234 & $-0,234$ & 0,850 \\
\hline hsa-miR-502-5p & 6,967 & 0,049 & 6,734 & 0,038 & 0,234 & $-0,234$ & 0,850 \\
\hline No known hsa target & 6,835 & 0,043 & 6,599 & 0,025 & 0,236 & $-0,236$ & 0,849 \\
\hline mmu-miR-582-5p & 6,906 & 0,084 & 6,668 & 0,059 & 0,237 & $-0,237$ & 0,848 \\
\hline mmu-miR-504 & 6,832 & 0,022 & 6,594 & 0,034 & 0,238 & $-0,238$ & 0,848 \\
\hline miRPlus_17819 & 6,810 & 0,084 & 6,571 & 0,044 & 0,239 & $-0,239$ & 0,847 \\
\hline hsa-miR-595 & 7,283 & 0,088 & 7,043 & 0,877 & 0,239 & $-0,239$ & 0,847 \\
\hline mmu-miR-470 & 6,927 & 0,041 & 6,688 & 0,042 & 0,239 & $-0,239$ & 0,847 \\
\hline miRPlus_27839 & 7,026 & 0,016 & 6,786 & 0,047 & 0,240 & $-0,240$ & 0,847 \\
\hline mmu-miR-680 & 6,867 & 0,051 & 6,627 & 0,029 & 0,240 & $-0,240$ & 0,847 \\
\hline
\end{tabular}




\begin{tabular}{|c|c|c|c|c|c|c|c|}
\hline hsa-miR-655 & 6,735 & 0,037 & 6,490 & 0,027 & 0,244 & $-0,244$ & 0,844 \\
\hline mmu-miR-29b* & 6,927 & 0,021 & 6,682 & 0,039 & 0,246 & $-0,246$ & 0,843 \\
\hline hsa-miR-646 & 6,876 & 0,061 & 6,628 & 0,014 & 0,248 & $-0,248$ & 0,842 \\
\hline hsa-miR-100* & 6,899 & 0,041 & 6,651 & 0,023 & 0,248 & $-0,248$ & 0,842 \\
\hline hsa-miR-34a* & 6,764 & 0,081 & 6,516 & 0,067 & 0,248 & $-0,248$ & 0,842 \\
\hline mmu-miR-150 & 7,063 & 0,078 & 6,814 & 0,032 & 0,248 & $-0,248$ & 0,842 \\
\hline mmu-miR-329 & 7,055 & 0,037 & 6,806 & 0,021 & 0,249 & $-0,249$ & 0,842 \\
\hline hsa-miR-650 & 6,873 & 0,131 & 6,623 & 0,045 & 0,250 & $-0,250$ & 0,841 \\
\hline mmu-miR-293 & 6,858 & 0,041 & 6,606 & 0,013 & 0,252 & $-0,252$ & 0,840 \\
\hline miRPlus_17926 & 6,788 & 0,024 & 6,536 & 0,050 & 0,252 & $-0,252$ & 0,839 \\
\hline mmu-miR-374* & 6,884 & 0,100 & 6,629 & 0,027 & 0,255 & $-0,255$ & 0,838 \\
\hline mmu-miR-96 & 7,302 & 0,165 & 7,047 & 0,081 & 0,255 & $-0,255$ & 0,838 \\
\hline mmu-miR-216a & 6,815 & 0,090 & 6,560 & 0,023 & 0,255 & $-0,255$ & 0,838 \\
\hline mmu-miR-345-5p & 6,912 & 0,240 & 6,656 & 0,052 & 0,256 & $-0,256$ & 0,837 \\
\hline hsa_negative_control_1 & 6,890 & 0,025 & 6,634 & 0,031 & 0,256 & $-0,256$ & 0,837 \\
\hline hsa-miR-372 & 6,832 & 0,106 & 6,576 & 0,044 & 0,256 & $-0,256$ & 0,837 \\
\hline miRPlus_17925 & 6,874 & 0,046 & 6,616 & 0,011 & 0,258 & $-0,258$ & 0,836 \\
\hline hsa-miR-553 & 6,959 & 0,069 & 6,701 & 0,029 & 0,258 & $-0,258$ & 0,836 \\
\hline mmu-miR-148a & 6,773 & 0,060 & 6,515 & 0,040 & 0,258 & $-0,258$ & 0,836 \\
\hline mmu-miR-758 & 6,894 & 0,037 & 6,635 & 0,002 & 0,259 & $-0,259$ & 0,836 \\
\hline hsa-let-7f-2* & 6,824 & 0,344 & 6,565 & 0,124 & 0,259 & $-0,259$ & 0,835 \\
\hline hsa-miR-563 & 6,830 & 0,056 & 6,570 & 0,039 & 0,260 & $-0,260$ & 0,835 \\
\hline rno-miR-333 & 6,886 & 0,025 & 6,625 & 0,016 & 0,261 & $-0,261$ & 0,835 \\
\hline mmu-miR-124 & 6,925 & 0,250 & 6,663 & 0,057 & 0,262 & $-0,262$ & 0,834 \\
\hline hsa-miR-629 & 6,982 & 0,037 & 6,718 & 0,018 & 0,264 & $-0,264$ & 0,833 \\
\hline hsa-miR-30d* & 6,890 & 0,065 & 6,625 & 0,030 & 0,265 & $-0,265$ & 0,832 \\
\hline mmu-miR-712 & 6,979 & 0,097 & 6,713 & 0,014 & 0,265 & $-0,265$ & 0,832 \\
\hline hsa-miR-518c & 6,855 & 0,299 & 6,590 & 0,034 & 0,266 & $-0,266$ & 0,832 \\
\hline hsa-miR-520a-3p & 6,829 & 0,032 & 6,561 & 0,028 & 0,268 & $-0,268$ & 0,831 \\
\hline mmu-miR-199b* & 7,126 & 0,035 & 6,858 & 0,034 & 0,268 & $-0,268$ & 0,830 \\
\hline hsa-miR-374a & 6,977 & 0,058 & 6,709 & 0,031 & 0,269 & $-0,269$ & 0,830 \\
\hline mmu-miR-497 & 6,928 & 0,048 & 6,659 & 0,041 & 0,269 & $-0,269$ & 0,830 \\
\hline miRPlus_17827 & 7,055 & 0,035 & 6,785 & 0,007 & 0,270 & $-0,270$ & 0,830 \\
\hline mmu-miR-652 & 6,829 & 0,047 & 6,559 & 0,021 & 0,270 & $-0,270$ & 0,829 \\
\hline hsa_negative_control_6 & 6,933 & 0,095 & 6,662 & 0,027 & 0,271 & $-0,271$ & 0,829 \\
\hline mmu-miR-325* & 6,869 & 0,310 & 6,599 & 0,037 & 0,271 & $-0,271$ & 0,829 \\
\hline hsa-miR-520a-5p & 6,905 & 0,017 & 6,633 & 0,052 & 0,272 & $-0,272$ & 0,828 \\
\hline miRPlus_17957 & 6,877 & 0,290 & 6,604 & 0,058 & 0,273 & $-0,273$ & 0,827 \\
\hline hsa-miR-505 & 7,212 & 0,042 & 6,938 & 0,043 & 0,274 & $-0,274$ & 0,827 \\
\hline hsa-miR-380 & 6,829 & 0,068 & 6,554 & 0,053 & 0,275 & $-0,275$ & 0,826 \\
\hline hsa-miR-586 & 6,898 & 0,037 & 6,622 & 0,016 & 0,276 & $-0,276$ & 0,826 \\
\hline hsa-miR-601 & 7,001 & 0,028 & 6,722 & 0,034 & 0,278 & $-0,278$ & 0,825 \\
\hline mmu-miR-7a* & 6,878 & 0,122 & 6,599 & 0,043 & 0,279 & $-0,279$ & 0,824 \\
\hline mmu-miR-126-5p & 6,922 & 0,036 & 6,642 & 0,051 & 0,280 & $-0,280$ & 0,824 \\
\hline mmu-miR-216b & 6,916 & 0,035 & 6,635 & 0,038 & 0,281 & $-0,281$ & 0,823 \\
\hline mmu-miR-707 & 6,858 & 0,025 & 6,577 & 0,018 & 0,281 & $-0,281$ & 0,823 \\
\hline hsa-miR-301b & 7,305 & 0,065 & 7,023 & 0,046 & 0,283 & $-0,283$ & 0,822 \\
\hline mmu-miR-764-3p & 6,932 & 0,046 & 6,649 & 0,040 & 0,283 & $-0,283$ & 0,822 \\
\hline mmu-miR-130b* & 6,843 & 0,100 & 6,560 & 0,045 & 0,283 & $-0,283$ & 0,822 \\
\hline hsa-miR-633 & 6,934 & 0,062 & 6,651 & 0,031 & 0,283 & $-0,283$ & 0,822 \\
\hline hsa-miR-598 & 7,134 & 0,118 & 6,850 & 0,359 & 0,285 & $-0,285$ & 0,821 \\
\hline mmu-miR-615-3p & 7,083 & 0,036 & 6,798 & 0,024 & 0,285 & $-0,285$ & 0,821 \\
\hline rno-miR-344-3p & 6,913 & 0,051 & 6,627 & 0,034 & 0,287 & $-0,287$ & 0,820 \\
\hline hsa-miR-523 & 6,915 & 0,053 & 6,628 & 0,024 & 0,287 & $-0,287$ & 0,820 \\
\hline mmu-miR-698 & 7,361 & 0,043 & 7,073 & 0,651 & 0,287 & $-0,287$ & 0,819 \\
\hline mmu-miR-200b & 6,873 & 0,069 & 6,584 & 0,013 & 0,290 & $-0,290$ & 0,818 \\
\hline mmu-miR-682 & 6,789 & 0,017 & 6,498 & 0,042 & 0,291 & $-0,291$ & 0,818 \\
\hline
\end{tabular}




\begin{tabular}{|c|c|c|c|c|c|c|c|}
\hline mmu-miR-382 & 6,971 & 0,040 & 6,680 & 0,016 & 0,291 & $-0,291$ & 0,817 \\
\hline hsa-miR-642 & 7,490 & 0,357 & 7,199 & 0,106 & 0,291 & $-0,291$ & 0,817 \\
\hline hsa-miR-548d-3p & 6,974 & 0,071 & 6,683 & 0,025 & 0,292 & $-0,292$ & 0,817 \\
\hline hsa-miR-588 & 6,877 & 0,031 & 6,584 & 0,016 & 0,292 & $-0,292$ & 0,817 \\
\hline hsa-miR-634 & 7,122 & 0,067 & 6,828 & 0,178 & 0,294 & $-0,294$ & 0,815 \\
\hline mmu-miR-18a* & 6,931 & 0,051 & 6,635 & 0,013 & 0,296 & $-0,296$ & 0,814 \\
\hline mmu-let-7g* & 6,908 & 0,014 & 6,612 & 0,011 & 0,296 & $-0,296$ & 0,814 \\
\hline hsa-miR-28-3p & 6,842 & 0,059 & 6,546 & 0,026 & 0,297 & $-0,297$ & 0,814 \\
\hline mmu-miR-30 $e^{*}$ & 7,223 & 0,034 & 6,925 & 0,025 & 0,298 & $-0,298$ & 0,813 \\
\hline mmu-miR-200b* & 7,041 & 0,051 & 6,741 & 0,037 & 0,300 & $-0,300$ & 0,812 \\
\hline hsa-miR-581 & 6,948 & 0,050 & 6,647 & 0,049 & 0,301 & $-0,301$ & 0,812 \\
\hline$m m u-m i R-128 a / 128 b$ & 7,196 & 0,073 & 6,895 & 0,028 & 0,301 & $-0,301$ & 0,812 \\
\hline hsa-miR-363* & 6,915 & 0,040 & 6,614 & 0,008 & 0,301 & $-0,301$ & 0,812 \\
\hline hsa-miR-651 & 6,799 & 0,405 & 6,496 & 0,081 & 0,303 & $-0,303$ & 0,811 \\
\hline miRPlus_17897 & 7,026 & 0,039 & 6,719 & 0,027 & 0,307 & $-0,307$ & 0,808 \\
\hline mmu-miR-200a* & 6,951 & 0,048 & 6,644 & 0,139 & 0,307 & $-0,307$ & 0,808 \\
\hline mmu-miR-590-3p & 6,889 & 0,019 & 6,582 & 0,046 & 0,307 & $-0,307$ & 0,808 \\
\hline hsa-miR-612 & 6,929 & 0,195 & 6,621 & 0,053 & 0,308 & $-0,308$ & 0,808 \\
\hline mmu-miR-106b* & 6,994 & 0,151 & 6,685 & 0,029 & 0,309 & $-0,309$ & 0,807 \\
\hline mmu-miR-367 & 6,965 & 0,032 & 6,654 & 0,056 & 0,311 & $-0,311$ & 0,806 \\
\hline hsa-miR-632 & 6,895 & 0,138 & 6,582 & 0,037 & 0,313 & $-0,313$ & 0,805 \\
\hline rno-miR-292-5p & 6,960 & 0,087 & 6,646 & 0,016 & 0,314 & $-0,314$ & 0,804 \\
\hline hsa-miR-511 & 6,937 & 0,249 & 6,623 & 0,043 & 0,315 & $-0,315$ & 0,804 \\
\hline hsa-miR-454 & 6,921 & 0,039 & 6,606 & 0,011 & 0,315 & $-0,315$ & 0,804 \\
\hline mmu-miR-872 & 6,848 & 0,063 & 6,533 & 0,048 & 0,316 & $-0,316$ & 0,804 \\
\hline mmu-miR-339-5p & 6,983 & 0,037 & 6,664 & 0,012 & 0,318 & $-0,318$ & 0,802 \\
\hline mmu-miR-133b & 6,957 & 0,207 & 6,638 & 0,063 & 0,318 & $-0,318$ & 0,802 \\
\hline mmu-miR-93* & 6,986 & 0,060 & 6,668 & 0,017 & 0,319 & $-0,319$ & 0,802 \\
\hline hsa-miR-504 & 6,922 & 0,251 & 6,603 & 0,066 & 0,319 & $-0,319$ & 0,802 \\
\hline hsa-miR-362-5p & 7,060 & 0,056 & 6,740 & 0,037 & 0,320 & $-0,320$ & 0,801 \\
\hline $\begin{array}{l}\text { hsa-miR-518d- } \\
5 p / 518 f^{\star} / 520 c-5 p / 526 a\end{array}$ & 7,154 & 0,032 & 6,834 & 0,010 & 0,320 & $-0,320$ & 0,801 \\
\hline mmu-miR-434-5p & 6,870 & 0,071 & 6,549 & 0,027 & 0,321 & $-0,321$ & 0,801 \\
\hline hsa-miR-626 & 6,945 & 0,045 & 6,623 & 0,029 & 0,321 & $-0,321$ & 0,800 \\
\hline mmu-miR-702 & 7,052 & 0,311 & 6,731 & 0,133 & 0,322 & $-0,322$ & 0,800 \\
\hline mmu-miR-328 & 6,866 & 0,100 & 6,544 & 0,047 & 0,322 & $-0,322$ & 0,800 \\
\hline miRPlus_29878 & 7,050 & 0,036 & 6,723 & 0,034 & 0,327 & $-0,327$ & 0,797 \\
\hline mmu-miR-351 & 7,418 & 0,032 & 7,091 & 0,048 & 0,328 & $-0,328$ & 0,797 \\
\hline mmu-miR-344 & 6,895 & 0,054 & 6,568 & 0,021 & 0,328 & $-0,328$ & 0,797 \\
\hline rno-miR-1* & 6,908 & 0,240 & 6,580 & 0,077 & 0,329 & $-0,329$ & 0,796 \\
\hline mmu-miR-302b* & 6,912 & 0,014 & 6,583 & 0,016 & 0,329 & $-0,329$ & 0,796 \\
\hline mmu-miR-654-3p & 6,925 & 0,045 & 6,596 & 0,010 & 0,329 & $-0,329$ & 0,796 \\
\hline mmu-miR-297b-5p & 6,954 & 0,073 & 6,624 & 0,018 & 0,329 & $-0,329$ & 0,796 \\
\hline hsa-miR-509-3p & 6,982 & 0,042 & 6,653 & 0,025 & 0,330 & $-0,330$ & 0,796 \\
\hline mmu-miR-27a* & 6,971 & 0,056 & 6,639 & 0,030 & 0,332 & $-0,332$ & 0,794 \\
\hline mmu-miR-499 & 6,869 & 0,300 & 6,536 & 0,096 & 0,333 & $-0,333$ & 0,794 \\
\hline mmu-miR-485* & 6,973 & 0,037 & 6,640 & 0,020 & 0,334 & $-0,334$ & 0,794 \\
\hline hsa-miR-516a-3p/516b* & 6,928 & 0,119 & 6,594 & 0,016 & 0,334 & $-0,334$ & 0,793 \\
\hline hsa-miR-888 & 6,886 & 0,043 & 6,552 & 0,021 & 0,334 & $-0,334$ & 0,793 \\
\hline hsa-miR-886-3p & 6,993 & 0,042 & 6,658 & 0,021 & 0,335 & $-0,335$ & 0,793 \\
\hline hsa-miR-514 & 6,937 & 0,071 & 6,601 & 0,053 & 0,336 & $-0,336$ & 0,792 \\
\hline mmu-miR-692 & 6,956 & 0,024 & 6,619 & 0,030 & 0,338 & $-0,338$ & 0,791 \\
\hline hsa-miR-508-3p & 6,962 & 0,061 & 6,624 & 0,039 & 0,338 & $-0,338$ & 0,791 \\
\hline mmu-miR-181a-1* & 7,092 & 0,064 & 6,754 & 0,058 & 0,339 & $-0,339$ & 0,791 \\
\hline hsa-miR-493* & 7,011 & 0,079 & 6,672 & 0,017 & 0,339 & $-0,339$ & 0,791 \\
\hline rno-miR-10a-3p & 6,990 & 0,207 & 6,650 & 0,041 & 0,339 & $-0,339$ & 0,790 \\
\hline hsa-miR-491-3p & 7,504 & 0,086 & 7,162 & 0,069 & 0,341 & $-0,341$ & 0,789 \\
\hline
\end{tabular}




\begin{tabular}{|c|c|c|c|c|c|c|c|}
\hline mmu-miR-669b & 6,974 & 0,014 & 6,632 & 0,046 & 0,342 & $-0,342$ & 0,789 \\
\hline mmu-miR-708* & 6,910 & 0,370 & 6,566 & 0,077 & 0,344 & $-0,344$ & 0,788 \\
\hline hsa-miR-561 & 6,986 & 0,066 & 6,641 & 0,021 & 0,346 & $-0,346$ & 0,787 \\
\hline hsa-miR-383 & 6,883 & 0,042 & 6,536 & 0,042 & 0,347 & $-0,347$ & 0,786 \\
\hline miRPlus_17812 & 7,062 & 0,089 & 6,714 & 0,023 & 0,348 & $-0,348$ & 0,786 \\
\hline hsa-miR-608 & 6,952 & 0,299 & 6,604 & 0,046 & 0,348 & $-0,348$ & 0,785 \\
\hline hsa-miR-510 & 7,011 & 0,572 & 6,661 & 0,093 & 0,349 & $-0,349$ & 0,785 \\
\hline mmu-miR-450b-3p & 6,944 & 0,007 & 6,591 & 0,109 & 0,353 & $-0,353$ & 0,783 \\
\hline hsa-miR-132* & 7,021 & 0,034 & 6,667 & 0,017 & 0,354 & $-0,354$ & 0,782 \\
\hline mmu-miR-484 & 7,262 & 0,030 & 6,907 & 0,021 & 0,355 & $-0,355$ & 0,782 \\
\hline mmu-miR-101a* & 6,882 & 0,053 & 6,526 & 0,068 & 0,356 & $-0,356$ & 0,781 \\
\hline No known hsa target & 6,872 & 0,139 & 6,516 & 0,055 & 0,356 & $-0,356$ & 0,781 \\
\hline mmu-miR-299* & 7,059 & 0,031 & 6,702 & 0,011 & 0,357 & $-0,357$ & 0,781 \\
\hline miRPlus_17937 & 7,034 & 0,057 & 6,677 & 0,013 & 0,357 & $-0,357$ & 0,781 \\
\hline mmu-miR-201 & 6,953 & 0,080 & 6,596 & 0,015 & 0,358 & $-0,358$ & 0,780 \\
\hline miRPlus_17920 & 6,986 & 0,033 & 6,627 & 0,010 & 0,359 & $-0,359$ & 0,780 \\
\hline rno-miR-349 & 6,944 & 0,076 & 6,584 & 0,085 & 0,360 & $-0,360$ & 0,779 \\
\hline mmu-miR-676 & 7,010 & 0,004 & 6,650 & 0,025 & 0,360 & $-0,360$ & 0,779 \\
\hline mmu-miR-335-3p & 7,010 & 0,031 & 6,647 & 0,030 & 0,363 & $-0,363$ & 0,777 \\
\hline miRPlus_17828 & 7,271 & 0,061 & 6,905 & 0,040 & 0,366 & $-0,366$ & 0,776 \\
\hline hsa-miR-639 & 6,891 & 0,273 & 6,525 & 0,071 & 0,366 & $-0,366$ & 0,776 \\
\hline mmu-miR-485 & 6,858 & 0,112 & 6,490 & 0,091 & 0,368 & $-0,368$ & 0,775 \\
\hline miRPlus_28350 & 6,968 & 0,047 & 6,599 & 0,012 & 0,369 & $-0,369$ & 0,774 \\
\hline rno-miR-291a-3p & 6,966 & 0,100 & 6,596 & 0,020 & 0,369 & $-0,369$ & 0,774 \\
\hline hsa-miR-33b & 7,018 & 0,174 & 6,649 & 0,009 & 0,369 & $-0,369$ & 0,774 \\
\hline hsa-miR-520e & 7,017 & 0,053 & 6,648 & 0,031 & 0,369 & $-0,369$ & 0,774 \\
\hline mmu-miR-542-3p & 7,054 & 0,099 & 6,683 & 0,025 & 0,371 & $-0,371$ & 0,773 \\
\hline hsa-miR-517c & 6,941 & 0,057 & 6,569 & 0,017 & 0,372 & $-0,372$ & 0,773 \\
\hline hsa-miR-524-5p & 7,044 & 0,073 & 6,672 & 0,036 & 0,372 & $-0,372$ & 0,773 \\
\hline rno-miR-327 & 7,022 & 0,035 & 6,650 & 0,071 & 0,372 & $-0,372$ & 0,773 \\
\hline hsa-miR-627 & 6,994 & 0,090 & 6,622 & 0,036 & 0,372 & $-0,372$ & 0,773 \\
\hline hsa-miR-628-5p & 7,010 & 0,084 & 6,632 & 0,031 & 0,377 & $-0,377$ & 0,770 \\
\hline hsa-miR-512-5p & 7,141 & 0,022 & 6,763 & 0,037 & 0,377 & $-0,377$ & 0,770 \\
\hline hsa-miR-573 & 7,050 & 0,042 & 6,672 & 0,027 & 0,378 & $-0,378$ & 0,770 \\
\hline mmu-miR-145 & 6,978 & 0,061 & 6,599 & 0,036 & 0,379 & $-0,379$ & 0,769 \\
\hline mmu-miR-206 & 6,998 & 0,332 & 6,618 & 0,057 & 0,380 & $-0,380$ & 0,769 \\
\hline mmu-miR-292-3p & 6,928 & 0,061 & 6,547 & 0,042 & 0,381 & $-0,381$ & 0,768 \\
\hline hsa-miR-147 & 7,043 & 0,051 & 6,660 & 0,040 & 0,383 & $-0,383$ & 0,767 \\
\hline mmu-miR-214* & 6,976 & 0,097 & 6,593 & 0,047 & 0,383 & $-0,383$ & 0,767 \\
\hline mmu-miR-302b & 6,991 & 0,024 & 6,607 & 0,017 & 0,384 & $-0,384$ & 0,766 \\
\hline mmu-miR-433* & 7,272 & 0,051 & 6,887 & 0,013 & 0,385 & $-0,385$ & 0,766 \\
\hline rno-miR-224 & 7,075 & 0,018 & 6,689 & 0,020 & 0,386 & $-0,386$ & 0,765 \\
\hline mmu-miR-187 & 7,061 & 0,030 & 6,673 & 0,023 & 0,388 & $-0,388$ & 0,764 \\
\hline hsa-miR-517a/517b & 6,914 & 0,245 & 6,525 & 0,081 & 0,389 & $-0,389$ & 0,764 \\
\hline hsa-miR-648 & 7,146 & 0,561 & 6,756 & 0,319 & 0,391 & $-0,391$ & 0,763 \\
\hline mmu-miR-302a & 7,055 & 0,033 & 6,664 & 0,013 & 0,391 & $-0,391$ & 0,763 \\
\hline rno-miR-343 & 6,982 & 0,195 & 6,590 & 0,039 & 0,392 & $-0,392$ & 0,762 \\
\hline mmu-miR-22* & 7,140 & 0,030 & 6,746 & 0,022 & 0,393 & $-0,393$ & 0,761 \\
\hline hsa-miR-622 & 7,088 & 0,037 & 6,692 & 0,017 & 0,396 & $-0,396$ & 0,760 \\
\hline hsa_negative_control_4 & 6,976 & 0,034 & 6,580 & 0,029 & 0,396 & $-0,396$ & 0,760 \\
\hline hsa-miR-620 & 6,969 & 0,027 & 6,572 & 0,017 & 0,397 & $-0,397$ & 0,760 \\
\hline miRPlus_17838 & 6,944 & 0,040 & 6,547 & 0,046 & 0,397 & $-0,397$ & 0,759 \\
\hline hsa-miR-580 & 7,009 & 0,055 & 6,611 & 0,022 & 0,398 & $-0,398$ & 0,759 \\
\hline mmu-miR-200c* & 7,003 & 0,204 & 6,604 & 0,036 & 0,399 & $-0,399$ & 0,758 \\
\hline mmu-miR-449c & 7,024 & 0,073 & 6,625 & 0,027 & 0,400 & $-0,400$ & 0,758 \\
\hline mmu-miR-696 & 6,996 & 0,023 & 6,593 & 0,028 & 0,403 & $-0,403$ & 0,756 \\
\hline mmu-miR-125a-3p & 7,132 & 0,054 & 6,728 & 0,027 & 0,404 & $-0,404$ & 0,755 \\
\hline
\end{tabular}




\begin{tabular}{|c|c|c|c|c|c|c|c|}
\hline mmu-miR-326 & 7,723 & 0,028 & 7,316 & 0,257 & 0,407 & $-0,407$ & 0,754 \\
\hline hsa-miR-376b & 6,907 & 0,345 & 6,499 & 0,080 & 0,409 & $-0,409$ & 0,753 \\
\hline mmu-miR-154 & 7,059 & 0,038 & 6,648 & 0,014 & 0,410 & $-0,410$ & 0,753 \\
\hline mmu-miR-302c & 7,133 & 0,117 & 6,723 & 0,130 & 0,410 & $-0,410$ & 0,752 \\
\hline hsa-miR-199b-5p & 7,104 & 0,039 & 6,694 & 0,071 & 0,411 & $-0,411$ & 0,752 \\
\hline hsa-miR-570 & 7,111 & 0,069 & 6,699 & 0,013 & 0,412 & $-0,412$ & 0,752 \\
\hline hsa-miR-520c-3p/520f & 6,981 & 0,090 & 6,569 & 0,052 & 0,412 & $-0,412$ & 0,752 \\
\hline mmu-miR-324-3p & 7,166 & 0,131 & 6,754 & 0,035 & 0,413 & $-0,413$ & 0,751 \\
\hline rno-miR-34b & 7,209 & 0,029 & 6,796 & 0,113 & 0,413 & $-0,413$ & 0,751 \\
\hline hsa-miR-519c-3p & 7,014 & 0,027 & 6,600 & 0,020 & 0,415 & $-0,415$ & 0,750 \\
\hline mmu-miR-151-3p & 7,036 & 0,045 & 6,619 & 0,027 & 0,418 & $-0,418$ & 0,749 \\
\hline mmu-miR-592 & 7,069 & 0,050 & 6,651 & 0,020 & 0,418 & $-0,418$ & 0,749 \\
\hline hsa-miR-507 & 7,030 & 0,066 & 6,611 & 0,022 & 0,419 & $-0,419$ & 0,748 \\
\hline miRPlus_17833 & 7,178 & 0,056 & 6,758 & 0,007 & 0,420 & $-0,420$ & 0,747 \\
\hline mmu-miR-469 & 7,010 & 0,039 & 6,587 & 0,028 & 0,423 & $-0,423$ & 0,746 \\
\hline mmu-miR-685 & 7,341 & 0,049 & 6,917 & 0,012 & 0,424 & $-0,424$ & 0,745 \\
\hline mmu-miR-338-3p & 7,133 & 0,282 & 6,709 & 0,081 & 0,424 & $-0,424$ & 0,745 \\
\hline mmu-miR-505 & 7,040 & 0,056 & 6,616 & 0,029 & 0,424 & $-0,424$ & 0,745 \\
\hline miRPlus_17848 & 7,069 & 0,039 & 6,645 & 0,035 & 0,425 & $-0,425$ & 0,745 \\
\hline mmu-miR-341 & 7,010 & 0,040 & 6,584 & 0,049 & 0,426 & $-0,426$ & 0,745 \\
\hline hsa-miR-591 & 7,097 & 0,123 & 6,671 & 0,298 & 0,426 & $-0,426$ & 0,744 \\
\hline hsa-miR-520d-3p & 7,021 & 0,068 & 6,590 & 0,015 & 0,431 & $-0,431$ & 0,742 \\
\hline rno-miR-297 & 6,957 & 0,071 & 6,524 & 0,056 & 0,433 & $-0,433$ & 0,741 \\
\hline miRPlus_17912 & 7,044 & 0,073 & 6,610 & 0,016 & 0,433 & $-0,433$ & 0,740 \\
\hline hsa-miR-624* & 7,038 & 0,092 & 6,604 & 0,016 & 0,434 & $-0,434$ & 0,740 \\
\hline hsa-miR-575 & 7,026 & 0,093 & 6,590 & 0,101 & 0,436 & $-0,436$ & 0,739 \\
\hline mmu-miR-488 & 7,126 & 0,050 & 6,690 & 0,100 & 0,436 & $-0,436$ & 0,739 \\
\hline mmu-miR-122 & 7,036 & 0,077 & 6,598 & 0,046 & 0,438 & $-0,438$ & 0,738 \\
\hline mmu-miR-468 & 7,148 & 0,098 & 6,706 & 0,010 & 0,442 & $-0,442$ & 0,736 \\
\hline mmu-miR-719 & 7,119 & 0,061 & 6,677 & 0,032 & 0,442 & $-0,442$ & 0,736 \\
\hline hsa-miR-191* & 7,033 & 0,041 & 6,591 & 0,033 & 0,442 & $-0,442$ & 0,736 \\
\hline mmu-miR-19a* & 7,027 & 0,045 & 6,584 & 0,031 & 0,443 & $-0,443$ & 0,736 \\
\hline mmu-miR-10a* & 7,008 & 0,067 & 6,565 & 0,072 & 0,443 & $-0,443$ & 0,736 \\
\hline miRPlus_17821 & 7,091 & 0,058 & 6,647 & 0,023 & 0,444 & $-0,444$ & 0,735 \\
\hline mmu-miR-450a-5p & 7,156 & 0,045 & 6,707 & 0,017 & 0,449 & $-0,449$ & 0,732 \\
\hline mmu-miR-204 & 7,133 & 0,038 & 6,682 & 0,024 & 0,451 & $-0,451$ & 0,731 \\
\hline hsa-miR-548a-3p & 7,040 & 0,093 & 6,588 & 0,050 & 0,452 & $-0,452$ & 0,731 \\
\hline hsa-miR-424 & 7,152 & 0,037 & 6,698 & 0,030 & 0,454 & $-0,454$ & 0,730 \\
\hline mmu-miR-29c* & 7,135 & 0,076 & 6,681 & 0,024 & 0,454 & $-0,454$ & 0,730 \\
\hline mmu-miR-296-5p & 7,208 & 0,041 & 6,751 & 0,065 & 0,456 & $-0,456$ & 0,729 \\
\hline mmu-miR-701 & 7,169 & 0,186 & 6,712 & 0,111 & 0,457 & $-0,457$ & 0,728 \\
\hline hsa-miR-875-3p & 7,084 & 0,003 & 6,624 & 0,025 & 0,460 & $-0,460$ & 0,727 \\
\hline mmu-miR-677 & 7,148 & 0,078 & 6,682 & 0,051 & 0,466 & $-0,466$ & 0,724 \\
\hline mmu-let-7a*/mmu-let-7c-2* & 7,282 & 0,069 & 6,813 & 0,109 & 0,469 & $-0,469$ & 0,722 \\
\hline mmu-let-7d* & 7,039 & 0,055 & 6,566 & 0,027 & 0,473 & $-0,473$ & 0,721 \\
\hline mmu-miR-463* & 7,039 & 0,053 & 6,565 & 0,018 & 0,474 & $-0,474$ & 0,720 \\
\hline hsa-miR-940 & 7,314 & 0,119 & 6,837 & 0,086 & 0,476 & $-0,476$ & 0,719 \\
\hline mmu-miR-129-3p & 7,150 & 0,054 & 6,670 & 0,025 & 0,481 & $-0,481$ & 0,717 \\
\hline hsa-miR-373 & 7,124 & 0,023 & 6,640 & 0,029 & 0,484 & $-0,484$ & 0,715 \\
\hline hsa-miR-518b & 7,101 & 0,082 & 6,615 & 0,034 & 0,486 & $-0,486$ & 0,714 \\
\hline mmu-miR-135b & 7,085 & 0,118 & 6,598 & 0,036 & 0,487 & $-0,487$ & 0,714 \\
\hline hsa-miR-155 & 7,147 & 0,115 & 6,659 & 0,008 & 0,488 & $-0,488$ & 0,713 \\
\hline hsa-miR-483-3p & 7,395 & 0,057 & 6,907 & 0,020 & 0,488 & $-0,488$ & 0,713 \\
\hline mmu-miR-7b & 7,112 & 0,015 & 6,621 & 0,013 & 0,491 & $-0,491$ & 0,712 \\
\hline mmu-miR-679 & 7,088 & 0,080 & 6,597 & 0,026 & 0,491 & $-0,491$ & 0,712 \\
\hline mmu-miR-181d & 7,348 & 0,068 & 6,849 & 0,024 & 0,499 & $-0,499$ & 0,708 \\
\hline mmu-miR-181c & 7,158 & 0,242 & 6,656 & 0,027 & 0,501 & $-0,501$ & 0,706 \\
\hline
\end{tabular}




\begin{tabular}{|c|c|c|c|c|c|c|c|}
\hline mmu-miR-29a* & 7,134 & 0,057 & 6,631 & 0,028 & 0,503 & $-0,503$ & 0,706 \\
\hline hsa-miR-603 & 7,214 & 0,285 & 6,704 & 0,100 & 0,510 & $-0,510$ & 0,702 \\
\hline hsa_SNORD12 & 7,337 & 0,028 & 6,826 & 0,014 & 0,511 & $-0,511$ & 0,702 \\
\hline mmu-miR-376b* & 7,104 & 0,051 & 6,592 & 0,015 & 0,511 & $-0,511$ & 0,702 \\
\hline hsa-miR-211 & 7,160 & 0,132 & 6,639 & 0,022 & 0,521 & $-0,521$ & 0,697 \\
\hline hsa_SNORD14B & 7,503 & 0,112 & 6,981 & 0,167 & 0,522 & $-0,522$ & 0,696 \\
\hline mmu-miR-322 & 7,118 & 0,062 & 6,594 & 0,030 & 0,524 & $-0,524$ & 0,695 \\
\hline hsa-miR-374a* & 7,133 & 0,045 & 6,604 & 0,039 & 0,529 & $-0,529$ & 0,693 \\
\hline mmu-miR-330 & 7,090 & 0,080 & 6,550 & 0,038 & 0,540 & $-0,540$ & 0,688 \\
\hline hsa-miR-518e & 7,085 & 0,115 & 6,541 & 0,039 & 0,544 & $-0,544$ & 0,686 \\
\hline rno-miR-483 & 7,634 & 0,068 & 7,089 & 0,029 & 0,545 & $-0,545$ & 0,686 \\
\hline mmu-miR-17* & 7,190 & 0,045 & 6,644 & 0,124 & 0,546 & $-0,546$ & 0,685 \\
\hline mmu-miR-717 & 7,249 & 0,028 & 6,701 & 0,005 & 0,547 & $-0,547$ & 0,684 \\
\hline hsa-miR-548b-3p & 7,199 & 0,043 & 6,651 & 0,022 & 0,548 & $-0,548$ & 0,684 \\
\hline mmu-miR-547 & 7,280 & 0,038 & 6,728 & 0,009 & 0,552 & $-0,552$ & 0,682 \\
\hline hsa-miR-361-3p & 7,173 & 0,115 & 6,620 & 0,018 & 0,553 & $-0,553$ & 0,682 \\
\hline mmu-miR-375 & 7,141 & 0,121 & 6,582 & 0,056 & 0,560 & $-0,560$ & 0,678 \\
\hline hsa-miR-141* & 7,186 & 0,060 & 6,625 & 0,018 & 0,561 & $-0,561$ & 0,678 \\
\hline mmu-miR-294 & 7,245 & 0,067 & 6,679 & 0,025 & 0,566 & $-0,566$ & 0,675 \\
\hline hsa-miR-616* & 7,253 & 0,060 & 6,686 & 0,013 & 0,567 & $-0,567$ & 0,675 \\
\hline rno-miR-290 & 7,286 & 0,030 & 6,715 & 0,022 & 0,572 & $-0,572$ & 0,673 \\
\hline mmu-miR-338-5p & 7,234 & 0,012 & 6,658 & 0,126 & 0,577 & $-0,577$ & 0,671 \\
\hline hsa-miR-659 & 7,327 & 0,111 & 6,750 & 0,040 & 0,577 & $-0,577$ & 0,670 \\
\hline hsa-miR-545 & 7,160 & 0,040 & 6,576 & 0,027 & 0,584 & $-0,584$ & 0,667 \\
\hline miRPlus_17858 & 7,505 & 0,125 & 6,917 & 0,073 & 0,588 & $-0,588$ & 0,665 \\
\hline mmu-miR-694 & 7,212 & 0,060 & 6,618 & 0,058 & 0,594 & $-0,594$ & 0,663 \\
\hline hsa-miR-432 & 7,121 & 0,146 & 6,524 & 0,048 & 0,597 & $-0,597$ & 0,661 \\
\hline hsa-miR-578 & 7,386 & 0,212 & 6,786 & 0,233 & 0,600 & $-0,600$ & 0,660 \\
\hline mmu-miR-715 & 7,446 & 0,067 & 6,846 & 0,202 & 0,600 & $-0,600$ & 0,660 \\
\hline mmu-miR-135a & 7,173 & 0,021 & 6,572 & 0,040 & 0,601 & $-0,601$ & 0,659 \\
\hline No known hsa target & 7,380 & 0,236 & 6,778 & 0,052 & 0,602 & $-0,602$ & 0,659 \\
\hline hsa-miR-571 & 7,152 & 0,169 & 6,549 & 0,036 & 0,603 & $-0,603$ & 0,659 \\
\hline mmu-miR-136 & 7,311 & 0,031 & 6,704 & 0,022 & 0,607 & $-0,607$ & 0,657 \\
\hline hsa-miR-371-3p & 7,134 & 0,125 & 6,527 & 0,037 & 0,607 & $-0,607$ & 0,657 \\
\hline mmu-miR-147 & 7,191 & 0,054 & 6,575 & 0,042 & 0,616 & $-0,616$ & 0,652 \\
\hline mmu-miR-501-3p & 7,170 & 0,008 & 6,554 & 0,037 & 0,616 & $-0,616$ & 0,652 \\
\hline mmu-miR-15b* & 7,576 & 0,684 & 6,958 & 0,565 & 0,618 & $-0,618$ & 0,652 \\
\hline miRPlus_17892 & 7,221 & 0,292 & 6,598 & 0,069 & 0,623 & $-0,623$ & 0,649 \\
\hline mmu-miR-672 & 7,353 & 0,112 & 6,708 & 0,027 & 0,645 & $-0,645$ & 0,639 \\
\hline mmu-miR-211 & 7,311 & 0,081 & 6,664 & 0,009 & 0,647 & $-0,647$ & 0,638 \\
\hline hsa-miR-625* & 7,485 & 0,047 & 6,834 & 0,030 & 0,652 & $-0,652$ & 0,637 \\
\hline mmu-miR-302d & 7,288 & 0,131 & 6,611 & 0,012 & 0,676 & $-0,676$ & 0,626 \\
\hline hsa-miR-618 & 7,426 & 0,205 & 6,741 & 0,135 & 0,685 & $-0,685$ & 0,622 \\
\hline hsa-miR-609 & 7,384 & 0,040 & 6,676 & 0,021 & 0,708 & $-0,708$ & 0,612 \\
\hline mmu-miR-190b & 7,367 & 0,103 & 6,646 & 0,027 & 0,721 & $-0,721$ & 0,607 \\
\hline miRPlus_17843 & 7,376 & 0,036 & 6,648 & 0,063 & 0,729 & $-0,729$ & 0,604 \\
\hline hsa-miR-99a* & 7,397 & 0,053 & 6,664 & 0,022 & 0,733 & $-0,733$ & 0,601 \\
\hline mmu-miR-465a-5p & 7,402 & 0,052 & 6,661 & 0,019 & 0,741 & $-0,741$ & 0,598 \\
\hline mmu-miR-155 & 7,360 & 0,025 & 6,586 & 0,073 & 0,774 & $-0,774$ & 0,585 \\
\hline mmu-miR-683 & 7,419 & 0,076 & 6,641 & 0,027 & 0,778 & $-0,778$ & 0,583 \\
\hline mmu-miR-142-3p & 7,431 & 0,120 & 6,592 & 0,047 & 0,839 & $-0,839$ & 0,559 \\
\hline
\end{tabular}




\section{References}

Adimoolam, S., Sirisawad, M., Chen, J., Thiemann, P., Ford, J. M., and Buggy, J. J. (2007). HDAC inhibitor PCl-24781 decreases RAD51 expression and inhibits homologous recombination. Proc Natl Acad Sci U S A 104, 19482-19487.

Alcendor, R. R., Kirshenbaum, L. A., Imai, S., Vatner, S. F., and Sadoshima, J. (2004). Silent information regulator 2alpha, a longevity factor and class III histone deacetylase, is an essential endogenous apoptosis inhibitor in cardiac myocytes. Circ Res 95, 971-980.

Ambros, V. (2004). The functions of animal microRNAs. Nature 431, 350-355.

Ambros, V., and Lee, R. C. (2004). Identification of microRNAs and other tiny noncoding RNAs by cDNA cloning. Methods Mol Biol 265, 131-158.

Axelson, H., Fredlund, E., Ovenberger, M., Landberg, G., and Pahlman, S. (2005). Hypoxiainduced dedifferentiation of tumor cells--a mechanism behind heterogeneity and aggressiveness of solid tumors. Semin Cell Dev Biol 16, 554-563.

Bals, R., Beisswenger, C., Blouquit, S., and Chinet, T. (2004). Isolation and air-liquid interface culture of human large airway and bronchiolar epithelial cells. J Cyst Fibros 3 Suppl 2, 49-51.

Bartel, D. P. (2004). MicroRNAs: genomics, biogenesis, mechanism, and function. Cell 116, 281-297.

Bartkova, J., Horejsi, Z., Koed, K., Kramer, A., Tort, F., Zieger, K., Guldberg, P., Sehested, M., Nesland, J. M., Lukas, C., et al. (2005). DNA damage response as a candidate anticancer barrier in early human tumorigenesis. Nature 434, 864-870.

Bartkova, J., Rezaei, N., Liontos, M., Karakaidos, P., Kletsas, D., Issaeva, N., Vassiliou, L. V., Kolettas, E., Niforou, K., Zoumpourlis, V. C., et al. (2006). Oncogene-induced senescence is part of the tumorigenesis barrier imposed by DNA damage checkpoints. Nature 444, 633-637.

Bates, S., Phillips, A. C., Clark, P. A., Stott, F., Peters, G., Ludwig, R. L., and Vousden, K. H. (1998). p14ARF links the tumour suppressors RB and p53. Nature 395, 124-125.

Beisswenger, C., Platz, J., Seifart, C., Vogelmeier, C., and Bals, R. (2004). Exposure of differentiated airway epithelial cells to volatile smoke in vitro. Respiration 71, 402-409.

Bell, L. A., and Ryan, K. M. (2004). Life and death decisions by E2F-1. Cell Death Differ 11, 137-142.

Bhaskaran, M., Wang, Y., Zhang, H., Weng, T., Baviskar, P., Guo, Y., Gou, D., and Liu, L. (2009). MicroRNA-127 modulates fetal lung development. Physiol Genomics 37, 268-278.

Bommer, G. T., Gerin, I., Feng, Y., Kaczorowski, A. J., Kuick, R., Love, R. E., Zhai, Y., Giordano, T. J., Qin, Z. S., Moore, B. B., et al. (2007). p53-mediated activation of miRNA34 candidate tumor-suppressor genes. Curr Biol 17, 1298-1307.

Braun, C. J., Zhang, X., Savelyeva, I., Wolff, S., Moll, U. M., Schepeler, T., Orntoft, T. F., Andersen, C. L., and Dobbelstein, M. (2008). p53-Responsive micrornas 192 and 215 are capable of inducing cell cycle arrest. Cancer Res 68, 10094-10104.

Brody, S. L., Yan, X. H., Wuerffel, M. K., Song, S. K., and Shapiro, S. D. (2000). Ciliogenesis and left-right axis defects in forkhead factor HFH-4-null mice. Am J Respir Cell Mol Biol 23, 45-51.

Bryant, H. E., Schultz, N., Thomas, H. D., Parker, K. M., Flower, D., Lopez, E., Kyle, S., Meuth, M., Curtin, N. J., and Helleday, T. (2005). Specific killing of BRCA2-deficient tumours with inhibitors of poly(ADP-ribose) polymerase. Nature 434, 913-917.

Budihardjo, I., Oliver, H., Lutter, M., Luo, X., and Wang, X. (1999). Biochemical pathways of caspase activation during apoptosis. Annu Rev Cell Dev Biol 15, 269-290. 
Bunz, F., Dutriaux, A., Lengauer, C., Waldman, T., Zhou, S., Brown, J. P., Sedivy, J. M., Kinzler, K. W., and Vogelstein, B. (1998). Requirement for p53 and p21 to sustain G2 arrest after DNA damage. Science 282, 1497-1501.

Cain, K., Bratton, S. B., and Cohen, G. M. (2002). The Apaf-1 apoptosome: a large caspaseactivating complex. Biochimie 84, 203-214.

Calin, G. A., and Croce, C. M. (2006). MicroRNA signatures in human cancers. Nat Rev Cancer 6, 857-866.

Canman, C. E. (2001). Replication checkpoint: preventing mitotic catastrophe. Curr Biol 11, R121-124.

Carew, J. S., Giles, F. J., and Nawrocki, S. T. (2008). Histone deacetylase inhibitors:

mechanisms of cell death and promise in combination cancer therapy. Cancer Lett 269, 7-17.

Chang, T. C., Wentzel, E. A., Kent, O. A., Ramachandran, K., Mullendore, M., Lee, K. H., Feldmann, G., Yamakuchi, M., Ferlito, M., Lowenstein, C. J., et al. (2007). Transactivation of miR-34a by p53 broadly influences gene expression and promotes apoptosis. Mol Cell 26, 745-752.

Chen, J., Knowles, H. J., Hebert, J. L., and Hackett, B. P. (1998). Mutation of the mouse hepatocyte nuclear factor/forkhead homologue 4 gene results in an absence of cilia and random left-right asymmetry. J Clin Invest 102, 1077-1082.

Cho, W. C. (2007). OncomiRs: the discovery and progress of microRNAs in cancers. Mol Cancer 6, 60.

Chuang, P. T., and McMahon, A. P. (2003). Branching morphogenesis of the lung: new molecular insights into an old problem. Trends Cell Biol 13, 86-91.

Coppola, V., De Maria, R., and Bonci, D. (2010). MicroRNAs and prostate cancer. Endocr Relat Cancer 17, F1-17.

Corney, D. C., Flesken-Nikitin, A., Godwin, A. K., Wang, W., and Nikitin, A. Y. (2007). MicroRNA-34b and MicroRNA-34c are targets of p53 and cooperate in control of cell proliferation and adhesion-independent growth. Cancer Res 67, 8433-8438.

Croce, C. M. (2009). Causes and consequences of microRNA dysregulation in cancer. Nat Rev Genet 10, 704-714.

Dai, Y., and Grant, S. (2010). New insights into checkpoint kinase 1 in the DNA damage response signaling network. Clin Cancer Res 16, 376-383.

Dannenberg, J. H., David, G., Zhong, S., van der Torre, J., Wong, W. H., and Depinho, R. A. (2005). mSin3A corepressor regulates diverse transcriptional networks governing normal and neoplastic growth and survival. Genes Dev 19, 1581-1595.

DeGregori, J., and Johnson, D. G. (2006). Distinct and Overlapping Roles for E2F Family Members in Transcription, Proliferation and Apoptosis. Curr Mol Med 6, 739-748.

Di Micco, R., Fumagalli, M., Cicalese, A., Piccinin, S., Gasparini, P., Luise, C., Schurra, C., Garre, M., Nuciforo, P. G., Bensimon, A., et al. (2006). Oncogene-induced senescence is a DNA damage response triggered by DNA hyper-replication. Nature 444, 638-642.

Dong, J., Jiang, G., Asmann, Y. W., Tomaszek, S., Jen, J., Kislinger, T., and Wigle, D. A. (2010). MicroRNA Networks in Mouse Lung Organogenesis. PLoS ONE 5, e10854.

Droge, P., and Davey, C. A. (2008). Do cells let-7 determine stemness? Cell Stem Cell 2, 89.

Dyer, B. W., Ferrer, F. A., Klinedinst, D. K., and Rodriguez, R. (2000). A noncommercial dual luciferase enzyme assay system for reporter gene analysis. Anal Biochem 282, 158-161.

Elaut, G., Rogiers, V., and Vanhaecke, T. (2007). The pharmaceutical potential of histone deacetylase inhibitors. Curr Pharm Des 13, 2584-2620. 
Ellis, L., Atadja, P. W., and Johnstone, R. W. (2009). Epigenetics in cancer: targeting chromatin modifications. Mol Cancer Ther 8, 1409-1420.

Enders, G. H. (2008). Expanded roles for Chk1 in genome maintenance. J Biol Chem 283, 17749-17752.

Espino, P. S., Drobic, B., Dunn, K. L., and Davie, J. R. (2005). Histone modifications as a platform for cancer therapy. J Cell Biochem 94, 1088-1102.

Esquela-Kerscher, A., and Slack, F. J. (2006). Oncomirs - microRNAs with a role in cancer. Nat Rev Cancer 6, 259-269.

Farmer, H., McCabe, N., Lord, C. J., Tutt, A. N., Johnson, D. A., Richardson, T. B., Santarosa, M., Dillon, K. J., Hickson, I., Knights, C., et al. (2005). Targeting the DNA repair defect in BRCA mutant cells as a therapeutic strategy. Nature 434, 917-921.

Fearon, E. R., and Vogelstein, B. (1990). A genetic model for colorectal tumorigenesis. Cell 61, 759-767.

Filipowicz, W., Bhattacharyya, S. N., and Sonenberg, N. (2008). Mechanisms of posttranscriptional regulation by microRNAs: are the answers in sight? Nat Rev Genet 9, $102-$ 114.

Fishler, T., Li, Y. Y., Wang, R. H., Kim, H. S., Sengupta, K., Vassilopoulos, A., Lahusen, T., Xu, X., Lee, M. H., Liu, Q., et al. (2010). Genetic instability and mammary tumor formation in mice carrying mammary-specific disruption of Chk1 and p53. Oncogene.

Flynt, A. S., and Lai, E. C. (2008). Biological principles of microRNA-mediated regulation: shared themes amid diversity. Nat Rev Genet 9, 831-842.

Fong, P. C., Boss, D. S., Yap, T. A., Tutt, A., Wu, P., Mergui-Roelvink, M., Mortimer, P., Swaisland, H., Lau, A., O'Connor, M. J., et al. (2009). Inhibition of poly(ADP-ribose) polymerase in tumors from BRCA mutation carriers. N Engl J Med 361, 123-134.

Franklin, E. E., and Robertson, J. D. (2007). Requirement of Apaf-1 for mitochondrial events and the cleavage or activation of all procaspases during genotoxic stress-induced apoptosis. Biochem J 405, 115-122.

Friedman, J. M., Jones, P. A., and Liang, G. (2009a). The tumor suppressor microRNA-101 becomes an epigenetic player by targeting the polycomb group protein $\mathrm{EZH} 2$ in cancer. Cell Cycle 8, 2313-2314.

Friedman, R. C., Farh, K. K., Burge, C. B., and Bartel, D. P. (2009b). Most mammalian mRNAs are conserved targets of microRNAs. Genome Res 19, 92-105.

Furukawa, Y., Nishimura, N., Satoh, M., Endo, H., Iwase, S., Yamada, H., Matsuda, M., Kano, Y., and Nakamura, M. (2002). Apaf-1 is a mediator of E2F-1-induced apoptosis. J Biol Chem 277, 39760-39768.

Georges, S. A., Biery, M. C., Kim, S. Y., Schelter, J. M., Guo, J., Chang, A. N., Jackson, A. L., Carleton, M. O., Linsley, P. S., Cleary, M. A., and Chau, B. N. (2008). Coordinated regulation of cell cycle transcripts by p53-Inducible microRNAs, miR-192 and miR-215. Cancer Res 68, 10105-10112.

Georges, S. A., Chau, B. N., Braun, C. J., Zhang, X., and Dobbelstein, M. (2009). Cell cycle arrest or apoptosis by p53: are microRNAs-192/215 and -34 making the decision? Cell Cycle 8, 680-681.

Gialitakis, M., Kretsovali, A., Spilianakis, C., Kravariti, L., Mages, J., Hoffmann, R., Hatzopoulos, A. K., and Papamatheakis, J. (2006). Coordinated changes of histone modifications and HDAC mobilization regulate the induction of $\mathrm{MHC}$ class II genes by Trichostatin A. Nucleic Acids Res 34, 765-772.

Griffiths-Jones, S. (2004). The microRNA Registry. Nucleic Acids Res 32, D109-111.

Griffiths-Jones, S. (2006). miRBase: the microRNA sequence database. Methods Mol Biol 342, 129-138. 
Griffiths-Jones, S., Grocock, R. J., van Dongen, S., Bateman, A., and Enright, A. J. (2006). miRBase: microRNA sequences, targets and gene nomenclature. Nucleic Acids Res 34 , D140-144.

Griffiths-Jones, S., Saini, H. K., van Dongen, S., and Enright, A. J. (2008). miRBase: tools for microRNA genomics. Nucleic Acids Res 36, D154-158.

Halkidou, K., Gaughan, L., Cook, S., Leung, H. Y., Neal, D. E., and Robson, C. N. (2004). Upregulation and nuclear recruitment of HDAC1 in hormone refractory prostate cancer. Prostate 59, 177-189.

Hanahan, D., and Weinberg, R. A. (2000). The hallmarks of cancer. Cell 100, 57-70.

Harris, K. S., Zhang, Z., McManus, M. T., Harfe, B. D., and Sun, X. (2006). Dicer function is essential for lung epithelium morphogenesis. Proc Natl Acad Sci U S A 103, 2208-2213.

Haupt, Y., Maya, R., Kazaz, A., and Oren, M. (1997). Mdm2 promotes the rapid degradation of p53. Nature 387, 296-299.

He, L., and Hannon, G. J. (2004). MicroRNAs: small RNAs with a big role in gene regulation. Nat Rev Genet 5, 522-531.

He, L., He, X., Lim, L. P., de Stanchina, E., Xuan, Z., Liang, Y., Xue, W., Zender, L., Magnus, J., Ridzon, D., et al. (2007a). A microRNA component of the p53 tumour suppressor network. Nature 447, 1130-1134.

He, L., He, X., Lowe, S. W., and Hannon, G. J. (2007b). microRNAs join the p53 network-another piece in the tumour-suppression puzzle. Nat Rev Cancer 7, 819-822.

He, X., He, L., and Hannon, G. J. (2007c). The guardian's little helper: microRNAs in the p53 tumor suppressor network. Cancer Res 67, 11099-11101.

Helleday, T. (2010). Homologous recombination in cancer development, treatment and development of drug resistance. Carcinogenesis 31, 955-960.

Helleday, T., Bryant, H. E., and Schultz, N. (2005). Poly(ADP-ribose) polymerase (PARP-1) in homologous recombination and as a target for cancer therapy. Cell Cycle 4, 1176-1178.

Helleday, T., Petermann, E., Lundin, C., Hodgson, B., and Sharma, R. A. (2008). DNA repair pathways as targets for cancer therapy. Nat Rev Cancer 8, 193-204.

Hermeking, H. (2007). p53 enters the microRNA world. Cancer Cell 12, 414-418.

Hermeking, H. (2009a). The miR-34 family in cancer and apoptosis. Cell Death Differ.

Hermeking, H. (2009b). MiR-34a and p53. Cell Cycle 8, 1308.

Hershko, T., Korotayev, K., Polager, S., and Ginsberg, D. (2006). E2F1 modulates p38 MAPK phosphorylation via transcriptional regulation of ASK1 and Wip1. J Biol Chem 281, 31309-31316.

Hoesel, B., Bhujabal, Z., Przemeck, G. K., Kurz-Drexler, A., Weisenhorn, D. M., Angelis, M. $\mathrm{H}$., and Beckers, J. (2010). Combination of in silico and insitu hybridisation approaches to identify potential DII1 associated miRNAs during mouse embryogenesis. Gene Expr Patterns.

Huang, X., Tran, T., Zhang, L., Hatcher, R., and Zhang, P. (2005). DNA damage-induced mitotic catastrophe is mediated by the Chk1-dependent mitotic exit DNA damage checkpoint. Proc Natl Acad Sci U S A 102, 1065-1070.

Irwin, M., Marin, M. C., Phillips, A. C., Seelan, R. S., Smith, D. I., Liu, W., Flores, E. R., Tsai, K. Y., Jacks, T., Vousden, K. H., and Kaelin, W. G., Jr. (2000). Role for the p53 homologue p73 in E2F-1-induced apoptosis. Nature 407, 645-648.

Jackson, S. P., and Bartek, J. (2009). The DNA-damage response in human biology and disease. Nature 461, 1071-1078. 
Ji, Q., Hao, X., Meng, Y., Zhang, M., Desano, J., Fan, D., and Xu, L. (2008). Restoration of tumor suppressor miR-34 inhibits human p53-mutant gastric cancer tumorspheres. BMC Cancer 8, 266.

Ji, Q., Hao, X., Zhang, M., Tang, W., Yang, M., Li, L., Xiang, D., Desano, J. T., Bommer, G. T., Fan, D., et al. (2009). MicroRNA miR-34 inhibits human pancreatic cancer tumor-initiating cells. PLoS ONE 4, e6816.

John, B., Enright, A. J., Aravin, A., Tuschl, T., Sander, C., and Marks, D. S. (2004). Human MicroRNA targets. PLoS Biol 2, e363.

Johnson, D. G. (2000). The paradox of E2F1: oncogene and tumor suppressor gene. Mol Carcinog 27, 151-157.

Johnson, D. G., Cress, W. D., Jakoi, L., and Nevins, J. R. (1994). Oncogenic capacity of the E2F1 gene. Proc Natl Acad Sci U S A 91, 12823-12827.

Kalebic, T. (2003). Epigenetic changes: potential therapeutic targets. Ann N Y Acad Sci 983, 278-285.

Kastan, M. B., and Bartek, J. (2004). Cell-cycle checkpoints and cancer. Nature 432, 316323.

Kim, D., Frank, C. L., Dobbin, M. M., Tsunemoto, R. K., Tu, W., Peng, P. L., Guan, J. S., Lee, B. H., Moy, L. Y., Giusti, P., et al. (2008). Deregulation of HDAC1 by p25/Cdk5 in neurotoxicity. Neuron 60, 803-817.

Kim, V. N. (2005). MicroRNA biogenesis: coordinated cropping and dicing. Nat Rev Mol Cell Biol 6, 376-385.

Kubbutat, M. H., Jones, S. N., and Vousden, K. H. (1997). Regulation of p53 stability by Mdm2. Nature 387, 299-303.

Kumar, M. S., Lu, J., Mercer, K. L., Golub, T. R., and Jacks, T. (2007). Impaired microRNA processing enhances cellular transformation and tumorigenesis. Nat Genet 39, 673-677.

Lagos-Quintana, M., Rauhut, R., Yalcin, A., Meyer, J., Lendeckel, W., and Tuschl, T. (2002). Identification of tissue-specific microRNAs from mouse. Curr Biol 12, 735-739.

Landgraf, P., Rusu, M., Sheridan, R., Sewer, A., lovino, N., Aravin, A., Pfeffer, S., Rice, A., Kamphorst, A. O., Landthaler, M., et al. (2007). A mammalian microRNA expression atlas based on small RNA library sequencing. Cell 129, 1401-1414.

Langley, E., Pearson, M., Faretta, M., Bauer, U. M., Frye, R. A., Minucci, S., Pelicci, P. G., and Kouzarides, T. (2002). Human SIR2 deacetylates p53 and antagonizes PML/p53induced cellular senescence. Embo J 21, 2383-2396.

Lee, H. J., Hwang, H. I., and Jang, Y. J. (2010). Mitotic DNA damage response: Polo-like kinase-1 is dephosphorylated through ATM-Chk1 pathway. Cell Cycle 9.

Lee, K. H., Chen, Y. L., Yeh, S. D., Hsiao, M., Lin, J. T., Goan, Y. G., and Lu, P. J. (2009). MicroRNA-330 acts as tumor suppressor and induces apoptosis of prostate cancer cells through E2F1-mediated suppression of Akt phosphorylation. Oncogene 28, 3360-3370.

Lee, Y. S., and Dutta, A. (2007). The tumor suppressor microRNA let-7 represses the HMGA2 oncogene. Genes Dev 21, 1025-1030.

Lin, T., Chao, C., Saito, S., Mazur, S. J., Murphy, M. E., Appella, E., and Xu, Y. (2005). p53 induces differentiation of mouse embryonic stem cells by suppressing Nanog expression. Nat Cell Biol 7, 165-171.

Lin, T., Dong, W., Huang, J., Pan, Q., Fan, X., Zhang, C., and Huang, L. (2009). MicroRNA143 as a tumor suppressor for bladder cancer. J Urol 181, 1372-1380.

Lin, W. C., Lin, F. T., and Nevins, J. R. (2001). Selective induction of E2F1 in response to DNA damage, mediated by ATM-dependent phosphorylation. Genes Dev 15, 1833-1844. 
Lissy, N. A., Davis, P. K., Irwin, M., Kaelin, W. G., and Dowdy, S. F. (2000). A common E2F1 and p73 pathway mediates cell death induced by TCR activation. Nature 407, 642-645.

Lize, M., Pilarski, S., and Dobbelstein, M. (2010). E2F1-inducible microRNA 449a/b suppresses cell proliferation and promotes apoptosis. Cell Death Differ 17, 452-458.

Lodygin, D., Tarasov, V., Epanchintsev, A., Berking, C., Knyazeva, T., Korner, H., Knyazev, P., Diebold, J., and Hermeking, H. (2008). Inactivation of miR-34a by aberrant CpG methylation in multiple types of cancer. Cell Cycle 7, 2591-2600.

Lu, J., Getz, G., Miska, E. A., Alvarez-Saavedra, E., Lamb, J., Peck, D., Sweet-Cordero, A., Ebert, B. L., Mak, R. H., Ferrando, A. A., et al. (2005). MicroRNA expression profiles classify human cancers. Nature 435, 834-838.

Lu, Y., Okubo, T., Rawlins, E., and Hogan, B. L. (2008). Epithelial progenitor cells of the embryonic lung and the role of microRNAs in their proliferation. Proc Am Thorac Soc 5, 300304.

Luo, J., Nikolaev, A. Y., Imai, S., Chen, D., Su, F., Shiloh, A., Guarente, L., and Gu, W. (2001). Negative control of p53 by Sir2alpha promotes cell survival under stress. Cell 107, 137-148.

Maeda, Y., Dave, V., and Whitsett, J. A. (2007). Transcriptional control of lung morphogenesis. Physiol Rev 87, 219-244.

Markey, M., and Berberich, S. J. (2008). Full-length hdmX transcripts decrease following genotoxic stress. Oncogene 27, 6657-6666.

Milutinovic, S., Zhuang, Q., and Szyf, M. (2002). Proliferating cell nuclear antigen associates with histone deacetylase activity, integrating DNA replication and chromatin modification. J Biol Chem 277, 20974-20978.

Moradei, O., Vaisburg, A., and Martell, R. E. (2008). Histone deacetylase inhibitors in cancer therapy: new compounds and clinical update of benzamide-type agents. Curr Top Med Chem 8, 841-858.

Moroni, M. C., Hickman, E. S., Lazzerini Denchi, E., Caprara, G., Colli, E., Cecconi, F., Muller, H., and Helin, K. (2001). Apaf-1 is a transcriptional target for E2F and p53. Nat Cell Biol 3, 552-558.

Naguibneva, I., Ameyar-Zazoua, M., Nonne, N., Polesskaya, A., Ait-Si-Ali, S., Groisman, R., Souidi, M., Pritchard, L. L., and Harel-Bellan, A. (2006). An LNA-based loss-of-function assay for micro-RNAs. Biomed Pharmacother 60, 633-638.

Noonan, E. J., Place, R. F., Pookot, D., Basak, S., Whitson, J. M., Hirata, H., Giardina, C., and Dahiya, R. (2009). miR-449a targets HDAC-1 and induces growth arrest in prostate cancer. Oncogene 28, 1714-1724.

Novotny, G. W., Sonne, S. B., Nielsen, J. E., Jonstrup, S. P., Hansen, M. A., Skakkebaek, N. E., Rajpert-De Meyts, E., Kjems, J., and Leffers, H. (2007). Translational repression of E2F1 mRNA in carcinoma in situ and normal testis correlates with expression of the miR-17-92 cluster. Cell Death Differ 14, 879-882.

O'Donovan, P. J., and Livingston, D. M. (2010). BRCA1 and BRCA2: breast/ovarian cancer susceptibility gene products and participants in DNA double-strand break repair. Carcinogenesis 31, 961-967.

Pan, Y., Ren, K. H., He, H. W., and Shao, R. G. (2009). Knockdown of Chk1 sensitizes human colon carcinoma HCT116 cells in a p53-dependent manner to lidamycin through abrogation of a G2/M checkpoint and induction of apoptosis. Cancer Biol Ther 8, 1559-1566.

Patra, S. K., Patra, A., and Dahiya, R. (2001). Histone deacetylase and DNA methyltransferase in human prostate cancer. Biochem Biophys Res Commun 287, 705-713.

Petrocca, F., Vecchione, A., and Croce, C. M. (2008a). Emerging role of miR-106b-25/miR17-92 clusters in the control of transforming growth factor beta signaling. Cancer Res 68 , 8191-8194. 
Petrocca, F., Visone, R., Onelli, M. R., Shah, M. H., Nicoloso, M. S., de Martino, I., lliopoulos, D., Pilozzi, E., Liu, C. G., Negrini, M., et al. (2008b). E2F1-regulated microRNAs impair TGFbeta-dependent cell-cycle arrest and apoptosis in gastric cancer. Cancer Cell 13, 272286.

Phillips, A. C., Ernst, M. K., Bates, S., Rice, N. R., and Vousden, K. H. (1999). E2F-1 potentiates cell death by blocking antiapoptotic signaling pathways. Mol Cell 4, 771-781.

Pickering, M. T., Stadler, B. M., and Kowalik, T. F. (2009). miR-17 and miR-20a temper an E2F1-induced G1 checkpoint to regulate cell cycle progression. Oncogene 28, 140-145.

Polager, S., and Ginsberg, D. (2009). p53 and E2f: partners in life and death. Nat Rev Cancer 9, 738-748.

Pomerantz, J., Schreiber-Agus, N., Liegeois, N. J., Silverman, A., Alland, L., Chin, L., Potes, J., Chen, K., Orlow, I., Lee, H. W., et al. (1998). The Ink4a tumor suppressor gene product, p19Arf, interacts with MDM2 and neutralizes MDM2's inhibition of p53. Cell 92, 713-723.

Qin, X. Q., Livingston, D. M., Ewen, M., Sellers, W. R., Arany, Z., and Kaelin, W. G., Jr. (1995). The transcription factor E2F-1 is a downstream target of RB action. Mol Cell Biol 15, 742-755.

Raver-Shapira, N., Marciano, E., Meiri, E., Spector, Y., Rosenfeld, N., Moskovits, N., Bentwich, Z., and Oren, M. (2007). Transcriptional activation of miR-34a contributes to p53mediated apoptosis. Mol Cell 26, 731-743.

Redshaw, N., Wheeler, G., Hajihosseini, M. K., and Dalmay, T. (2009). microRNA-449 is a putative regulator of choroid plexus development and function. Brain Res 1250, 20-26.

Reid, G., Metivier, R., Lin, C. Y., Denger, S., Ibberson, D., Ivacevic, T., Brand, H., Benes, V., Liu, E. T., and Gannon, F. (2005). Multiple mechanisms induce transcriptional silencing of a subset of genes, including oestrogen receptor alpha, in response to deacetylase inhibition by valproic acid and trichostatin A. Oncogene 24, 4894-4907.

Ren, B., Cam, H., Takahashi, Y., Volkert, T., Terragni, J., Young, R. A., and Dynlacht, B. D. (2002). E2F integrates cell cycle progression with DNA repair, replication, and $G(2) / M$ checkpoints. Genes Dev 16, 245-256.

Rodriguez, J., and Lazebnik, Y. (1999). Caspase-9 and APAF-1 form an active holoenzyme. Genes Dev 13, 3179-3184.

Rogoff, H. A., and Kowalik, T. F. (2004). Life, death and E2F: linking proliferation control and DNA damage signaling via E2F1. Cell Cycle 3, 845-846.

Romagnoli, S., Fasoli, E., Vaira, V., Falleni, M., Pellegrini, C., Catania, A., Roncalli, M., Marchetti, A., Santambrogio, L., Coggi, G., and Bosari, S. (2009). Identification of potential therapeutic targets in malignant mesothelioma using cell-cycle gene expression analysis. Am J Pathol 174, 762-770.

Ross, A. J., Dailey, L. A., Brighton, L. E., and Devlin, R. B. (2007). Transcriptional profiling of mucociliary differentiation in human airway epithelial cells. Am J Respir Cell Mol Biol 37, 169185.

Saleh, A., Srinivasula, S. M., Acharya, S., Fishel, R., and Alnemri, E. S. (1999). Cytochrome $C$ and dATP-mediated oligomerization of Apaf- 1 is a prerequisite for procaspase- 9 activation. J Biol Chem 274, 17941-17945.

Schembri, F., Sridhar, S., Perdomo, C., Gustafson, A. M., Zhang, X., Ergun, A., Lu, J., Liu, G., Bowers, J., Vaziri, C., et al. (2009). MicroRNAs as modulators of smoking-induced gene expression changes in human airway epithelium. Proc Natl Acad Sci U S A 106, 2319-2324.

Sell, S. (1993). Cellular origin of cancer: dedifferentiation or stem cell maturation arrest? Environ Health Perspect 101 Suppl 5, 15-26.

Shan, B., and Lee, W. H. (1994). Deregulated expression of E2F-1 induces S-phase entry and leads to apoptosis. Mol Cell Biol 14, 8166-8173. 
Shankar, S., and Srivastava, R. K. (2008). Histone deacetylase inhibitors: mechanisms and clinical significance in cancer: HDAC inhibitor-induced apoptosis. Adv Exp Med Biol 615, 261-298.

Shenouda, S. K., and Alahari, S. K. (2009). MicroRNA function in cancer: oncogene or a tumor suppressor? Cancer Metastasis Rev 28, 369-378.

Sherr, C. J., and McCormick, F. (2002). The RB and p53 pathways in cancer. Cancer Cell 2, 103-112.

Sherr, C. J., and Roberts, J. M. (1999). CDK inhibitors: positive and negative regulators of G1-phase progression. Genes Dev 13, 1501-1512.

Sionov, R. V., and Haupt, Y. (1999). The cellular response to p53: the decision between life and death. Oncogene 18, 6145-6157.

Solomon, J. M., Pasupuleti, R., Xu, L., McDonagh, T., Curtis, R., DiStefano, P. S., and Huber, L. J. (2006). Inhibition of SIRT1 catalytic activity increases p53 acetylation but does not alter cell survival following DNA damage. Mol Cell Biol 26, 28-38.

Stevens, C., Smith, L., and La Thangue, N. B. (2003). Chk2 activates E2F-1 in response to DNA damage. Nat Cell Biol 5, 401-409.

Stiewe, T., and Putzer, B. M. (2000). Role of the p53-homologue p73 in E2F1-induced apoptosis. Nat Genet 26, 464-469.

Stracker, T. H., Usui, T., and Petrini, J. H. (2009). Taking the time to make important decisions: the checkpoint effector kinases Chk1 and Chk2 and the DNA damage response. DNA Repair (Amst) 8, 1047-1054.

Stunkel, W., Peh, B. K., Tan, Y. C., Nayagam, V. M., Wang, X., Salto-Tellez, M., Ni, B., Entzeroth, M., and Wood, J. (2007). Function of the SIRT1 protein deacetylase in cancer. Biotechnol J 2, 1360-1368.

Sun, F., Fu, H., Liu, Q., Tie, Y., Zhu, J., Xing, R., Sun, Z., and Zheng, X. (2008).

Downregulation of CCND1 and CDK6 by miR-34a induces cell cycle arrest. FEBS Lett 582, 1564-1568.

Sun, Y., Sun, D., Li, F., Tian, L., Li, C., Li, L., Lin, R., and Wang, S. (2007). Downregulation of Sirt1 by antisense oligonucleotides induces apoptosis and enhances radiation sensitization in A549 lung cancer cells. Lung Cancer 58, 21-29.

Sylvestre, Y., De Guire, V., Querido, E., Mukhopadhyay, U. K., Bourdeau, V., Major, F., Ferbeyre, G., and Chartrand, P. (2007). An E2F/miR-20a autoregulatory feedback loop. J Biol Chem 282, 2135-2143.

Takahashi, K., and Yamanaka, S. (2006). Induction of pluripotent stem cells from mouse embryonic and adult fibroblast cultures by defined factors. Cell 126, 663-676.

Tarasov, V., Jung, P., Verdoodt, B., Lodygin, D., Epanchintsev, A., Menssen, A., Meister, G., and Hermeking, H. (2007). Differential regulation of microRNAs by p53 revealed by

massively parallel sequencing: miR-34a is a p53 target that induces apoptosis and G1-arrest. Cell Cycle 6, 1586-1593.

Tazawa, H., Tsuchiya, N., Izumiya, M., and Nakagama, H. (2007). Tumor-suppressive miR$34 \mathrm{a}$ induces senescence-like growth arrest through modulation of the E2F pathway in human colon cancer cells. Proc Natl Acad Sci U S A 104, 15472-15477.

Tominaga, Y., Wang, A., Wang, R. H., Wang, X., Cao, L., and Deng, C. X. (2007). Genistein inhibits Brca1 mutant tumor growth through activation of DNA damage checkpoints, cell cycle arrest, and mitotic catastrophe. Cell Death Differ 14, 472-479.

Trosko, J. E. (2009). Review paper: cancer stem cells and cancer nonstem cells: from adult stem cells or from reprogramming of differentiated somatic cells. Vet Pathol 46, 176-193. 
Tsai, K. Y., Hu, Y., Macleod, K. F., Crowley, D., Yamasaki, L., and Jacks, T. (1998). Mutation of E2f-1 suppresses apoptosis and inappropriate $S$ phase entry and extends survival of Rbdeficient mouse embryos. Mol Cell 2, 293-304.

Uhl, M., Csernok, A., Aydin, S., Kreienberg, R., Wiesmuller, L., and Gatz, S. A. (2010). Role of SIRT1 in homologous recombination. DNA Repair (Amst) 9, 383-393.

Vassilev, L. T., Vu, B. T., Graves, B., Carvajal, D., Podlaski, F., Filipovic, Z., Kong, N., Kammlott, U., Lukacs, C., Klein, C., et al. (2004). In vivo activation of the p53 pathway by small-molecule antagonists of MDM2. Science 303, 844-848.

Vaziri, H., Dessain, S. K., Ng Eaton, E., Imai, S. I., Frye, R. A., Pandita, T. K., Guarente, L., and Weinberg, R. A. (2001). hSIR2(SIRT1) functions as an NAD-dependent p53 deacetylase. Cell 107, 149-159.

Verlinden, L., Vanden Bempt, I., Eelen, G., Drijkoningen, M., Verlinden, I., Marchal, K., De Wolf-Peeters, C., Christiaens, M. R., Michiels, L., Bouillon, R., and Verstuyf, A. (2007). The E2F-regulated gene Chk1 is highly expressed in triple-negative estrogen receptor /progesterone receptor /HER-2 breast carcinomas. Cancer Res 67, 6574-6581.

Vert, J. P., Foveau, N., Lajaunie, C., and Vandenbrouck, Y. (2006). An accurate and interpretable model for siRNA efficacy prediction. BMC Bioinformatics 7, 520.

Vogelstein, B., and Kinzler, K. W. (1993). The multistep nature of cancer. Trends Genet 9, 138-141.

Volinia, S., Calin, G. A., Liu, C. G., Ambs, S., Cimmino, A., Petrocca, F., Visone, R., lorio, M., Roldo, C., Ferracin, M., et al. (2006). A microRNA expression signature of human solid tumors defines cancer gene targets. Proc Natl Acad Sci U S A 103, 2257-2261.

Voorhoeve, P. M., le Sage, C., Schrier, M., Gillis, A. J., Stoop, H., Nagel, R., Liu, Y. P., van Duijse, J., Drost, J., Griekspoor, A., et al. (2006). A genetic screen implicates miRNA-372 and miRNA-373 as oncogenes in testicular germ cell tumors. Cell 124, 1169-1181.

Wang, R. H., Sengupta, K., Li, C., Kim, H. S., Cao, L., Xiao, C., Kim, S., Xu, X., Zheng, Y., Chilton, B., et al. (2008). Impaired DNA damage response, genome instability, and tumorigenesis in SIRT1 mutant mice. Cancer Cell 14, 312-323.

Wang, Y., Brahmakshatriya, V., Zhu, H., Lupiani, B., Reddy, S. M., Yoon, B. J., Gunaratne, P. H., Kim, J. H., Chen, R., Wang, J., and Zhou, H. (2009). Identification of differentially expressed miRNAs in chicken lung and trachea with avian influenza virus infection by a deep sequencing approach. BMC Genomics 10, 512.

Wang, Y., Decker, S. J., and Sebolt-Leopold, J. (2004). Knockdown of Chk1, Wee1 and Myt1 by RNA interference abrogates G2 checkpoint and induces apoptosis. Cancer Biol Ther 3, 305-313.

Wang, Y., Weng, T., Gou, D., Chen, Z., Chintagari, N. R., and Liu, L. (2007). Identification of rat lung-specific microRNAs by micoRNA microarray: valuable discoveries for the facilitation of lung research. BMC Genomics 8, 29.

Weichert, W. (2009). HDAC expression and clinical prognosis in human malignancies. Cancer Lett 280, 168-176.

Weichert, W., Denkert, C., Noske, A., Darb-Esfahani, S., Dietel, M., Kalloger, S. E., Huntsman, D. G., and Kobel, M. (2008a). Expression of class I histone deacetylases indicates poor prognosis in endometrioid subtypes of ovarian and endometrial carcinomas. Neoplasia 10, 1021-1027.

Weichert, W., Roske, A., Gekeler, V., Beckers, T., Stephan, C., Jung, K., Fritzsche, F. R., Niesporek, S., Denkert, C., Dietel, M., and Kristiansen, G. (2008b). Histone deacetylases 1, 2 and 3 are highly expressed in prostate cancer and HDAC2 expression is associated with shorter PSA relapse time after radical prostatectomy. Br J Cancer 98, 604-610.

Welch, C., Chen, Y., and Stallings, R. L. (2007). MicroRNA-34a functions as a potential tumor suppressor by inducing apoptosis in neuroblastoma cells. Oncogene 26, 5017-5022. 
Williams, A. E., Moschos, S. A., Perry, M. M., Barnes, P. J., and Lindsay, M. A. (2007). Maternally imprinted microRNAs are differentially expressed during mouse and human lung development. Dev Dyn 236, 572-580.

Wilson, A. J., Byun, D. S., Popova, N., Murray, L. B., L'Italien, K., Sowa, Y., Arango, D., Velcich, A., Augenlicht, L. H., and Mariadason, J. M. (2006). Histone deacetylase 3 (HDAC3) and other class I HDACs regulate colon cell maturation and p21 expression and are deregulated in human colon cancer. J Biol Chem 281, 13548-13558.

Wong, S., and Weber, J. D. (2007). Deacetylation of the retinoblastoma tumour suppressor protein by SIRT1. Biochem J 407, 451-460.

Woods, K., Thomson, J. M., and Hammond, S. M. (2007). Direct regulation of an oncogenic micro-RNA cluster by E2F transcription factors. J Biol Chem 282, 2130-2134.

Wu, X., and Levine, A. J. (1994). p53 and E2F-1 cooperate to mediate apoptosis. Proc Natl Acad Sci U S A 91, 3602-3606.

Xiao, Z., Xue, J., Sowin, T. J., Rosenberg, S. H., and Zhang, H. (2005). A novel mechanism of checkpoint abrogation conferred by Chk1 downregulation. Oncogene 24, 1403-1411.

Yamakuchi, M., Ferlito, M., and Lowenstein, C. J. (2008). miR-34a repression of SIRT1 regulates apoptosis. Proc Natl Acad Sci U S A 105, 13421-13426.

Yamakuchi, M., and Lowenstein, C. J. (2009). MiR-34, SIRT1 and p53: the feedback loop. Cell Cycle 8, 712-715.

Yamasaki, L., Jacks, T., Bronson, R., Goillot, E., Harlow, E., and Dyson, N. J. (1996). Tumor induction and tissue atrophy in mice lacking E2F-1. Cell 85, 537-548.

Yan, H. L., Xue, G., Mei, Q., Wang, Y. Z., Ding, F. X., Liu, M. F., Lu, M. H., Tang, Y., Yu, H. Y., and Sun, S. H. (2009). Repression of the miR-17-92 cluster by p53 has an important function in hypoxia-induced apoptosis. Embo J 28, 2719-2732.

Yang, A., and McKeon, F. (2000). P63 and P73: P53 mimics, menaces and more. Nat Rev Mol Cell Biol 1, 199-207.

Yang, X., Feng, M., Jiang, X., Wu, Z., Li, Z., Aau, M., and Yu, Q. (2009). miR-449a and miR$449 \mathrm{~b}$ are direct transcriptional targets of E2F1 and negatively regulate pRb-E2F1 activity through a feedback loop by targeting CDK6 and CDC25A. Genes Dev 23, 2388-2393.

Yarden, R. I., and Brody, L. C. (1999). BRCA1 interacts with components of the histone deacetylase complex. Proc Natl Acad Sci U S A 96, 4983-4988.

Yarden, R. I., Pardo-Reoyo, S., Sgagias, M., Cowan, K. H., and Brody, L. C. (2002). BRCA1 regulates the G2/M checkpoint by activating Chk1 kinase upon DNA damage. Nat Genet 30, 285-289.

Yu, H. (2007). Cdc20: a WD40 activator for a cell cycle degradation machine. Mol Cell 27, 316.

Zhang, H., Mishra, A., Chintagari, N. R., Gou, D., and Liu, L. (2010). Micro-RNA-375 inhibits lung surfactant secretion by altering cytoskeleton reorganization. IUBMB Life 62, 78-83.

Zhang, Y., Xiong, Y., and Yarbrough, W. G. (1998). ARF promotes MDM2 degradation and stabilizes p53: ARF-INK4a locus deletion impairs both the Rb and p53 tumor suppression pathways. Cell 92, 725-734.

Zhang, Z., Yamashita, H., Toyama, T., Sugiura, H., Ando, Y., Mita, K., Hamaguchi, M., Hara, Y., Kobayashi, S., and Iwase, H. (2005). Quantitation of HDAC1 mRNA expression in invasive carcinoma of the breast ${ }^{*}$. Breast Cancer Res Treat 94, 11-16.

Zhao, T., and Xu, Y. (2010). p53 and stem cells: new developments and new concerns. Trends Cell Biol 20, 170-175.

Zou, H., Henzel, W. J., Liu, X., Lutschg, A., and Wang, X. (1997). Apaf-1, a human protein homologous to C. elegans CED-4, participates in cytochrome c-dependent activation of caspase-3. Cell 90, 405-413. 


\section{Acknowledgements}

First of all, I would like to thank my supervisor Matthias Dobbelstein for giving me the opportunity to work in his group, and for his support and scientific guidance throughout my $\mathrm{PhD}$ time. Our weekly meetings and vivid discussions helped me in many aspects, especially for the development of a critical scientific approach.

I thank my PhD committee members Tomas Pieler and Ralf Ficner for their time and support, and for the interesting and helpful discussions and suggestions.

Furthermore, I want to thank Magda Morawska-Onyszczuk, Konstantina Marinoglou, Xin Zhang, Ines Rudolf and Steven Johnsen for the incredibly helpful proof reading and the nice scientific discussions. I would also like to thank Frederik Köpper, Miriam Weiss and Ines Rudolf for their productive lab rotations and co-work on this project.

I thank all the lab members of the Molecular Oncology department for being such friendly and helpful colleagues, and for creating a wonderful atmosphere in the lab. Thank to you it is a nice place to be, even during stressful times. My thanks go especially to Cathrin Hippel, Antje Dickmanns and Claudia Buabe for their excellent technical assistance.

I am very grateful to my wonderful external collaborators Alex Klimke, Sven Pilarski, Christian Herr, Robert Bals and Michael Kessel. I t is a pleasure to work with such dedicated scientists.

I also thank Karen Vousden for the Saos2 cells with tet-inducible E2F1, Reuven Agami for the miR-Vec library and the transcriptome analysis unit at our University for help with the array hybridization. 


\section{Curiculum Vitae}

Name:

Date of birth:

Nationality:

\section{Muriel Lizé}

29.01.1981 in Pontoise, France

French

\section{Education}

From March 2007

Dissertation at the Department of Molecular Oncology, University of Goettingen, Germany. Topic: E2F1 and microRNAs in DNA damage and apoptosis.

February 2006 - Jan. 2007

Diploma thesis „Manipulation of the Mdm2-oncoprotein: pharmacological activation of p53-responsive genes“, overall grade 1.3 "very good”, Department of Molecular Oncology, University of Goettingen, Germany

January 2006

Diploma in Biology (master) final examination in Biochemistry (Major), Pharmacology und Human Genetics, overall grade 1.3 "very good", University of Goettingen, Germany

June 1999

High school diploma "Diplôme du Baccalauréat général scientifique avec mention", Major Natural Sciences, overall grade 1.8, France

\section{Work Experience}

From March 2007

Research assistant at the Department of Molecular Oncology, University of Goettingen, Germany April 2006 - Jan. 2007

Student assistant at the Department of Molecular Oncology, University of Goettingen, Germany Sept. 2005 - March 2007

Student assistant at the Department of Bioinformatics, Project EndoNet, University of Goettingen, Germany

Okt. 2005 - Dec. 2005

Student assistant, supervision of the module Biochemistry for Medical Students, University of Goettingen, Germany

\section{Volunteering}

From December 2007

Member of the registered non-profit association “Initiative Frieden e.V.", Initiative Peace, voluntary service in Germany and Tansania.

From May 2007- September 2008

Voluntary service for registered non-profit cultural institution „Rockbüro e.V.“, Goettingen, Germany February 2007 - December 2007

Voluntary service in the registered non-profit making youth welfare organisation „Blechtrommel“, Goettingen, Germany 


\section{Practical training}

Aug. 2005 - Sept. 2005

Non-curricular internship, Department of Molecular Structural Biology, University of Goettingen, Germany

June 2005 - July 2005

Laboratory practical training, Department of Plant Biochemistry, University of Goettingen, Germany

April 2005 - May 2005

Laboratory practical training, Department of Cytogenetics, University of Goettingen, Germany

Jan. 2005 - Feb. 2005

Laboratory practical training for Biochemistry, University of Goettingen, Germany

July 2004 - Aug. 2004

Laboratory practical training in Pharmacology and Toxicology, University of Goettingen, Germany

\section{Language skills}

Fluent in French (native speaker) and German (DSH certificate), very good English

(Cambridge Advanced Certificate grade A June 2009), elementary Suaheli and Italian.

\section{Poster presentations at conferences}

Genes \& Cancer 2009, 26th Meeting December 2009, University of Warwick, United Kingdom 15th International AEK Cancer Congress, Deutsche Krebsgesellschaft e. V., March 2009, Berlin, Germany

$5^{\text {th }}$ International PhD student Symposium Horizons in Molecular Biology, September 2008, Goettingen, Germany

International Advanced ICAS/ApopTrain Training Course on Advances in Cell Death Research, July 2008, Günzburg, Germany

\section{Talk at conference}

$21^{\text {st }}$ Meeting of the European Association for Cancer Research EACR-21, June 2010, Oslo, Norway. The Mattyasovsky-Meziani Bursary Award Talk at the Presidential Session I.

\section{Publications}

Manuscript in review (June 2010):

MicroRNA-449a levels increase by several orders of magnitude during mucociliary differentiation of airway epithelia.

M. Lizé, C. Herr, A. Klimke, R. Bals, and M. Dobbelstein

Department of Molecular Oncology, Ernst Caspari Haus, University of Goettingen

E2F1-inducible microRNA 449a/b suppresses cell proliferation and promotes apoptosis.

M Lizé, S Pilarski and M Dobbelstein.

Cell Death and Differentiation, 2010 Mar; 17(3):452-8.

Department of Molecular Oncology, Ernst Caspari Haus, University of Goettingen

EndoNet: an information resource about regulatory networks of cell-to-cell communication.

Dönitz J, Goemann B, Lizé M, Michael H, Sasse N, Wingender E, Potapov AP.

Nucleic Acids Res. 2008 Jan.

Department of Bioinformatics, University of Goettingen/Medical School.

http://endonet.bioinf.med.uni-goettingen.de/ 